\title{
ASPECTS OF THE FEEDING ECOLOGY OF MALLARD AND BLACK SWAN IN A SMALL
}

FRESHWATER LAKE

Kerry John Potts

Submitted for the degree of Doctor of Philosophy in Zoology at the

Victoria University of Wellington November 1982 


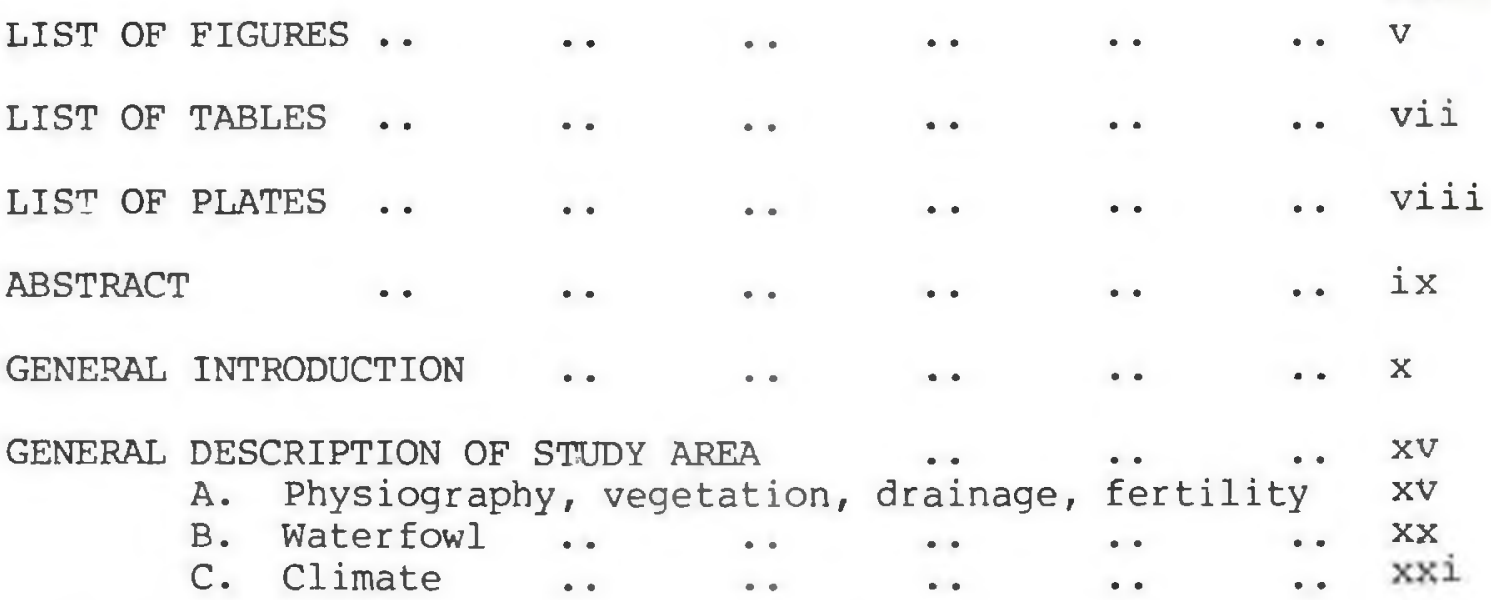

SECTION 1: GENERAL LIMNOLOGY AND HABITAT EVALUATION WITH SPECIAL REFERENCE TO (a) THE FACTORS REGULATING THE BALANCE BETWEEN MACROPHYTES AND PHYTOPLANKTON (INCLUDING THE MECHANISMS INVOLVED IN MACROPHYTE DECLINE), AND (b) THE POTENTIAL OF SWAN GRAZING TO STIMULATE CHANGE IN THE DIRECTION OF PHYTOPLANKTON DOMINANCE

\section{Ch. 1}

INTRODUCTION

$\cdots$

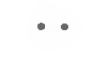

Ch. 2

METHODS . .

2.I Bathymetry ..

2.2 Aerial photography

2.3

2.4

Weather and water levels

Sampling stations and times

2.5 Water chemistry

2.6 Macrophyte sampling

2.6.1 Rake method ..

$\begin{array}{lll}\ldots & \cdots & 1 \\ \cdots & \cdots & 5 \\ \cdots & \cdots & 5 \\ \cdots & \cdots & 5 \\ \cdots & \cdots & 5 \\ \cdots & \cdots & 7 \\ \cdots & \cdots & 7\end{array}$

2.6.2 Trial comparing the efficiencies of the rake and modified Gerking methods to the direct hand cutting method

(a) Objectives

(b) Methods

(c) Results

(d) Conclusions

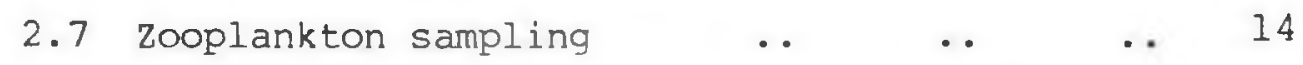

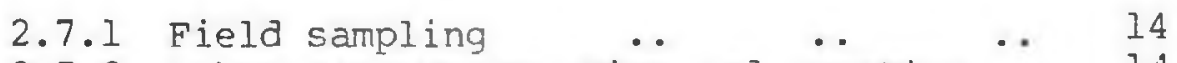

2.7.2 Laboratory preparation and counting .. 14

2.8 Phytoplankton and epiphytic algae sampling .. 15

2.8.1 Phytoplankton productivity .. $\quad \ldots \quad 15$

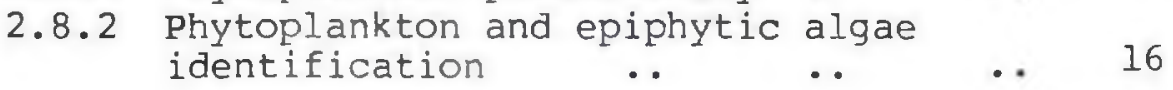

2.9 Aquatic invertebrate sampling $\quad \ldots \quad \ldots \quad \ldots \quad 16$

2.9.1 Gastropod - macrophyte relationship .. 16

$\begin{array}{lll}\text { 2.9.2 General seasonal availability of } & & \\ \text { plant-associated invertebrates } & \text {. . } & 17\end{array}$ 


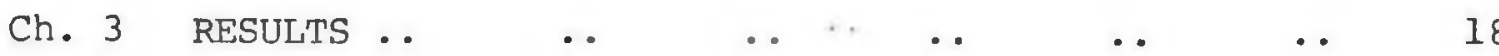

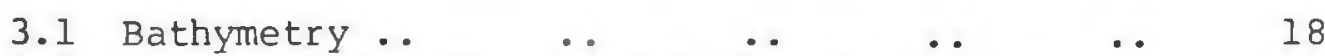

3.2 Water levels, flow, rainfall, air and water

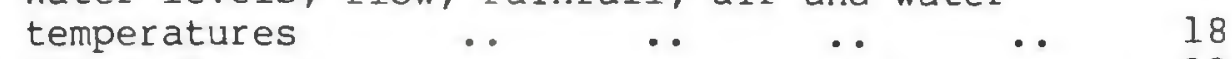

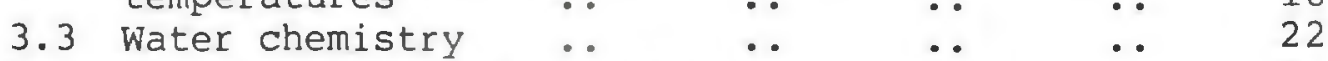

3.4 The occurrence of macrophytes $\quad \ldots \quad$... 22

3.4.1 Macrophyte development in $1977 / 78 \quad \ldots \quad 24$

3.4.2 Macrophyte development in 1978/79 $\ldots .29$

$\begin{array}{llllll}3.5 & \text { Aquatic invertebrates } & \ldots & \ldots & \ldots & 35\end{array}$

3.5.1 Gastropod-macrophyte relationship .. $\quad 35$

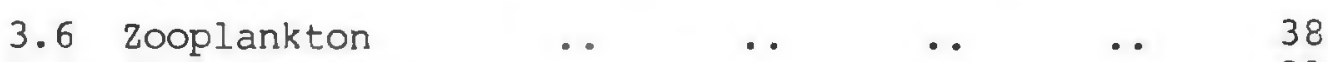

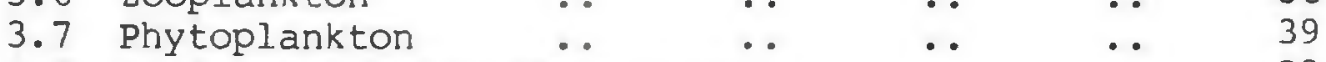

3.8 Spring epiphytic diatom pulse $\quad \ldots . \quad \ldots \quad 39$

$\begin{array}{llllllll}\text { Ch. } 4 & \text { DISCUSSION } & \ldots & \ldots & \ldots & \ldots & \ldots & 43\end{array}$

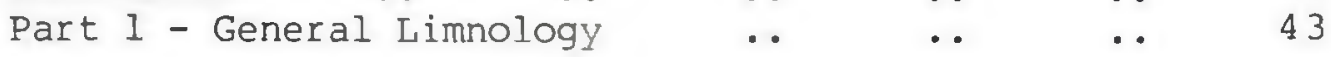

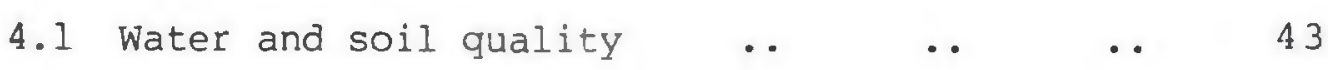

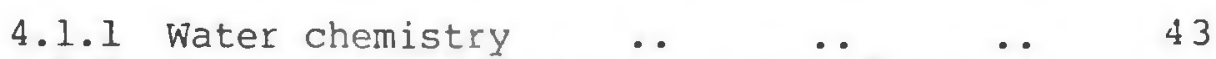

4.1.2 The relationship between specific water chemical parameters, primary and secondary productivity, and waterfowl habitat quality $\quad . . \quad$.. .

4.1.3 The relationship of water chemistry to soil chemistry and the role of Typha orientalis (raupo) in terms of nutrient recycling, organic debris contribution, and invertebrate production .. $\quad . .47$

4.2 Macrophytes 50

4.2.1 Macrophytes as trophic status indicators 50

4.2.2 The balance between $\underline{\mathrm{P}}$. $\underline{\text { crispus }}$ and $\underline{\mathrm{P}}$. pectinatus in deep open water ..

4.3 The seasonal availability of plant-associated

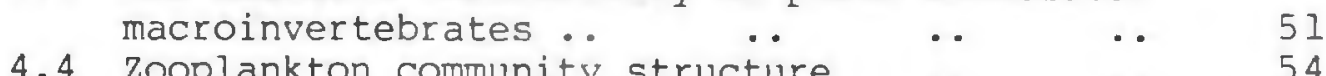

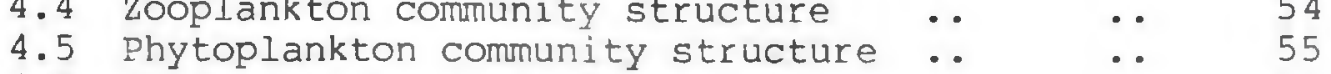

4.6 Spring epiphytic diatom pulse $\quad \ldots .615$

Part 2 - The balance between macrophytes and phytoplankton and the potential of swan grazing to stimulate changeovers from macrophyte to phytoplankton dominance

4.7 The balance between macrophy tes and phyto plankton ...

4.7.1 The mechanisms involved in changeovers from macrophyte to phytoplankton dominance

4.7.2 Could storm or heavy swan grazing damage trigger a sudden change to phytoplankton dominance at Pukepuke? 
SECTION 2: THE FEEDING ECOLOGY OF MALLARDS

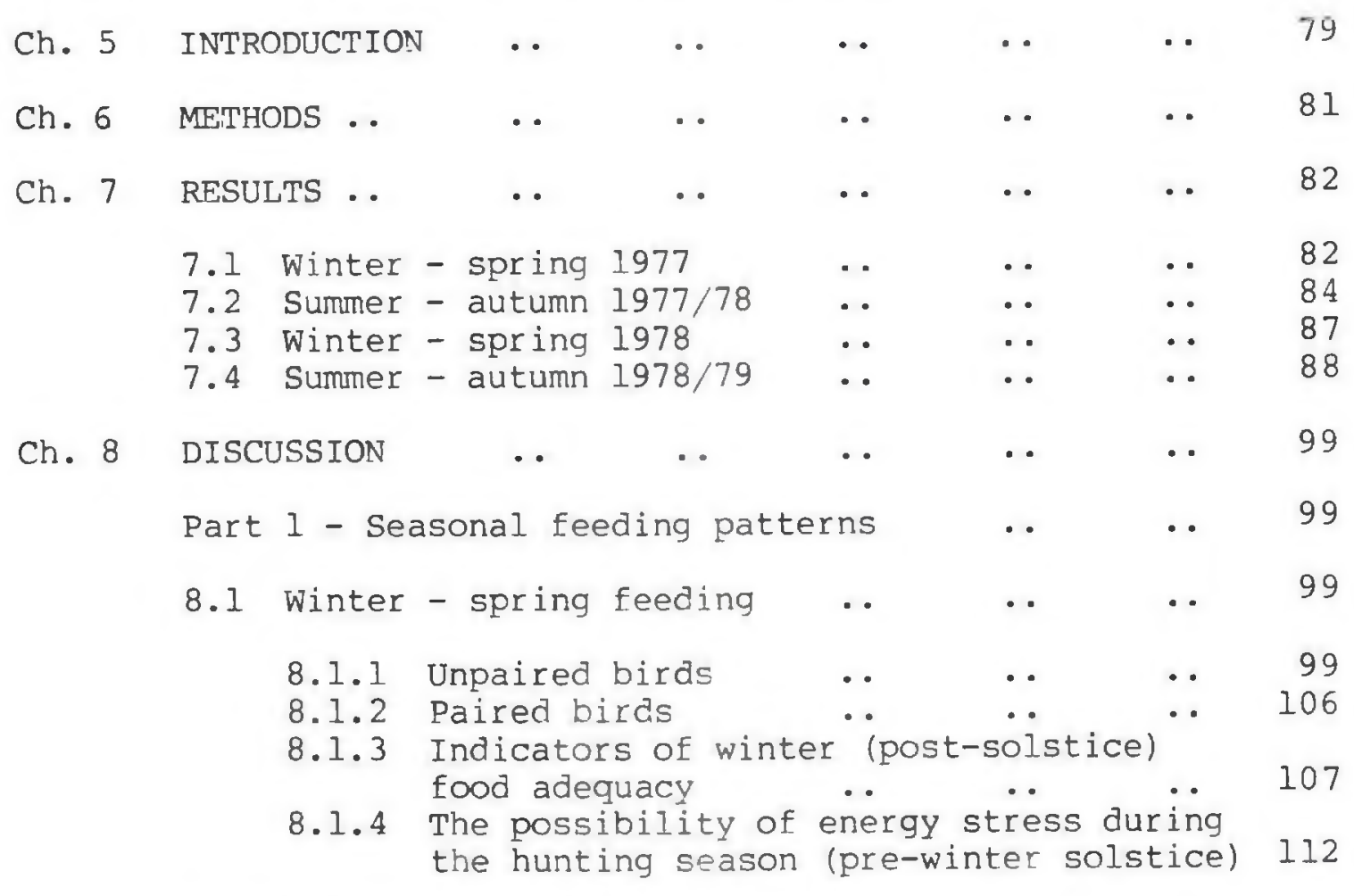

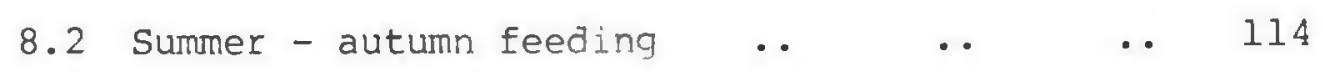

8.2.1 The feeding relationship between mallard and black swan in the summers of $1977 / 78$

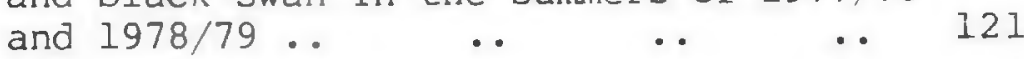

Part 2 - Breeding and brood production .. $\quad . .124$

8.3 The meaning of local production $\quad \ldots \quad$.. 124

8.4 The food requirements of ducklings. Is food likely to be limiting to duckling production on Pukepuke Lagoon? $\quad$.. $\quad \ldots \quad \ldots l 28$

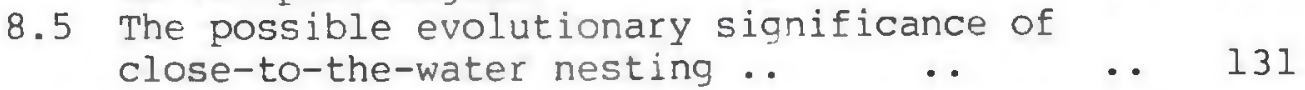

SECTION 3: FACTORS CONTROLLING THE PRESENCE AND DISTRIBUTION OF BLACK SWAN IN THE PUKEPUKE-CENTRED WETLAND COMPLEX

Ch. 9 SEASONAI OCCURRENCE AND PRODUCTION IN PUKEPUKE

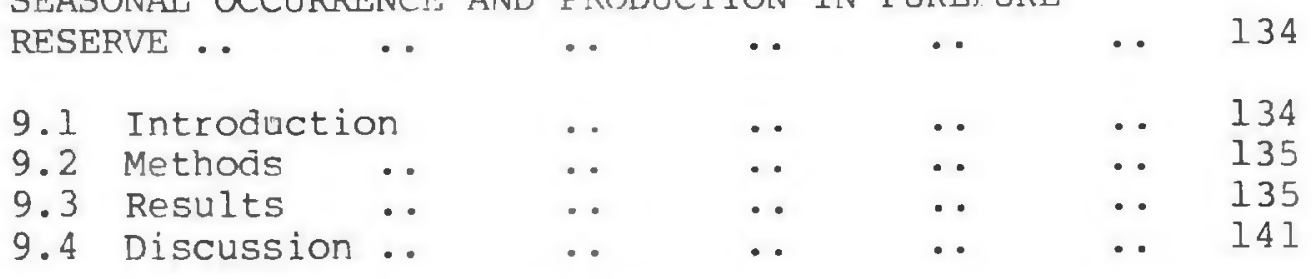

9.4.1 The relationship between Pukepuke Lagoon and outlying waters... $\quad$.. $\quad . .141$

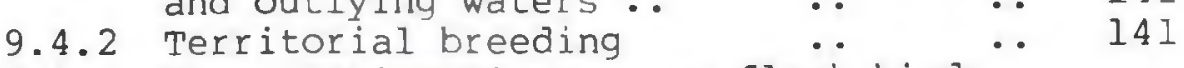

9.4.3 The relationship between flock birds 142

9.4.4 Production, survival, carrying capacity and timing of breeding $\quad$.. $\quad$.. 143 
Ch. 10 AN HYPOTHESIS TO ACCOUNT FOR FLOCK BIRD USE OF VARIOUS WATERS IN THE PUKEPUKE-CENTRED WETLAND COMPLEX

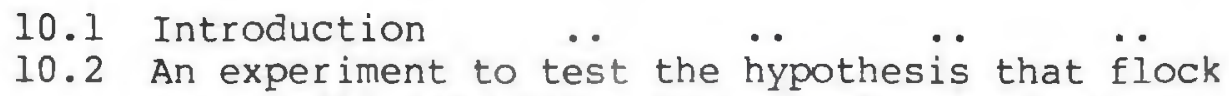
swans will only leave Pukepuke Lagoon in the spring if they are forced to do so by

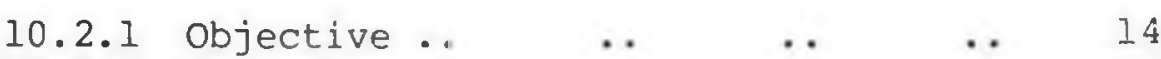

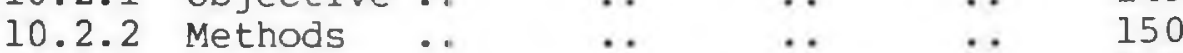

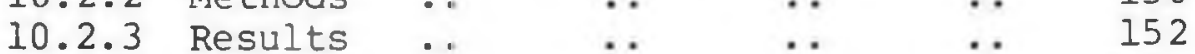

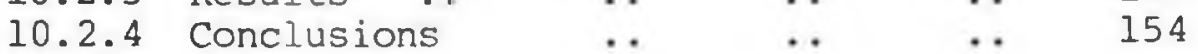

$\begin{array}{llllllllll}\text { SUMMARY } & \ldots & \ldots & \ldots & \ldots & \ldots & \ldots & \ldots & \ldots & 155\end{array}$

$\begin{array}{llllllll}\text { ACKNOWLEDGEMENTS } & \ldots & \ldots & \ldots & \ldots & \ldots & 162\end{array}$

$\begin{array}{lllllllll}\text { REFERENCES } & \ldots & \ldots & \ldots & \ldots & \ldots & \ldots & \ldots & 163\end{array}$

$\begin{array}{llllllll}\text { APPENDICES } & \ldots & \ldots & \ldots & \ldots & \ldots & \ldots & 173\end{array}$

Appendix 1 Monthly maximum densities of macrophytes obtained by the $0.1 \mathrm{~m}^{2}$ rake method $\mathrm{n} 1977$

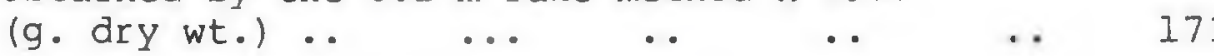

Appendix 2 Monthly maximum densities of macrophytes obtained by the $0.1 \mathrm{~m}^{2}$ rake method in 1978

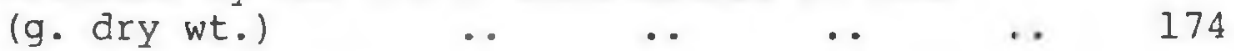

Appendix 3 Desophagal contents of mallards shot on

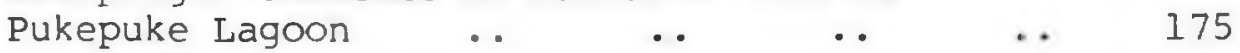

Appendix 4 Winter grain trapping attempts at Pukepuke .. $\quad 176$

Appendix 5 Mallard winter sex ratios in New Zealand: An examination of the major forces operating to produce these results, including the sexselective effect of hunting .. $\quad \ldots \quad \ldots . \quad \ldots \quad 178$ 


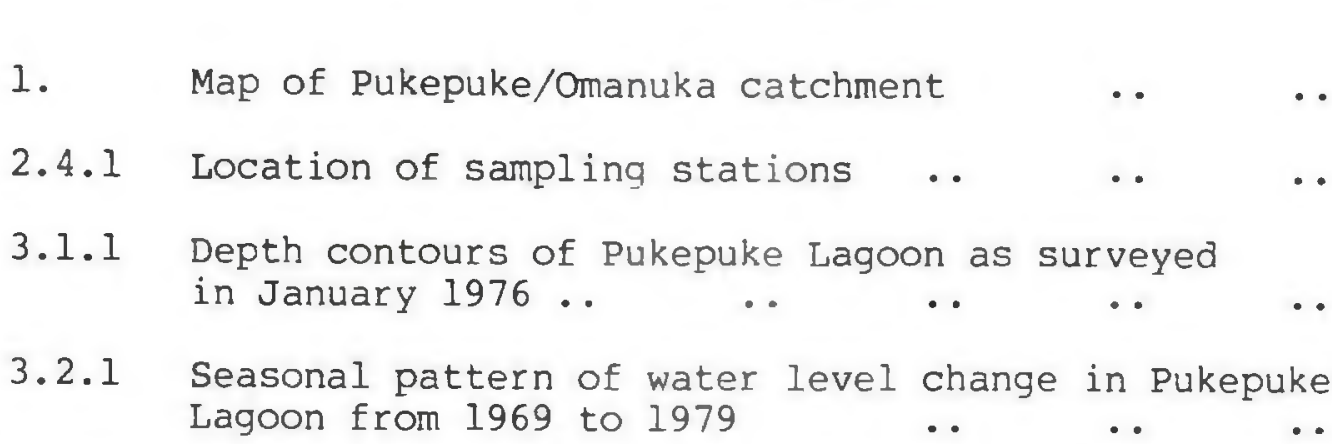

3.2.2 Monthly rainfall, water level, air temperature and surface water temperature $\quad . . \quad \ldots$

3.4.1 Occurrence and seasonal development of macrophytes sampled in 1977 ..

3.4.2 Summary of macrophyte development and decline in Pukepuke Lagoon in $1977 / 78$

3.4.3 Occurrence and seasonal development of macrophytes sampled in 1978

3.4.4 Summary of macrophyte development and decline in Pukepuke Lagoon in 1978/79 .. . . .

3.5.1 Gastropods per 9. dry wt. of macrophyte

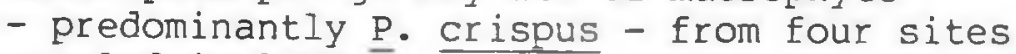
sampled in 1977

3.6.1 The seasonal pattern of zooplankton occurrence, phytoplankton productivity, and secchi disc extinction in Pukepuke Lagoon from 1977 to 1979 ..

4.7.1 Phytoplankton productivity in relation to water levels from March 1977 to April 1979

4.7.2 Hypothesis to account for decline in macrophyte populations when lakes are fertilised ..

7.1.0-7.2.5 Diurnal feeding patterns of mallards as determined by scan counts undertaken at monthly intervals from July 1977 to April 1978, and generally at two-monthly intervals from June 1978 to March 1979

7.1.0 July 20-23, 1977. Counts at two-hourly intervals over four days .. $\quad$. . $\quad \ldots \quad$. .

7.1.1 August 22-26, 1977. Counts at hourly intervals over five days ..

7.1.2 September 19-23, 1977. Counts at hourly intervals over five days

7.1 .3 October $23-27,1977$. Counts at hourly intervals over five days .. 
7.1.4 November 21-25, 1977. Counts at hourly intervals over five days .. $\quad$. $\quad \ldots \quad$. $\quad \ldots \quad$.

7.1.5 December 14-18, 1977. Counts at hourly intervals over five days .. $\quad$. . . . . . .

7.1.6 January 18-22, 1978. Counts at two-hourly intervals over five days .. ..

7.1.7 February 22-26, 1978. Counts at two-hourly

intervals over five days

7.1.8 March 16-19, 1978. Counts at two-hourly intervals over four days ... .

7.1.9 April 11-15, 1978. Counts at two-hourly

intervals over five days $\quad \ldots \quad \ldots 95$

7.2.0 June 20-24, 1978. Counts at two-hourly

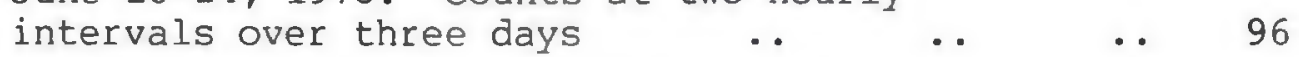

7.2.1 August 15-17, 1978. Counts at two-hourly

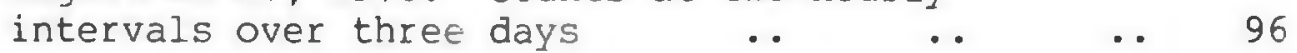

7.2.2 October 27-29, 1978. Counts at one and twohourly intervals over three days

7.2.3 December 11-13, 1978. Counts at two-hourly

intervals over three days

7.2.4 February 20-21, 1979. Counts at two-hourly

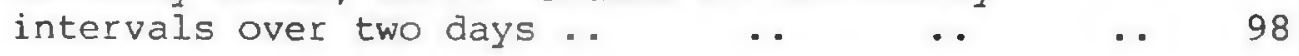

7.2.5 March 28, 1978. Count at two-hourly intervals over one day

9.3.1 to 9.3.5 The occurrence of black swan on Pukepuke Lagoon from 1971 to 1978

$\begin{array}{lllllllll}9.3 .1 & 1971 / 72 & \ldots & \ldots & \ldots & \ldots & \ldots & \ldots & 136 \\ 9.3 .2 & 1973 / 74 & \ldots & \ldots & \ldots & \ldots & \ldots & \ldots & 136 \\ 9.3 .3 & 1974 / 75 & \ldots & \ldots & \ldots & \ldots & \ldots & \ldots & 137 \\ 9.3 .4 & 1975 / 76 & \ldots & \ldots & \ldots & \ldots & \ldots & \ldots & 137 \\ 9.3 .5 & 1977 / 78 & \ldots & \ldots & \ldots & \ldots & \ldots & \ldots & 138 \\ 10.1 .1 & \begin{array}{l}\text { The occurrence of flock Swans on Pukepuke Lagoon } \\ \text { in relation to an induced delay and restriction } \\ \text { in hatching }\end{array} & \ldots & \ldots & \ldots & \ldots & \ldots & \\ 7\end{array}$




\section{LIST OF TABLES}

Page

2.6.1 Two-way analysis of variance of macrophyte data obtained by (a) the hand cut and rake sampler methods and (b) the hand cut and modified Gerking sampler methods .. $\quad$. $\quad \ldots \quad$..

3.3.1 Water chemical analyses undertaken from 1976 to 1979

3.5.1 Biomass of macrophyte samples obtained for gastropod macrophyte study in 1977 .. $\quad$.. $\quad$..

3.8.1 Epiphytic diatoms identified on $\underline{P}$. crispus shoots August 18, $1978 \ldots \ldots$

3.8.2 Epiphytic diatoms identified on $\underline{P}$. crispus shoots November $24,1978 \quad \ldots \quad \ldots \ldots$

3.8.3 Phytoplankton identified in sample of a 'bloom' occurring March 12, 1978 .. .. ..

9.1.1 Survival of black swan cygnets produced on Pukepuke Lagoon and on the Reserve as a whole in the spring breeding seasons of 1971 to 1977 .. ..

Appendix

1 Monthly maximum densities of macrophytes obtained by the $0.1 \mathrm{~m}^{2}$ rake method in 1977 (g. dry wt.) $\quad . \quad 173$

2 Monthly maximum densities of macrophytes obtained by the $0.1 \mathrm{~m}^{2}$ rake method in 1978 (g.dry wt.) .. 174 


\section{LIST OF PLATES}

Page.

1. Pukepuke Wildife Management Reserve in relation

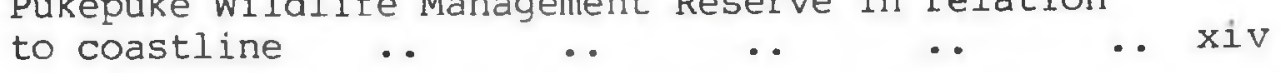

2. Aerial view of Pukepuke Reserve indicating important features (October 30,1977 ) $\quad$. $\quad \ldots \quad \ldots x v i$

3. Panoramas of Pukepuke Lagoon taken from hide no. 2 on October 2, 1977 (typical winter - spring water level) and March 21, 1978 (abnormally low summer autumn water level, zero inflow, high evaporation) xvii

4. Aerial view of Pukepuke Reserve in the spring (August) of $1976 \quad \ldots \quad \ldots \times \quad \ldots x i i$

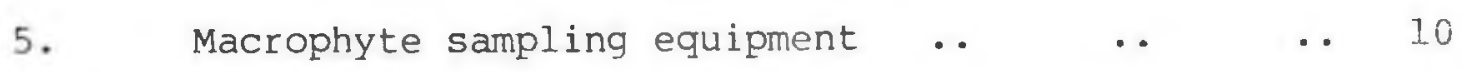

1. Gerking sampler

2. Rake sampler

3. Hand cutting frame

6. Dense Potamogeton crispus dominating open water of Pukepuke Lagoon, December 27, 1977 .. $\quad \ldots \quad 28$

7. The start of the summer phytoplankton 'bloom' and associated collapse of macrophytes, mid-January 197828

8. Aerial view of Pukepuke Lagoon, April 6, 1978, showing pronounced water recession and accompanying plant growth on exposed substrate $\quad \ldots \quad 3 \quad \ldots \quad 33$

9. Underwater growth of Veronica anagallis-aquatica typical of eastern half of Pukepuke Lagoon in the

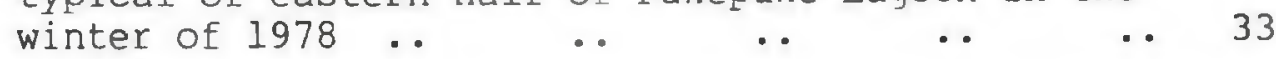

10. Vigorous Ranunculus sceleratus growth on exposed damp organic substrate, March 21, 1978 ... . 34 


\section{ABSTRACT}

Section 1. Limnological and waterfowl food supply characteristics of Pukepuke Lagoon are described. Emphasis is placed on describing how the baiance between macrophytes and phytoplankton is established (these two forms of vegetation tend to dominate alternately in the lagoon). The question of whether heavy swan grazing may potentially shift this balance in favour of phytoplankton dominance is examined.

Section 2. The year-round patterns of feeding exhibited by mallards are described on the basis of scan counts taken at one or two-hourly intervals from dawn to dusk. These feeding patterns, graphically depicted, are then interpreted and discussed against the background of what is known of the food content of the lagoon. Reference is made to the behavioural and physiological adaptability of the birds, and to the reserve capacity of the wetland complex - not just Pukepuke Lagoon - to sustain them. The relevance of these findings and interpretations to New Zealand in general is discussed.

Section 3. An hypothesis is developed to account for the way in which black swans use various waters in the Pukepuke-centred wetland complex. 


\section{GENERAL INTRODUCTION}

In seeking to influence the future direction of game waterfowl research Smith (1969) commented that although particular factors affecting the lives of waterfowl need to be researched - and in this regard he referred to predator/prey, nesting and food studies "there has often been a tendency to enshrine these kinds of studies as ends in themselves". He added, 'After years of studying individual aspects of a duck's life we should now begin to put the pieces together and concentrate on interrelationships of the various environmental elements'. This study of the feeding ecology of mallard (Anas p. platyrynchos) and black swan (Cygnus atratus) populations at Pukepuke Lagoon represents one such attempt to 'put the pieces together' and to 'concentrate on the various environmental elements'.

The basic structure of the thesis and the main research topics covered are outlined as follows: (Note: This outline is intended to provide an easily assimilable perspective of the work covered. More comprehensive introductions - including reference to the relevant literature - are given in each of the three sections.)

Section 1 General limnology and habitat evaluation with special reference to

(a) the factors regulating the balance between macrophytes and phytoplankton (including the mechanisms involved in macrophyte decline), and

(b) the potential of heavy swan grazing to stimulate change in the direction of phytoplankton dominance. 
A broad limnological study of Pukepuke Lagoon was carried out over a two year period (1977-1979) for two overlapping purposes:

(1) To provide information on the general character of the lagoon, including the seasonal availability of waterfowl food stocks, i.e. macrophytes and small invertebrates (this information served as a basis for feeding studies described in sections 2 and 3 ).

(2) To try to account for changeovers from macrophyte to phytoplankton dominance and vice versa.

One of the reasons for pursuing this latter line of enquiry was to try to establish a basis for assessing whether or not the lagoon was susceptible to radical limnological change as a consequence of swan grazing. Mitchell (1971) suggested that black swans, by inflicting heavy damage on macrophyte beds in Tomahawk Lagoon (a similar water to Pukepuke), may have been responsible for triggering, or helping to trigger, sudden change in the direction of phytoplankton dominance. Assuming swans have the potential to influence the character of waterfowl habitats in this way (and this is most likely since heavy damage to weed beds is a well documented cause of such change), then the implications for waterfowl management are clear. If swan populations are allowed to build up in an unrestricted manner on certain waters they may precipitate the ruination of their own feeding environment. (Mitchell (1971) reported that swans disappeared from Tomahawk Lagoon for the duration of the phytoplankton bloom.) In precipitating such change they may also be responsible for ruining the environment for mallards and other waterfowl species which feed on macrophytes and/or their associated invertebrates. 
Section 2 The feeding ecology of mallards.

The patterns of feeding exhibited by mallards during the course of the annual cycle were described on the basis of scan counts. These counts were carried out at hourly or two-hourly intervals during the period from dawn to dusk. In each count two states were distinguished: feeding and non-feeding. Sometimes components of the population (e.g. pairs, non-pairs) were dealt with separately to allow comparisons to be made. The quantitative data (later represented graphically on a month by month basis) was supplemented by notes on such things as intensity of feeding and degree of feeding in association with swans. The main features of the monthly feeding graphs were then interpreted and discussed against the background of what was known of the food content of the lagoon (described in section 1). This provided an opportunity to integrate and give local meaning to a wide variety of field and experimental information scattered in the literature.

The purpose of undertaking this research was two-fold:

(1) to provide a coherent picture of feeding and feeding conditions at Pukepuke, and

(2) in doing so, to pin-point elements and influences which may be typical of other locations throughout New Zealand.

Particular emphasis was placed on discussing winter feeding and the ease or otherwise with which mallards can maintain energy balance at this time. This aspect of the study has clear implications for assessing the susceptibility of the species to food and energy stress in the shooting season (May/June). At this time populations are often forced into unpreferred habitat. 
Section 3 Factors controlling the presence and distribution of black swans in the Pukepuke-centred wetland complex.

To understand the way in which swans tend to use various waters in the wetland complex it was necessary not only to look at the availability and distribution of food resources, but also at the behavioural factors involved. Although some of the broader aspects of black swan movement and distribution throughout New Zealand have been described (williams 1977, 1980), this is the first study to focus on factors governing distribution in a very localised wetland grouping. 


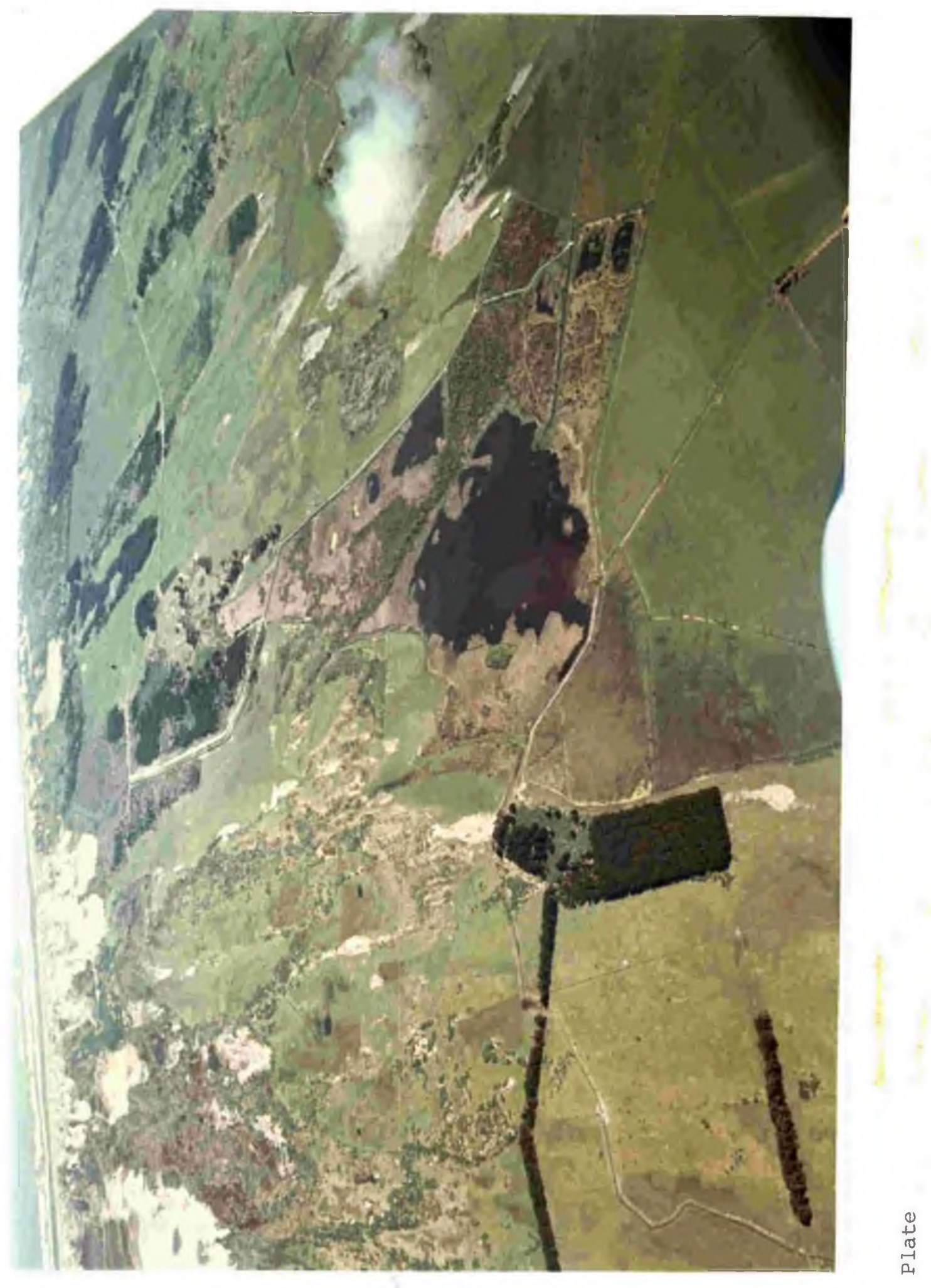




\section{GENERAL DESCRIPTION OF STUDY ARFA}

\section{A. Physiography, vegetation, drainage, fertility}

Pukepuke Reserve is a raupo (Typha orientalis) and flax (Phormium tenax) dominated swamp located approximately $3 \mathrm{~km}$ from the coast in the south-west of the North Island of New Zealand. The Manawatu-Rangitikei sand country region, of which Pukepuke is a part, is composed of a complex of dunes, sand plains and peaty swamps, and extends from Hokio Beach in the south to Wanganui River in the north. It slopes gently inland from the sea to a maximum height of $50 \mathrm{~m}$ some $10 \mathrm{~km}$ east of Pukepuke Lagoon (Cowie et al.' 1966). Pukepuke Reserve lies at the boundary between the younger and older dune complexes (Cowie and Smith, 1958). The younger unconsolidated dune complex borders the coast and extends inland for 0.4-6.4 km. The old consolidated complex further inland is intensively farmed. Dairying is the main type of farming.

Pukepuke Reserve contains several waters, the largest of which is Pukepuke Lagoon (see Plates 1, 2 and 3). This water is approximately 15 hectares in area and is regarded as a basin lake formed between consolidated and unconsolidated sand dunes (Cunningham et al. , 1953).

Since the late 1960s when management of the Reserve by the wildife Service began, the encroachment of raupo into the lagoon has been controlled by hand cutting.

Pukepuke Lagoon is quite shallow with a maximum depth of approximately $1.5 \mathrm{~m}$ in the winter. In the summer the water level lowers on average by about $0.6 \mathrm{~m}$ (max. approx. $1.0 \mathrm{~m}$ ). The two 
Plate 2

Aerial view of Pukepuke indicating important features (Oct. 30, 1977 ). Key :

1. Omanuka Inlet Drain (from Omanuka Lagoon and general catchment).

2. Pukepuke Lagoon

3. Interconnecting Drain

4. Small Lagoon

5. I.A.D. Pond

6. Outlet Drain

7. Road leading to accomodation and laboratory compound.

8. House Pond

9. New Pond

10. Four Islands West Pond

11. Four Islands East Pond

Artificially constructed ponds unconnected to other waters in Reserve.

12. Clover Leaf Ponds ( 3 ponds)

13. Barber's Pump Inlet

14. Typha orientalis (raupo)

15. Mixed flax (Phormium tenax)/cabbage tree (Corduline australis) vegetation.

16. Developed agricultural pasture (mainly dairy)

17. Willow trees (the 'willows')

18. No. 2 observation hide 


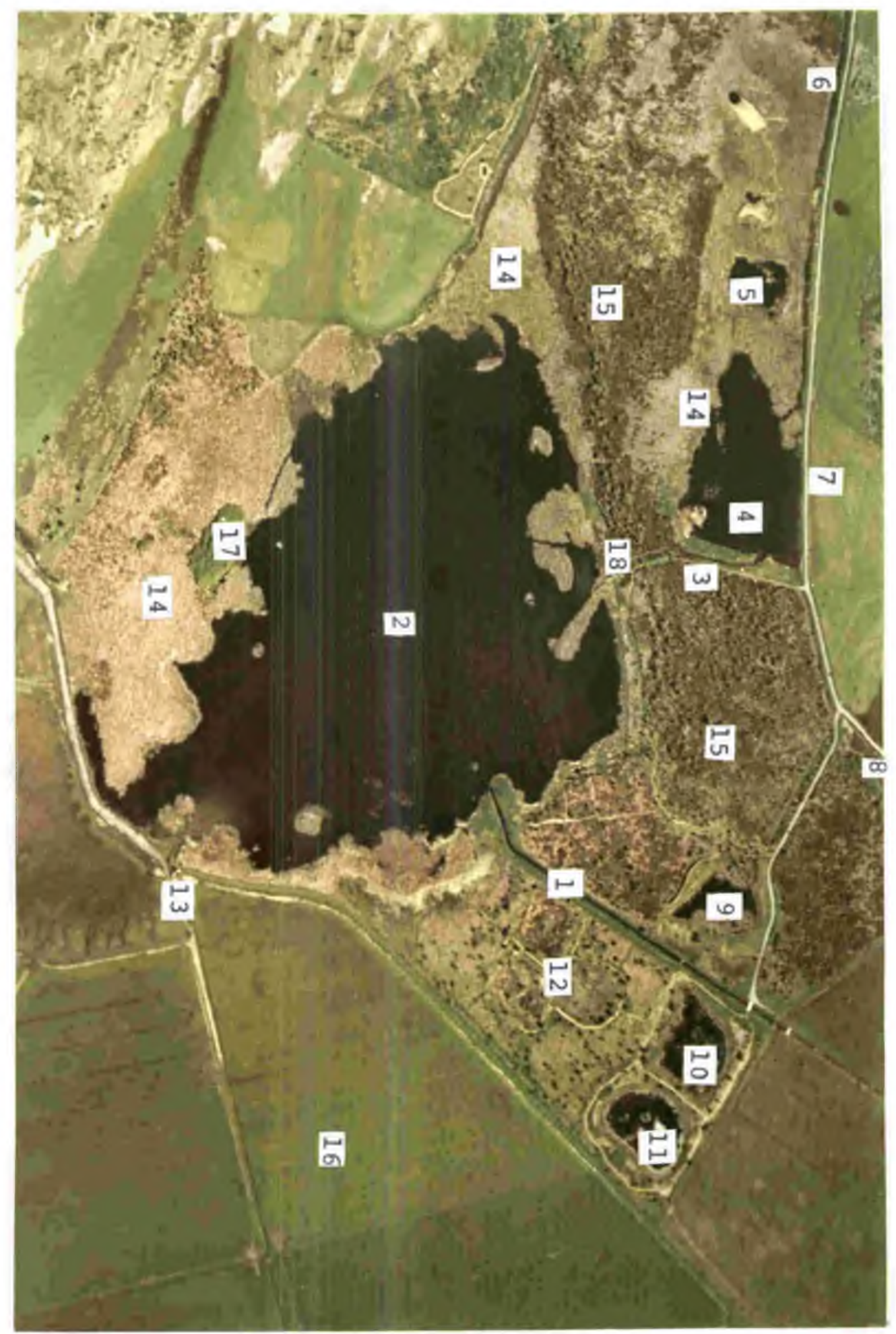




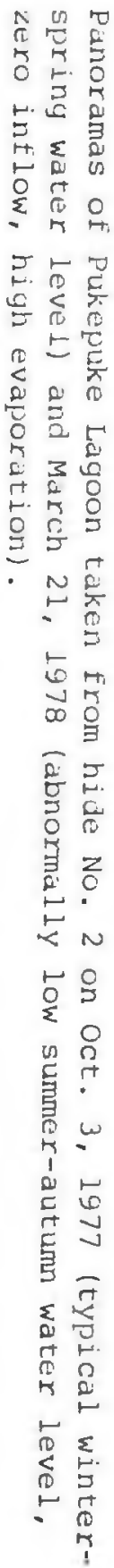


xvii

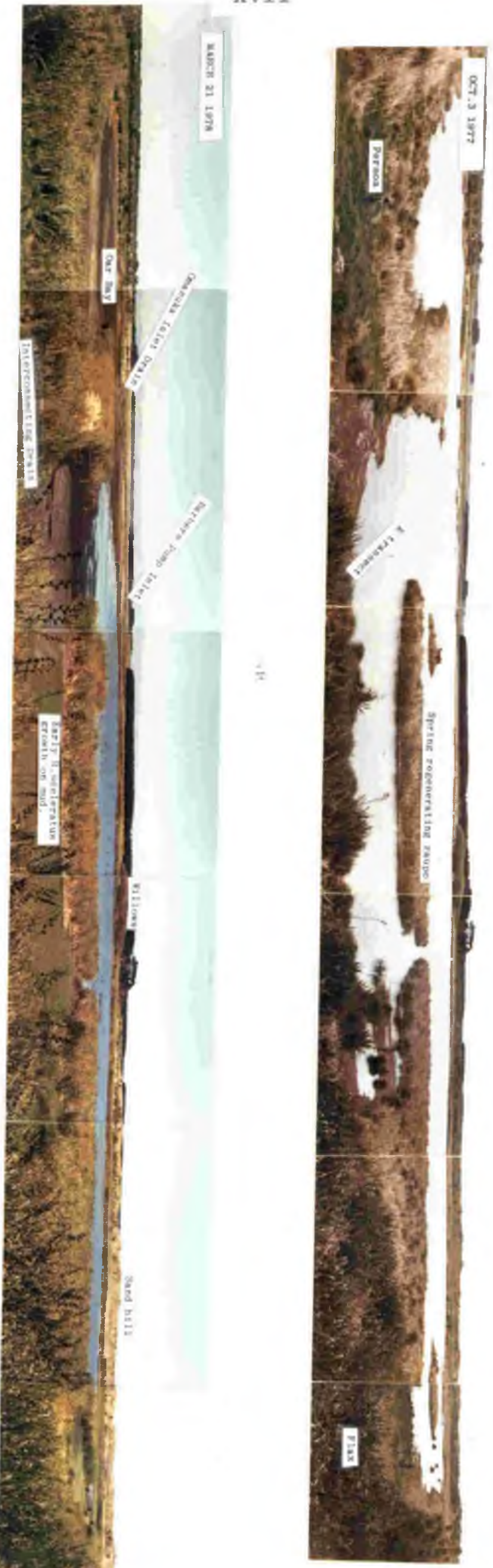


xviii

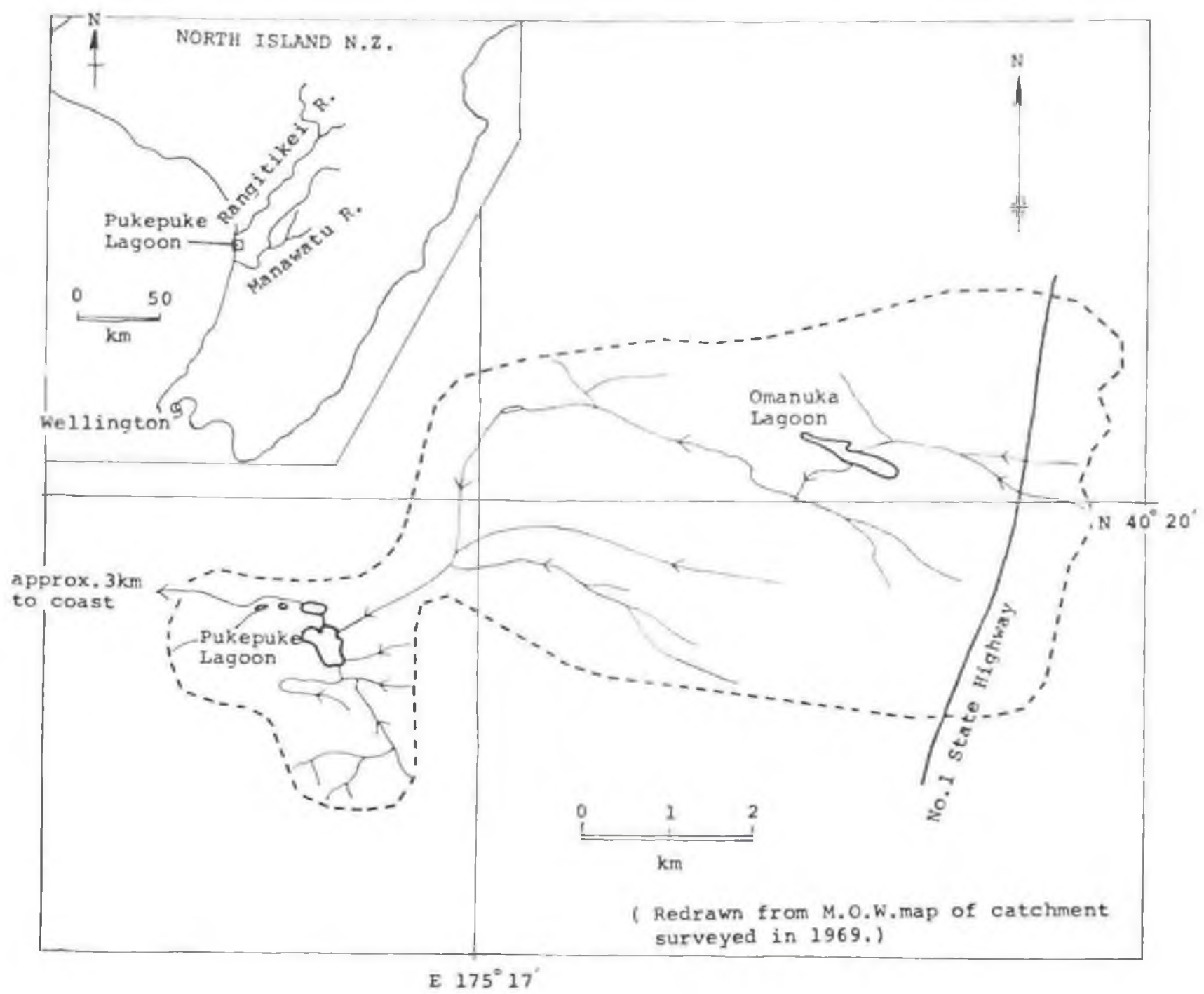

Fig. 1. Map of Fukepulie/Omanuka catchmart. 
inlet channels which supply water to the lagoon from a catchment area of some $26 \mathrm{~km}^{2}$ of farmland generally cease to flow at this time. One inlet drain, Omanuka Inlet Drain, enters the lagoon from the north-east. The other, Barber's Pump Inlet Drain, is controlled by an automatic pump and enters from the south-east. (The general catchment is shown in Fig. 1.) Flow proceeds through pukepuke Lagoon via the so-called Interconnecting Drain to the Small Lagoon and Internal Affairs Department Ponds (I.A.D. Ponds) - all about half the depth of Pukepuke. It then proceeds towards the coast via the Outlet Drain. A concrete water level control structure is situated on this drain at the boundary of the Reserve. The purpose of this is to maintain stable water level and to prevent an excess of build-up in the event of a flood. (This possibility is particularly undesirable in the period of August to December when mallara nests are vulnerable to flooding - see Caithness and Pengelly, 1973.)

The above described waters of the Reserve are highly eutrophic, due mainly to the extensive run-off from the large agricultural catchment. The prevalence of the submerged macrophyte potamogeton pectinatus, an obligate eutrophic species (Seddon, 1972), is one biological indicator of this high trophic status.

Water in the Reserve may be termed fresh, although some very slight salinity (max. approx. 0.6ppt) occurs due to wind-blown salt from the sea. Also, during the summer when Pukepuke Lagoon and associated waters typically become isolated from the general catchment, the water they retain may become slightly brackish due to the high concentration of solutes caused by evaporation. Although the largest water in the Reserve has traditionally been referred to 
as a lagoon and has been named as such on official maps and in the literature, it may be argued that the term has been rather too loosely applied - at least insofar as it is generally understood. (The Shorter Oxford Dictionary describes a lagoon as a 'stretch of salt water parted from the sea by a low sandbank; enclosed water of atoll'.) Subsequent reference to this water as a lagoon is therefore made on the basis of its name rather than on the basis of any exact definition.

Except for the small House Pond, the other waters in the Reserve not hitherto mentioned, namely the New, Four Island and Clover Leaf Ponds (all less than I ha), are isolated from the general catchment. (The House Pond, although separated from the main flow, is connected to the wider catchment system via a channel leading off the Omanuka Inlet system and by a narrow drain to the Small Lagoon.)

\section{B. Waterfow 1}

Three species of dabbling duck - mallard (Anas p. platyrynchos), grey (Anas s. superciliosa), and New Zealand shoveler (Anas rhynchotis variegata) - as well as black swan (Cygnus atratus), use the Reserve waters regularly. Grey teal (Anas gibberifrons gracilis) are common visitors. Occasional sightings are made of the brown duck (Anas aucklandica chlorotis), particularly since recent introductions have been made.

Caithness and Pengelly (1973) described the broad pattern of mallard, grey and shoveler use of the lagoon together with information on sex ratios and other basic population details.

To prevent the Reserve from becoming a refuge, and to maintain conditions similar to other non-refuge waters, shooting is permitted in season. 


\section{Climate}

Cowie et al. (1966) described the general climatic nature of the Manawatu-Rangitikei coastal region. Most of the rain is brought by the dominant west and north-west winds. These often reach gale force in spring and early summer. There is a generally well defined increase in rainfall towards the end of March, the driest month, to June, the wettest month. This is followed by a gradual decrease in September, an increase in October, and a decrease thereon over the summer months. Air temperatures are highest in February and lowest in July (means $17.2^{\circ} \mathrm{C}$ and $8.0^{\circ} \mathrm{C}$ respectively). The winters are moist and relatively mild, although some frosts may occur, especially in dune hollows. During the summer rainfall is comparatively low so that drought conditions may occur. 
Flate 4. Aerial view of Pukepuke Reserve in the spring (August) of 1976. Note high volume of water in inflow channels and the high seasonal availability of external temporary and sem-permanert waters. 
xxii

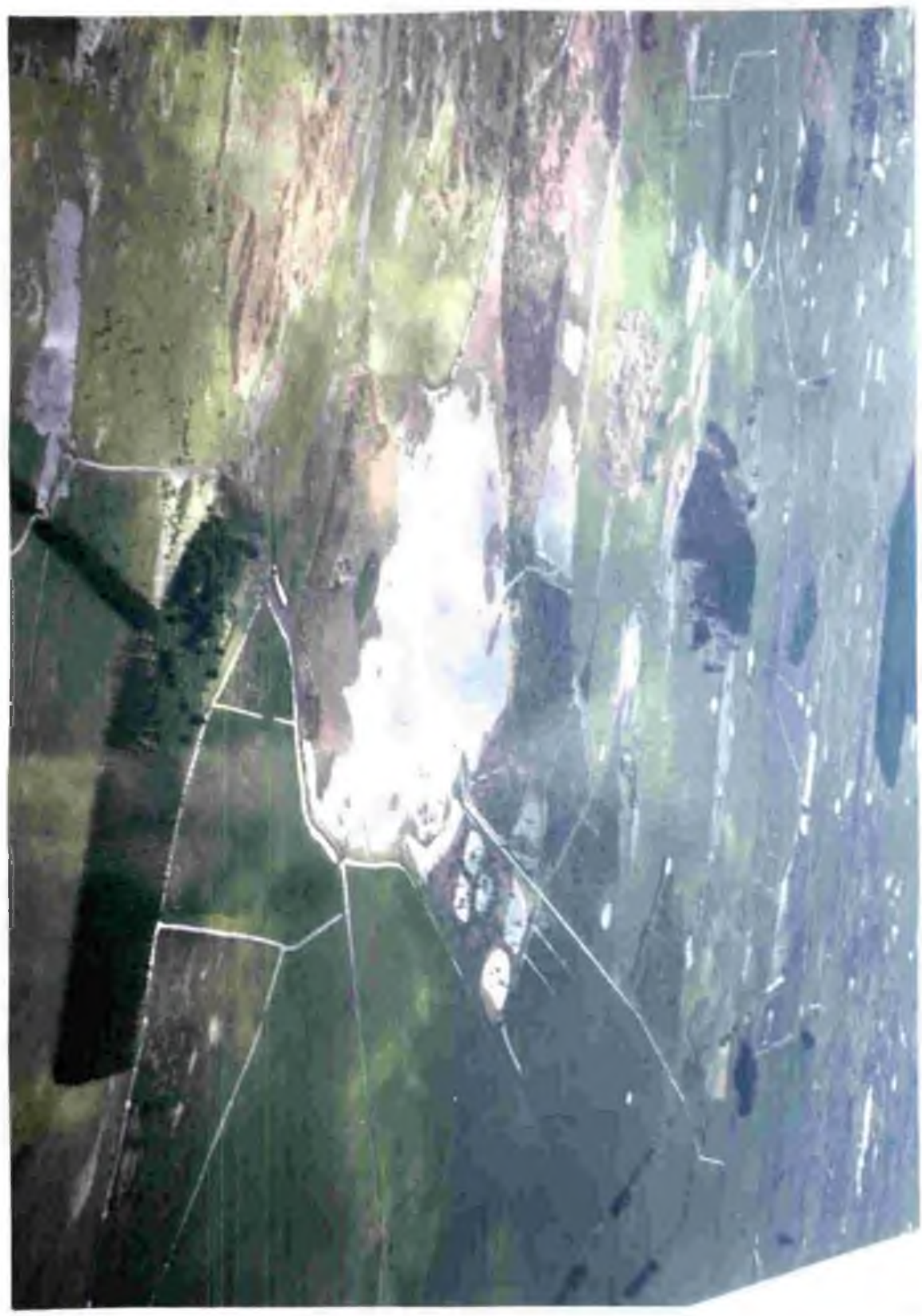




\section{SECTION 1}

GENERAL LIMNOLOGY AND HABITAT EVALUATION WITH SPECIAL REFERENCE TO:

(a) THE FACTORS REGULATING THE BALANCE BETWEEN MACROPHYTES AND PHYTOPLANKTON (INCLUTDING THE MECHANISMS INVOLVED IN MACROPHYTE DECLINE), AND

(b) THE POTENTIAL OF SWAN GRAZING TO STIMULATE CHANGE IN THE DIRECTION OF PHYTOPLANKTON DOMINANCE. 


\section{INTRODUCTION}

A variety of physical, chemical, and biological aspects, of Pukepuke Lagoon were investigated over a two year period (1977-1979). This was done for two purposes:

(1) To provide information on the general character of the lagoon, including the seasonal availability of waterfowl food stocks, i.e. macrophytes and small invertebrates. This information served as background for studies described in sections 2 and 3.

(2) To try to account for changeovers from macrophyte to phytoplankton dominance and vice versa.

This work was essentially a continuation of an earlier study undertaken at Pukepuke by Gibbs (1973). Gibbs described changes in macrophyte and phytoplankton dominance over a three year period (1970-1973) and sought to explain the balance between the two forms of vegetation by comparing his findings to those of Mitchell (1971) for Tomahawk Lagoon (a lagoon of similar depth and enrichment to Pukepuke in the South Island). Although he speculated on the factors which may have contributed to differences between the two lagoons he concluded that "Much more information is required before we can explain the important changeovers". I decided to follow-up on this line of enquiry for two reasons:

(i) If it was possible to explain why Pukepuke tended to produce macrophytes for a large part of the year, then one of the essences of its character as a waterfowl habitat would be defined. (Macrophytes and their associated invertebrates are important waterfow food resources; dense phytoplankton prevents the growth of macrophytes.) 
(ii) By coming to terms with how the macrophyte/phytoplankton balance is maintained one could hopefully then say how stable the macrophyte phase is likely to be in the face of storms or heavy swan grazing. Mitchell (1971) suggested that black swans, by inflicting heavy damage on macrophyte beds in Tomahawk Lagoon, may have been fully or partially responsible for promoting sudden change in the direction of phytoplankton dominance. (Because swans rely heavily on macrophytes for food they deserted the Lagoon for the 16 month duration of the phytoplankton bloom.) Because of hunting restrictions black swan numbers have increased dramatically at Pukepuke since 1973 (see Section 3). As a result, grazing impact is often conspicuously high, particularly in the winter when large pre-breeding flocks gather and weed recovery is low.

There is overwhelming evidence, of both an empirical and a theoretical nature, to show that damage inflicted on macrophytes can lead to the development of phytoplankton and hence the replacement of macrophytes by phytoplankton. For instance, such effects have been shown to be produced when macrophytes have been damaged by boat propellers (e.g. Phillips et al., 1978) and cutting devices (e.g. Johnstone, 1972). The potential of swan grazing, with its typically high level of wastage, to do likewise (a logical corollary) appears to have been largely ignored in the waterfowl literature. Possible reasons for this are discussed. 
Several papers have pointed to components which may be involved in setting the balance between macrophytes and phytoplankton. However, it is clear from the sum of this work that each lake, to a large extent, represents a separate challenge. Past studies may draw attention to certain possibilities, but success in this kind of research is by no means a foregone conclusion (at least in the short term).

Research by Johnson and Walker (1972/73) at Loch Leven suggested that the stability of a macrophyte dominating phase may depend in part on the nature of the accompanying zooplankton (certain forms appear to buffer against sudden phytoplankton irruptions).

In lakes where the decline of a macrophyte dominating phase coincides with the ascendency of a phytoplankton bloom (a relationship commonly observed at Pukepuke) this decline has usually been attributed to shading and/or other effects associated with the presence of phytoplankton (see e.g. Allen, 1973; Campbell and Spence, 1976). However, Phillips et al., (1978) challenged the applicability of this hypothesis to all such cases. They arqued that under certain circumstances the development of the phytoplankton may be an effect of the decline of the macrophytes rather than a cause. This hypothesis is examined closely with respect to events at Pukepuke.

Previous limnological studies at Pukepuke (apart from that of Gibbs, 1973):

Cunningham et al. (1953) undertook a general limnological survey of coastal dune lakes in the west of the North Island, including Pukepuke Lagoon. 
Mark-Brown (1978) edited a technical report by the Rangitikei-Wanganui Catchment Board. This was mainly concerned with hydrological aspects in the region of Pukepuke, Kaikokopu and Omanuka Lagoons. Some water chemistry was monitored and aquatic plant species noted.

Ogden and Caithness (1982). This paper is the first in a series which will describe studies carried out during 1968-1973 on the ecology of raupo (Typha orientalis). 
Chapter 2

\section{METHODS}

\subsection{Bathymetry}

In January 1976 depth measurements were recorded at $20 \mathrm{~m}$ intervals along 12 compass sighted transects of Pukepuke Lagoon. Additional measurements were taken at points within $20 \mathrm{~m}$ of the margin.

\subsection{Aerial photography}

Periodic flights were arranged with the Civil Aviation Division of the Ministry of Transport to photograph Pukepuke Lagoon and surrounding areas. This assisted in the recording of seasonal vegetational patterns and water coverage.

\subsection{Weather and water levels}

Air temperature and rainfall data were obtained from equipment located next to the House Pond.

Water levels were monitored by an automatic recorder situated in the drain connecting Pukepuke Lagoon to the Small Lagoon. The height of the water level control structure located in the outlet Drain at the western boundary of the Reserve was $6.24 \mathrm{~m}$ above mean sea level (the lagoon itself is about five to six meters above sea level).

\subsection{Sampling stations and times}

Sixty-eight permanent sampling stations (steel stakes) were established along several margin transects and in open water locations, mainly to permit adequate measurement of aquatic plant communities (see Fig. 2.4.1). Limnological sampling was carried out in most months, although never during the hunting season (May and sometimes June) . 


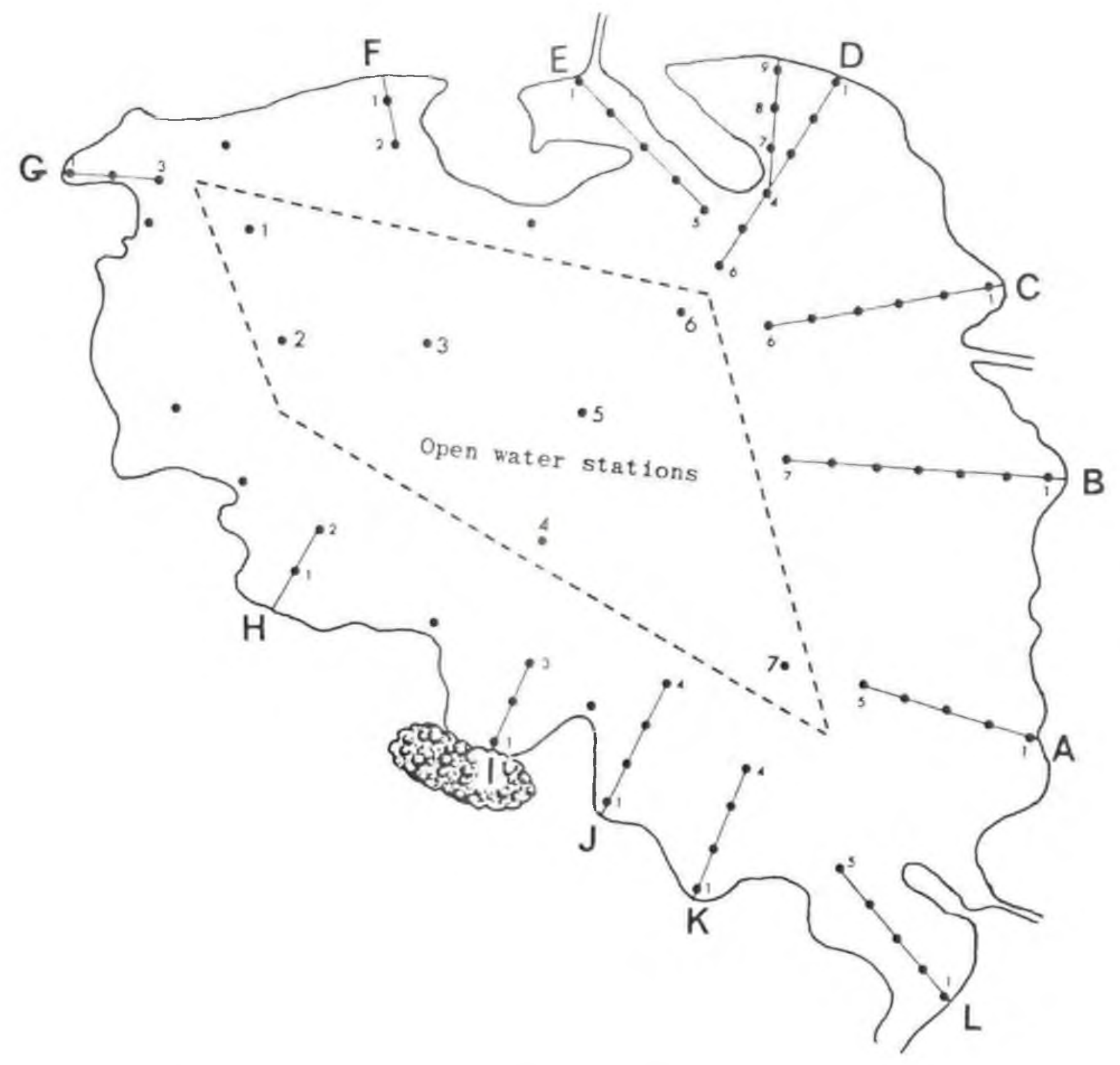

Fig. 2.4.1. Location of samplirg stations. 


\subsection{Water chemistry}

Mid-water samples were collected at irregular intervals from open water stations 1 and 5 . The majority of the analyses were undertaken in the wellington city Council Laboratories by arrangement with Mr I. L. Vidal. These included the following parameters: nitrite - N, nitrate - N, free ammonia - N, total Kjela. - N, alb. amm. - N, reactive $\mathrm{P}$, total $\mathrm{P}, \mathrm{Cl}$, alkalinity, $\mathrm{SiO}_{2}, \mathrm{SO}_{4}, \mathrm{Fe}, \mathrm{Ca}, \mathrm{Mg}, \mathrm{Na}, \mathrm{K}, \mathrm{Mn}$. In addition, the following analyses were carried out in the field: $\mathrm{pH}$ (using a Lovibond "1000" Comparator), conductivity and salinity (using a YSI Model 33 salinity-conductivity-temperature meter).

\subsection{Macrophyte sampling}

2.6.1 Rake method

The problems involved in quantitatively sampling macrophytes located in water deeper than wading depth, particularly where substrate is soft silt or mud (as is partly the case at Pukepuke), are well known. Direct cutting using diving equipment is made difficult in mud or silt by reduced visibility associated with clouding of the water. A Geriing sampler (Gerking, 1975) used in preliminary trials at Pukepuke presented difficulties of operation - including proper slide closure - in water more than about $0.5 \mathrm{~m}$ deep; this was especially so when soft mud encouraged the sinking of the device.

Since the main purpose of sampling macrophytes in this study was to follow the seasonal pattern of development, a highly precise method of biomass measurement was not essential. Consistency of sampling was the main requirement, although a good approximation of absolute density at each sampling site was deemed desirable. 
After considerable experimentation the device developed and used in routine sampling was a common garden rake (316 $\mathrm{mm}$ wide) with $15 \mathrm{~mm}$ diameter chicken mesh stretched across it as shown in Plate 5. This was placed in the water at a slight angle, drawn across the substrate for a distance estimated to be the equivalent of the width of the rake, and hauled up. Theoretically a $0.1 \mathrm{~m}^{2}$ area would be sampled in this way. Preliminary and subsequent routine application of the method indicated that, in the relatively shallow water of Pukepuke Lagoon, it was extremely efficient in terms of its ability to both cut and withdraw the macrophytes present.

In the winter to early summer months rake samples were obtained from all 68 stations. In the mid-summer to autumn period, when some of these stations became exposed and most or all of the weed had disappeared, sampling was confined to open water stations.

In the laboratory macrophyte samples were washed, sorted to type, genus or species, and placed in an air-dried oven at $105^{\circ} \mathrm{C}$ for 24 hours before weighing.

To avoid the possibility of species misrepresentation on occasions, Myriophyllum was listed only to genus (this plant is notoriously difficult to identify to species from vegetative parts alone). ecause Zannichellia palustris and Ruppia polycarpa were often very difficult to distinguish when seeds or fruits were unavailable, all fragments of these species, positively distinguished or not, were registered as Zannichellia/Ruppia. 
2.6.2 Trial comparing the efficiencies of the rake and modified Gerking methods to the direct hand cutting method

(a) Objectives

1. To test the efficiency of the rake method relative to the hand cutting method (an exact method).

2. To test the efficiency of the Gerking method lagain relative to the exact hand cutting method). I had reservations about the accuracy of the Gerking method, even though various workers have employed it (or modifications thereof) as a quantitative method of measurement (Gibbs, 1973, used it on a very limited scale at Pukepuke). My own experience showed that the placement of the box-like frame produced considerable flattening of the weed.

(b) Methods

Three sampling techniques - hand cutting (using a two-part hand placed frame), Gerking (modified), and rake - were applied side by side $(40 \mathrm{~cm}$ apart) at 30 randomly placed sites in an almost pure stand of surface-reaching Ranunculus fluitans located in the Four Islands West Pond. The substrate was sand. Water depth ranged from 55-70 cm. The sampling devices are shown in Plate 5. All theorectically sampled a $0.1 \mathrm{~m}^{2}$ area of weed.

Each part of the two-part hand placed frame was teased into position through the weed strands to avoid a flattening effect.

Only the frame of the Gerking sampler was used in the trial. That is, instead of inserting the slide to try to cut and retain the weed 
Flate 5. Macrophyte sampling equipment.

1. Gerking sampler

2. Rake sampler

3. Hand-cutting frame 

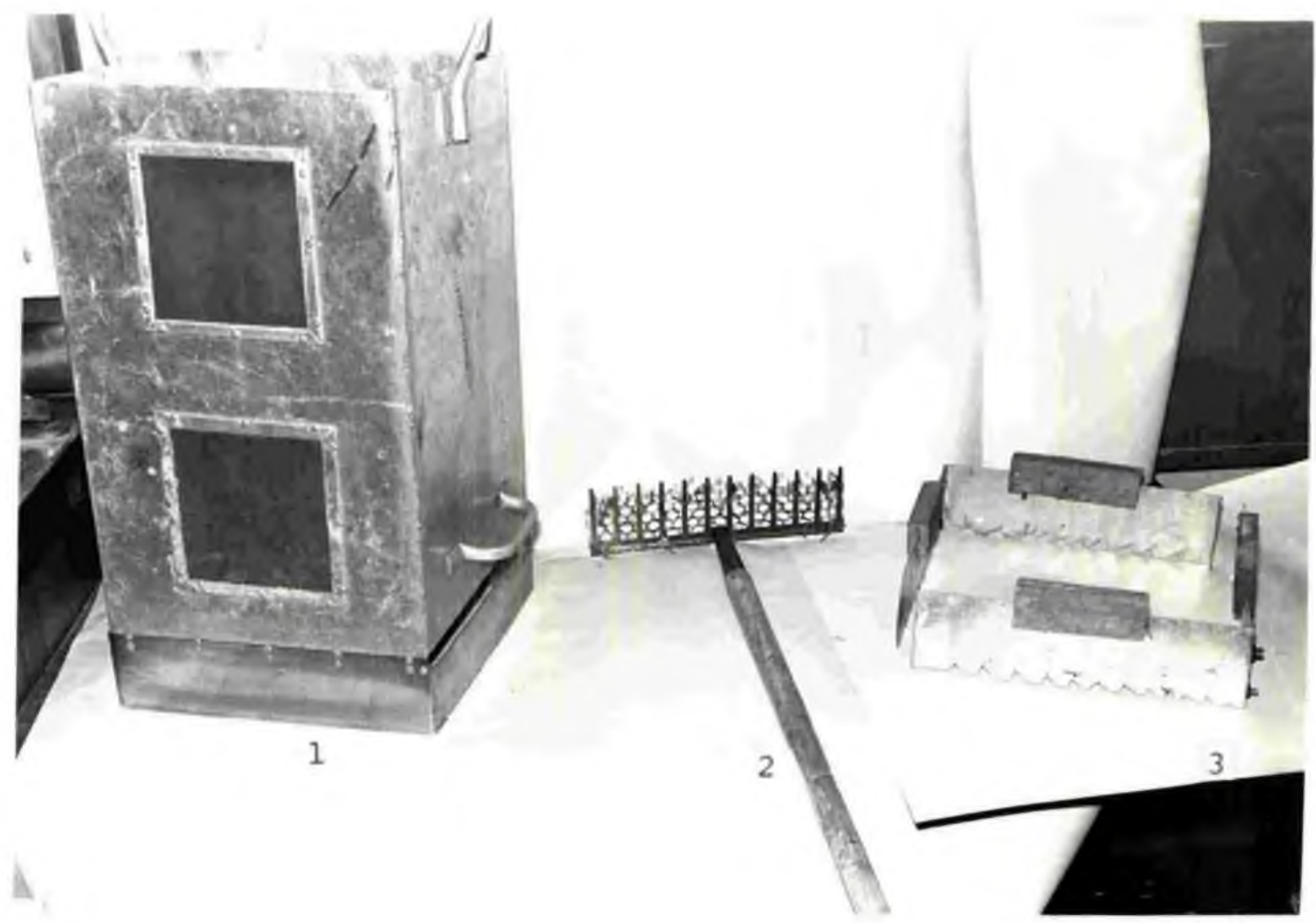
prior to uplift, the weed was removed by hand in the same manner was was done with the weed enclosed in the low, two-part hand placed frame - the so-called hand cutting method.

\section{(c) Results}

A two-way analysis of variance undertaken on the 'hand-cut' and rake data showed that both blocks and treatments were significantly different (blocks: $\mathrm{F}_{23,23}=3.154, \mathrm{P}<.01$; treatments: $\mathrm{F}_{1,23}=5.279$, $\mathrm{P}<.05$ (see Table 2.6.1(a)). Such an analysis when applied to the 'hand-cut' and Gerking data showed that although there was some variation due to site (blocks: $F_{23,23}=2.216, \mathrm{P}_{2} .05$ ) there was no significant variation due to method (treatments: $F_{1,23}=0.326$ ) (see Table 2.6.I(b)).

The mean of 30 samples of weed collected by the rake method was $30.625 \mathrm{~g}$ dry weight compared to $24.029 \mathrm{~g}$ for the direct hand cutting method and $24.113 \mathrm{~g}$ for the Gerking.

\section{(d) Conclusions}

The flattening effect produced by the Gerking sampler did not appear to introduce error - at least under the conditions of the trial. The mean biomass obtained using the rake method exceeded the Gerking and hand cut means by some 270 . The extent of this overestimation is unlikely to be constant in all circumstances. As with other indirect sampling methods, efficiency must be greatly influenced by such variables as weed type, density, depth, water current and operator bias.

Despite the fact that the rake method tended to overestimate in the trial conditions, it is nonetheless believed that where routine 
2-WAY ANOVA

(a) Hand cutting/Rake method (30 pairs)

\begin{tabular}{|c|c|c|c|c|}
\hline Source of variation & Sum of squares & df & E (mean square) & F-ratios \\
\hline Blocks & 7174.638 & 23 & 311.94 & $F_{23,23}=3.154^{* *}$ \\
\hline Treatments & 522.1 & 1 & 522.1 & $F_{1,23}=5.279$ \\
\hline Residual & 2274.654 & 23 & 98.898 & \\
\hline Tota 1 & 9971.392 & 47 & & \\
\hline
\end{tabular}

Critical values:

(1) Block effects:

$E_{20,23}(18)=2.7805$

(2) Treatment effects:

$F_{1,23}(58)=4.280$

(b) Hand cutting/Gerking sampler ( 30 pairs)

\begin{tabular}{|c|c|c|c|c|}
\hline Source of variation & Sum of squares & $d f$ & (mean square) & F-ratios \\
\cline { 2 - 5 } Blocks & 3483.865 & 23 & 151.472 & $F_{23,23}=2.216$ \\
Treatments & 22.298 & 1 & 22.298 & $F_{1,23}=0.326$ n.s \\
Residual & 1572.127 & 23 & 68.353 & \\
& 5078.29 & 47 & & \\
\hline
\end{tabular}

Critical values:

(1) Block effects:

$F_{20,23}(18)=2.7805 \quad F_{20,23}(58)=2.0267$

(2) Treatment effects:

$F_{1,23}(5)=4.280$

Table 2.6.1. Two-way analysıs of varıance of macrophyte data obtained by (a) the hand cut and rake sampler methods and (b) the hand cut and modified Gorking sampler methods 
monthly rake biomass maximums are given - be they in terms of any combination of species (Figs. 3.4 .2 and 3.4.4) or in terms of individual species (Appendix 1 and 2) - these maximums can reasonably be expected to be conservative indicators of the kinds of densities attained in the lagoon. This contention is based on statistical inference backed by some empirical evidence. Statistical inference: floristically Pukepuke Lagoon is extremely heterogenous with respect to plant species representation and density. It is improbable that the relatively limited number of routine spot samples taken in any one month (maximum 68) would have encompassed the upper limits of biomass variability (the combined substrate area sampled at the 68 stations constituted only 0.0048 of the total area of the lagoon). Empirical evidence: the two most dominant submerged macrophyte species in the summer of 1977 were Chara and Potamogeton crispus. To test whether the maximum densities of these species, as obtained in the routine rake samples near the height of production in December 1977 (see Fig. 3.4.2), were not gross overestimates of the true maximums, hand cut Gerking samples were taken from dense, almost pure stands of each of these species. (The stands used for sampling were selected by eye as being likely to approximate the highest densities in the lagoon.) The maximum routine rake figure for Chara was $206.1 \mathrm{~g}$ dry weight. Whearas For P. crispus the maximum rake figure was $38.2 \mathrm{~g}$ compared to a 9 dry wt maximum hand cut figure of 56.6. In the case of both macrophyte species, therefore, the routine rake densities were considerably less than the visually selected hand cut samples.

The routine $0.1 \mathrm{~m}^{2}$ rake results were not expanded to square metre values (such a procedure would have been followed had hand cut samples been obtained). 
Westlake (1975) lists several references which indicate that submerged macrophyte species may exceed a biomass of $500 \mathrm{~g}$ dry weight per $\mathrm{m}^{2}$ at fertile sites. By expanding the hand cut Gerking figures obtained for Chara and $\underline{\underline{P}}$. crispus (as shown above) to square metre values it can be seen that the levels reached easily fall within the fertile site category (Chara $2061 \mathrm{~g}$ and $\underline{\mathrm{P}}$. crispus $566 \mathrm{~g}$ dry weight $\left./ \mathrm{m}^{2}\right)$.

\subsection{Zooplankton sampling}

\subsubsection{Field sampling}

A van Dorn sampler was used to obtain monthly mid-water samples. Samples were taken from each of the open water stations 1, 2, 6 and 7, except in February, March and April 1978. In these months only stations 1 and 2 were sampled (stations 6 and 7 were exposed due to the influence of a drought). More than one sample was obtained from the lagoon in each month since two of the most dominant groups occurring therein, cladocerans and copepods, exhibit a strong tendency toward clumping (see also Kott, 1953; Cassie,1971).

The samples were transferred to the laboratory in jars containing $50 \mathrm{ml}$ of $\mathrm{l}: 1$ formalin/ethyl alcohol.

\subsubsection{Laboratory preparation and counting}

water samples were filtered through $600 \mu \mathrm{m}$ and $250 \mu \mathrm{m}$ diameter Endicott sieves placed in series. Each of the fractions were then processed in the following way:

The material was washed into a plastic funnel which was inserted tightly into the neck of a $25 \mathrm{ml}$ glass vial. Several $10 \mathrm{~mm}$ apertures drilled into the neck of the funnel down to the point of insertion into the vial were covered with $75 \mathrm{~mm}$ monofilament mesh. 
This retained the zooplankters, allowing the removal of water. The attached funnel and vial was then inclined to remove about one third of the water in the vial. A fine jet of water was then applied to the funnel mesh to remove adhering zooplankters. The zooplankton concentrated in the vial were then transferred by aropper into a rotating counting wheel attached to the stage of a microscope (modified after that described by Swanson and Thornsberry, 1972).

Organisms were classified according to class. No attempt was made to distinguish between immature and mature stages.

\subsection{Phytoplankton and epiphytic algae sampling}

2.8.1 Phytoplankton productivity

Measurements of phytoplankton productivity were obtained at monthly intervals from open water station 5 using the light and dark bottle oxygen method described by Gaarder and Gran (1927). A self-stirring BOD probe (Yellow Springs Instrument Co. No. 5720) with $0.001 \mathrm{~mm}$ membranes was used to measure dissolved oxygen concentration (after the method of Carrit and Kanwisher, 1959). This was adapted to fit a YSI Model 54 ABP oxygen meter. A 6-volt car battery powered the probe stirrer so that measurements could be made in the field.

The incubation period was two hours between 1200 and $1400 \mathrm{~S} . \mathrm{T}$. Duplicate $250 \mathrm{ml}$ Pyrex bottles were suspended vertically from a float just below the water surface.

Productivity was expressed as milligrams of carbon per litre per hour.

Secchi disc readings were used to supplement productivity measurements. 
2.8.2 Phytoplankton and epiphytic algae indentification Samples of phytoplankton and epiphytic algae (the latter covering macrophytes in the spring) were forwarded for identification to $\mathrm{Dr}$ V. Cassie, Botany Division, D.S.I.R., Auckland.

\subsection{Aquatic invertebrate sampling}

\subsubsection{Gastropod - macrophyte relationship}

A pilot study of the seasonal pattern of production and availability of gastropods was begun in the winter of 1977. At this time the most accessible and abundant quantities of submerged macrophyte stock occurred very close to the margin in raupo-free bays. One of these beds, located within $1 \mathrm{~m}$ of the margin in Dar Bay (near transect D) and composed mostly of Potamogeton crispus, was chosen as a site to begin the study. Six macrophyte samples were collected at random using the standard $0.1 \mathrm{~m}^{2}$ rake method. Each sample was placed in a plastic bag. In the laboratory snails were removed from the plants by high pressure washing, then separated into two size groups using $850 \mu \mathrm{m}$ and $600 \mu \mathrm{m}$ mesh diameter Endicott sieves placed in series. The groups were counted. Results were expressed as gastropods per gram dry weight of plant material. Some details of relative species abundance was also noted. (In the first two months of sampling each snail was identified, but this was discontinued due to the laboriousness of the task, and because the study was proceeding purely as an exploratory exercise.)

The above procedure was followed at monthly or two-monthly intervals until November 1977, at which time it was noted that the spring-initiated macrophyte growth of the open water - again predominantly $\underline{P}$. crispus - was almost never used for feeding by ducks, even though it was by then dense and surface-reaching. 
Random net sweeps, as well as general observation, indicated that the fauna occupying this weed was extremely sparse compared to the position applying in smeltered inshore areas. At this point the snail study was expanded to include both inshore and open water sites. That is, in addition to sampling the margin tract, samples were collected in the same way from two open water sites. One site was arbitrarily chosen in an area underlain by sand (near station 5), the other was similarly chosen in an area underlain by mud (near station 2). Samples were taken as well from spring-initiated $\underline{\mathrm{P}}$. crispus growth in the shelter of Oar Bay (beyond the immediate margin zone). This expanded programme was repeated in December.

Note: Although the methodology of this study was less than ideal in terms of the fact that individual snail species were lumped together, it must be stressed that the study evolved purely as an exploratory exercise. I have chosen to incorporate it into the main body of the thesis since it makes a very worthwhile and clear-cut point about the way in which a particular invertebrate form (a valuable mallard food source) relates to the seasonal development and distribution of macrophytes.

\subsubsection{General seasonal availability of plant-associated invertebrates}

Notes were taken on the general seasonal availability of plant-associated macroinvertebrates. These were based on ad hoc 'standara' net sweeps. A net with an 18 × $45 \mathrm{~cm}$ gape was drawn through the water for an estimated $50 \mathrm{~cm}$ (the top of the long dimension was at surface level). The mesh size was $1.5 \mathrm{~mm}$. 
Chapter 3

\section{RESULTS}

\subsection{Bathymetry}

Depth contours and substrate type are shown in Fig. 3.1 .1 (note water level calibration to $6.2 \mathrm{~m}$ above m.s.l.). The physical reasons for the accumulation of organic material in the western half of the lagoon are discussed in the caption.

\subsection{Water levels, flow, rainfall, air and water temperatures} The pattern of water level fluctuation from 1969 to 1979 is shown in Fig. 3.2.1. This indicates a general pattern of high winter levels (due to high inflow) and low summer levels due to zero inflow and surface evaporation loss). Flow through the basin (flushing) is indicated when the graph goes above the shown height of the water level control structure situated in the outlet Drain. Although some hydrological data from the locality are available from records kept by the Rangitikei-Wanganui Catchment Board, the N.Z. Metereological Service, and the Ministry of Works and Development, these do not include information allowing for the calculation of monthly flow rates or turnover. In a published report on the water resources of the Oroua Downs drainage area, the Rangitikei-Wanganui Catchment Board described winter inflows into Pukepuke as being 'large' (Mark-Brown, 1978).

Monthly water levels, rainfall, and air and water temperatures for 1977 to 1979 are shown in Fig. 3.2.2. 
Fig. 3.1.1. Depth (m.) contours of Pukepuke lagoon as surveyed in January 1976 (calibrated to $6.2 \mathrm{~m}$ above m.s.l.). The unshaded area indicates firm sano substrate, the shaded area soft organic material derived mainly from raupo decomposition. Red contcur lines represent the continuation of the sandy base substrate of the eastern half of the lagoon. The sand basin deepens further toward the west from where the present raupo front has advanced. The accumulation. of organic material in the western half of the lagoon is a function of increasing depth comtined with the influence of currents (from inflows) in this direction. 


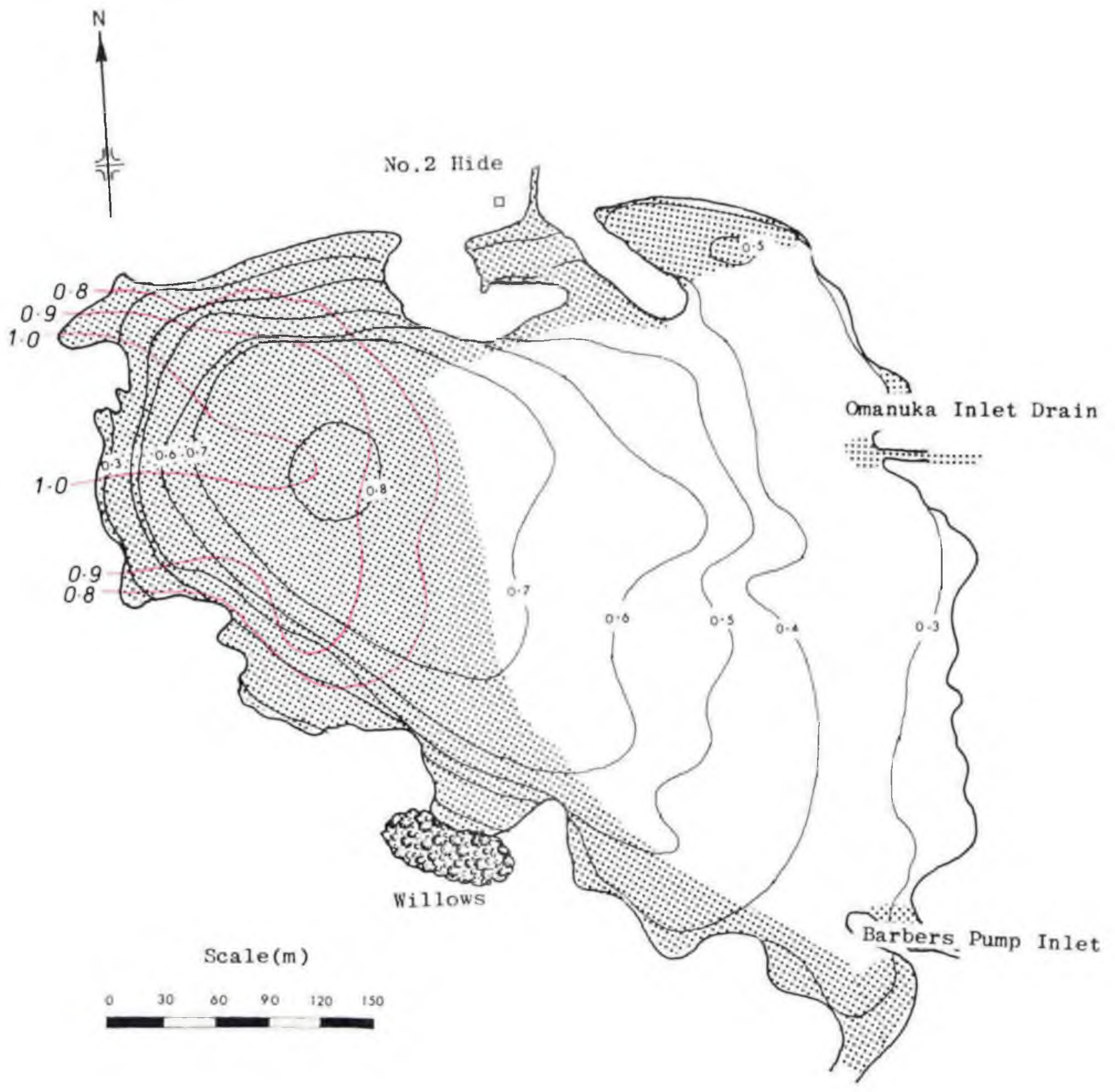


Metres above M.S.L.

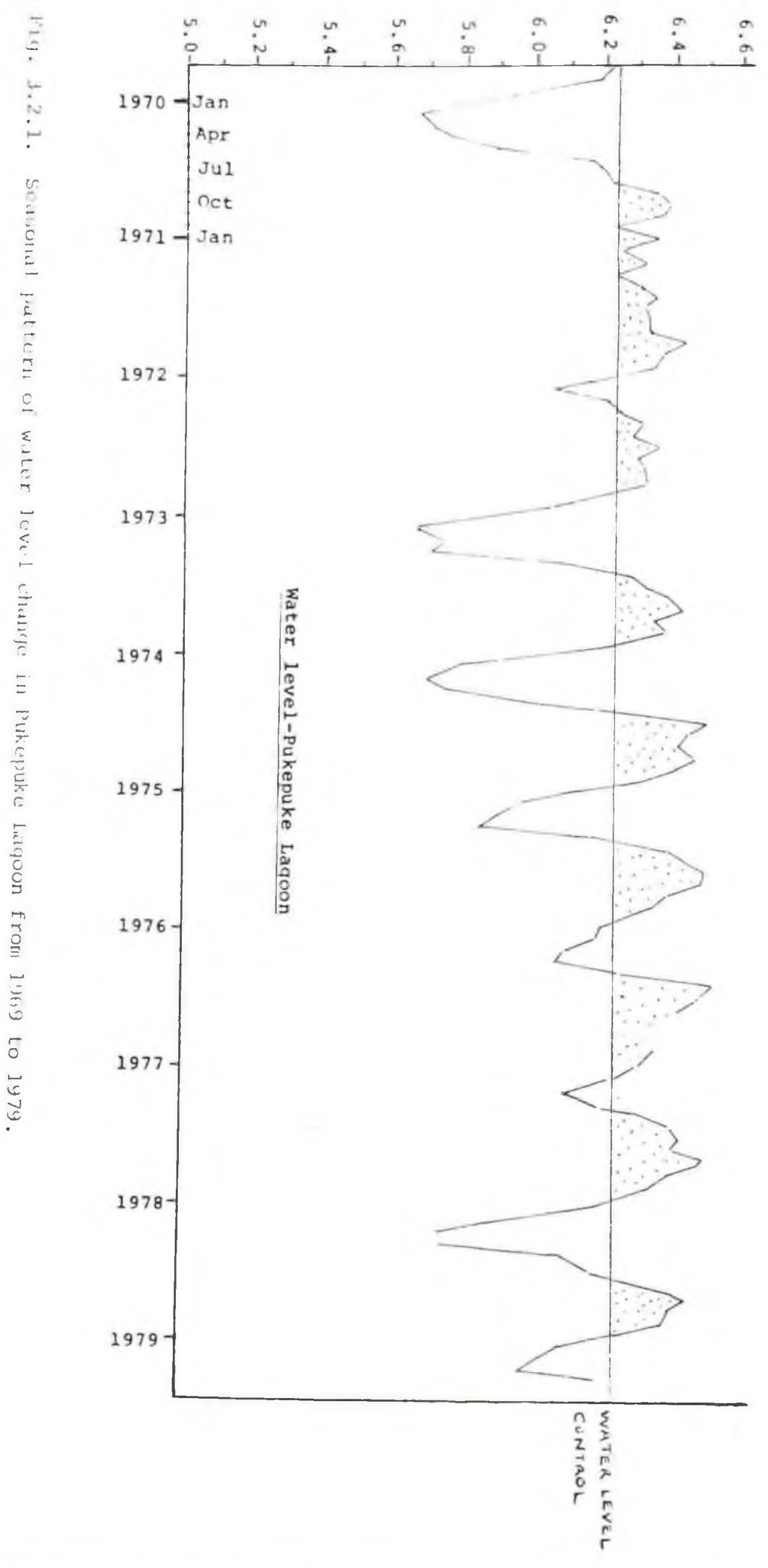



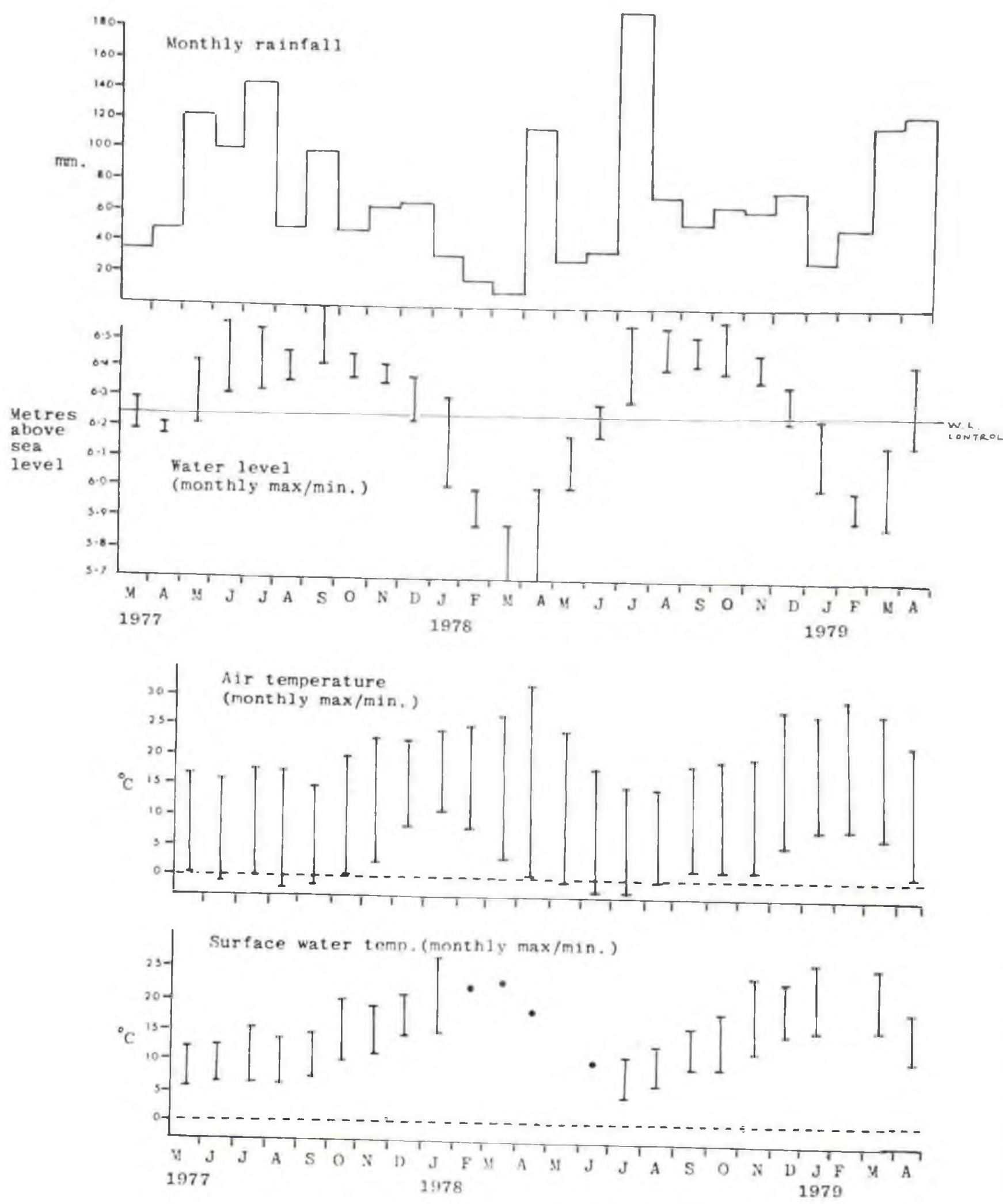

Fig. 3.2.2. Monthly rainfall, water level, air temrerature and surface water tem erature. 


\subsection{Water chemistry}

Water chemistry data are presented in Table 3.3.1. I have reserved a description of major trends in this information until the discussion in Chapter 4. This is because the Rangitikei-Wanganui Catchment Board (Mark-Brown, 1978) also collected water chemical data for a period overlapping with my own monitoring period. Because some of their information supplemented my own (and vice versa) a more comprehensive summary can be given by reference to both sets of results.

\subsection{The occurrence of macrophytes}

The following submerged macrophytes were identified at Pukepuke: Angiosperms: Potamogeton pectinatus, Potamogeton crispus, Ranunculus fluitans, Myriophyllum elatinoides (other species of this genus may occur), Zannichellia palustris, Ruppia polycarpa.

Charophyte: $\quad$ Chara globularis.

Filamentous algae: Vaucheria sp. and Enteromorpha sp. lother filamentous algal species certainly occur.)

A variety of low to medium height emergent species were identified. These included Veronica anagallis-aquatica, Polygonum decipiens, Juncus articulatus, Cotula coronopifolia, Scirpus lacustris, Nasturtium officianale, Alismo plantago- aquatica and Ranunculus sceleratus.

The pattern of occurrence and seasonal development of macrophytes and emergents as determined by systematic surveys at fixed stations is described as follows: 
23

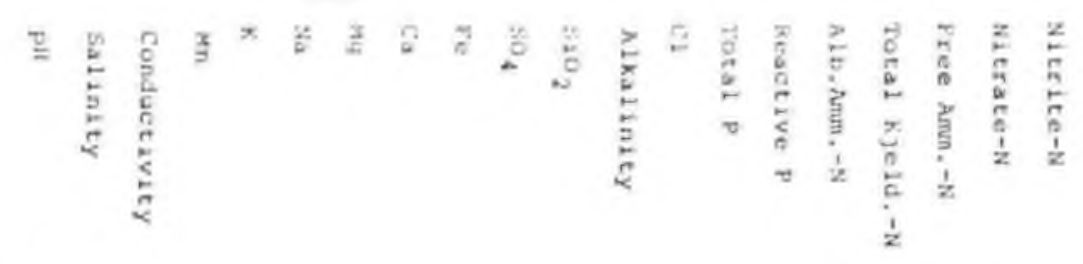

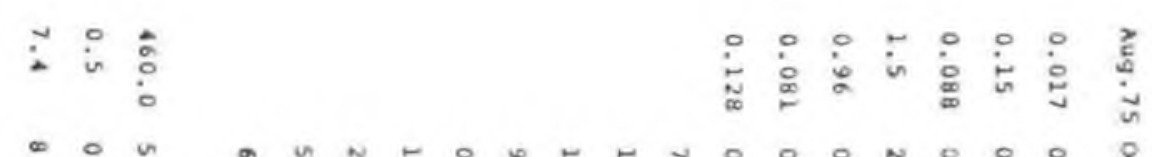

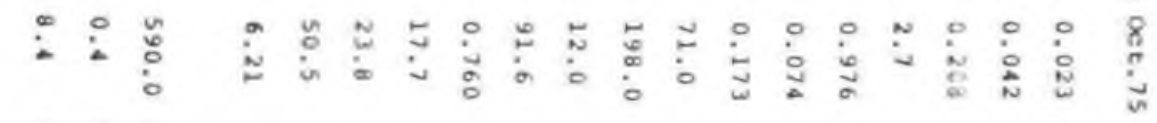

$\stackrel{i}{i} \underset{0}{\infty}$

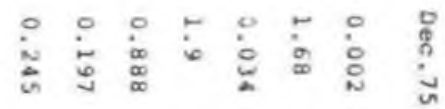

$\stackrel{i}{i} \stackrel{0}{\stackrel{0}{\circ}}$

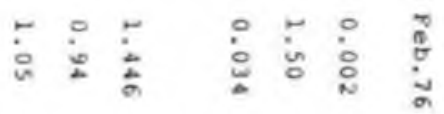

$\stackrel{i}{i} \underset{0}{0}$

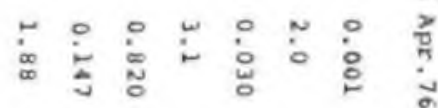

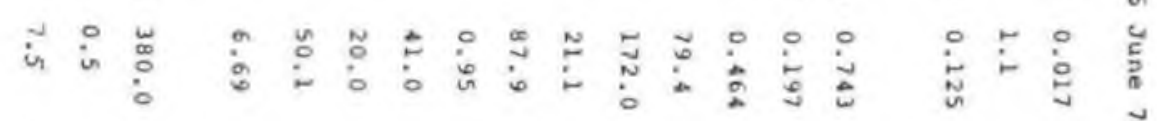

$\dot{i}$ is :

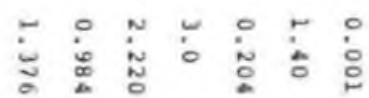

«

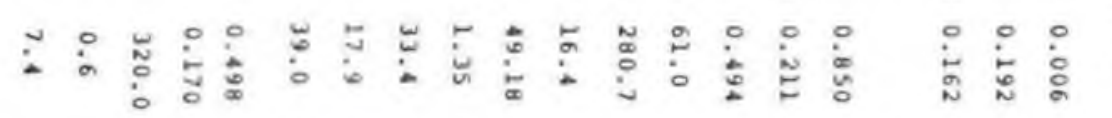

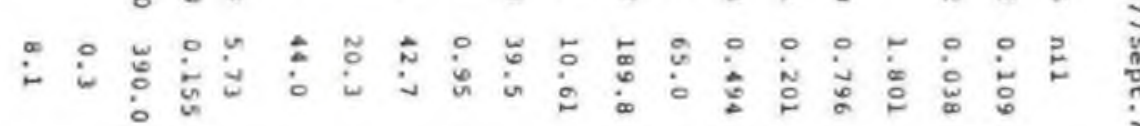

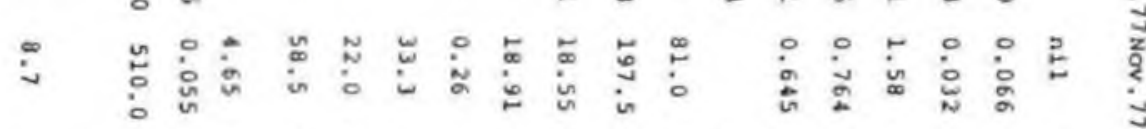

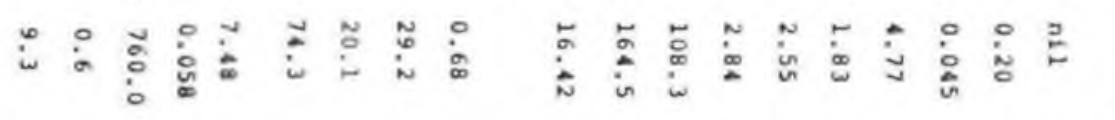

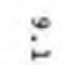

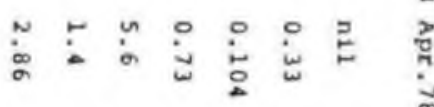

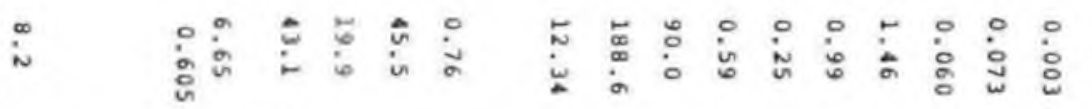

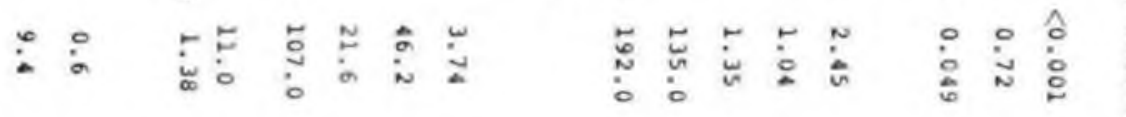

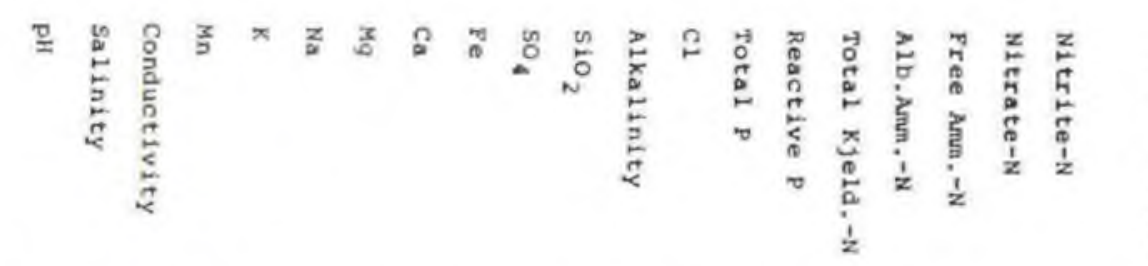

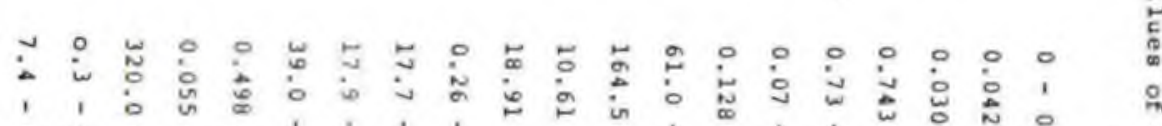

• 
3.4.1 Macrophyte development in 1977/78 (commencing July 1977) The location and seasonal spread of particular macrophytes is depicted in Fig. 3.4.1.(a)-(d). Biomass data is summarised in relation to the occurrence of a summer phytoplankton bloom in Fig. 3.4.2. (Note: although the year-round pattern of phytoplankton productivity is presented elsewhere (Fig. 3.6.1.) it was considered desirable to present the macrophyte data in relation to the summer bloom; as will be discussed later, the decline of macrophytes in the summer may be linked to the presence of phytoplankton.) Monthly maximum densities recorded for particular macrophytes are given in Appendix 1 .

In the summer prior to commencing macrophyte sampling, i.e. in the sumner of $1976 / 77$, all or most of the macrophytes disappeared. Because the water level in this summer did not recede to expose much of the substrate, widespread aerial colonisation of this plane by Veronica seedlings, such as was described by Gibbs (1973) for the drought summer of 1970, did not occur. However, the very slight exposure of margin zones that did occur encouraged the development of a wide variety of emergent plants and grasses. These became Elooded as water levels rose in the autumn and winter.

In the winter patches of Chara occurred in the otherwise rather sparsely vegetated open water area. The visual impact of this species was non-existent since it grew in very dense mats well below the surface.

Rapid growth of a wide variety of species occurred over the lagoon in the spring. Filamentous algae was an important component of this growth. By December the open water was clogged with 

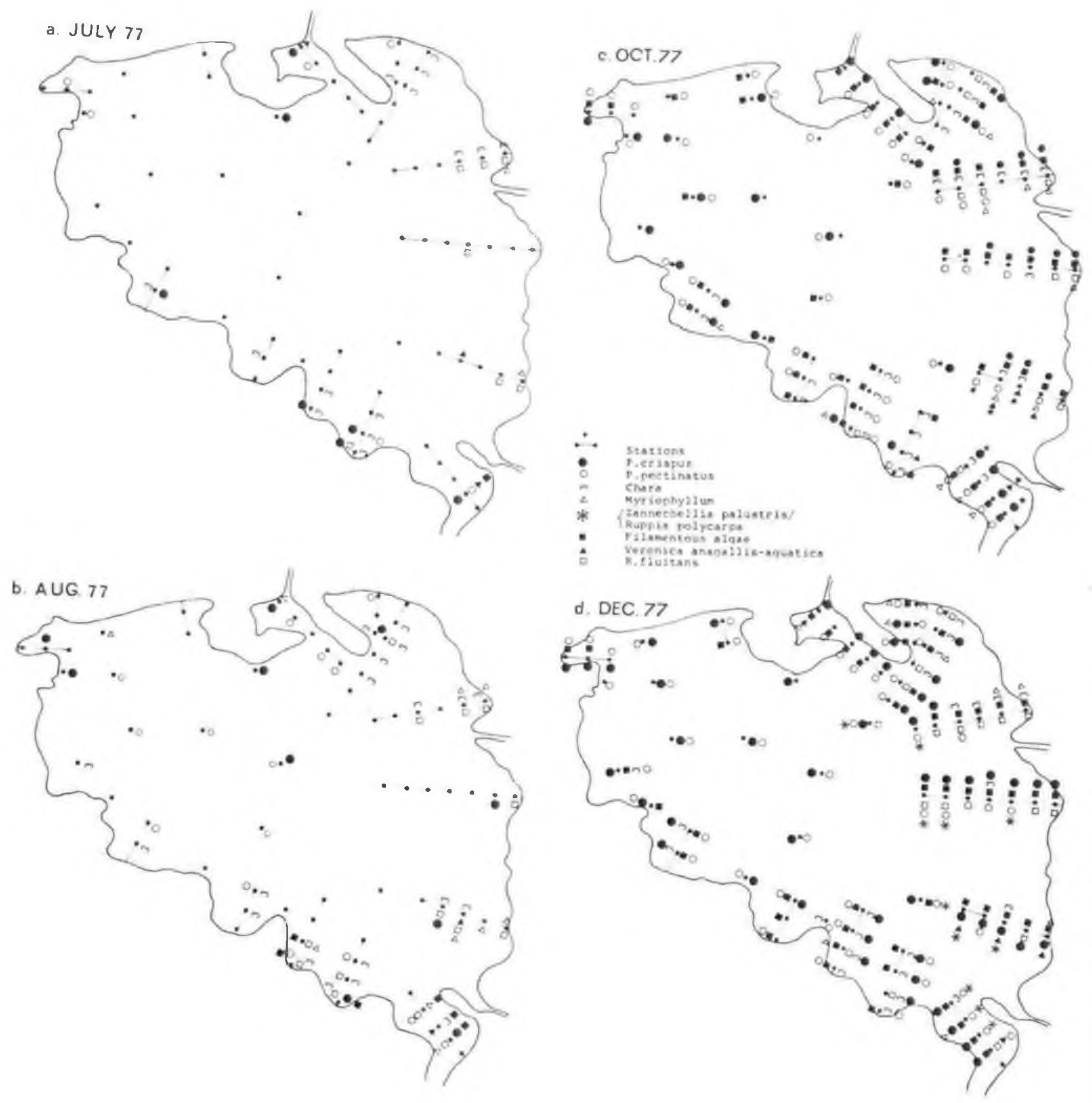

Fig. 3.4.I. Occurrence and seasonal development of macrophytes sampled in 1977. 


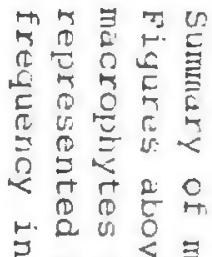
$\exists$ 可运

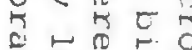

西告

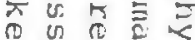

ज. +8 i

E

$=$ F.

$v^{2} \mathrm{c}$

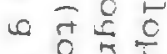

可唯告

क

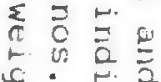

‥

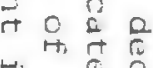

o. को

步市高

है

$30.5=$

$\vec{z} \div 0$

言的要

2.

- 3 品

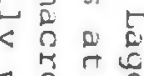

$\sum 0 \pi$

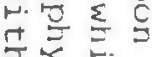

的完合

क

范 


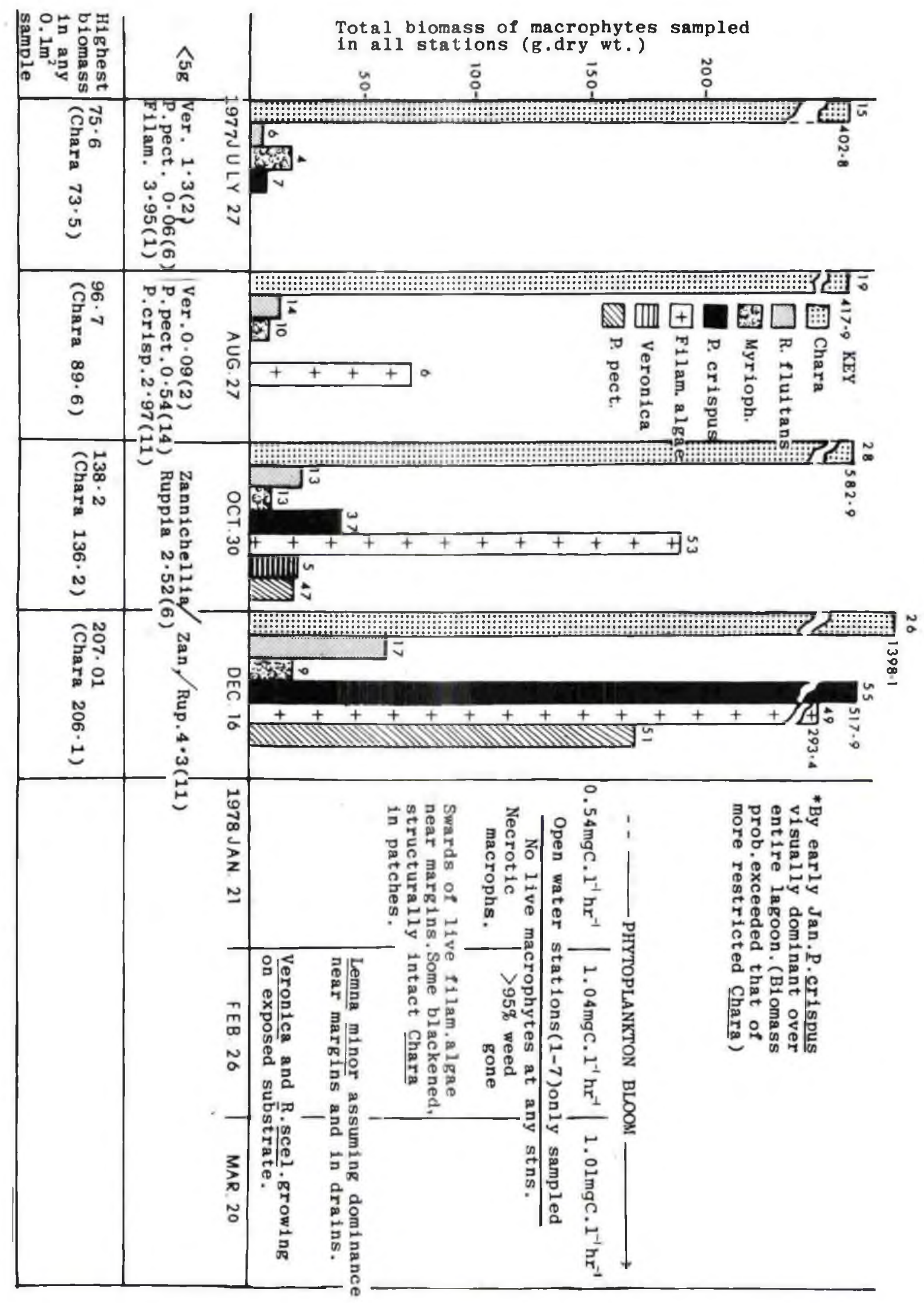


surface-reaching macrophytes, mainly $\underline{\text {. }}$ crispus (see Plate 6). Wave action was prevented. The extent of the dominance of $\underline{P}-\underline{\text { crispus up }}$ until January 1978 is under-emphasised by the biomass data presented in Fig. 3.4.4 since its main zone of occupation, the large open water area, was represented by only seven sampling stations.

As water levels receded and inflows ceased, under the influence of a severe drought, an intense phytoplankton bloom developed. This was accompanied by a general collapse and decay of the macrophytes (see Plate 7). Chara was the last species to physically disintegrate under the phytoplankton bloom. (Observations in previous years indicated that the species was particularly resistant to decay. In the summer of $1976 / 77$, for instance, when a phytoplankton bloom developed and all other macrophyte species had disappeared, much of the Chara remained structurally intact, although blackened, for up to six weeks. This became the conspicuous focus of intense mallard, grey and shoveler feeding since it contained great quantities of invertebrates such as snails. The resistance of Chara to disintegration is probably due to the fact that it is highly calcified and tends to form into a low dense mat. This seems to allow it to retain its structure well after its photosynthetic capacity is lost.)

By March over half the lagoon floor was exposed. Growth of Veronica seedlings had begun to occur on this exposed area, including the large area of sand substrate which had become dry and hard. Iush

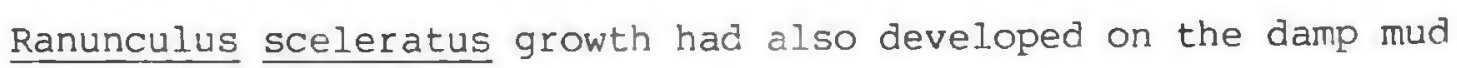
areas located in the bays of the western half of the lagoon (see Plates 3,8 and 10 ). 
Plate 6. Dense Potomogeton crispus dominating open water of Fukepuke Lagoon December 27, 1977. (Photograph taken near open water station 3 looking south-east to the 'willows!

Plate 7. The start of the summer phytoplankton 'bloom' and associated collapse of macrophytes mid-January 1978. 

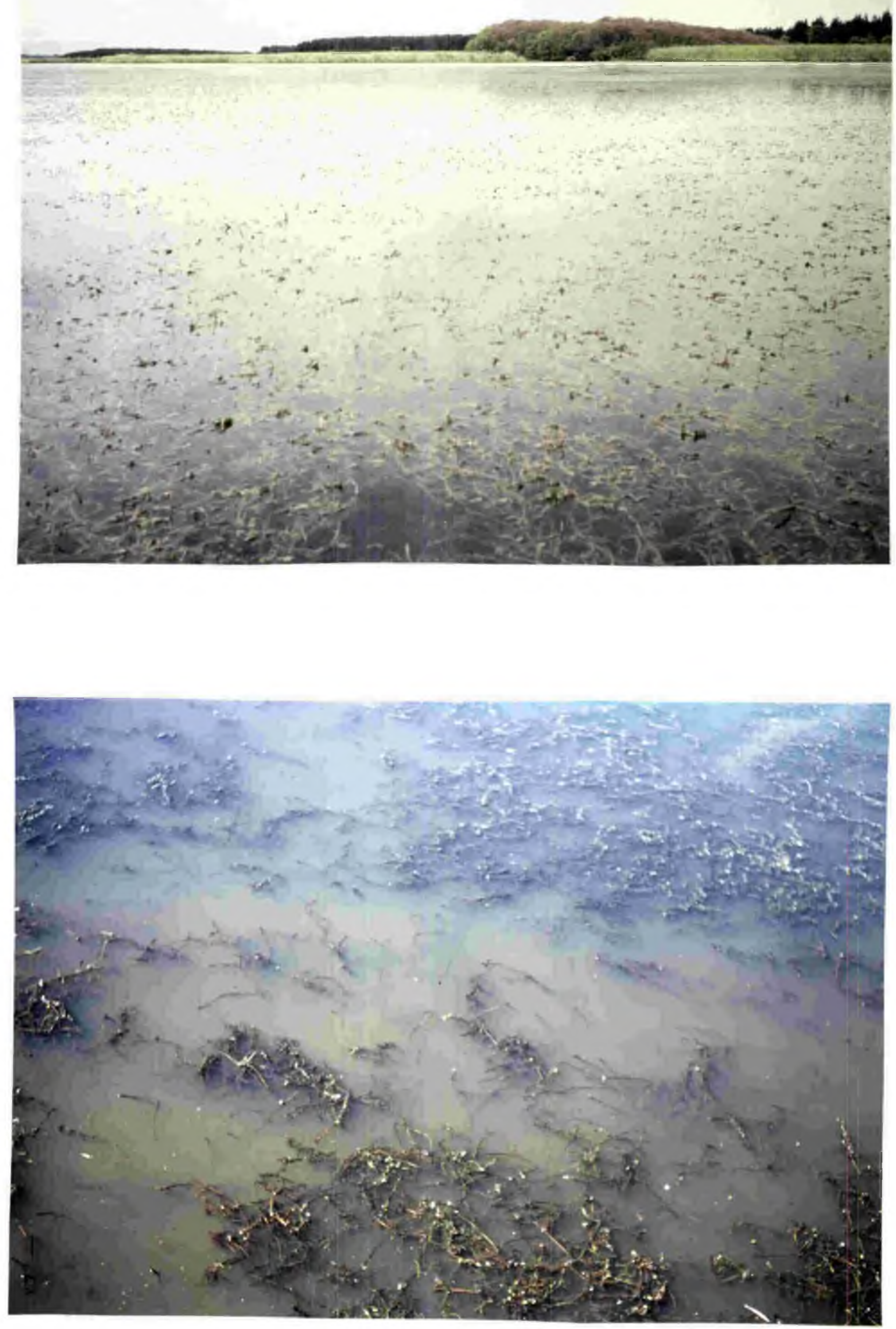
A feature of the spring to early summer flora of 1977 was the $\mathrm{r}$ ise to prominence and intensified reddening of floating mats of Azolla rubra. Such mats occurred in sheltered bays and drains. This species had largely died away by January 1978 and was replaced by a prominent Lemna minor (duckweed) growth which continued into autumn.

\subsubsection{Macrophyte development in 1978/79}

The location and seasonal spread of particular macrophytes is depicted in Fig. 3.4.3 (a)-(d). Biomass data is summarised in relation to the occurrence of a summer phytoplankton bloom in Fig. 3.4.4. Monthly maximum densities recorded for particular macrophytes are given in Appendix 2.

Once water levels rose in the autumn of 1978, the Veronica and R. sceleratus, which began to appear on the exposed substrate in the previous summer, continued to grow vigorously - the Veronica entirely underwater (Plate 9). Some R. fluitans joined the Veronica in the sandy zones.

In about the middle of May, as water temperatures lowered and light diminished, plant growth appeared to slow considerably. At this point the extensive, lush growth of Veronica and $\underline{R}$. sceleratus began to be severely grazed by black swans (since 1973 large flocks of swans have gathered on Pukepuke after the shooting season, i.e. from May or June to about September - see Section 3). By around late August about three quarters of this growth had been depleted. $\mathrm{R}$. sceleratus was largely eliminated, not only because it was eaten, but also because of its celery-like brittleness and hollow stem. Once it was broken by swans moving through it, or feeding on it, it 
quickly rotted as rain or lagoon water entered its hollow centre. Grazing impact was particularly severe in the winter because of the low rate of growth.

The same pattern of accelerated spring growth occurred as in the previous year. Again $\underline{P}_{\text {. }}$ crispus developed to dominate in the lagoon. This prevented wave action.

Water levels lowered somewhat in December, but during the rest of the summer did not reach the low levels of the previous year.

The phytoplankton bloom occurring in the summer was less intense than in the previous year (Fig. 3.6.1). Only a partial collapse of the macrophyte beds occurred. The bloom dissipated in March as heavy rainfall and hence inflow occurred.

The change from Azolla rubra to Lemna minor occurred around January as in the previous year.

Veronica, R. sceleratus, and other emergent plants and grasses began to develop on the very small area of substrate which became exposed in the summer.

The main differences between the floral compositions and sequences of 1977 and 1978 were:

1977 (Beginning July)

- Small winter-spring intrusion of emergents into the lake because of a small water level recession in the previous summer. 

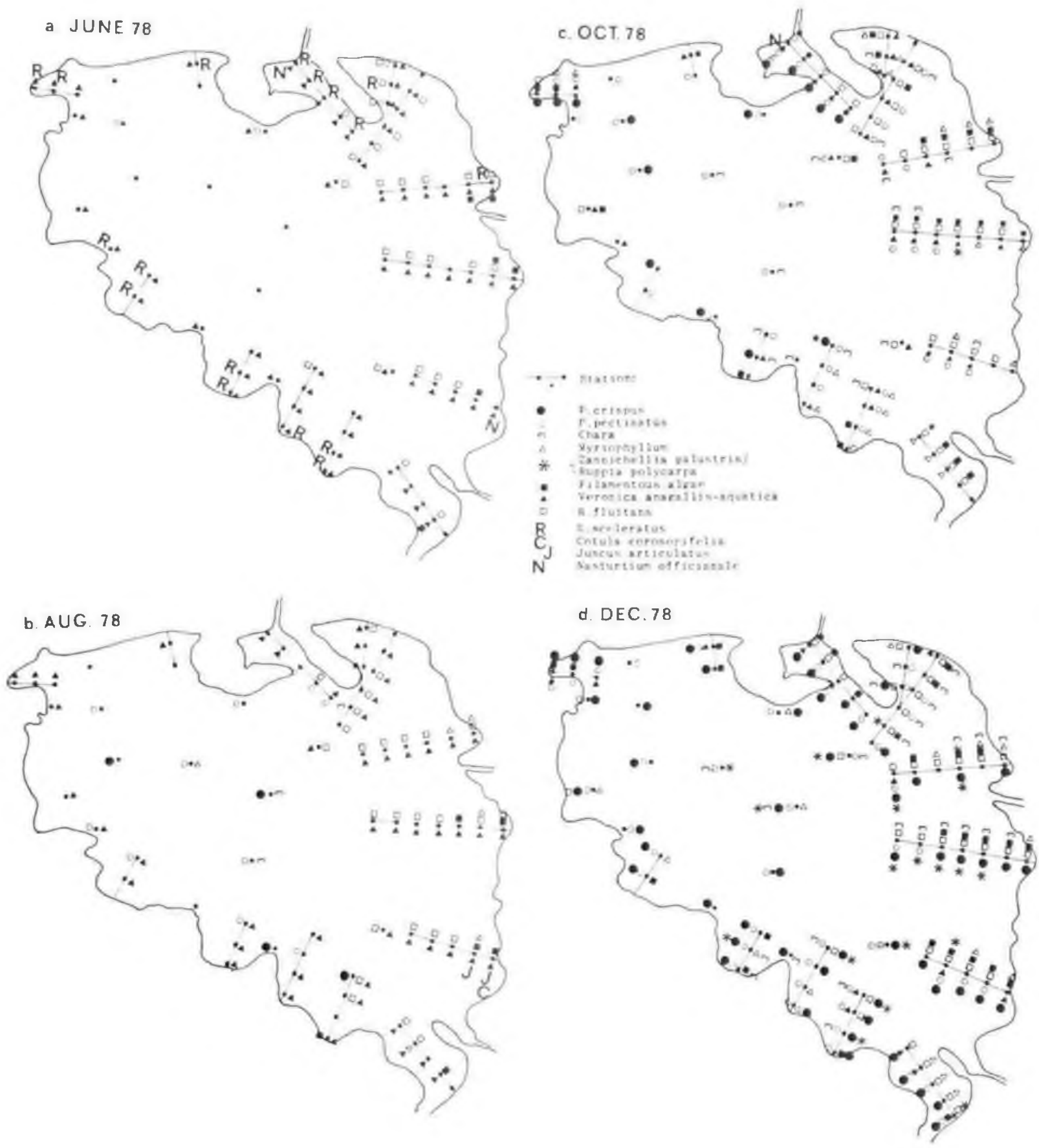

Fig. 3.4.3. Occurrence and seasonal development of macrophytes sampled in 1978. 

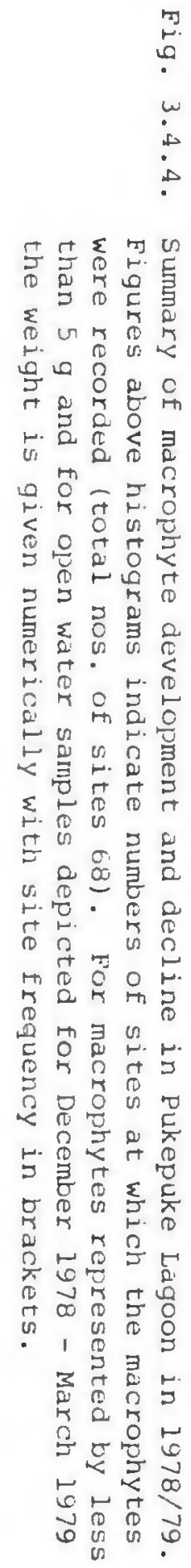


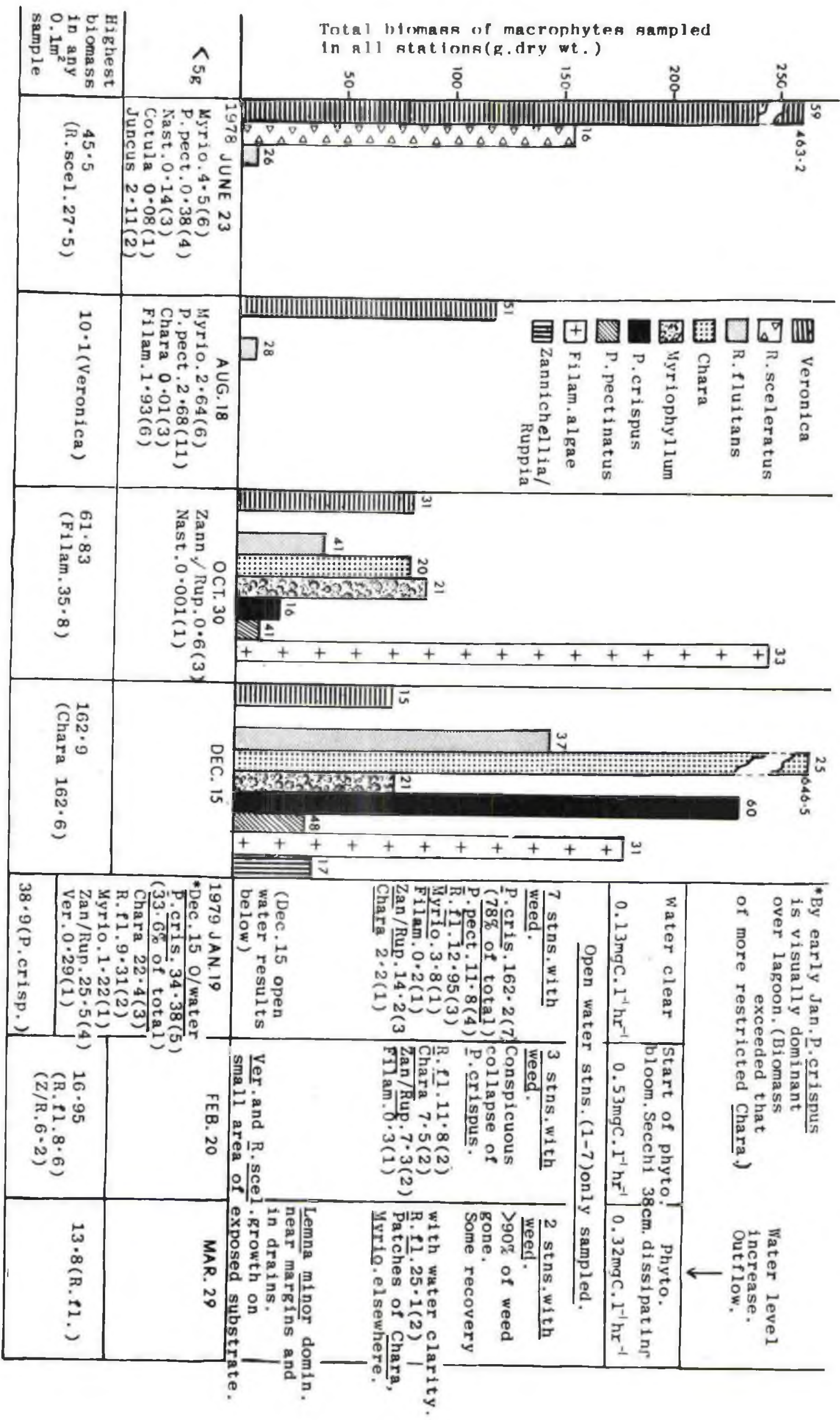


Plate 8. Aerial view of Pukepuke Lagoon April 6, 1978 showing pronounced water recession ard accompanying plant growth on exposed substrate.

Key: 1. Ranunculus sceleratus. Seedlings of this species quickly flourished on the rich, damp organic deposits typical of bays in the western half of the lagoon. (Some Veronica anagaliz-aquatica was associated with this growth.)

2. Veronica anagalzis-aquatica. Seedlings of this species dominated on the relatively hard, dry sand flats of the eastern half of the lagoon. ( $R$. sceleratus was absent).

3. Waterline.

4. Cut Tupha orientalis (white zones).

Plate 9. Underwater growth of Veronica anagallis-aquatica typical of eastern half of Pukepuke in the winter of 1978. (Photograph taken at station A3 July 20). 

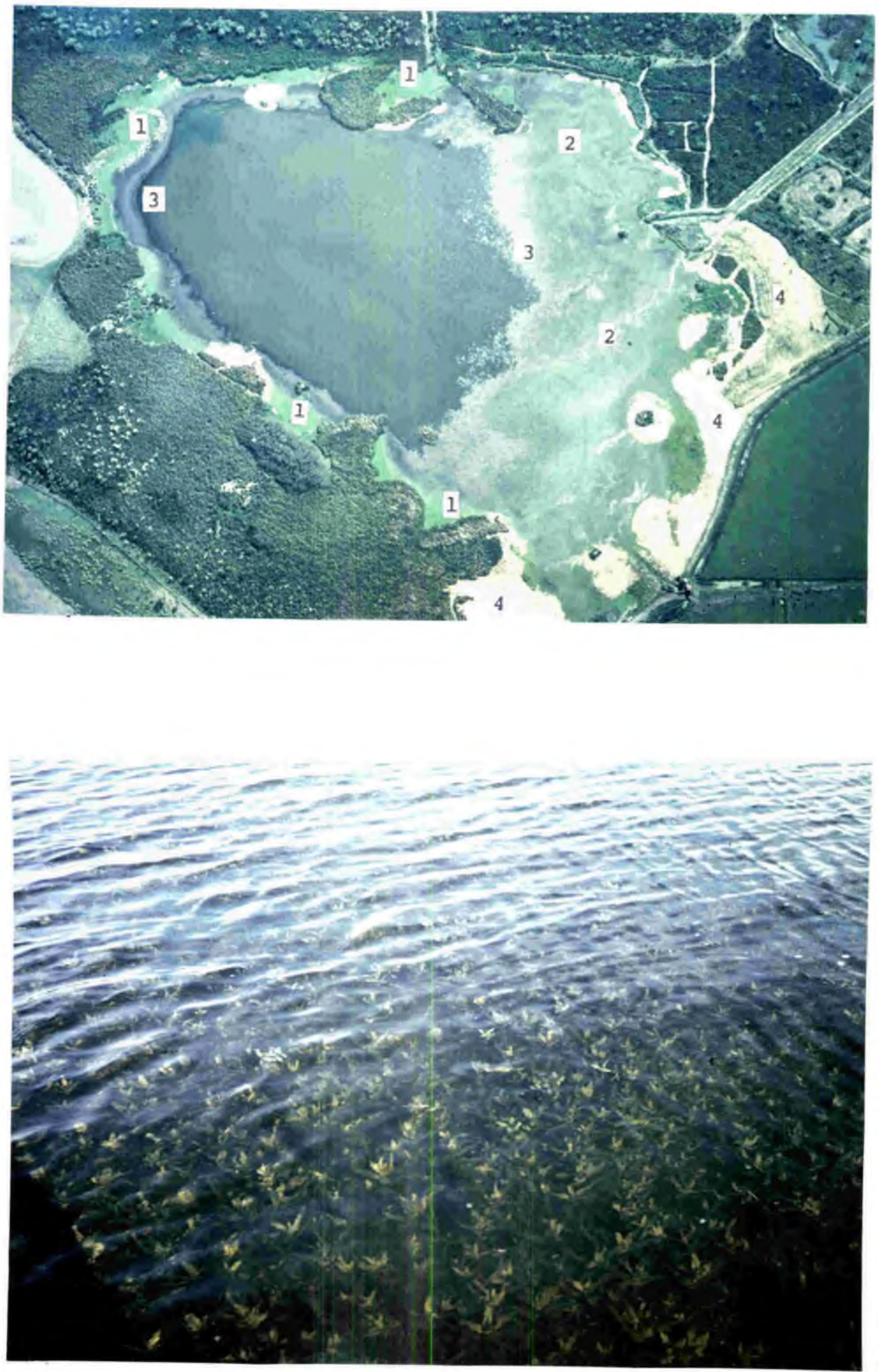
Flate 10. Vigorous Ranunculus sceleratus growth on exposed damp organic substrate March 21, 1978.

(Photograph taken from margin near transect $F$ looking south-east toward Barber's Pump). 


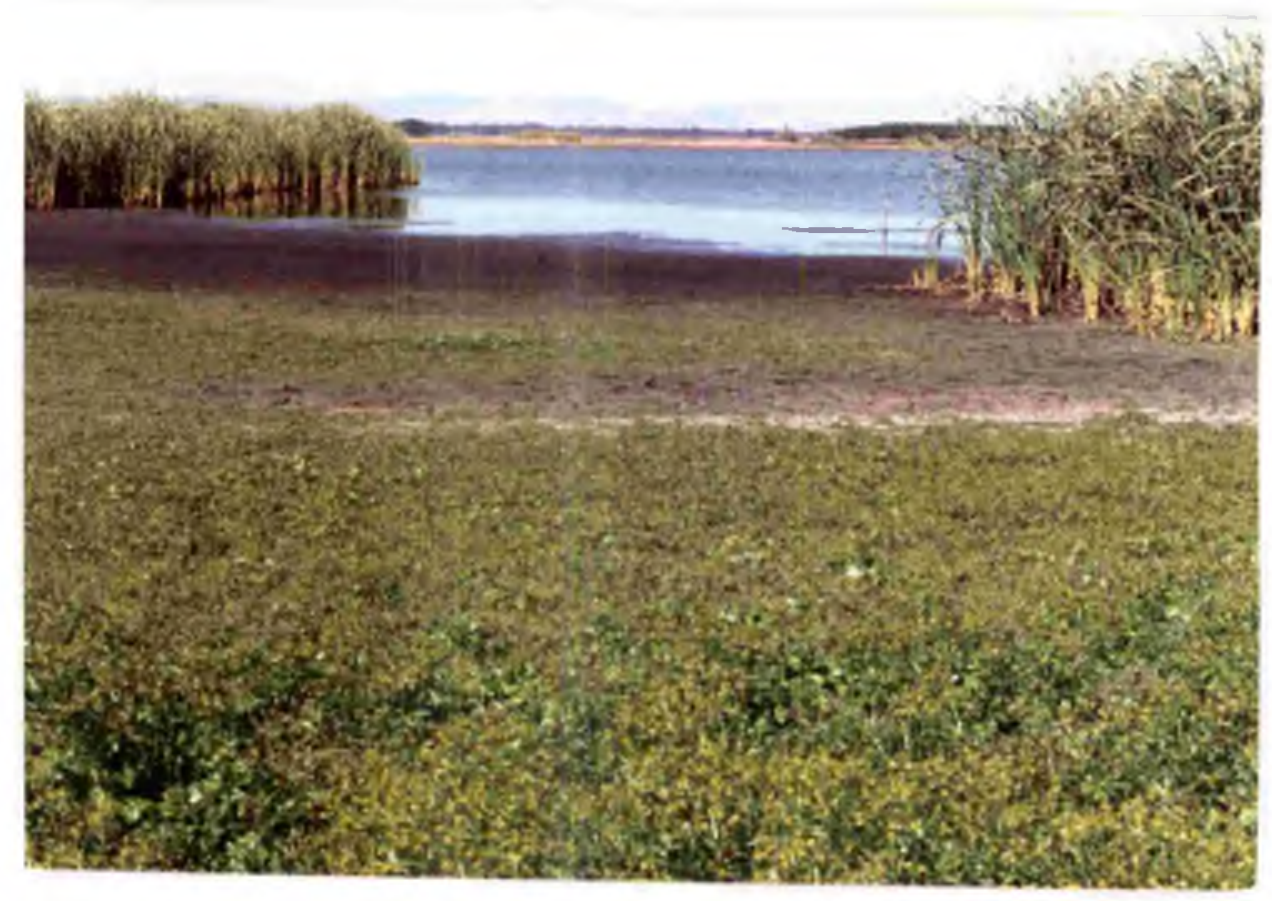


- Complete summer collapse of macrophyte phase associated with a heavy phytoplankton bloom.

1978 (Beginning June)

- Large winter-spring Veronica intrusion into the lake due to a pronounced water level recession in the previous summer (swan grazing removed much of this growth by spring).

- Partial summer collapse of macrophyte phase associated with lower phytoplankton level than in the previous drought year.

\subsection{Aquatic invertebrates}

\subsubsection{Gastropod - macrophyte relationship}

Details of gastropod density per gram dry weight of macrophyte are shown in Fig. 3.5.1 (a)-(d). The dominant species were Gyraulus corinna and Physa sp.. Potamopyrgus antipodarum, whilst on the plants to some degree, tended to occur more on the substrate.

The dry weights of the macrophytes sampled at each station (mean and range) and the proportion of Potamogeton crispus (never less than 80.5\%) are given in Table 3.5.1.

Fig. 3.5.1(a) shows that a comparatively low density of gastropods occurred on the edge macrophytes in the winter (July, August). In the spring production began to increase markedly (large numbers of individuals of less than $850 \mu \mathrm{m}$ diameter occurred).

In November the sampling programe was expanded to include spring-initiated macrophyte communities, i.e. those communities (again mainly $\underline{\text { P. }}$ crispus) which, since spring, had developed away 
Fig. 3.5.1 (a) $-(d)$

Gastropods per g dry wt. of macrophyte - predominantly $P$. crispus - from four sites sampled in 1977. The inset shows the location of the sampling sites and the general pattern of plant growth. Horizontal lines, means; vertical bars, 95\% Confidence Interval; the figures above vertical C.I. bars represent number of macrophyte samples; unbroken lines connect means of large snail fraction i.e. > $850 \mu \mathrm{m}$ diameter; broken lines connect means of total snail sample i.e. $>600 \mu \mathrm{m} \mathrm{dia}$. including the fraction $>850 \mu \mathrm{m}$. 

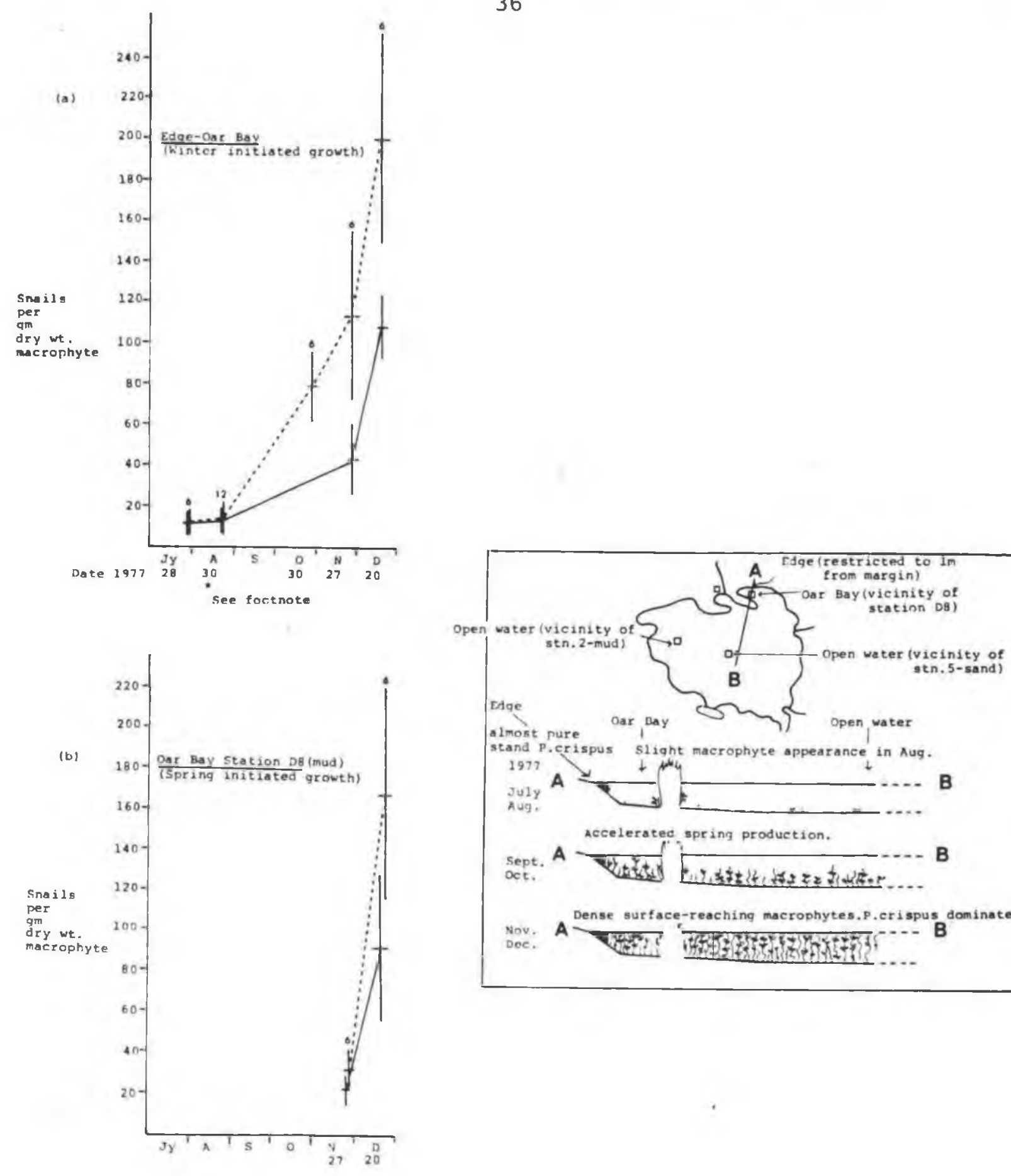

almost pure

Oar , Day

stand P.Crispus slight macrophyte appearance in Aug.

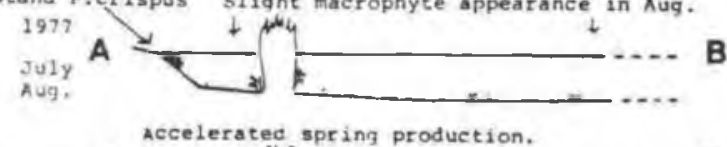

Sept. A Decelerated spring production.
Oct.

Dense surface-reaching macrophytes.p.erispus dominated Nov. A - $\mathrm{A}$ -
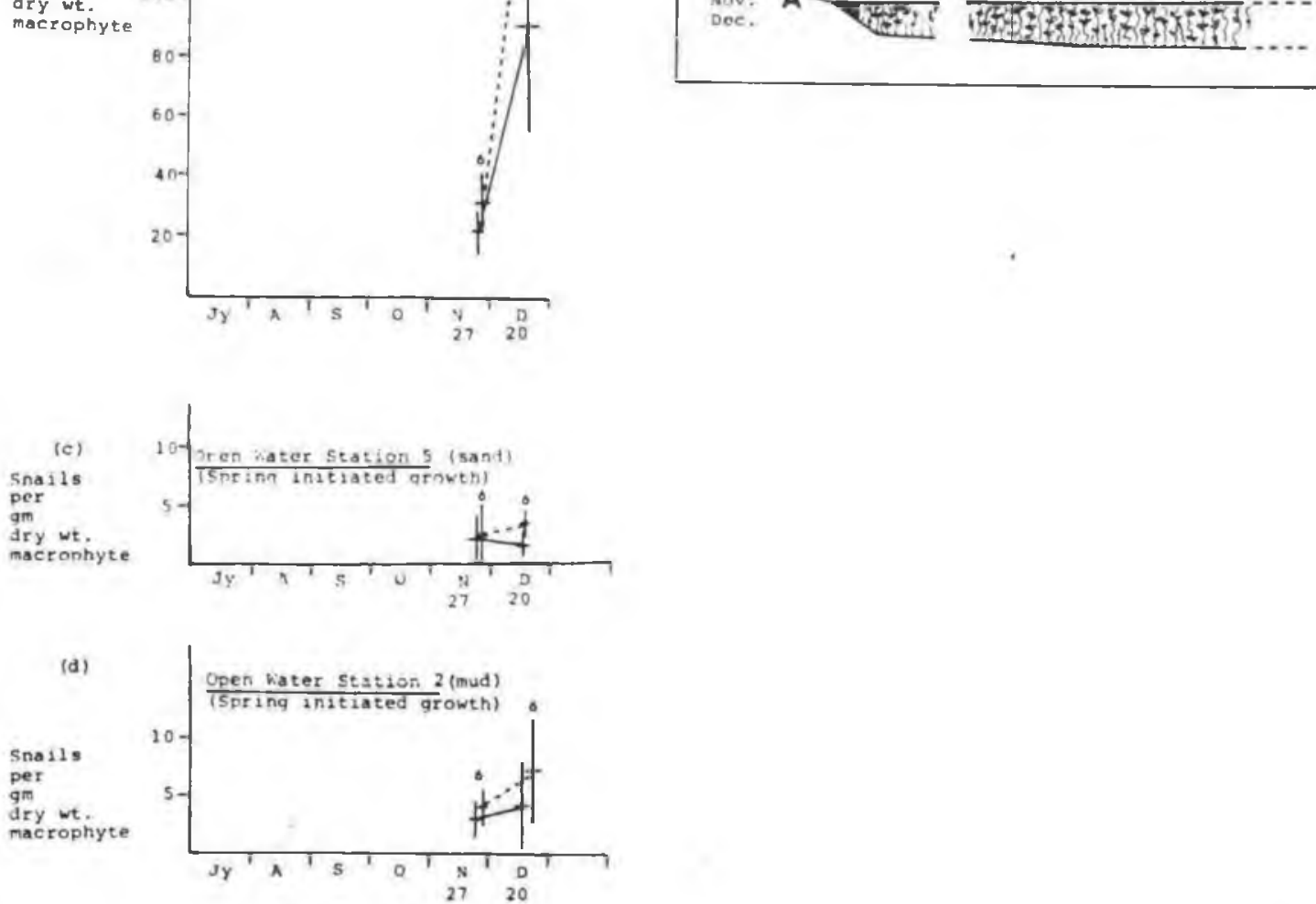

Footnote :

Edge Nar Bay Mag. 30: A heavy diatom qrowth necurred on the macrophyte shoots in the spring months. Such growth heavily coverel plane samples were colincted whe wisually decned to be 'clean' and what were deemed to be

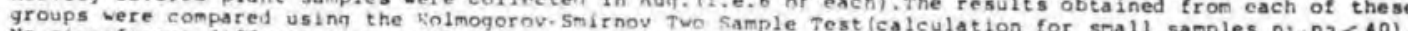

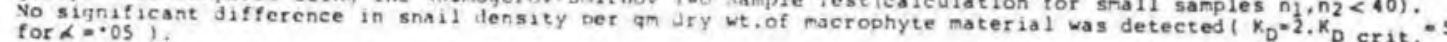


(a) Edge - Oar Bay (winter-initiated growth)

Mean biomass macrophyte

(g. dry wt.)

$0.1 \mathrm{~m}^{2}$ rake-up)

Range

\%. crispus

$$
11.1 \quad 10.3
$$

16.8

29.9

23.6

$16.3-2.1 \quad 14.5-5.7$

$26.3-12.8 \quad 58.3-11.6 \quad 48.1-16.3$

$97.0 \quad 95.2$

943

84.4

92.1

1977 Jy

A

S

o

N

D

(b) Oar Bay station 8 (mud) (spring-initiated growth)

Mean biomass

macrophyte

(g. dry wt.)

$0.1 \mathrm{~m}^{2}$ rake-up)

Range

\% $\underline{\text { P. crispus }}$

1977

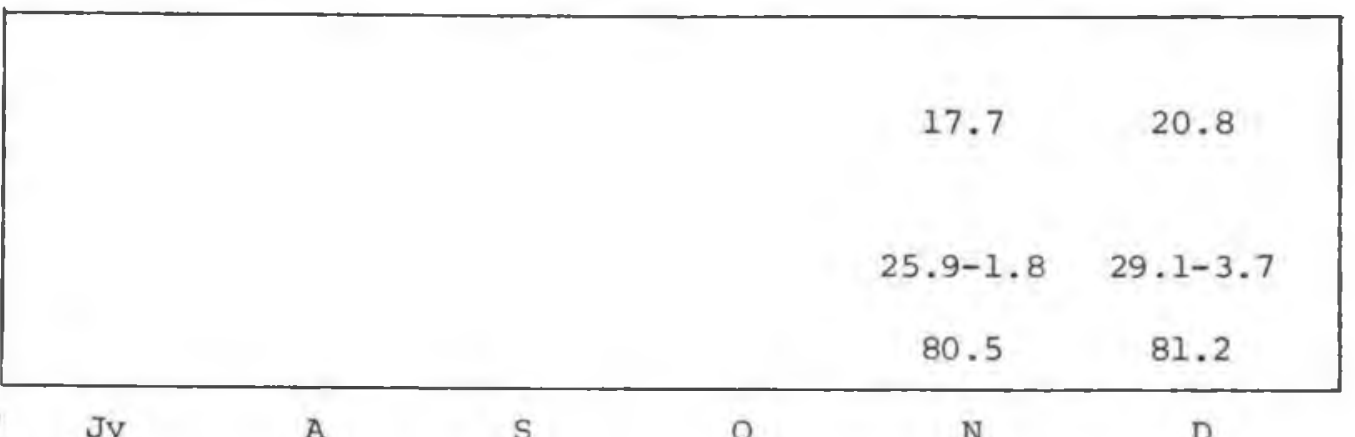

N

D

(c) Open water station 2 (mud) (spring-initiated growth)

Mean biomass macrophyte

(g. dry wt.) $0 . \mathrm{Im}^{2}$ rake-up)

Range

\% $\underline{\text { P. crispus }}$

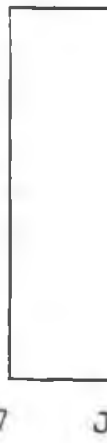

15.4

26.2

$28.5-2.3 \quad 49.4-4.6$

84.6

89.9

(d) Open water station 5 (sand) (spring-initiated growth)

\section{Mean biomass macrophyte \\ (g. dry wt./ \\ $0.1 \mathrm{~m}^{2}$ rake-up) \\ Range \\ f.}

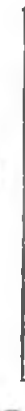

977
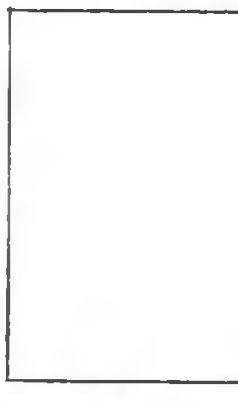

Jy

A

S

11.4

19.8

21. 5-1.9

$38.4-8.6$

94.1

96.9

N

D

N 
from the margin and into the centre of the lagoon. One of the stations was in the shelter of Oar Bay (about $5 \mathrm{~m}$ from the winter-initiated edge growth previously sampled). The other two were in the open water.

In November the number of snails per gram dry weight of macrophyte from the edge station was about 30 times greater than at each of the open water sites (compare Fig. 3.5.I(a) with (c) and (d)) and about six times greater than in the nearby Oar Bay station (compare Fig. 3.5.1 (a) and (b)). In December (when densities of macrophytes at all stations were similar) no significant difference was found between the edge station and the spring-initiated Oar Bay station, although the difference between these two and the open water stations was marked (about 20 to 30 times higher in the sheltered stations compared to the open water stations).

\section{6 zooplankton}

The seasonal pattern of zooplankton occurrence is shown in the top half of the composite zooplankton/phytoplankton graph of Fig. 3.6.1. (Note: the zooplankton is divided into two size groups, one above and the other below the horizontal monthly axis).

Copepods and, to some extent, rotifers, dominated in all summers. Rotifers were more evident after all or most of the macrophytes collapsed in the mid to late summer period.

The large filter-feeding (as opposed to predatory) cladoceran Daphnia carinata dominated the winter-spring zooplankton community in both 1977 and 1978. The occurrence of high concentrations of this actively swimming species has been a distinctive feature of 
Pukepuke during the winter and spring in all years since I first visited the lagoon in 1975. Simocephalus sp. was the only other cladoceran identified at Pukepuke, but this was extremely rare by comparison to Daphnia. It tended to be associated closely with macrophytes rather than being fully planktonic.

\subsection{Phytoplankton}

The pattern of phytoplankton productivity (together with Secchi disc readings) is shown in the bottom half of Fig. 3.6.1. The stippled peaks indicate high levels of phytoplankton development ('blooms') in the mid-summer to autumn periods of all years.

A sample of a phytoplankton bloom was collected on March 12, 1979 and forwarded to Dr V. Cassie for identification. She wrote: "The presence of Euglena (probably E. acus), Closterium cornu and Scenedesmus spp. (S. quadricauda, s. acuminatus) together with

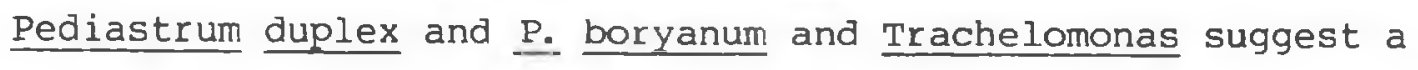
eutrophic, mainly chlorococcalean phytoplankton, supplemented by Euglenales. The diatoms Cyclotelia, Gomphonema and Nitzschia acicularis are also common in eutrophic to polluted waters, especially in small bodies of water such as garden ponds and oxidation ponds".

For a full list of species identified see Table 3.8.3.

\subsection{Spring epiphytic diatom pulse}

In August of both 1977 and 1978, a very heavy brown, mucilaginous sludge of epiphytic diatoms suddenly appeared on the aquatic plants. It also appeared on plants within the drains leading into Pukepuke. This lasted until about early October, whereupon it fell away almost 

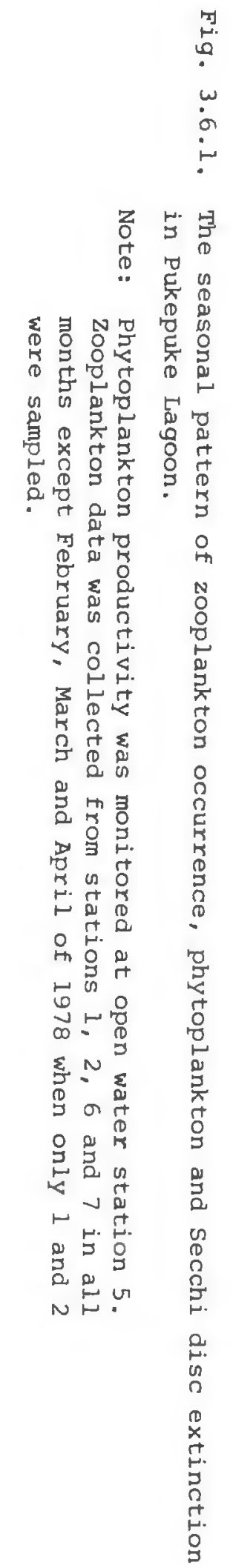


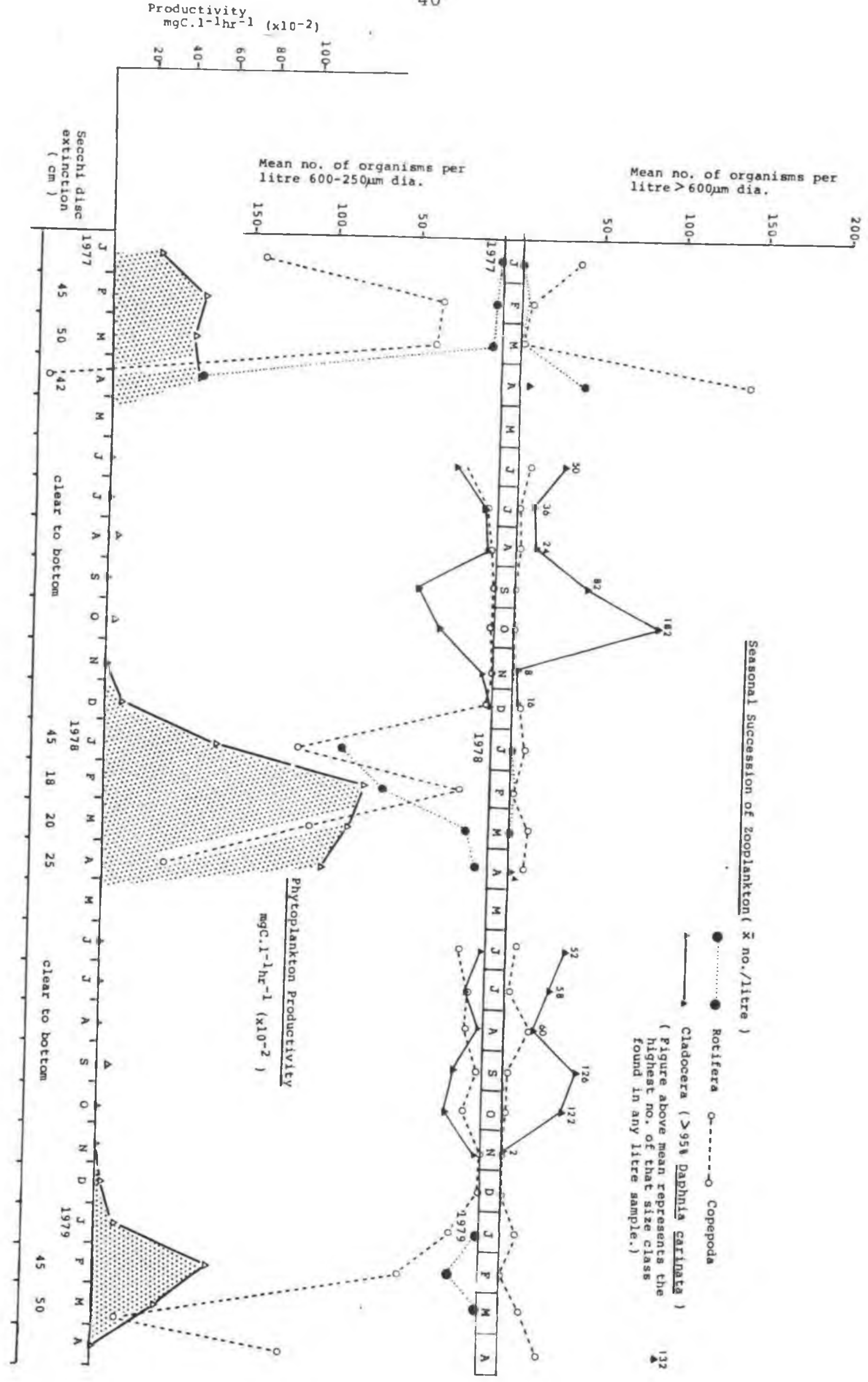


as suddenly as it appeared. Only a comparatively light biomass of less mucilaginous material remained going into summer. This was confined almost entirely to plants within sheltered bays.

The slimy character of the material present from August to October was due to the mucilaginous stalks of the dominating species Gomphonema truncatum var. turgidum. The presence of this and other diatom species found in sludge randomly collected from p. crispus plants in August and November 1978 is shown in Tables 3.8 .1 and 3.8.2. 
Table 3.8.1. Epiphytic diatoms identified on $P$. crispus shoots, August 18, 1978

Table 3.8.2. Epiphytic diatoms identified on $P$. crispus shoots, November 24, 1978

Table 3.8.3. Phytoplankton identified in sample of a 'bloom' occurring March 12, 1978 
Epsphytic diatoms Aug. 18 th 1978

Dominant:

Gomphonema truncatum var.turaidum (Ehr.) Patrick

The thick mucilaginous quality of the brown sludge was

determined by the gelatinous nature of the stalks attachinq

this pennate epiphytic form to the macrophytes.)

Scarce:

Synedra ulna (ivitzsch) Ehrenb.

cocconeis placentula

Navizula so.

Cymbella sp.

Epiphytic diatoms Nov.24th 1978

Relative abundance gcale (gubjective)

5 - dominant

4 abundant

$3=$ common

$1=$ scarce

$r=1$ specimen seen

Synedra ulna (Nitzsch)Ehr.

Gomphorema truncatum var.turqidum 3

cymbella sp. 2

Epithemia sorex I

Melosira yarians 1

Frustulia rhomboides

Note: The biomass of the material coating individual plants was only only amall fraction of that of Aug. Septionty plant the sheltered areas were coated to any shnifen water was 'clean'. largely spring-initiated growth of the openat we celatinous There was a dramatic decline.

Phytoplankton bloom Mar.12th 1979

Rel.abundance scale as for epiphytic diatom

analysis Nov. 24th 1978. Isee above

CHLOROPHYCEAE

Chlorococcales:

chlorella sp. (or Micratinium sp.) 5

Selenactrum minutum

Scenedegmus guadricauda (Turp. I kite.

scenedesmug acuminatus $\quad 2$

Pediastrum duplex var.gracillimum 2

Pediastrum boryanum ITuro.lMenegh. 1

oocystis sp.

Dictyosphaerium sp.

Coelastrum microporum Naq.

Zygnematales:

clogterium cornu

MYXOPHYCEAE

Merismopedia glauca? 2

Oscillatoria nigra?

DIRTONOPHYCEAE

Cyclotella sp. 3

Nitzschia acicularis w.smith 3

Nitzschia sp.

Gomphonema truncatum var.turgidum I

Gomphonema parvulum

Melosira granulata var.angustissima 0. Mull. I

EUGLENINEAE

Euglena sp.

Trachelomonas sydneyensis

Colourless flagellates- 2 species 


\section{DISCUSSION}

The discussion is divided into two parts: Part 1 focuses on elements of the limnological research presented in the previous chapter. Part 2 looks at the research as a whole in an attempt to shed light on the nature of the macrophyte/ phytoplankton balance. The knowledge gained from this overview is then used to assess whether storms and/or swan grazing may potentially alter this balance in favour of phytoplankton.

\section{PART 1 - GENERAL LIMNOLOGY}

\subsection{Water and soil quality}

\subsubsection{Water chemistry}

The water chemical results presented in Table 3.3 .1 and those presented by the Rangitikei-Wanganui Catchment Board (Mark-Brown, 1978) (sampling period 1976-78) reflect a similar winter to summer trend, i.e. far lower concentrations of ions and nutrients in the winter compared to the summer (a summary of differences between the two seasons will be given later).

Although the Catchment Board results included fewer parameters than are shown in Table 3.3.1, they did, unlike Table 3.3.1, include dissolved oxygen (D.O.) readings. Whilst these readings were given without reference to the times they were recorded (levels may fluctuate widely over a 24 hour period), they are still useful from the point of view of indicating high summer primary productivity. That is, when they were related to oxygen solubility coefficients (obtained for the water temperatures accompanying the D.O. figures) the resulting calculations showed a consistent pattern of high 
supersaturation in the summer and saturation (equilibrium with atmospheric oxygen) or near-saturation in the winter. In the summer when plant biomass is high and productivity is high (due to good growing conditions) D.O. levels tend to move from extreme supersaturation in the late afternoon (due to oxygen produced in photosynthesis exceeding oxygen consumed in plant and animal respiration) to extreme undersaturation just before dawn (due to commity respiration). The absence of flushing in the summer means that the process of daytime oxygenation and night-time deoxygenation produces its influence in the surrounding water. In the winter, because of low primary productivity and because of flushing, D.O. levels remain at or near saturation over 24 hours.

This seasonal trend was both predictable and highly obvious from my own phytoplankton productivity studies (using the light and dark bottle oxygen method). Just after midday in the summer it was usual for the level of saturation to approach 200\%. Spot checks made in the late afternoon often indicated levels in excess of $300 \%$.

Pukepuke is only very slightly saline $(0.3-0.6$ ppt salinity; $61-135$ $\left.\mathrm{mg} / \mathrm{Cl}^{-}\right)$. This undoubtedly derives from wind-blown salt from the sea. Although on the basis of salinity Pukepuke is what may be termed a freshwater lake, it may be noted that a distinction between freshwater and brackish water has also been made by stewart and Kantrud (1972) on the basis of total ionised material in the water. This is related to total hardness and may be indexed by electrical conductance. The cut-off level between freshwater and brackish water was arbitraily designated by the aforementioned authors to be $400-500 \mu m h o s / c m$ conductivity. It is evident that on this basis the lagoon tends to be fresh in the winter but brackish in the 
summer when flushing ceases, evaporation occurs and salts concentrate.

The pattern of water chemical change between winter and summer may be summarised thus:

Winter: - dissolved oxygen levels maintained at or near saturation day and night

- pH: slightly alkaline

- generally lower ion and nutrient levels than in summer

Summer: - daytime oxygen supersaturation due to high plant biomass and photosynthetic activity in unflushed conditions (extreme night-time undersaturation)

- pH: highly alkaline due to high carbon dioxide extraction from the water in photosynthesis

- decreasing water volume and evaporation causing increased ion and nutrient levels.

4.1.2 The relationship between specific water chemical parameters, primary and secondary productivity, and waterfowl habitat quality (Note: Chemical readings given for Pukepuke refer to those shown in Table 3.3.1, not those given by Mark-Brown, 1978.)

Total alkalinity (carbonate hardness) has frequently been used as an index of general water fertility (Moyle, 1956; Kadlec, 1960;

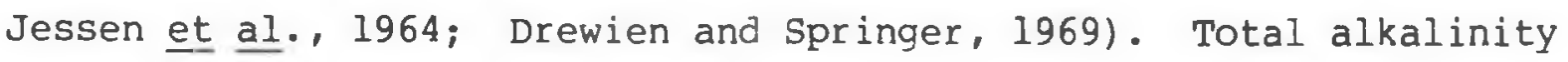
measurements for Pukepuke were very high $(164.5-280.7 \mathrm{mg} / 1)$ putting it is the very hard water category. Readings below $40 \mathrm{mg} / 1$ were considered 'low' by Moyle (1956) and are usually associated with sparse aquatic vegetation. The high calcium carbonate level of the 
lagoon was often evident in the summer when scaly coatings of calcareous precipitate often occurred on the leaves of the macrophytes. Due to increased photosynthesis at this time there is a depletion of the amount of carbon dioxide and soluble bicarbonate from the water. The insoluble acid carbonates are precipitated as the temperature rises (see e.g. Brown, 1971).

The highly waterfowl-productive seasonal wetlands of the drift plain of North Dakota were found to have a mean total alkalinity of $223 \pm$ $71 \mathrm{mg} / 1$ (Swanson et al., 1974). Wheeler and March (1979) also reported high total alkalinities $(170-303 \mathrm{mg} / \mathrm{l})$ for the highly waterfowl-productive southeast wisconsin wetlands.

On the whole 'hard' water will support a wider variety of animal life than the 'soft' calcium-deficient waters of moorland bogs and streams which originate from acid, peaty soils (Brown, 1971). Juday's (1942) comparison of two hard water lakes with two soft water lakes showed that the standing crop of plants were three to five times larger in the hard water lakes. Animal populations were two to three times greater.

Patterson (1972) attempted to establish direct correlations between various invertebrates and inorganic chemical parameters in several ponds. He concluded that "...most of the correlations between invertebrate numbers and water chemical concentrations are interpreted as indications of relationships with the aquatic vegetation, which is to a great degree the result of the chemical concentrations of the ponds". 
Sulphate salts which may, according to Moyle (1965), influence the distribution of aquatic plants even more than carbonate salts, occur in moderate to high levels in Pukepuke $(18.91-91.6 \mathrm{mg} / 1$ compared to 18-43 $\mathrm{mg} / \mathrm{l}$ for the waterfowl-rich wetlands of southeast Wisconsin Wheeler and March, 1979).

Total nitrogen and total phosphorus are high with $0.73-4.77 \mathrm{mg} / 1$ and $0.128-2.86 \mathrm{mg} / 1$ ranges respectively. Moyle (1956) reported that the best waterfowl lakes in Minnesota were those with concentrations of nitrogen at 0.5 to $>1.0 \mathrm{mg} / \mathrm{I}$ total nitrogen and 0.05 to $0.10 \mathrm{mg} / \mathrm{I}$ total phosphorus. Nitrogen probably enters Pukepuke mainly as nitrate from agricultural fertilisers which are used extensively in the highly developed catchment area. Likewise phosphate input is probably derived from fertilizer, although other sources such as the faeces of waterfowl and farm animals iugt nave some effect.

\subsubsection{The relationship of water chemistry to soil chemistry and the role of Typha orientalis (raupo) in terms of nutrient recycling, organic debris contribution, and invertebrate production.}

Although water quality is highly relevant to the general question of primary productivity and hence secondary productivity, so too is wetland soil type. This relevance may be in terms of (i) its influence on water chemistry (Patterson, (1972) for example, found the nature of the substrate to be a major controlling factor in the availability of certain important nutrients in the water), and (ii) its direct contribution to macrophyte growth (macrophytes are less dependent on water-dissolved nutrients than are phytoplankton since, although capable of significant uptake from the water, they derive them mainly from the sediment - see e.g. Bristow and whitcombe). 
The Pukepuke basin is comprised of sand which is overlain over much of its surface with a dense layer of rich organic mud. J. G. Gibb (Department of Geology, Victoria University) examined the mineral structure of the Rangitikei beach sands, of which Pukepuke is a part, and found that the material is derived mainly from sediment loadings from a greywacke source in the Tararua and Ruahine Ranges. His report (Gibb, 1977) showed that this rock contains particularly high proportions of silica-bearing minerals. This would undoubtedly explain the very high silica levels in the water. (The heavy diatom pulse typical of the lagoon in spring must to some extent reflect this.)

The organic mud layer derives mainly from the annual decay of the highly productive Typha orientalis which abounds on the margins. Although specific details of the place of Typha orientalis in the nutrient recycling process are lacking, it is interesting to note that Klopatek (1974) reported that on Theresa Marsh in Wisconsin, emergent plants, particularly typha spp. (cattails), were probably the controlling influence on the availability of soil nutrients. He found that soil nutrient levels in this marsh were higher than levels required for most agricultural crops.

Typha orientalis probably requires at least mesotrophic water conditions to develop, if the studies of Seddon (1972) for Typha angustifolia and $\underline{T}$. latifolia are any indication.

On the basis of growth studies of Typha orientalis undertaken at Pukepuke from 1969 to 1972 by J. Ogden* (in prep.) the following

*Present address: Department of Botany, University of Auckland. 
estimates of annual net production were calculated.

$\begin{array}{ll}\text { Pioneer stands } & 3.0-3.4 \mathrm{~kg} \mathrm{dry} \mathrm{wgt} / \mathrm{m}^{2} / \text { year } \\ \text { Mature stands } & 2.3 \mathrm{~kg} \mathrm{dry} \mathrm{wgt} / \mathrm{m}^{2} / \text { year } \\ \text { Seedlings in lst year of growth } 2.5 \mathrm{~kg} \mathrm{dry} \mathrm{wgt} / \mathrm{m}^{2} / \text { year }\end{array}$

Ogden (pers. comm.) commented that "...these figures are in the upper range for Typha, and wider comparison indicates that this community, in common with other reedswamps, must be considered one of the most productive known (see e.g. Westlake, 1963)" .

Bottom areas rich in organic debris are known to contain a far greater abundance of invertebrates than areas poor in debris (e.g. Tebro, 1955; Hartley, 1977). Ogden found that marginal pioneer stands of Typha contributes approximately $1.7 \mathrm{~kg}$ dry $\mathrm{wgt} / \mathrm{m}^{2}$ of dead material into the Pukepuke swamp every year. He conservatively estimates that this in turn produces $0.035 \mathrm{~kg} / \mathrm{m}^{2} /$ year of invertebrates.

Although water and soil chemical factors have an ultimate bearing on the degree of primary or secondary productivity, the question of what form the primary production takes, be it predominantly macrophytic or phytoplanktonic, may be dependant on other factors, such as the degree of flushing or the nature of the zooplankton community (see Part 2). This in turn may have a fundamental bearing on whether particular types of waterfowl are present or absent. For instance, a highly enriched system where phytoplankton tends to dominate will be far less likely to support swans than a less enriched one which tends to favour macrophyte growth. 


\subsection{Macrophytes}

4.2.1 Macrophytes as trophic status indicators.

of the macrophytes found in Pukepuke the following have been

reported as being indicators of eutrophic conditions: $\underline{\text { p. pectinatus }}$ (an obligate eutrophic species, Spence, 1964; Seddon, 1972), P. crispus (Seddon, 1972), Z. palustris (Spence, 1964), Enteromorpha sp. (Jupp and Spence, 1977).

Seddon (1972) found that many emergent species are indifferent to water quality. Of the species referred to by this author only two occur at Pukepuke. One, Scirpus lacustris, appears to be indifferent. The other, Alismo plantago-aquatica, embraces mesotrophic as well as eutrophic conditions.

\subsubsection{The balance between Potamogeton crispus and $\underline{\text { P. pectinatus }}$ in deep open water.}

One of the above potamogetons has always formed the main component of the deep, muddy open water zone of the lagoon in the summer period prior to a phytoplankton bloom. In both 1977 and 1978, P. crispus easily dominated over p. pectinatus (see Plate 6.) In my experience since 1975 I have noted that in the spring there is a strong tendency for the two species to appear together on the generally rather bare open water substrate (see Fig. 3.4.1 and 3.4.3 with respect to 1977 and 1978). One - generally p. crispus gradually asserts dominance over the other. As was first alluded to in a preliminary account of some of my limnological studies at Pukepuke (Potts, 1977) it appears that when water maintains deeper than usual levels throughout the spring, or when high winds or flooding encourages turbidity, $\underline{\text {. pectinatus }}$ is more likely to become dominant on the muddy open water zones of the lake. (This 
slender species is a well-known silt and turbidity tolerant species - see e.g. Butcher, 1933; Robel, 1961). In 1970, the only year of the 1970-79 period when water levels did not drop appreciably going into the summer (see Figure 3.2.1), P. pectinatus developed to dominate in the deep muddy zones of the open water (Gibbs, 1973).

\subsection{Seasonal availability of plant-associated macro- inver tebrates.}

Large numbers of plant-associated invertebrates (such as gastropods and insect larvae) were available to ducks for most of the 1977 to 1979 study period. The only time such forms were scarce was in the late summer of $1977 / 78$ when the macrophyte community collapsed in toto and the waterline receded from the emergent vegetation around the margins (Plate 8 ).

The great intrusion of Veronica anagallis-aquatica into the lake in the winter and spring of 1978 represented a considerably larger flooded emergent phase than in the corresponding period of 1977. However, whilst massive quantities of small invertebrates were associated with this dense wave-dampening growth (reflected in conspicuous shoveler and mallard feeding therein), it is doubtful if, at any place within it, densities of invertebrates exceeded those available in some locations within the more limited flooded emergent plant zones in the previous year. For instance, in 1977 random net sweeps in many of the narrow tracts of partially submerged, rotting Mercer grass (Paspalum distichum) often produced hundreds, even thousands, of organisms per $50 \mathrm{~cm}$ net sweep. (These included large numbers of amphipods and gastropods.) 
As would be expected in a temperate zone water the main period of invertebrate production was in the spring - summer period.* For example, in late October the first swarms of early instar waterboatmen (Sigara arguta) were noted. Likewise, as is apparent in Figures 3.5.1(a) and (b), gastropods began to multiply rapidly in October and November.

Whilst the spring - summer period was clearly the main period of invertebrate production it was obviously not the only time when certain invertebrate forms multiplied rapidly. For instance, although the gastropod/macrophyte study terminated at the end of 1977, it was evident that breeding was greatly stimulated in the following autumn when the large biomass of Veronica anagallisaquatica seedlings were inundated by rising water levels. Ostracods and caddis larvae were also highly prolific in this growth. Many hundreds of the former could be obtained in a single $50 \mathrm{~cm}$ net sweep. Given the still rather warm conditions applying at this time of year, and the fast underwater growth of the Veronica, this was not surprising.

When water levels $\mathrm{r}$ ise to flood drawdown vegetation, shallow marsh, wet meadow zones and occasionally terrestrial vegetation, invertebrates are stimulated to increase rapidly by the abundant organic food base (Frey, 1967; Petr, 1975). Swanson and Meyer (1977) reported that gastropods in experimental ponds responded to a rising water level by depositing a large number of egg masses

*The onset of this phase of accelerated production appeared to be a month or two behind the early spring flush of macrophyte growth. 
within recently flooded vegetation. They also responded to an increase in food availability in an aquarium environment. The occurrence of extremely large numbers of gastropods, amphipods, and other invertebrates in the flooded, rotting Mercer grass around the margins in the winter (referred to above) was probably another example of this kind of reproductive response. The grass may have produced a 'hay infusion' effect. That is, the bacteria and protozoa associated with such decomposition may have provided a prolific food base for higher food chain production. (In the spring of 1978 Winstanley (1979) noted very high numbers of invertebrates in the temporary Clover Leaf North Pond of Pukepuke Reserve. He considered that this was probably due to a massive 'hay infusion' effect caused by the flooding and decay of large quantities of rushes and other plant material mown in the previous summer when the pond was dry.)

The trend was for invertebrates to become available toward the centre of the lagoon as macrophytes spread outward in the spring and summer (see Figs. 3.4.1 and 3.4.3). However, in 1977 (when Veronica did not intrude significantly into the lagoon) it was evident that a considerable lag was involved in this, largely due to the influence of heavy turbulence created by the high prevailing winds (typical of the area in the spring). In October, for instance, the first swarms of early instar waterboatmen (Sigara arguta) were always seen in sheltered raupo bays. As the open water weed grew to a point where it dampened the influence of wind on the water (about early November) dispersion into these zones gradually accelerated. The rate at which different species moved in appeared to depend to a large extent on their degree of mobility. The extremely mobile water bugs and mites were prominent first arrivals. At the height 
of macrophyte abundance in mid-summer, gastropods had not reached anywhere near the densities attained on similar quantities of plant material in the margin zones (compare Figs. 3.5 .1 (a), (b) and (c), (d)) .

The relative scarcity of invertebrates in the open water zones during the spring-summer period of 1977 was evidenced not only by the results of the gastropod study and many ad hoc net sweeps, but also by the fact that until about mid-December mallard feeding was confined (most conspicuously) to the near-margin zones. When the waterline receded from the margins in mid-summer, and the entire macrophyte community decayed (Fig. 3.4.2), the mallards then began to feed in the substrate (there was evidence to suggest that at this point they began to experience food stress - see Section 2).

In the summer of $1978 / 79$ when only part of the macrophyte community collapsed (Figure 3.4.4) large numbers of near-surface invertebrates continued to be available.

The high availability of invertebrates in the summer (immediately prior to any macrophyte collapse) is undoubtedly partly due to the concentrating effect of lowered water levels.

\subsection{Zooplankton community structure}

To say why particular zooplankton forms and communities occur at particular times at Pukepuke (or anywhere else) is difficult. However, it may be that the occurrence of Rotifera in the mid to late summer period - and their confinement to this period (see Fig. 3.6.1) - was related to the cessation of flushing (unlike cladocerans and copepods they are not strong swimmers) and the 
collapse of all or most of the macrophytes (Hasler and Jones, 1949 demonstrated that macrophytes have an antagonistic effect on Rotifera, but not on planktonic Crustacea).

Notes and records kept by Dr G. W. Gibbs and myself during the period from 1970-80 indicate that populations of Daphnia carinata were a distinctive feature of the winter - early summer zooplankton community in all years except in 1971. This exception may have been related to the exceptionally high water levels applying in the preceding summer $(1970 / 71)$ - see Fig. 3.2.1.

\subsection{Phytoplankton community structure}

It would appear that the chlorococcolean character of the summer phytoplankton bloom sampled in 1979 (Table 3.8.3) may be typical of blooms occurring in the lagoon during this period. Flint (1975) examined a sample of a summer bloom at Pukepuke as part of a general survey of New Zealand lakes (date of collection unspecified) and referered to the dominance of chlorococcolean forms ("Dictyosphaerium together with Ankistrodesmus was dominant.").

\subsection{Spring epiphytic diatom pulse}

Many studies of temperate lakes have reported spring peaks of phytoplankton - commonly diatom dominated (see e.g. Hutchinson, 1967; Nichols, 1976). On the basis of his phytoplankton monitoring programme at Pukepuke during the period from 1970-73 Gibbs (1973) found no evidence for a spring pulse. He stated, "...it seems that the spring flush of growth is taken up by the macrophytes." My finding of an epiphytic diatom pulse suggests that Gibbs overlooked this possibility during his period of study. (As will be noted in Part 2 the occurrence of an epiphytic as opposed to a 
phytoplanktonic diatom pulse is probably indicative of the high level of flushing occurring in the spring.)

According to previous studies (e.g. Macan, 1970; Bayly and Williams, 1973) the initiation of a spring diatom pulse is due to the influence of increasing daylength, its decline to the depletion of dissolved silica (some species appear to be unable to efficiently extract silica below certain critical levels of availability).

$\mathrm{SiO}_{2}$ analyses carried out from 1975-79 (Table 3.3.1) indicate that the lowest levels occur around september and October (undoubtedly the period of highest absorption).* Whether the figures of around 10 to $12 \mathrm{mg} / \mathrm{l}$ shown for this period represent the very lowest levels reached is unknown. Perhaps for a brief period in late september or early October, when the pulse declines rather dramatically, the level is much lower. What the critical concentration is for Gomphonema (the main constituent of the spring sludge) and why it does not re-establish itself to the same extent after silica levels increase, has yet to be ascertained (perhaps silica depletion is not the whole answer).

* Thick sludges of diatom occur in drains throughout the catchment so that absorption is not just restricted to Pukepuke. 
THE BALANCE BETWEEN MACROPHYTES AND PHYTOPLANKTON AND THE POTENTIAL OF SWAN GRAZING TO STIMULATE CHANGEOVERS FROM MACROPHYTE TO PHYTOPLANKTON DOMINANCE

\subsection{The balance between macrophytes and phytoplankton}

The question of why macrophytes and phytoplankton tend to dominate at different times at Pukepuke was first discussed by Gibbs (1973). He sought to shed light on this problem by comparing his findings to those of MitchelI (1971) for Tomahawk Lagoon, a similar water to Pukepuke in the South Island. He concluded that "The balance between these two forms of vegetation is a delicate one and in this comparison may be simply a function of depth - Tomahawk being about twice the depth of Pukepuke Lagoon. In the deeper water the competitive advantage is more often with the phytoplankton. Much more information is required before we can explain the important changeovers".

My own research - including an investigation into the findings of Gibbs - indicates that the balance referred to is not in fact such a delicate one in Pukepuke, even though it may well be at Tomahawk. Tomahawk was found by Mitchell to exhibit irregular long-term periods of either phytoplankton or macrophyte dominance, whereas the alternations shown at Pukepuke tended to be regular and short term, both phases alternating within a single year. Differences between the two eutrophic waters clearly does not relate to differences in depth as Gibbs suggested may be the case. 
Firstly, Gibbs' statement that Tomahawk "... is about twice the depth of Pukepuke..." must be called into question. Mitchell in describing Tomahawk Lagoon wrote, "Its depth is between 1.0 and 1.2 metres over much of the basin, but this has been increased by dredging to between 2.0 and 2.6 metres in an area of about 2000 square metres near the centre of the basin". This deeper 2000 square metre area only represents 0.2 hectare which is only one forty-eighth of the total area of the lagoon. Mitchell did not report any marked seasonal water level change at Tomahawk. In the winter-spring period Pukepuke has an average depth of about $0.75-1.0 \mathrm{~m}$ and a maximum of around $1.5 \mathrm{~m}$. A significant proportion of the lagoon - say half - would be around one metre deep. To say, therefore, that Tomahawk is about twice the depth of Pukepuke is to overstate the comparative situation somewhat. Certainly it does not take proper account of the seasonal differences at Pukepuke and the fact that relative depths between the two waters in the winter are similar.

A much better understanding of the factors governing macrophyte phytoplankton balance has emerged with the extension of Gibbs' (1973) study. It is now clear that macrophytes always dominate in the winter to early summer period because of the high flow maintained through the basin at this time. Phytoplankton can only concentrate in the summer when inflows - and hence flushing ceases. Records kept from 1970 to 1979 by Dr Gibbs and myself show that at no stage has phytoplankton discolouration occurred during the winter to early summer period. Only on one occasion has the water not been discoloured during the summer due to phytoplankton. 
This was in the abnormally wet summer of $1970 / 71$ when water levels were the highest ever recorded during this period (Fig. 3.2.1), being maintained at or near winter flushing levels.* (Note: A visible phytoplankton presence - as in the summer of $1978 / 79$ - is not necessarily associated with a wholesale disappearance of macrophytes. Even if a large proportion of the macrophyte community collapses it cannot be assumed that phytoplankton shading was the cause. Various subtleties of the relationship between macrophytes and phytoplankton are discussed later (in 4.8 .1 ) with respect to the summers of $1977 / 78$ and 1978/79.)

Figure 4.7 .1 shows the occurrence of phytoplankton blooms in relation to water levels during the 1977-79 study period (the monthly water levels shown were recorded on the same day as the phytoplankton productivity readings.) The height of the water level control structure situated at the outlet is drawn in as a horizontal line at the $6.24 \mathrm{~m}$ level. The water level shown above this line indicates overflow and hence flushing.

The ascendency of chlorococcalean phytoplankton forms throughout the summer has been noted by several authors for a number of lakes and ponds (e.g. Zafar, 1967; Nichols, 1976). It is widely believed that these forms thrive in warm summer temperatures. Rodhe (1948) found that the optimum temperature for the growth of Scenedesmus,

\footnotetext{
*Gibbs (1973) reported an 'absence of discolouration due to phytoplankton' in the summer of 1970/71. Using the chlorophyll method (Strictland, 1960) he began monthly phytoplankton standing crop measurements in May 1971. He recorded heavy phytoplankton blooms in the summers of 1971/72 and 1972/73. He continued his phytoplankton sampling programme for two years after publishing his findings up to the end of the summer of 1972/73. Pronounced blooms were also recorded in the summers of $1973 / 74$ and $1974 / 75$ (Gibbs, pers. conm.). Upon taking over from Gibbs in 1975 I observed a heavy bloom in the summer of 1975/76 and recorded (using the light and dark bottle method) blooms in 1976/77. $77 / 78$ and $78 / 79$ (see Fig. 3.6.1). Phytoplankton presence was insignificant - certainly not visible - in all winter - spring periods from 1970 to 1979.
} 

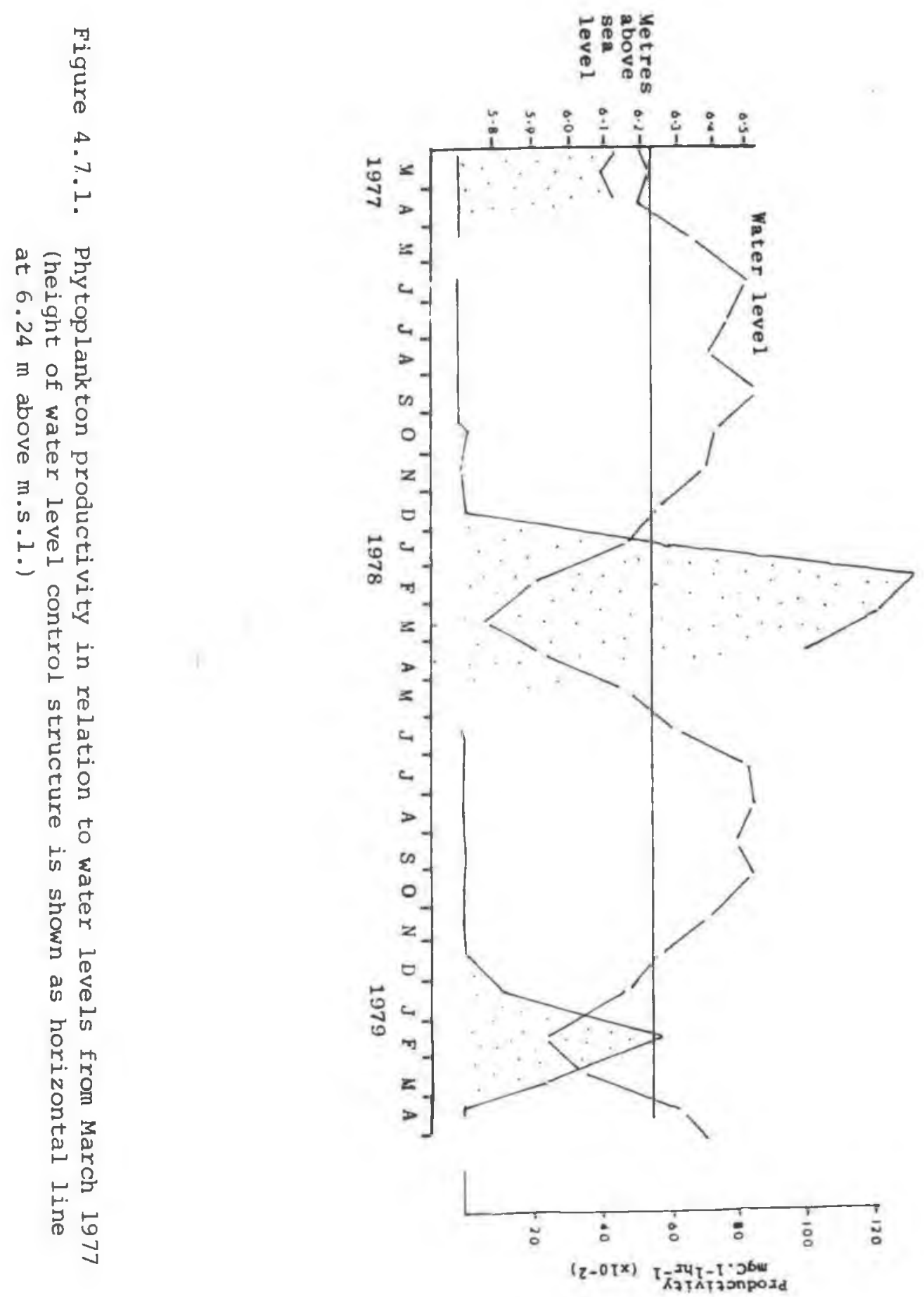
Chlorella, Pediastrum and Coelastrum - all of which were found in some profusion in the sample taken from Pukepuke in March 1979, (Table 3.8.3) - is between $20^{\circ}$ and $25^{\circ} \mathrm{C}$. (This range is typical of daytime water temperatures at Pukepuke in the summer - see Fig. 3.2.2.)

The greater intensity of the phytoplankton bloom in $1977 / 78$ compared to $1976 / 77$ and $1978 / 79$ (Figs. 3.6 .1 and 4.7 .1 ) was probably mainly due to the hot drought conditions occurring in that year. High evaporation caused the water level to drop to about $0.5 \mathrm{~m}$ below the water level control board (Fig. 4.7.1). This would have allowed for greater water heating and concentration of nutrients - both factors presumably favouring phytoplankton growth.

Only once have I observed closely the events accompanying the decline of a phytoplankton bloom. Because the lagoon is declared off-limits a few weeks before the duck shooting season at the beginning of May, this has meant that when water levels have begun to rise rather rapidly due to late autumn or early winter rainfall, it is generally well into this off-limits period. One could only deduce, therefore, that because the water levels had risen, and inflows commenced in the period between the implementation of this restriction and the end of the shooting season, that this was involved in a bloom dissipation. However, in the 1978/79 season particularly early and sustained heavy rainfall occurred. This provided an ideal opportunity to record the transition to water clarity. In January the first real signs of a phytoplankon pulse appeared and by February what may be termed a bloom had developed (Secchi disc extinction was $38 \mathrm{~cm}$ ) From the 19 th of March a particularly heavy period of rainfall lasting well into April 
occurred. $118 \mathrm{~mm}$ of rain fell from the 19th to the 31 st of March compared to an average of $42 \mathrm{~mm}$ in each of the two previous months. This resulted in a quick $30 \mathrm{~cm}$ water level increase associated with the inflow of clear water and considerable dissipation of the phytoplankton. Water levels rose by about another $30 \mathrm{~cm}$ by the end of April resulting therefore in about a $60 \mathrm{~cm}$ increase over a period of a little more than a month. A quick check made on water clarity near the deepest part of the lagoon in mid-April revealed that the phytoplankton was no longer visible. The Secchi disc easily reached the bottom without extinction.

It should be noted, however, that evidence from other freshwater studies indicates that even if this dilution or flushing effect did not occur then in such unflushed circumstances nutrient limitation may come into effect to terminate the bloom. As Nichols (1976) pointed out, the termination of summer phytoplankton blooms where they occur in freshwater are not generally regarded as being related to zooplankton grazing as in many seawater situations. They are considered more likely to be due to the depletion of some nutrient. Nichols, for example, suggested nitrogen depletion may have been responsible for the disappearance of a summer chlorococcalean phytoplankton peak in the shallow Holland Marsh. Chlorococcalean algae, which also dominate the Pukepuke summer bloom, are, unlike the blue-greens, incapable of manufacturing their own nitrogen. (For further discussion on phytoplankton limitation see Goulder, 1969; Moss, 1969; Ryther and Dunstan, 1971). Therefore, although I am satisfied that autumn flushing guarantees the termination of summer blooms at Pukepuke I do not discount the possibility that in many years this dilution and physical removal effect may be pre-empted, even if only slightly, by the effect of nutrient Iimitation. 
The spring pulses of epiphytic - as opposed to planktonic - diatoms (see 3.8 ) could be interpreted as evidence of the high level of flushing occurring at this time. When spring diatom pulses occur in streams and rivers they are invariably epiphytic (see e.g. Douglas, 1958); whereas in standing water they are typically planktonic (such forms being able to concentrate) (see e.g. Macan, 1970).

Although flushing undoubtedly guarantees that phytoplankton cannot develop in Pukepuke in the winter and spring, it would appear that this guarantee is further reinforced by the characteristic presence of high populations of the large filter-feeding cladoceran Daphnia carinata (see Fig. 3.6.1). Johnson and walker (1972/73) noted that in years when filter-feeding Daphnia species formed a part of the zooplankton community in Loch Leven "...this was concurrent with widespread changes in the Loch, notably algal blooms becoming less prominent and an increase in macrophytes".*

Referring back to the comparison between Pukepuke and Tomahawk Lagoons: it is evident that the single most important difference between the two lagoons - the one most responsible for differences in macrophyte/phytoplankton balance - is hydrological. Tomahawk has a far smaller catchment than Pukepuke $\left(1.8 \mathrm{~km}^{2}\right.$ compared to $\left.26 \mathrm{~km}^{2}\right)$. The surface run-off from this catchment in the winter and spring is far less than at Pukepuke; therefore the rate of flow through

*It may be noted from the composite zooplankton/phytoplankton graph (Fig. 3.6.1) that the summer phytoplankton blooms appeared just as the Daphnia disappeared. Although it may be tempting to assume that the phytoplankton develops because these Daphnia disappear, this very clearly is not the case. The disappearance of these grazing forms almost certainly allows each of the blooms to develop, but if they were absent in the winter and spring a phytoplankton bloom similar to that shown in the summer would not develop. It is interesting to note that when no summer phytoplankton discolouration occurred in the flushed summer of 1970/71, no Daphnia occurred in the lagoon (Gibbs, pers. comm.). 
the Tomahawk basin could be expected to be far less than through Pukepuke. The fact that Mitchell (1971) reported a changeover from macrophyte to phytoplankton dominance in the winter clearly points to this difference. The balance between macrophytes and phytoplankton at this stage is therefore more delicate at Tomahawk than it is at Pukepuke. It is physically possible for phytoplankton to dominate year-round at Tomahawk; at Pukepuke it is not.

Although Mitchell (1971) referred to the presence of various zooplankton species in Tomahawk Lagoon, he did not record the presence of filter-feeding cladoceran populations. Perhaps the lack of a large algae-grazing component in the zooplankton community made the winter changeover from macrophytes to phytoplankton (whatever the stimulus) possible.

\subsubsection{The mechanisms involved in changeovers from macrophyte to phytoplankton dominance}

For the purpose of providing a general understanding of why the macrophyte/phytoplankton balance tends to be as it is at Pukepuke, the previously discussed role of hydrology is perhaps the most critical point to be stressed. To avoid obscuring this point I have thus far refrained from commenting on more subtle aspects of the balance. These aspects revolve around the question of what causes the collapse of the macrophytes in the summer - be the collapse total, as in $1977 / 78$, or partial as in $1978 / 79$.

When flushing continues throughout the summer, phytoplankton accumulation is prevented and macrophytes will continue to dominate (as in 1970/71 - see Gibbs, 1973). However, although macrophytes, as a broad category, will continue to dominate, there is evidence, 
both from the literature and from the results of this study, that certain of the species represented will in fact die back. That is, even though they may be perennial species they have an inherent tendency to die back vegetatively around this time. What may be termed a 'partial' collapse should therefore occur about mid-summer even though phytoplankton is not significantly represented or of sufficient intensity to exert a negative influence (by shading and possibly in other ways as well). This latter point raises some interesting theoretical possibilities concerning the relationship between phytoplankton and macrophytes in various summers particularly with respect to the mechanisms involved in causing the decline of the macrophytes.

Superficially the observed association between a phytoplankton upsurge and the complete or partial collapse of the macrophytes would seem to conform to the classical hypothesis that the phytoplankton caused the decline of the macrophytes. In lakes where a submerged macrophyte phase has been replaced by a phytoplankton phase, either temporarily or permanently, this change has usually been attributed to shading by increased populations of phytoplankton. As well as producing shading effects it has been speculated that high chlorophyll levels in phytoplankton may signify competition for available nutrients (e.g. Campbell and Spence, 1976), or that the phytoplankton may act to inhibit the growth of macrophytes through effects on photosynthesis of the high $\mathrm{pH}$ developed during a bloom (Allen, 1973; Black, 1973). During the course of this study a paper published by Phillips, Eminson and Moss (1978) challenged this general hypothesis, at least insofar as it applied to the long-term disappearance of macrophytes in artificially fertilised waters. They hypothesised that instead of a 
sudden phytoplankton blom acting to cause the decline of the macrophytes, the development of the phytoplankton may in fact be an effect of this decline. That is, filamentous and epiphytic algae may act to shade the macrophytes which in turn collapse and allow a phytoplankton bloom to develop (for a diagrammatic summary of this hypothesis see Fig. 4.7.2). This mechanism was unconvincing as a simple answer to events at Pukepuke.*

Although Phillips et al. (1978) felt that 'a general mechanism must be sought' to account for the long-term loss of macrophytes when increased nutrient loadings occur, they qualified this by saying '... that the biology of individual species may be such as to require modification of the theme'. This qualification was not elaborated on, but it provided the essential idea for what proved to be a fruitful line of enquiry into the processes involved at Pukepuke. An investigation of the growth characteristics of the individual macrophyte species in the lagoon was duly undertaken.

Potamogeton crispus and $\underline{P}$. pectinatus, both important macrophytes at Pukepuke, appear to be different in their growth patterns to the other submerged species represented. Both perennials appear to have an inherent tendency to die back vegetatively after seeding. Westlake (1965), referring to the growth patterns of plants, stated that the annual regrowth pattern

* Blanketing of the vast majority of weed does not typically occur prior to summer collapses at Pukepuke. In both $1977 / 78$ and $1978 / 79$ the large open water macrophyte community was extremely 'clean' with respect to both filamentous and epiphytic algae. Insofar as inshore weed was concerned, the density of epiphytic aigae was considerably less that in the spring, although swards of filamentous algae did occur in some of the bays. In addition, in both summers the ascendency of the phytoplankton began well in advance of the macrophyte collapses. 


\section{Shallow water}

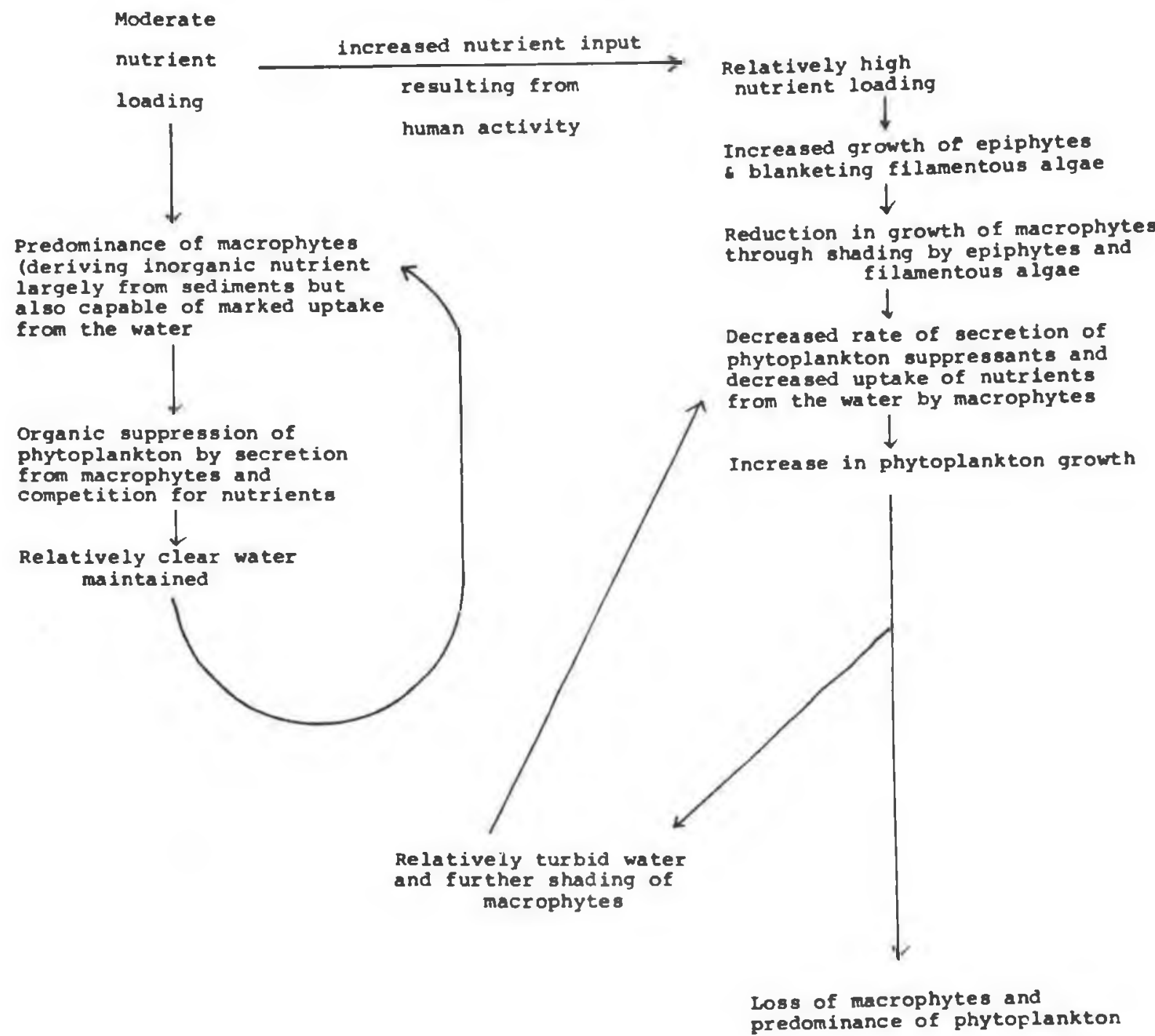

Fig. 4.7.2. Hypothesis to account for decline in macrophyte populations when lakes are fertilised. (Redrawn from Dhillips, Eminson and Moss, 1978). 
'... is manifest when the plants die down to a small quantity of perennating organs, but less obvious when much of the plant survives until the next spring. Many submerged perennial macrophytes in temperate climates appear to be plants of annual regrowth, but this should always be checked. some species always die down (e.g. Potamogeton natans and pectinatus), others persist (e.g. Ranunculus fluitans, Elodea canadensis), and some may vary with local conditions (e.g. Callitriche stagnalis and Myriophyllum spp.)'.

Butcher (1933) stated that the tendency to persist or die down after seeding appears to be inherent in certain perennial species. After monitoring the occurrence and survival of macrophytes in a variety of British rivers he developed tentative lists of species which do and do not die back. Of the species on his lists which occur at Pukepuke, i.e. Myriophyllum spp., R. fluitans, Nasturtium

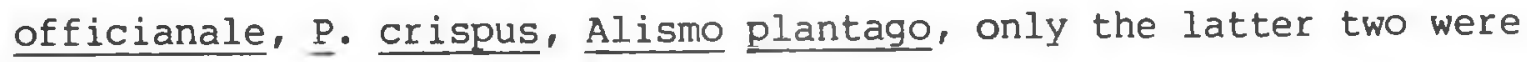
classified as species which always die back. Apart from $\underline{\mathrm{P}}$. crispus and $\underline{P}$. pectinatus (the latter referred to by Westlake), none of the other submerged macrophytes found at Pukepuke appear to have an inherent tendency to die back, although in the case of Zannechellia and Ruppia more information is required.*

*Zannechellia palustris and Ruppia polycarpa, both represented as relatively minor constituents of Pukepuke, are the only two macrophytes for which no information has been obtained, i.e. either by direct reference to growth character or by reference to records of survival through the autumn in particular studies. R. fluitans and Myriophyllum spp., plants which according to Butcher's text clearly do not always die down, have also been reported by Mitchell (1971) to have survived the autumn in Tomahawk Lagoon. Chara globularis was shown by Gibbs (1973) to have survived the autumn. Other authors such as Sculthorpe (1967) have made reference to the growth of Chara spp. for periods Ionger than one year. Apart from the paper by Butcher (1933) and the later paper on plant productivity by westlake (1965) very little information on basic growth patterns of macrophytes appears to be available. This is probably because variation in local conditions may mask inherent growth tendencies. 
$\underline{\text { P. }}$ crispus and $\underline{\mathrm{P}}$. pectinatus develop highly obvious perennating organs which make them extremely specialised for overwintering in reduced form. In the case of each $\underline{\mathrm{P}}$. pectinatus plant the perennating organ is a fleshy tuber up to about $10 \mathrm{~mm}$ in length. Each $\underline{P}$. crispus plant develops several clusters of large fleshy winter buds (turions) in the summer. Each bud grows to about $5 \mathrm{~mm}$ to $8 \mathrm{~mm}$ in length. This, according to sculthorpe (1967), makes for the most specialise perennating arrangement of the whole potamogeton genus (a genus distinctive for its often advanced development of this type of overwintering organ).

Given: (1) That there is evidence from the literature that $\underline{P}$. crispus and $\underline{\mathrm{P}}$. pectinatus have an inherent tendency to die back vegetatively after seeding, (2) that the timing of such a decline in shallow water - uninfluenced by phytoplankton - could be expected to be far earlier than in rivers, i.e. more toward mid-summer rather than in autumn.*

(3) that either of the above species may form a dominant component of the summer macrophyte community at Pukepuke ( $\underline{P}$. crispus was dominant in the summers of both $1977 / 78$ and $78 / 79$ ),

it is reasonable to question whether full or partial summer macrophyte collapses in this water are necessarily linked to the influence of phytoplankton, even when the latter is present to a significant degree. To explore this possibility further the findings relating to the summers of $1977 / 78$ and $1978 / 79$ are considered.

*Butcher (1933), referring to rivers, described the die-back of perennials like $\mathrm{P}$. crispus as occurring in autumn. Plant communities generally reach their climax earlier in ponds compared to deeper waters and rivers - see e.g. Westlake, (1965). In Pukepuke the maturation of feeds of $\underline{P}$. crispus and $P$. pectinatus, and the appearance of winter buds in the former, Is very early - indeed usually in the early to mid-summer period. 
1977/78 (summer of full collapse): In December, well before any macrophyte decline or obvious loss of vigour in the macrophyte community, the first sign of an ascending phytoplankton presence was recorded (compare Figs. 3.4.2. and 3.6.1). This indicated that early phytoplankton development was not caused by the decay of Potamogeton or any other macrophyte.

In January phytoplankton intensity had increased significantly (Secchi ext. $45 \mathrm{~cm}$ ). Macrophtes were in the first stages of collapse, but had not yet disappeared and phytoplankton had developed into a very dense bloom (Secchi ext. $45 \mathrm{~cm}$ ).* This dramatic phytoplankton intensification was probably due largely to a combination of the nutrients released by the general macrophyte collapse, and the ideal growing conditions created for chlorococcalean plankton by the hot, sunny weather associated with the prevailing drought.

Despite theoretical possibilities relating to an independent Potamogeton collapse triggering a general collapse by feeding a bloom, there is no substantial evidence contained within the $1977 / 78$ findings to warrant a rejection of the classical phytoplankton causation hypothesis. That is, there is nothing to suggest that all macrophytes did not collapse simultaneously under the influence of a phytoplankton bloom.

1978/79 (summer of partial collapse): There is evidence that the partial, albeit substantial, collapse of this summer (Fig. 3.4.4) was not caused by the influence of phytoplankton. Unlike in the previous year phytoplankton appeared to be of insufficient intensity to have had any primary effect. The continued survival and vigour

* All of the residual macrophyte material was blackened, structurally intact Chara. 
through the summer of conspicuously dense beds of $\underline{R}$. fluitans lover most of the eastern half of the lagoon) is evidence of this conclusion. Conversely, the wholesale collapse of the hitherto dominant $\underline{\text { P. }}$ crispus suggested the partial decline was essentially a manifestation of this species' intrinsic tendency to decline vegetatively after seeding.

It should be noted that whilst $\underline{R}$. fluitans survived virtually en masse, there was at least some thinning of its beds after the Potamogeton collapse. This also applied to other species. The low lying Zannichellia/Ruppia component was not recorded in the open water stations after the partial collapse. This thinning could be explained as follows: when $\underline{P}$. crispus died down in the unflushed conditions it began to decompose, thus causing an anaerobic state near the substrate. This was not monitored, but any heavy decomposition of this sort would be exected to produce such an effect in stagnant water. This would rot the bases of the associated live plants. (The disappearance of weed beds in some years in part of Lake Ellesmere has been attributed to the base of the plants rotting during anaerobic conditions developing near the substrate in stagnant conditions (Hughes, McColl and Rawlence, 1974). In addition to this rotting effect at the bases, the fact that the macrophytes grew in mixed stands may have meant that as the Potamogeton collapsed some of the non-potamogeton element became entangled with it (or, in the case of low lying species, covered by it), and so became subjected to the same rotting process.

The resistance to decay of Lemna minor (duckweed), which typically continued to flourish through the summer period and into the autumn of both 1978 and 1979, would no doubt be explaind by the fact that as a free-floater it is not susceptible either to phytoplankton 
shading or to anaerobic conditions associated with large scale macrophyte decay near the substrate.

Whilst in $1978 / 79$ the intrinsic decline factor of $\underline{P}$. crispus was likely to have been the primary factor in producing the partial collapse, there is a possibility that phytoplankton may have contributed in a secondary or convergent kind of way. That is, by losing vigour after seeding, the potamogeton may have become more vulnerable to the effects of phytoplankton shading than would have species like $\underline{R}$. fluitans.

The difference between the summers of $1977 / 78$ and $1978 / 79$ may be summarised thus:

In $1977 / 78$ the phytoplankton causation hypothesis was considered the most likely explanation for macrophyte decline. That is, the shading effect of the phytoplankton (greatly encouraged by the warm, shallow conditions associated with a drought) probably pre-empted any independent tendency for the potamogeton to collapse.

In $1978 / 79$ a much lighter phytoplankton bloom occurred than in the previous year. Given that the most dominant species in the lagoon, Potamogeton crispus, died back in toto, while the non-annual regrowth species Ranunculus fluitans survived and grew vigorously in great quantity despite the presence of phytoplankton, it was concluded that the phytoplankton was of insufficient intensity to have caused the partial collapse. 
4.8.2 Could storm or heavy swan grazing damage trigger a sudden change to phytoplankton dominance at Pukepuke?

since in temperate waters the productivity of macrophytes tends to be especially low in the winter, their recovery at this time in the face of heavy silting or physical damage is often poor. This may result in a competitive advantage applying to phytoplankton. Two shallow eutrophic lakes in New Zealand which have suddenly switched to phytoplankton dominance in the winter are Lake Ellesmere and Tomahawk Lagoon. The nationally important black swan breeding population at Lake Ellesmere declined dramatically after such a change occurred following the so-called wahine storm in the winter of 1968 (Bucknell, 1969; Adams, 1971; Williams, 1979). Physical damage to macrophytes - 'scouring' - was thought to be the cause (Hughes, McColl and Rawlence, 1974). Mitchell (1971) suggested that storm-induced silting and/or heavy swan damage may have been involved at Tomahawk. (The pattern of swan use at Tomahawk is evidently similar to that shown at Pukepuke - see section 3. Mitchell stated that "Up to 200 of these large birds arrived at the lagoon each year in May, and most of them leave again in July and August".)

Is Pukepuke susceptible to the above kind of change? There are strong indications that it is not.

winter and spring:

There is no chance of a phytoplankton bloom developing at this time because of the characteristic flushing and presence of very high populations of algae-grazing Daphnia. When a large pre-breeding flock of swans caused severe damage to the heavy Veronica anagallisaquatica and Ranunculus sceleratus growth in the winter of 1978 
(3.4.2) no perceptible increase in phytoplankton was detected (see Fig. 3.6.1)

Gibbs (1973) reported that a major flood occurred at Pukepuke in the spring of 1971 . This resulted in heavy silting. Whilst the macrophytes suffered some decay they recovered fully when transparency was restored in November. Although Gibbs expressed some uncertainty as to the effect of this flood on the phytoplankton bloom which occurred in the following summer, it is now evident that the timing of the bloom was entirely normal, and that the influence of spring silting was not required to account for it.

\section{Summer :}

When flushing ceases in December considerable phytoplankton development and macrophyte collapse is inevitable, i.e. without the influence of swan grazing. Swan numbers do not generally build up greatly before a mid-summer macrophyte collapse occurs (the few pairs which hold territories over the spring-early summer period do not normally relinquish them until early or mid-January - see Section 3).

Although the damage inflicted by swans at Pukepuke in the winter of 1978 was severe it is probable that even more severe damage has been registered elsewhere.* However it cannot be assumed that heavy damage is always required to trigger a changeover to phytoplankton.

*Although Mitchell (1971) did not attempt to measure the extent of the winter impact at Tomahawk, it is possible that it was even more devastating that at Pukepuke. Tomahawk is smaller than Pukepuke (less than 10 hectares compared to 16) and the maximum number of swans reported present ('Up to 200 ...') was far in excess of winter populations recorded at pukepuke. 
If the balance between macrophytes and phytoplankton is already finely poised then in theory even a very light impact may be sufficient to tip it in favour of complete phytoplankton dominance. This impact may exert its influence in two ways:

(1) It may stimulate sufficient phytoplankton development (by various means described below) to make the difference between a standing crop which does not screen out a critical amount of light to macrophytes and one which does.

(2) The cropping of near-surface shoots may enhance the shading influence of existing phytoplankton. If, for example, some phytoplankton-induced turbidity accompanied a macrophyte growth, then for the macrophytes to remain competitive they may need to reach quite near the surface. If the near-surface shoots were cropped then the capacity of the plants to photosynthesise may be impaired due to insufficient light penetration at lower levels.

In situations where flushing is not high it is extremely difficult to predict the level of grazing required to stimulate a changeover to phytoplankton dominance. Apart from the effect of cropping (described above), many other phytoplankton-favouring effects may result from grazing and the wastage this inevitably involves. Nutrients would be released into the water from decaying macrophytes and from the excreta of swans; the inhibiting effect of phytoplankton suppressants, presumed to be released by macrophytes (see e.g. Hasler and Jones, 1949; Hogetsu et al., 1960), would be reduced; the removal of macrophytes would mean that phytoplankon would have less competition for available nutrients; damaged plants may lose vigour. The extent to which phytoplankton would then be 
able to capitalise on these changes would depend on other factors, the operation of which - like that of phytoplankton suppressants is often little understood and/or difficult to measure. These factors include the rate of water retention (or turnover) and the extent to which algae-grazing zooplankton (not just cladocerans) may be present. The nature of the macrophytes and the availability of obscure vitamins and trace elements may also be important.

Although it is readily deducible from theory that swans have the potential to stimulate change to phytoplankton dominance, it appears that there is very little awareness of this among waterfowl biologists (certainly I have been unable to locate reference to it in the literature pertaining to swan feeding). This may have to do with the fact that clear-cut examples - such as are available for storm or cutter-induced damage - are lacking. Without this kind of specific documentation the potential of swans in this regard may not be brought to notice sufficiently to foster a general awareness. The nature of grazing may be such that it is difficult for limnologists to produce this documentation.

It would seem that two basic types of 'evidence' may be used to link particular forms of macrophyte damage (e.g. storm or swan-induced) to phytoplankton changeovers: (1) empirical evidence, i.e. where a causal relationship is held to exist simply on the basis of the immediacy of the assumed cause and effect, and (2) descriptive or analytical evidence, i.e. where the pathways and interactions mediating cause and effect are described (and possibly quantified). The only evidence I have been able to find with respect to any kind of macrophyte damage (be it storm, boat propellor or cutter-induced damage) has been empirical in form (considering the theoretical 
problems still remaining in this field of research it may be unrealistic to look for analytical evidence). The nature of swan grazing may be such as to make empirical evidence difficult to obtain. A comparison between damage inflicted by storms and weed-cutting on the one hand and swan grazing on the other may serve to illustrate this point: Storms and weed cutting have sometimes occurred as highly conspicuous cataclysmc events, so that when these events have coincided with sudden and unusual phytoplankton blooms (such as occurred at Lake Ellesmere after the so-called Wahine storm) there can be little doubt as to the cause and effect relationship. These are the kinds of examples which serve to foster an awareness that a particular form of damage may lead to a phytoplankton directed changeover. Swan impact on the other hand is unlikely ever to occur in such an all-or-nothing manner. It is more likely to increase gradually from year to year as the population builds up, so that when a sudden change to phytoplankton occurs (as at Tomahawk Lagoon) the relationship is not so clear-cut or certain.

Three major points may be made in summary:

(1) The problem is not one of deciding whether swan grazing can stimulate phytoplankton development, and hence can affect a changeover to phytoplankton dominance, but how to obtain evidence for this in particular situations. A lack of confirmed examples may help to explain why the potential of swans in this regard has been under. emphasised in the waterfowl literature. 
(2) It may be that swan grazing is a highly significant cause of waterfowl habitat degeneration. Again, this possibility appears to have been largely overlooked in the literature.

(3) Unlike Tomahawk Lagoon, Pukepuke Lagoon is not susceptible to phytoplankton irruptions in the winter, even though swan grazing impact may be high. This is because of the combined influences of flushing and zooplankton buffering. 


\section{SECTION 2}

THE FEEDING ECOLOGY OF MALLARDS 


\section{Chapter 5}

\section{INTRODUCTION}

The year-round patterns of feeding exhibited by mallards (including ducklings) were described on the basis of dawn to dusk scan counts lother feeding and population details were recorded to supplement this core of numerical information). These feeding patterns were then interpreted and discussed against the background of what was known of the food content of the lagoon (described in section 1).

In addition to looking at factors immediately and obviously relevant to the interpretation of feeding patterns (such as food availability and energy demand at different stages of the annual cycle) the significance of migration - or the apparent absence thereof in the case of mallards in New Zealand - was also considered. This factor, linked as it is to the subject of sex ratios in winter flocks (see e.g. Smith and Prince, 1973), is known to be a major indicator of the species' capacity to maintain energy balance. Data on sex ratios of mallard populations wintering at Pukepuke have been published by Caithness and Pengelly (1973).

This study provided an opportunity to collate and give local meaning to a wide range of field and experimental information scattered in the literature. It is intended that this focus on Pukepuke Lagoon will assist in understanding feeding and feeding conditions in other parts of New Zealand.

There appears to have been no previous attempt to quantitatively monitor and then interpret the feeding of mallards on a year-round basis at one particular site. (Much of the research of mallards has 
been carried out in climatic zones unsuited to this kind of study. In the intensively studied prairie regions of North America, for instance, wetlands tend to ice-over in the winter, thus preventing use). A major advantage of obtaining feeding counts over the span of the annual cycle is that counts referring to particular stages may assume meaning on the basis of their comparability (terms such as 'high' and 'low' may, for example, be used to describe feeding at particular stages). Absolute data and the diurnal patterns described will serve as baseline information for comparative studies.

No significant research into the feeding ecology of mallards has been undertaken in New Zealand. A small-scale food study was carried out by Balham (1952), although the results are now of limited value since they refer to gizzard contents. Such results tend to overemphasise the importance of seeds relative softer animal foods (since the early 1960s most food studies have been carried out on oesophagal contents to minimise the problem of differential digestion - see e.g. Perret, 1962; Bartonek, 1972). In a management-directed article potts (1977) reported on the oesophagal contents of mallards collected throughout New Zealand by Wildife Service personnel. This account merely confirmed what was already known from overseas studies about the occurrence of invertebrate forms (aquatic snails, insect larvae, etc.) in the diet. 


\section{METHODS}

Scan counts of mallards on Pukepuke Lagoon were made from hide no. 2 using a spotting telescope (×20 magnification). Counts were taken at hourly or two-hourly intervals from dawn to dusk over two to five consecutive days per month or every two months (from July 1977 to March 1979). The lagoon was left undisturbed for at least a week prior to counts being made.

Two states were distinguished in scan counts: feeding and non-feeding (no attempt was made to distinguish between feeding and drinking). A hand-held counter was used to record feeders. Pairs were counted separately from non-pairs. That is, a scan was made to record non-pairs and then another was made to record pairs. Feeding by individuals of these pairs was recorded by ticking columns labelled by sex. This system was also used to distinguish sexes of unpaired feeders in pre-breeding flocks (this was easily done, since feeding frequency among this group was characteristically very low). All feeding may be taken to reflect feeding in the water. Only very rarely were birds seen to feed away from it. Notes were taken on feeding intensity, sex activity and other aspects deemed to be of interpretive value.

Although some non-pairs may have been confused with pairs, and vice versa, it is unlikely that this confusion would have occurred often. Paired birds tended to move away from the flocks of unpaired birds. The drake typically had an attitude of altertness, particularly when other drakes approached. Mutual displays often occurred. Pairs and non-pairs were not distinguished after August since isolated drakes may or may not have been associated with nesting females. 


\section{RESULTS}

Details of monthly scan counts are given in Figs. 7.1.0-7.2.5 ('mean number per day' shown on the vertical axes refers to the mean number of birds recorded in a given time period over the days counted). All broods counted in monthly scans are depicted symbolically below the graphs. Although the salient features of each graph are presented in the text, I have chosen to caption each with a summary (including, in some cases, points raised in the discussion). This format is intended to provide a convenient form of reference once the text has been read.

\subsection{Winter - spring 1977 \\ July 1977 (Fig. 7.1.0)}

Counts began about one and a half months after the end of the shooting season (during which time the lagoon was largely deserted). About 60 birds had gathered for sexual display and pairing (Pukepuke Lagoon was the focal point for such activity in the area). Sex bias was slightly in favour of males, i.e. about 538. A higher proportion of paired individuals were seen feeding than unpaired birds. Of the birds recorded on the water $4.5 \%$ of unpaired birds were observed to feed (over the entire observation period) compared to 18.18 of paired individuals. This difference was highly significant $\left(\Psi^{2}=21.8, \mathrm{df}=1, \mathrm{P}<.001\right)$. Treating feeding by males and females of pairs as fully independent events, no significant difference in feeding frequency between the sexes was found $\left(\Psi^{2}=0.43, \mathrm{df}=1, \mathrm{P}<.05\right)$. However, where only one individual of a pair was observed feeding it was significantly more likely to be a female $\left(\psi^{2}=34.77, \mathrm{df}=1, \mathrm{P}<.001\right.$, with Yates' correction). The 
intensity of feeding by paired females was far higher and more sustained than that of flock birds or the male partner.

August 1977 (Fig. 7.1.1)

The findings for this month are essentially the same as for the preceding month. Of the birds recorded on the water, 3.58 of unpaired birds (flock birds) were observed to feed compared with 18.88 of paired individuals. This difference was highly significant $\left(\Psi^{2}=119.82, \mathrm{df}=1, \mathrm{P}<.001\right)$. Treating males and females of pairs as fully independent events no significant difference in feeding frequency between the sexes was found $\left(\Psi^{2}=2.086, \mathrm{df}=1, \mathrm{P}<.05\right)$. Where only one individual of a pair was observed feeding it was more likely to be a female $\left(\psi^{2}=134.4, \mathrm{df}=1, \mathrm{P}<.001\right.$, with Yates' correction). The feeding intensity of females of pairs was conspicuously high. At this stage some pairs were seen to visit waters external to the Reserve (probably on reconnaisance for nesting sites).

September 1977 (Fig. 7.1.2)

Sexual activity continued in this month. A far greater proportion of males occurred in the population compared to the previous two months (about 3 male : 1 female). This indicated that many females had paired and were engaging in nesting activty. Many pairs and a few broods were seen in outside waters. No broods were seen on Pukepuke Lagoon.

Differentiation of paired and unpaired birds was not made since isolated drakes may or may not have been associated with nesting hens. The overall feeding percentage was low, i.e. 6.58. However, females of pairs fed vigorously. 
As in the previous months feeding graphs were relatively flat, i.e. without peaks in the morning or evening. Also, as in the previous months, the birds tended to be highly visible, without much movement in and out of cover.

October 1977 (Fig. 7.1.3)

Most of the population was male in this month, i.e. about 808 . Total counts were considered to be less indicative of the true local population than were those of previous months. Many birds nested for much of the day in raupo (Typha orientalis) cover around the 'Willows' area. Males (usually in groups) were mobile within and without the Reserve. Rapes were common.

The first broods retorded for the season were observed in the early morning and torward dusk.

\subsection{Summer - autumn 1977/78}

November 1977 (Fig. 7.1.4)

This month saw the start of an influx of post-breeding males for moulting. About 908 were in the first stages of moult. About 58 of the visible total was juvenile. Females without broods were rarely seen. Sex activity had waned considerably (only one copulation was observed). There was evidence of an accelerating rate of feeding in the general population. Feeding and general activity increased going into the evening (in the $6-7 \mathrm{pm}$ period about $60 \%$ of the visible birds were feeding).

December 1977 (Fig. 7.1.5)

The numbers of birds coming into the lagoon to moult continued to 
increase. These were mostly males. The highest total counts of the day were considered to closely approximate the presence of all birds capable of flight (with perhaps a $10 \%$ shortfall as birds became obscured when resting behind foreground raupo). Very little movement occurred in and out of cover such as that provided by the 'Willows'. The highest counts tended to be around 8-9am when many of the birds moved back onto the gathering water of Pukepuke Lagoon after feeding at night on external waters. Birds in the secretive flightless phase (of wing moult) were frequently seen just after dawn in drains and other areas close to cover, indicating that most of their feeding was done at night.

Feeding was conspicuously vigorous in the population as a whole, reminiscent of the intensity shown by paired females in the winter and spring. In the first light before the initial daytime count and just on dusk after the last count, the majority of the flight-capable birds were seen to feed, suggesting feeding occurred mainly at night. Broods followed this general pattern.

Feeding was far more prevalent on dull days (particularly when rain fell) than on hot sunny days.

\section{January and February 1978 (Figs. 7.1 .6 and 7.1.7)}

These mid-summer months represented the peak of moulting. A larger proportion of the population were post-rearing females than in preceding months. Many juveniles also occurred. The summer water recession meant that many birds tended to loaf on exposed margins. No significant interchange in and out of the secluded 'Willows' area was observed. As in the previous month the totals tended to diminish in the daytime as activity slowed and birds moved to the 
margins (although they rested in the open they were often obscured from vision by foreground raupo. The usual late afternoon (outward) and early morning (inward) flights occurred, but these were rarely to or from waters outside the Reserve (most drains and ponds were dried up or had dense phytoplankton bloomsi).

As in December it is estimated that the percentages of the total population feeding just after dawn and at dusk were the highest of any stage of the year, being almost 1008. Feeding intensity was very high, with very little movement from a fixed spot (small invertebrate production and concentration in the lagoon was extremely high at this time).

Few broods were observed in January. None were seen (in the scans) in February.

March 1978 (Fig. 7.1.8)

In this month the distinction between birds on and off the water was often difficult to make due to the extreme shallowness of much of the water. Dense groups often rested in situations extending through deepish water to exposed substrate. Many slept standing on the bottom in water only a few centimetres deep.

Feeding intensity was very high. Very high percentages of totals were observed to feed just after dawn and before dusk. Figure 7.1.8 does not depict the full extent of this. Just after dawn, i.e. 5-6am, long shadows cast by the raupo margin obscured many birds. By the time the first count was made in the 6-7am period many birds had moved to the margin. Also, due to the particularly hot sunny days on which the counts were made the birds did not begin feeding 
until just after the sun had disappeared over the horizon. When this happened waterfowl (including mallards, swans and shoveler) moved onto the water quite suddenly and en masse and began to feed intensively or fly to the smaller permanent ponds within the Reserve. By this time it was too dark to obtain a reliable feeding count. As in the previous month 'total' counts were relatively consistent over the entire day. Resting birds became more visible as the water level receded further (see Plate 8). The complete disappearance of the macrophytes in this month meant that food was obtained from the substrate. Feeding was generally undertaken in close association with feeding swans.

\section{April 1978 (Fig. 7.1.9)}

Numbers dropped away considerably in this month. As in the previous month feeding intensity was high with most birds feeding at dawn and dusk. The high levels of dawn and dusk feeding are not indicated in the graph. As in the previous month rapidly fading light at dusk prevented a dramatic acceleration in feeding being recorded. The decline in feeding just after dusk was rapid. Again, this presented recording difficulties.

\subsection{Winter - spring 1978 \\ June 1978 (Fig. 7.2.0)}

The hunting season was confined to May in this year, compared to May/June in the previous year. Therefore counts began earlier in this winter than in 1977. Very little sexual display was observed in the flock at this stage (only two copulations were seen). Pairs (or what may have been construed as pairs) could rarely be distinguished. Feeding activity was very low both in terms of frequency and intensity. No morning or evening feeding peaks 
occurred. Feeding was seldom seen in waters peripheral to Pukepuke Lagoon.

August 1978 (Fig. 7.2.1)

As in August of the previous year sexual activity was high. Again, proportionately more paired individuals fed than unpaired individuals. Of the birds recorded on the water $5 \%$ of unpaired individuals were observed to feed, compared to 24.58 of paired individuals. This difference was highly significant $\left(\psi^{2}=37.2\right.$, $\mathrm{df}=1, \mathrm{P}<.001)$. Flock bird feeding was, again, conspicuously low, even in periods of quiescence between bouts of group display. Treating feeding by males and females of pairs as fully independent events, no significant difference in feeding frequency between the sexes was found $\left(\Psi^{2}=0.31, \mathrm{df}=1, \mathrm{P}<.05\right)$. However, where only one individual of a pair was observed feeding it was significantly more likely to be a female $\left(\Psi^{2}=35.1\right.$, df $\left.=1, \mathrm{P}<.001\right)$, with Yates' correction).

October 1978 (Fig. 7.2.2)

As described for October 1977.

\subsection{Summer - autumn 1978/79}

December 1978 (Fig. 7.2.3)

As described for December 1977.

February 1979

Essentially as in February 1978, with an extremely high frequency and intensity of dawn and dusk feeding. 
March 1979 (Fig. 7.2.5)

Most of the birds of the previous month had left the lagoon. The pattern and intensity of feeding was essentially as described for March 1978, except that considerably less feeding was undertaken in close association with swans. (In the summer of 1977/78 macrophytes disappeared completely. Therefore both swans and ducks were forced to seek food in the substrate. In the summer of $1978 / 79$ the macrophyte collapse was only partial (see Chapter 3), so that quite plentiful macrophyte associated food stocks continued to be available.)

The major seasonal features (applying to both the 1977/78 and 1978/79 annual cycles) may be summarised thus:

- low feeding by unpaired flock birds in the winter, i.e. both in terms of proportion of total birds counted and in terms of intensity

- intense feeding by females of pairs in the winter and spring

- intense feeding by moulting populations. Pronounced post-dawn and pre-dusk feeding peaks. 
Figs. 7.1.0 to 7.2 .5 .

Diurnal feeding patterns of mallards as determined by scan counts undertaken at monthly intervals from July 1977 to April 1978, and generally at two-monthly intervals from June 1978 to March 1979. 


\section{MALLARD COUNTS}

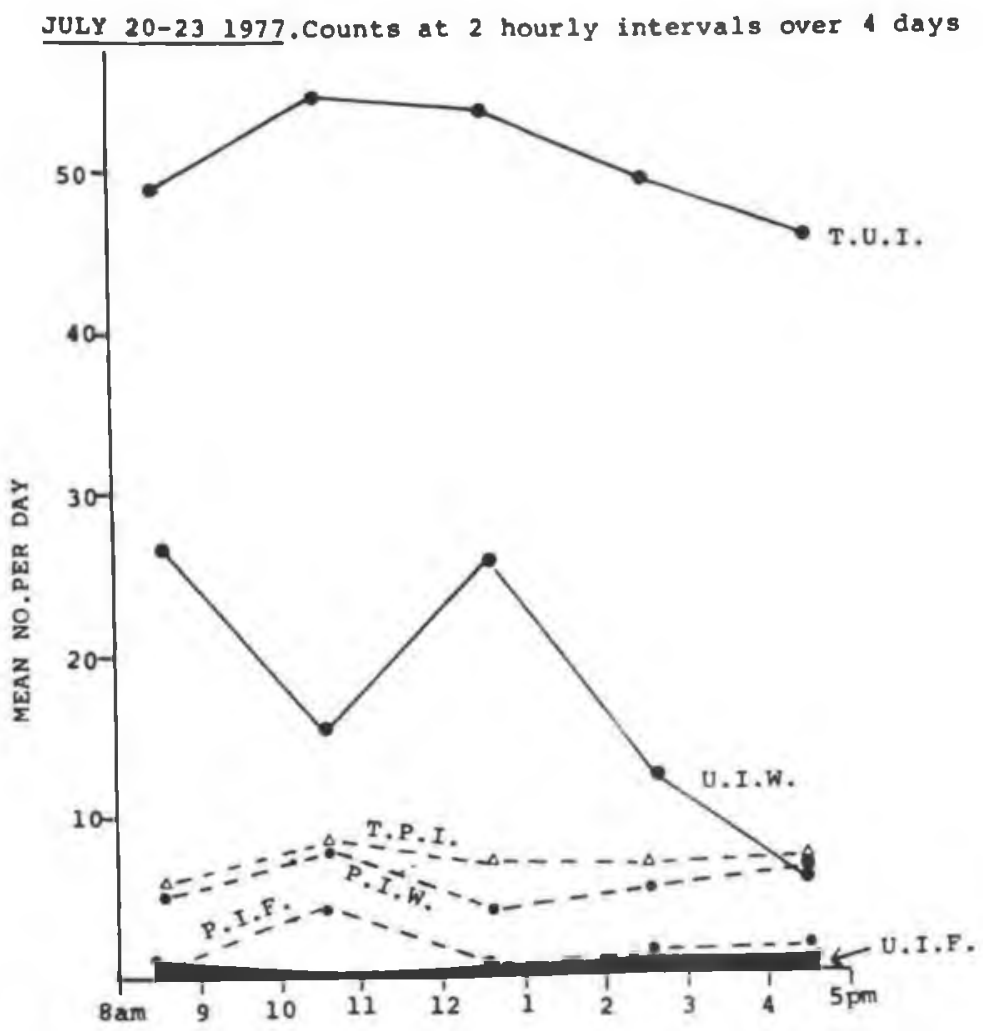

Total unpeired individs.(T.U.I.) Total paired individs.(T.P.I.) Unpaired individs.on water (U.I.W.) Paired individs.on water(P.I.W.) Unpared individs.feeding (U.I.F.) Paired individs.feeding(P.I.F.)

Summary of findings:

1. Sexual activity high. Sex bias slightly in favour of 2. males i.e.about 538 .

birds. Of the birds recorded on the water .5t of unpaired individs.were observed to feed compared to 18.1 of paired individs.This difference was highly significant ( $\psi 2=21.8, d f=1, P<.001)$. In terms of the total flock bird figure(T.U.I.) the proportion feeding was far less than 4.58. In the sexual flocking phase the birds tended to gather in an open position on or near the water making most total counts quite accurate near the water making most tocal population. Assuming fully paired birds were distributed away from these flocks it is estimated that an overall daytime feeding fiqure for unpaired birds would only be around 1 s.

3. Flock bird feeding frequency was conspicuously low group display. Social display tended to diminish as qusk approached. Feeding did not increase commensurately.

4. Paired birds tended to display and feed well away from the flock-undoubtedly to avoid interference. They were not seen in waters outside the Reserve.

5. Treating feeding by males and females of pairs as fully independant events no significant difference in feeding
frequency between the sexes was found $(\psi 2=0,43, d f=1$ P $>05)$. However, where only one individ. of a pair was observed feeding it was significantly more 1 ikely to be female $(\psi 2=34.77$ df $1.8<.001$ (with Yates correction)).

6. The intensity of feeding by paired females was conspicuousiy Far higher and more sustained than that of flock birds or the male partner. The latterg feeding tended to be itfull,being characterised by a general alertness associated with the defence of the female.This often made it difficult to decide whether to record the bird as feeding or not. Much of the male's feeding was probably stimulated by the
females intenge feeding. 
MALLARD COUNTS

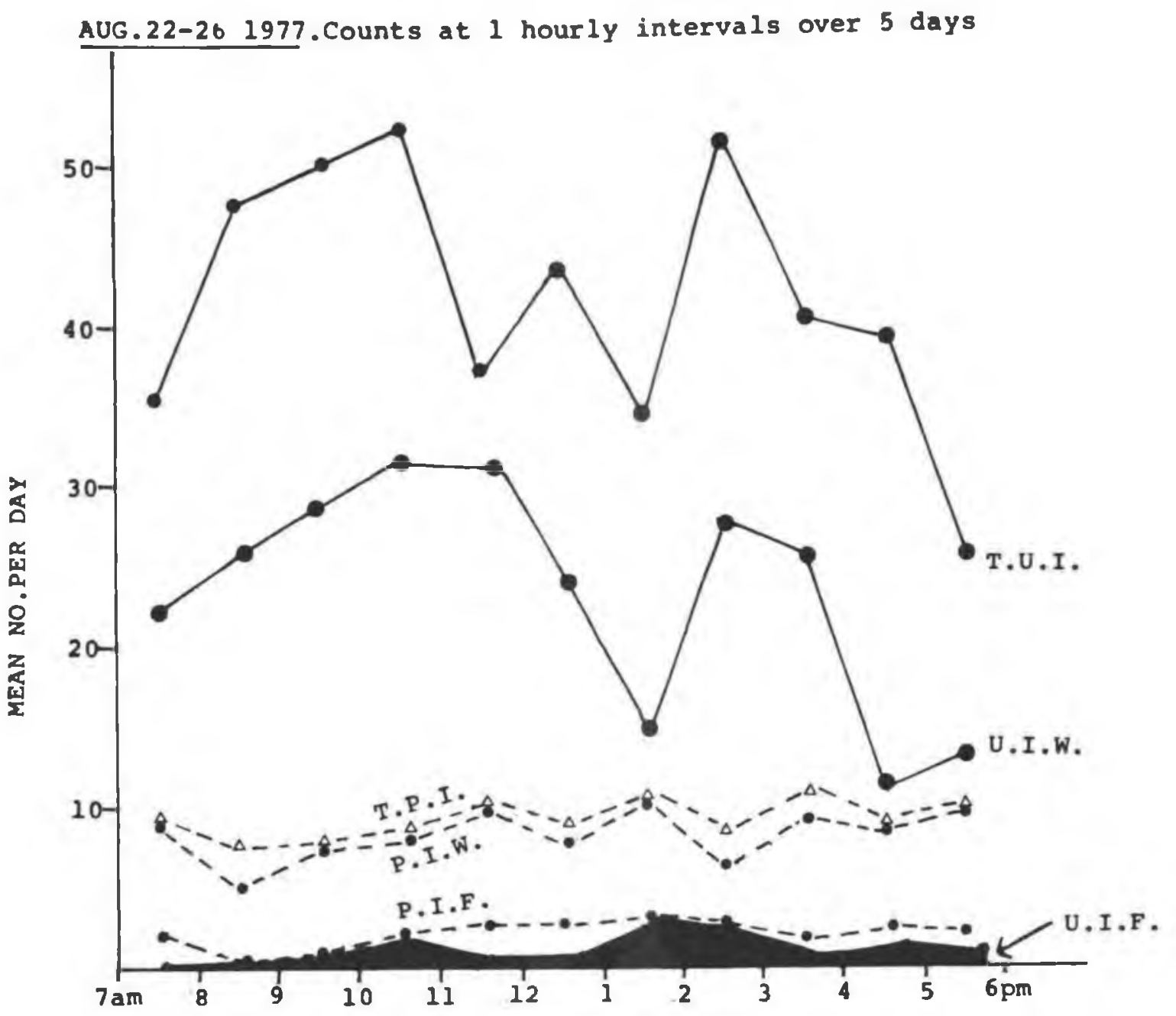

Total unpaired individs.(T.U.I.) Total paired individs.(T.P.I.) Unpaired individs.on water (U.I.W.) Paired individs.on water(P.I.W.) Unpaired individs.feeding(U.I.F.) Paired individs.feeding P.I.F.)

Summary of findings:

1. Sexual activity high.

Paired individs.fed more than unpaired birds.of the birds recorded on the water 3.58 of unpaired birs individs. This difference was highly significant ( $\psi 2=119.82$ df $=1, P<.001$ ).

3. As in point 3 of July summary.

4. As in point 4 of July summary.

5. Treating feeding by males and females of pairs as fully independant events no signif.diff. In feeding frequency between the sexes was found $(\psi 2=2.086, \mathrm{~d} f=1, \mathrm{P}) .05)$. Where only one individ. of a pair was observed feeding it was more likely to be a female $\left(\psi^{2}=134.4, \mathrm{df}=1, \mathrm{P}<.001\right.$ (with Yates correction)l.

6.As in point 6 of July summary.

7. Some pairs seen outside Reserve(mainly reconnaisance). 


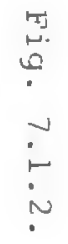
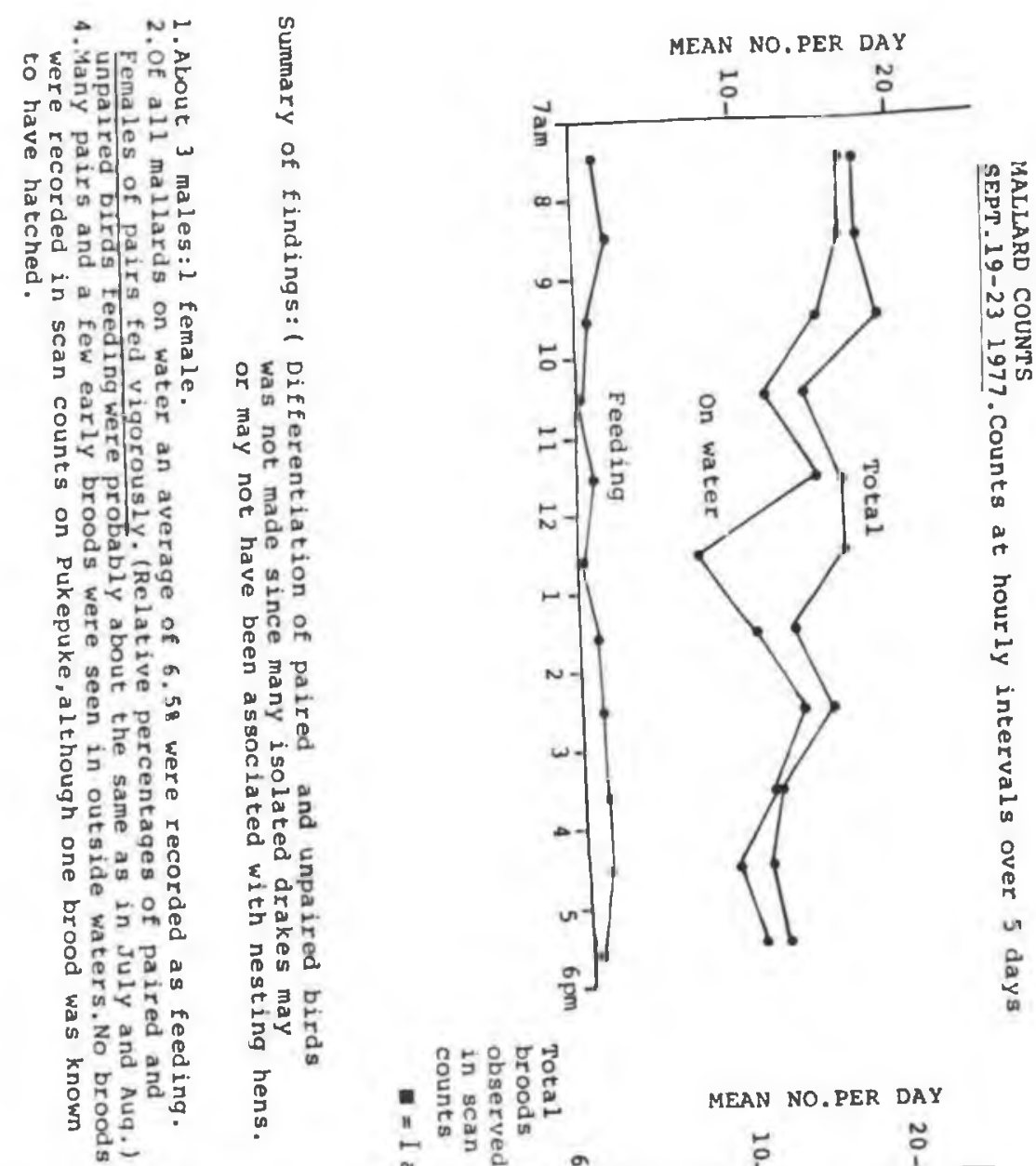

$\frac{1}{3}$

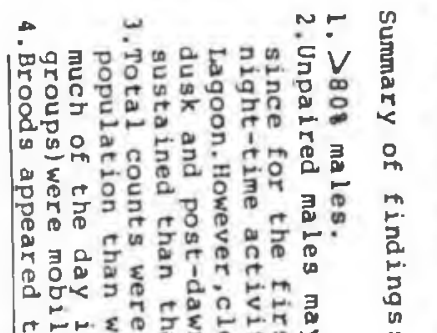

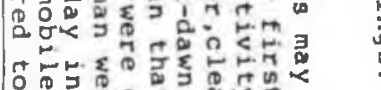

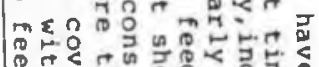

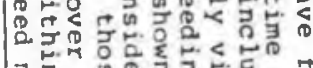

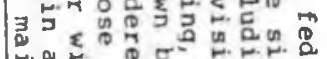

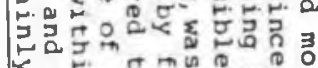
$<5$

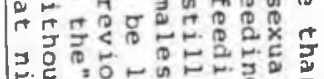

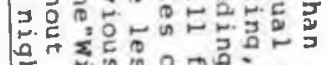

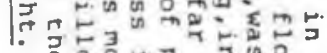

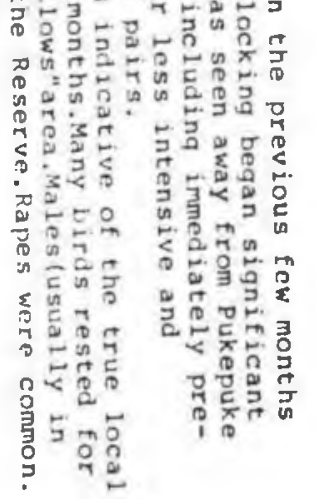

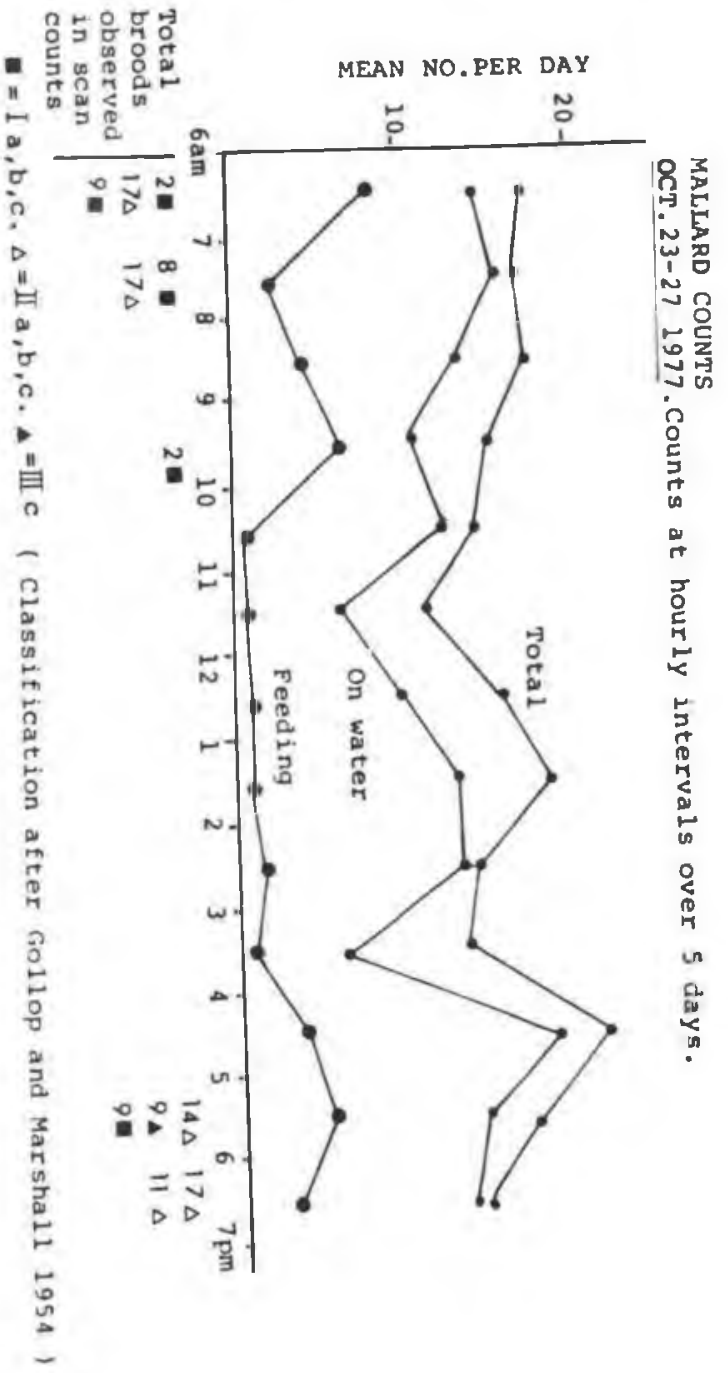


\begin{tabular}{l}
7 \\
5 \\
5 \\
\hline
\end{tabular}

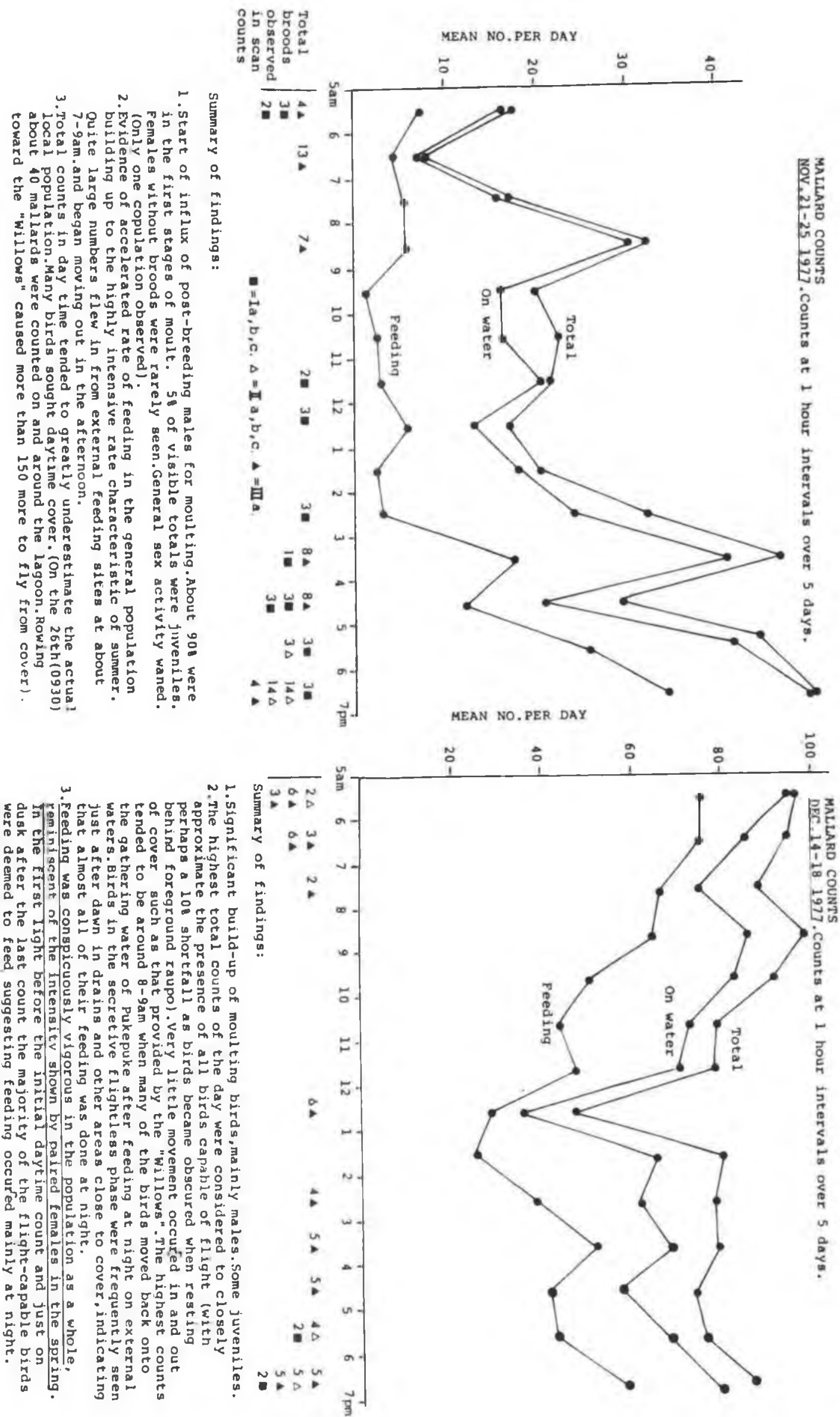



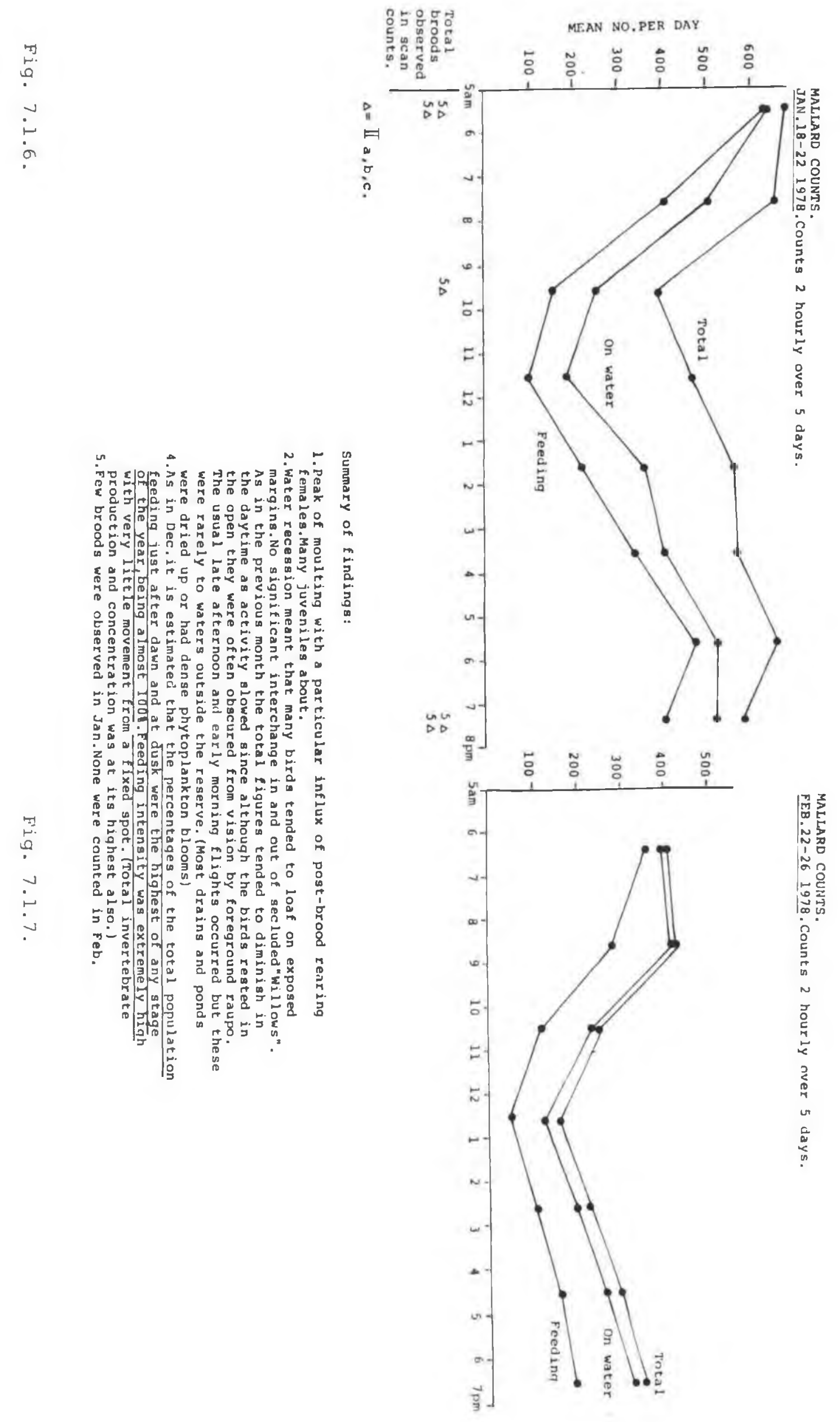

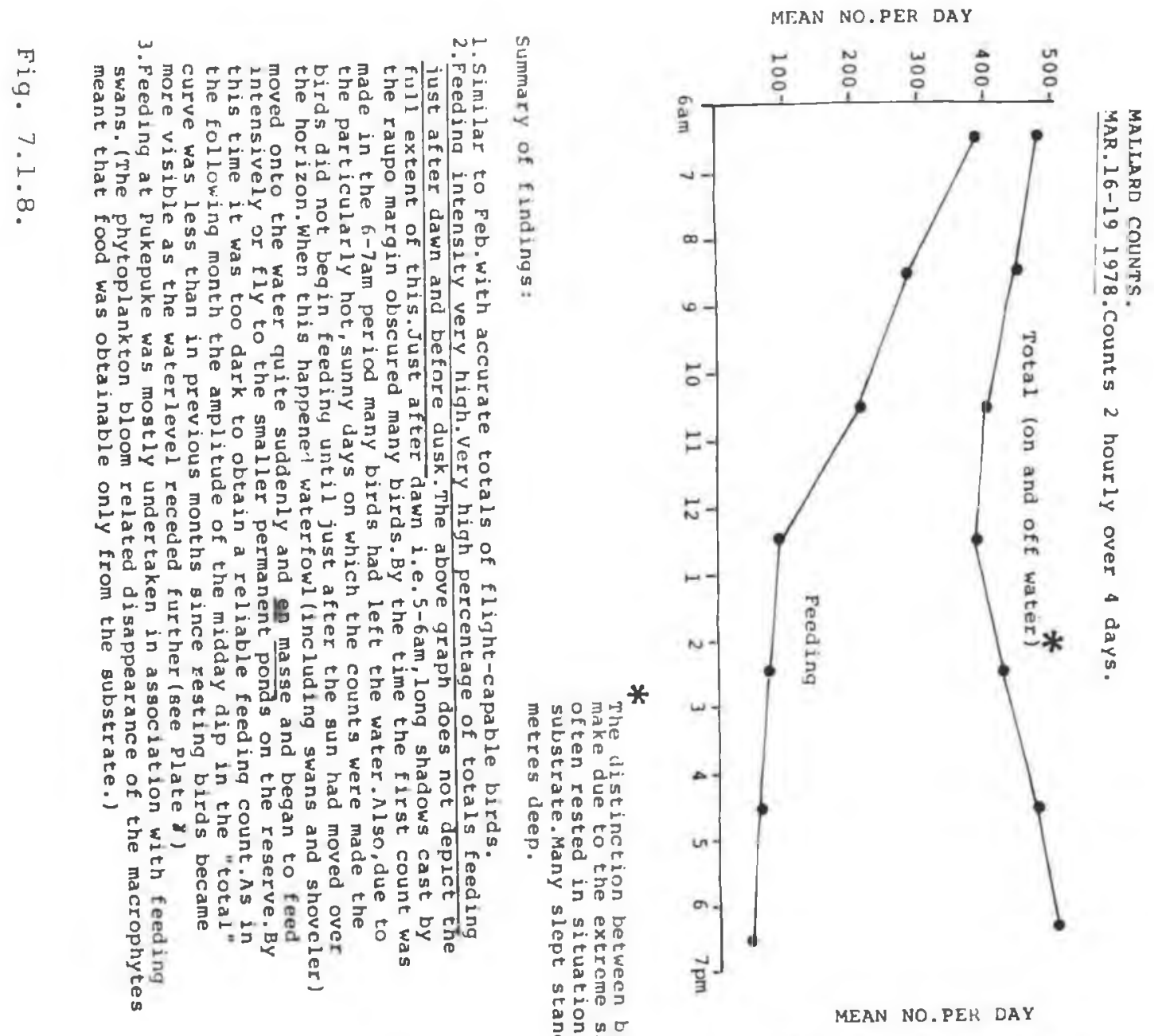

:
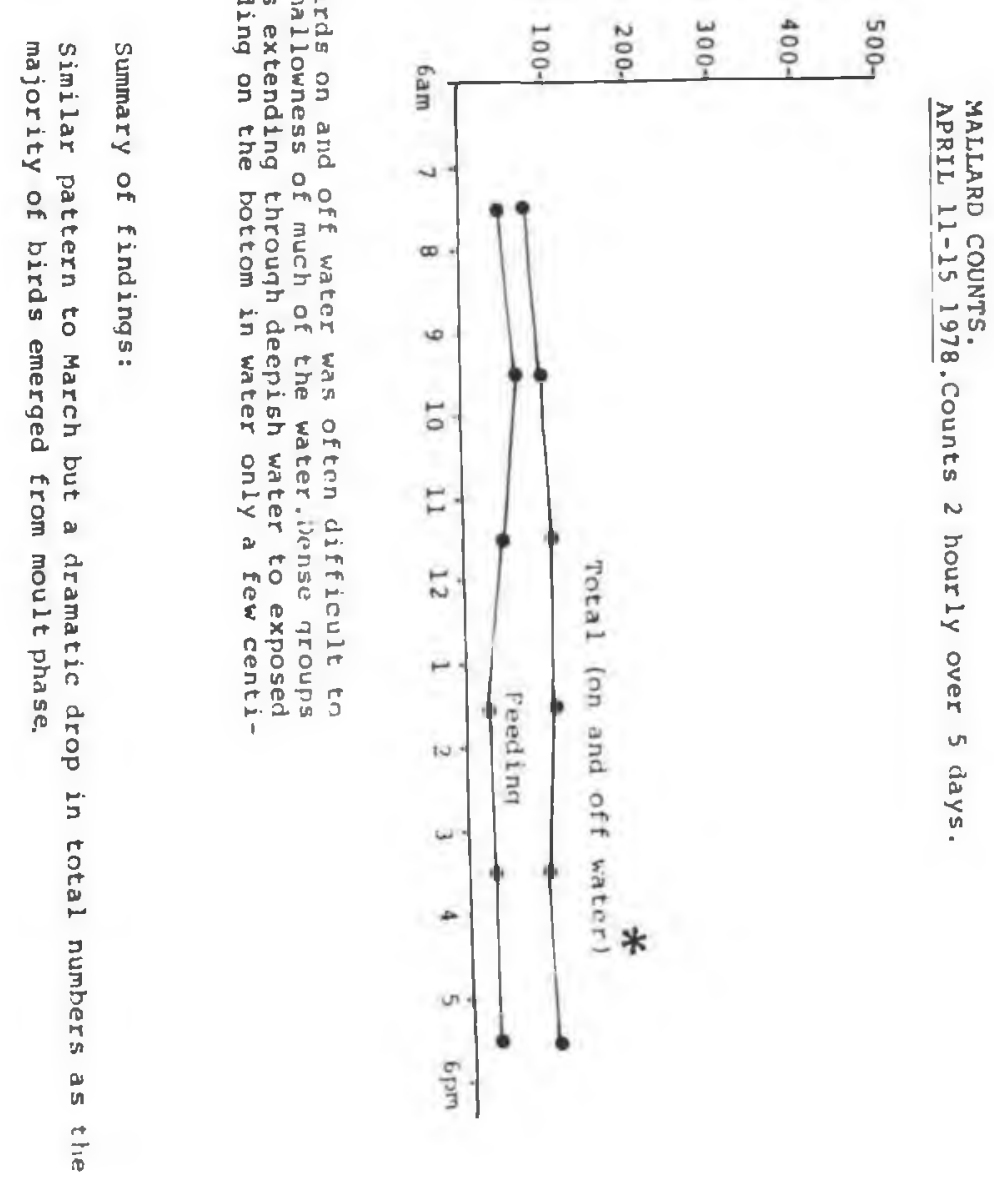

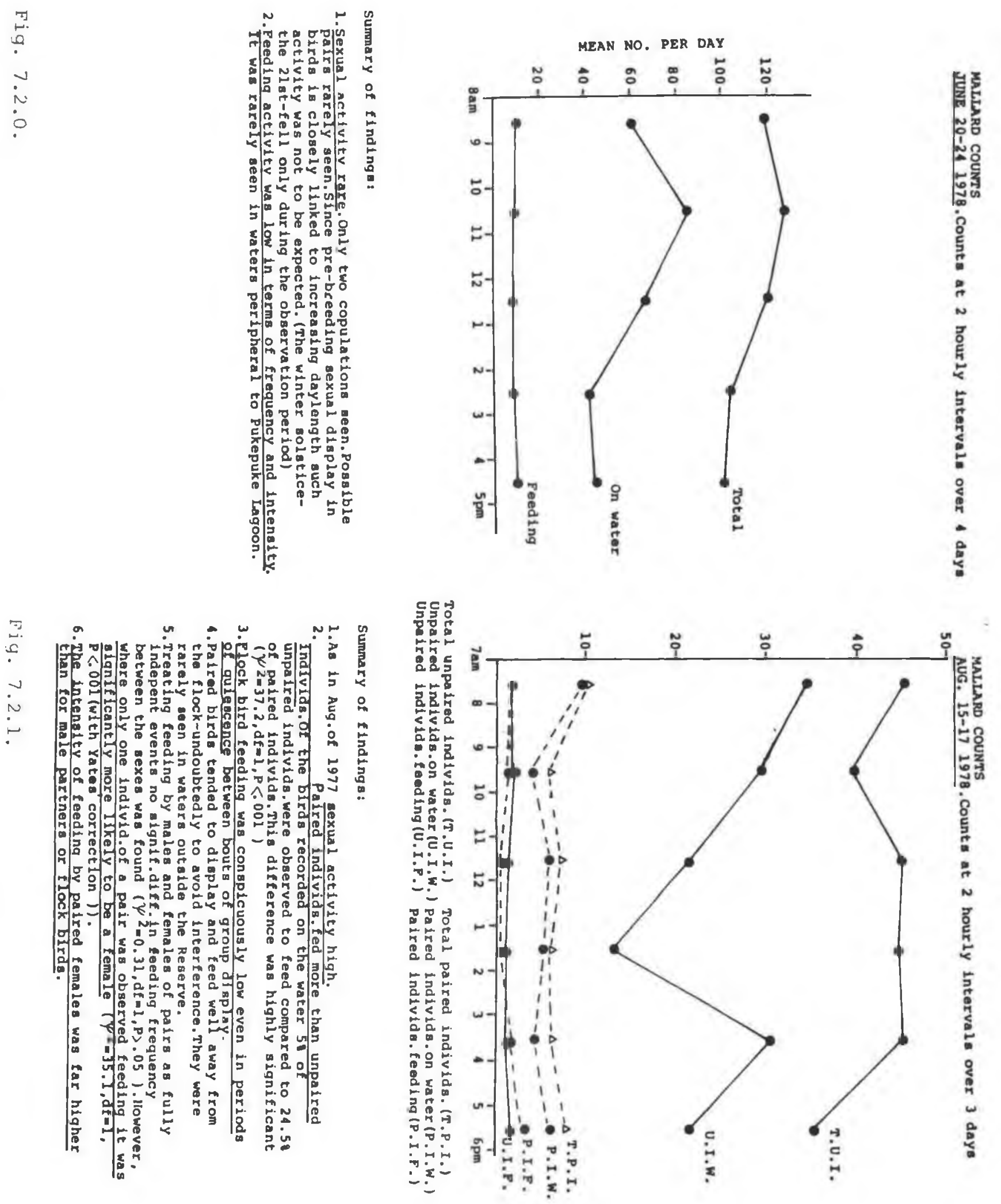


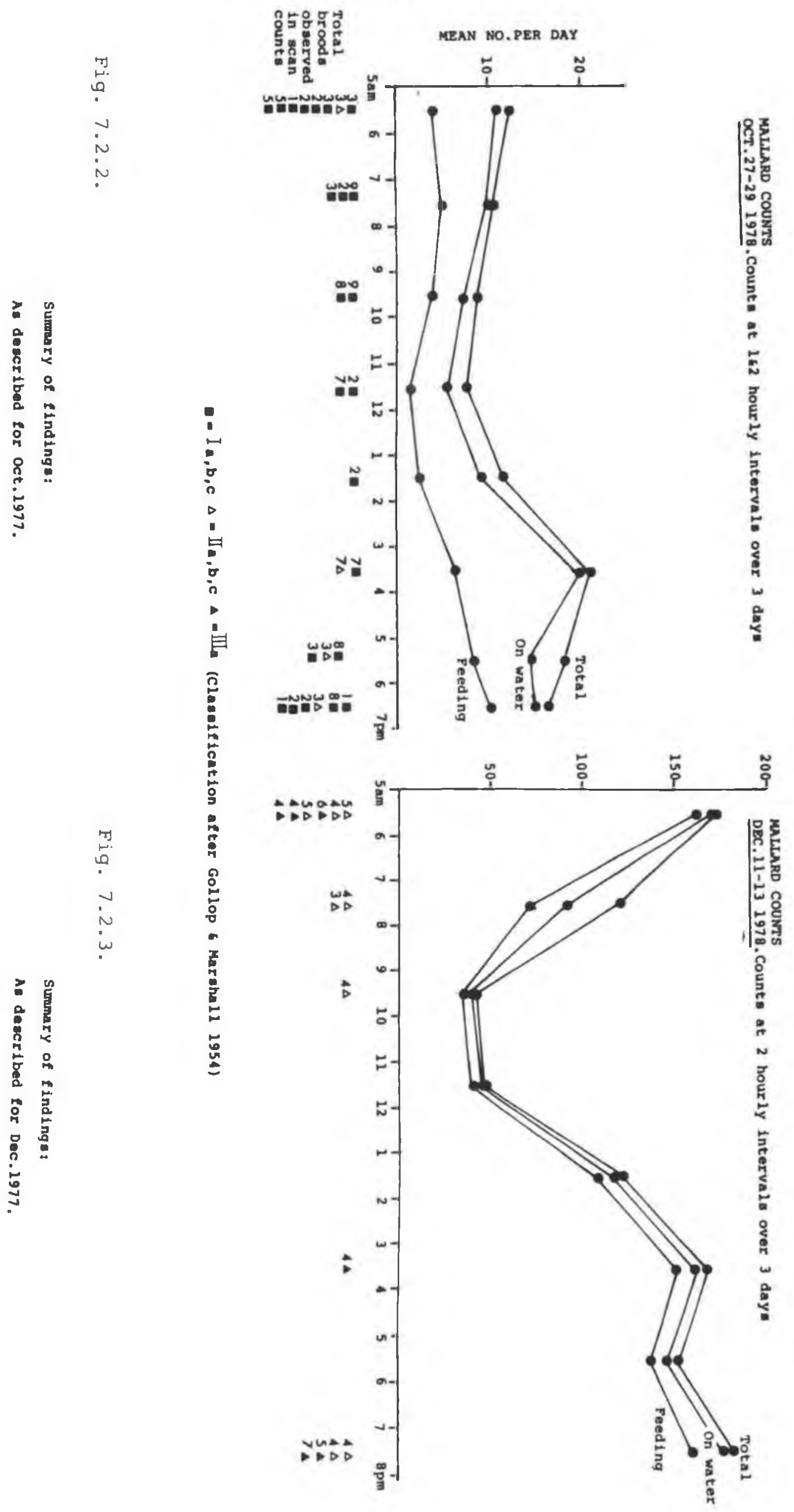




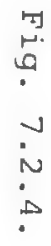
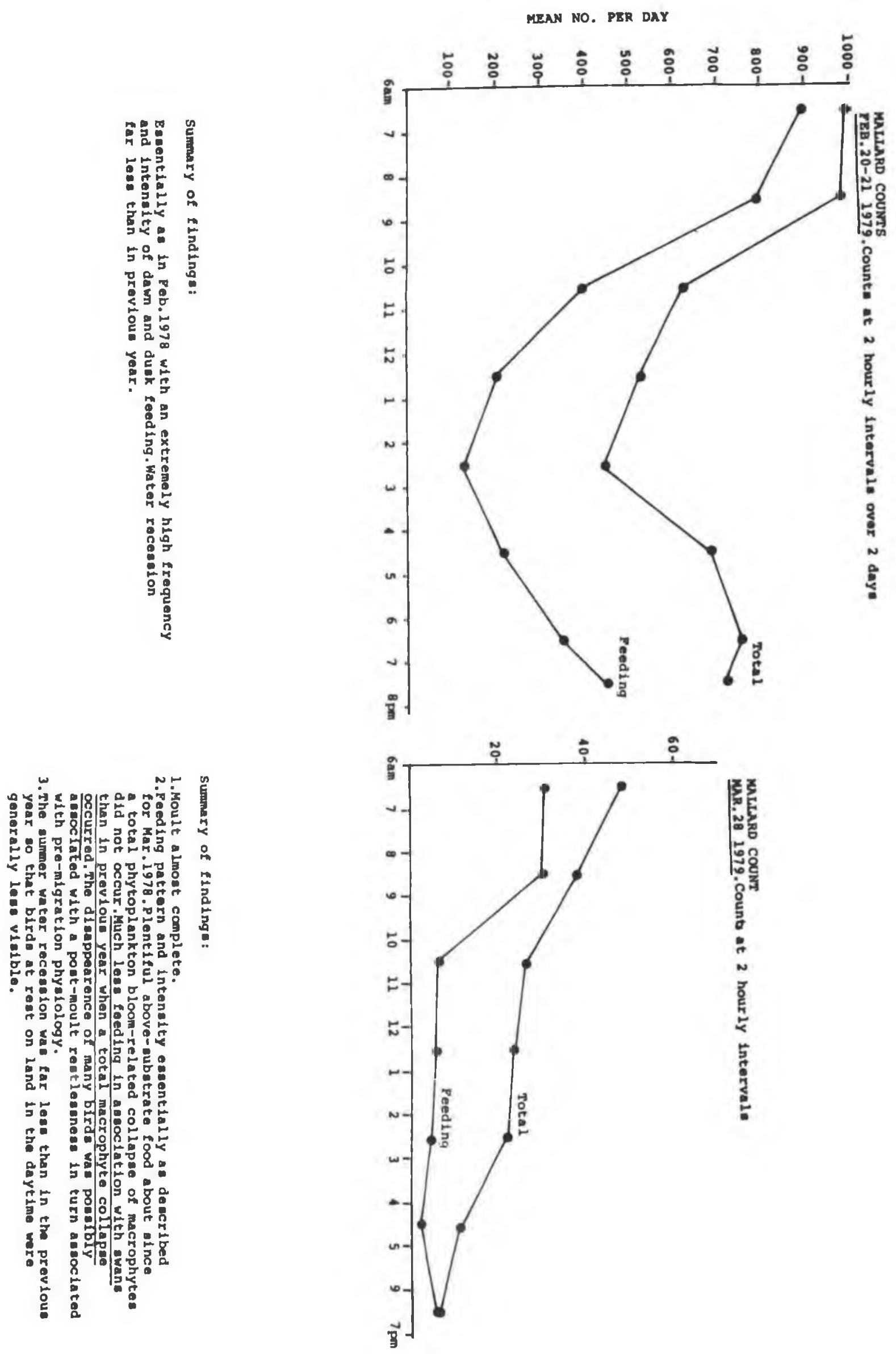

| 
Chapter 8

\section{DISCUSSION}

The discussion is divided into two parts: Part 1 is concerned with the interpretation of feeding graphs. Part 2 focuses specifically on breeding and brood production and their relation to local food supply

\section{PART 1 - SEASONAL FEEDING PATTERNS}

\subsection{Winter - spring feeding}

The discussion relating to this period concerns pre-breeding flocks. The birds in these flocks are considered under two headings: 'unpaired birds' and 'paired birds'. (Display activity in the flock led to pairing. Paired birds remained on the lagoon (together with unpaired members of the flock) for a short period prior to moving on to outside waters to nest (some nested on the flocking water itself). Behavioural and other indicators of winter food adequacy are listed. The possibility of energy stress occurring during the hunting season is also discussed.

\subsubsection{Unpaired birds}

It should first be noted that mallards did not settle on Pukepuke Lagoon during the period from autumn (approx. mid-April) to around mid-winter (approx. mid-June). This period coincided with disturbance created by pre-shooting and shooting activity. Therefore the scan counts undertaken in the winter pertain almost entirely to the latter half of that season, i.e. beginning after the winter solstice (shortest day) in late June. After the winter solstice there is a gradual increase in sexual display leading to 
pairing. Prior to it the birds are sexually quiescent.* There is some evidence from this study to suggest that the energy requirements of unpaired birds in the pre- and post-solstice periods of winter are not markedly dissimilar. When extremely low levels of feeding were recorded for unpaired birds in July and August 1977 (the first two months monitored in the study) it seemed possible that this may have been linked to heightened sexuality, i.e. overt, covert or both. However, this interpretation was challenged by findings obtained in the following winter, and in particular June, of that winter. Counts began one month earlier than in 1977 , i.e. in the period of June 20-24 (Fig. 7.2.0). The winter solstice occurred on the 2lst of June, so that sexual display activity among the hundred plus birds occupying the lagoon during the scan period had barely begun (only two copulations were seen over the entire five day count period). The birds were extremely inactive. Very low feeding figures were recorded (about the same as for sexually aroused flocks in the previous July and August and in August 1978). (It can be assumed that food was highly abundant in Pukepuke Lagoon during the winters of both 1977 and 1978. The flocks did not feed - to any significant degree - outside of this water. These aspects will be dealt with more fully later.)

\footnotetext{
*The reproductive cycle of the mallard in New Zealand is evidently the same, or similar to, that described for the grey duck (Anas s. superciliosa) by Williams (1967). Williams found that sexual display anong a population of grey ducks occurred in the autumn, waned in the pre-winter solstice period and then accelerated after this point. Increasing daylength or photoperiod is known to influence the breeding seasons of a large number of North American and Eurasian birds that breed where suitable conditions occur regularly, but for generaily short periods, each year (Braithwaite and Frith, 1969). Some sexual displays, including copulations, were seen among mallard populations at Pukepuke in the autumn, but these were few compared with the spring. Williams (1967) discussed the question of the internal regulation of breeding with respect to the grey duck. On the basis of the work of Marshall (196I) and Hohn (1947) it is apparent that only in the culmination phase of the reproductive cycle (occurring after the regeneration and acceleration phases) can insemination and ovulation occur. The culmination phase is triggered by increasing daylength after mid-winter.
} 
Feeding by unpaired birds in pre-breeding flocks was low-key thoughout the day, even during periods of quiescence between bouts of group display. Display activity tended to diminish greatly as dusk approached.* Feeding did not increase commensurately, suggesting that night-time feeding was also low.

The extremely low levels of feeding recorded for unpaired birds in the winter probably reflected the following combination of factors (apart from the fact that the birds were outside of the high energy demand period of breeding):

(i) the energy demands associated with feather replacement were minimal,(ii) the climate was moderate, (iii) there was a good supply of food on-site, and (iv) invertebrate foods were highly available. These four factors are considered separately.

(i) The energy demands associated with feather replacement were minimal.

During the winter and spring the adult female undergoes a pre-nuptial moult (involving the body feathers, not the wings). This moult is slow and inconspicuous. Relatively few feathers are replaced at any one time. In the summer both males and females undergo highly conspicuous moults (the post and pre-nuptial moults in the case of the adult male and the post-nuptial moult in the case of the adult female). These are of relatively short duration and involve the shedding and replacement of many feathers simultaneously. Because feather

*Raltasuo (1964) described sexual display in mallaras as being essentially a daytime activity, stating that it did not tend to occur in the dim periods of dawn and dusk. 
development is costly in energy (see e.g. Owen, 1980) it would be expected, therefore, that daily energy demands (associated with the moult) would be much higher in the summer compared to the winter.

(ii) A moderate climate

This means that pressure to feed to maintain thermal homeostasis is much less than in colder climates. (It has been well established in experimental studies on a variety of captive bird species, including ducks, that they respond to lowering temperatures, and consequent heat loss, by accelerating their metabolic rate and hence their food consumpton (e.g. Kendeigh, 1944, house sparrow; Owen, 1970, blue-winged teal; Smith and Prince, 1973, mallard). The mallard has a relatively low thermal conductivity (denoting good insulation) (Smith and Prince, 1973). The high thermal conductivity values, typical of many of the smaller ducks, greatly increases the cost of thermoregulation at low ambient temperatures (Lasiewski, 1963).

\section{(iii) A good on-site food supply}

The birds were not required to move out of the flocking water to feed (see also p.108).

(iv) The availability of abundant stocks of invertebrate foods

Although a comprehensive gut collection programme was considered to be incompatible with the observational requirements of this study 
(shooting and retrieval would have risked grossly disrupting the normal pattern of bird presence), nonetheless six individuals were collected from 1975 to 1978. (Collection and oesophagal analysis was carried out in accordance with the methods of Swanson and Bartonek, 1970.) Two of these oesophagae (both from unpaired males) were obtained in the winter. These contained high proportions of invertebrates.* For a description of oesophagal contents of the birds collected see Appendix 3.

There is considerable evidence in the waterfowl literature to show that feeding time-budgets are greatly influenced by the nature of the food exploited, be it predominantly animal or vegetable. Paulus (1982) described the feeding of gadwell (Anas strepera) populations in Louisiana in the winter. He found that when animal foods were scarce the birds were required to consume extremely large amounts of vegetation. Owen and Thomas (1979), in comparing the mid-winter feeding time-budgets of widgeon (Anas penelope) to those of other ducks in the Ouse Washes of England, attributed differences to diet, i.e. to whether they fed mainly on vegetable or animal matter. The widgeon, which fed mainly on vegetable matter, tended to feed throughout the entire day. (Just before dawn and at dusk the proportion of the population feeding was near 100\%. Around mid-day this dropped only slightly to a little over $80 \%$.) This budget was similar to that of grazing geese (Owen, 1972; Ebbinge et al., 1975), but different to that of seed eating and carnivorous ducks,

\footnotetext{
*These results may be compared to those of Balham (1952) for birds obtained in the Manawatu District during the hunting season (winter) in the early 1950's. His analysis of gizzard contents indicated an overwhelming predominance of seeds. As was noted in the introduction to this section the method of using gizzard contents to assess food habits is unsatisfactory. By the time foods have passed chrough the oesophagus and proventriculus and into the gizzard, animal forms, which tend to digest much faster than seeds, could be expected to have disappeared.
} 
including mallards. The latter devoted far less time to feeding. Owen and Thomas took this to reflect 'the difference in energy value and probably in digestibility of their foods, since vegetative material has a high water content and rather low digestibility, especially for geese'. Moyle (1961) reported that the protein content of plant parts other than seeds is between $1 \%$ and $2 \%$, seeds and fruit may average $10 \%$, and aquatic invertebrates between $10 \%$ and 25\%. The magnitude of the heat increment of feeding (the so-called calorogenic effect) is greater for protein than for carbohydrate and fats.

Perret's (1965) analysis of the oesophagal contents of large numbers of mallards shot in Manitoba, Canada, clearly pointed to a high intake of wetland plant seeds in the autumn - spring period. This seed emphasis gradually changed to an animal emphasis as spring progressed, ponds became ice-free and bottom fauna more numerous. In his summary of the diets of mallards which arrived in Manitoba in the spring he stated, "Undoubtedly, as shown by other food studies, mallards remain on a predominantly plant diet until they return to the breeding grounds in the spring".* Perret's findings serve to underscore the climatic advantage applying to mallards in New Zealand. Not only does it provide direct thermoregulatory advantage compared to harsher climates, but its moderation means that sources of high energy invertebrate food supply are not sealed off or prevented from surviving by widespread snow and ice cover.

\footnotetext{
*Mallards can potentially subsist on grain in the winter prior to pairing (see e.g. Pulliainen, 1963; Sugden et al., 1974). However, once breeding begins the availability of invertebrate foods becomes more critical. Prelaying hens will actively select a high proportion of animal foods (see e.g. Hawkins, 1964; Krul1, 1970; Swanson and Nelson, 1970; Krapu, 1974; Swanson and Meyer, 1977). Krapu (1977) referred to the active selection by dabbling ducks of animal protein and calcium during egg formation, and described experiments on mallards which showed the inadequacy of a wheat diet substitute.
} 
The graphs depicting diurnal feeding at Pukepuke in the winter are noticeably flat - particularly by comparison with the graphs showing feeding in the summer (these tend to show peaks after dawn and toward dusk). This eveness was probably attributable to the following combination of factors:

- Relatively low solar radiation and temperatures. (In the summer - autumn period very hot sunny days were characterised by general mid-morning to late afternoon inactivity.* Overcast or showery days encouraged much higher than average daytime feeding).

- Because energy demand was low and there was an abundant high energy invertebrate food supply on-site, feeding was probably as a consequence rather low-key throughout the day.

- Aquatic invertebrate activity did not fluctuate significantly over the 24 hour period. In the summer general invertebrate activity increases going into the evening. This aspect is considered more fully with respect to summer - autumn feeding (8.2). Suffice to say at this point that ducks - including mallards - have frequently been reported to have increased their feeding in response to increased night-time invertebrate activity and surface migration.

Owen and Thomas (1979) considered that most of the ducks which flocked on the Ouse washes in the winter fed outside the area mainly on crops. Such feeding was confined to the daytime. They to just on dusk, thus preventing the characteristic upturn in feeding being quantitatively recorded (see Results for March, April 1978 and March 1979). 
reasoned that this was because vegetative feeding was inefficient in poor light. They compared this to the dabbling mode of feeding where sight was not so important. My observations of dabbling mallards at Pukepuke during the winter did not point to a cessation of feeding at dusk, but neither $r_{\wedge}$ they suggest that it accelerated as it obviously did in the summer. Dabbling may have occurred at a rather low level throughout the 24 hour period during winter.

\subsubsection{Paired birds}

Paired birds tended to display and feed well away from the general flock - undoubtedly to avoid interference.

The intensity of feeding by paired females was conspicuously far higher and more sustained than that of flock birds or the male partner. The latter's feeding tended to be fitful, being characterised by an alertness associated with the defence of the female. This often made it difficult to decide whether to record the bird as feeding or not. Much of the male's feeding was probably stimulated by the female's intense feeding.

The intense feeding by females of pairs was explicable on the basis of the impending demands of egg production. Although the measurement of energy costs of ducks in various stages of the reproductive cycle in the wild is still in its infancy, data to hand confirms laboratory findings that the energy costs of laying hens are especially high. Wooley and Owen (1978), writing of black ducks, commented that "Part of this requirement may be met by body reserves accumulated prior to the laying phase, but intensive rates of feeding must be maintained through the laying phase of the breeding season to provide the essential energy and protein for egg formation. Night-time feeding may be important in meeting these needs." 
It is possible that the increased feeding shown by pairs (relative to non-pairs) is to some degree a reflection of a 'pre-migratory' fat deposition phase (in North American birds such reserves are accumulated for the northward migration). Even though the species does not need to migrate in this county it is nonetheless a migratory species of very recent introduction. As such it may be influenced to produce fat reserves by increasing and decreasing daylength. This aspect - and in particular the question of autumn fat deposition - is considered more fully in a discussion on energy balance during the hunting season (see 8.1.4).

\subsubsection{Indicators of winter (post-solstice) food adequacy}

The following indicators of winter (post-solstice) food adequacy were identified at Pukepuke. As well as pointing to the enormous food reserve of the locality at this time it is intended that this list will assist in the evaluation of food conditions elsewhere in New Zealand. (The possibility of food stress occurring in the pre-solstice period - including the shooting season - will be discussed later.)

\section{(i) Grain trapping unsuccess}

Grain trapping has been traditionally and successfully employed at Pukepuke in the late summer - autumn period as a method of obtaining large numbers of birds for banding (the reasons for this success are discussed later with reference to summer - autumn feeding).

However, this method has proved conspicuously unsuccessful in the winter, despite the concerted efforts made over the years. (For details of a trapping programe undertaken in the winter of 1977 see Appendix 4.) 
(ii) Absence of mallard/black swan feeding association That mallards will follow feeding swans to obtain food particles stirred up from the bottom or dislodged from wasted weed is widely documented (e.g. Bailey and Batt, 1974). Large numbers of swans were observed on Pukepuke in the winter of both 1977 and 1978, yet I did not see one instance of this association at this time or in the spring. Owen and Kear (1972), when reviewing the literature relating to duck/swan feeding, noted that these relationships are typical of wintering rather than breeding grounds. The only time this feeding association occurred at Pukepuke was after the macrophytes died off in the mid-summer period (see Chapter 3). It should be cautioned that this behavioural indicator must be interpreted with care insofar as duck species other than mallards are concerned, particularly when they form part of a mixed group. For example, whilst shoveler were not seen to associate in this way at Pukepuke, there is a possibility that they may have actively avoided such an association in the presence of the highly dominant mallard. Bailey and Batt (1974) described a mixed group of duck species forming a feeding heirarchy with respect to swans. Mallards were at the top of the heirarchy.

(iii) Conspicuously low feeding external to Pukepuke Lagoon If necessary mallards will fly out long distances from a flocking water to feed. Indeed such feeding may be exclusively and successfully undertaken in high energy demanding sub-zero conditions (see e.g. Reed and Prince, 1974). It was extremely rare to see any mallards feeding in the numerous waters around Pukepuke Lagoon. No inward and outward flights, such as occur in the morning and evening at other times of the year, were seen. (The absence of significant 
outside feeding at night was confirmed by frequent use of a night-scope in the vicinity. Carlight and moonlight observations were also made.)*

\section{(iv) Direct food assessment}

\section{Pukepuke Lagoon:}

It was evident that the flooded marginal vegetation within Pukepuke Lagoon (in both 1977 and 1978) contained extremely large concentrations of gastropods, insect larvae and other small invertebrates (see Chapter 3 ).

Waters external to Pukepuke:

A large number of seasonally flooded areas existed in the near vicinity of Pukepuke in the winter and spring. (There were also many permanent and semi-permanent stock ponds, see e.g. Plate 4.) General observations and ad hoc net sweeps revealled extremely high concentrations of small invertebrates of enormous variety. Shed wetland seeds, such as those of willowweed (Polygonum) and dock (Rumex. sp.) were also highly available. Most of these waters were on agricultural land, enriched by fertiliser applications and waste run-off from stock. The prevalence of potamogeton pectinatus and P. crispus - both eutrophic indicator species - in a great many ponds and drains within the general area attested to this high enrichment.

(v) The presence of large populations of relatively even sex proportions

That large numbers of mallards traditionally gather at Pukepuke in the winter suggests that they can easily maintain energy balance in

*The gradual appearance of paired birds in outside ponds in early August was a most conspicuous indicator that social and feeding activities were no longer being confined to Pukepuke Lagoon. (These pairs were often seen in loose groups, no doubt in the process of reconnalsance for breeding sites.) 
this area. No migration by this species has been reported in New Zealand; nor, on the basis of evidence given below, would any be expected. Large populations occur in all provinces throughout the country in the winter period. King (1974) wrote, "...it is not far-fetched to regard migration as a special case of thermoregulatory acclimatisation, or as a substitute for it, since the seasonal movements take the birds away from the regions in which they actually or potentially could not maintain energy balance in the winter".

That the sex balance in the Pukepuke population tends to be relatively even (with only a very slight bias toward males) is strong evidence for a complete lack of energy stress. Using field count data Caithness and Pengelly (1973) found that the mean percentage of males in winter pre-breeding flocks (post-shooting season) from 1969 to 1972 was 51.68 (total mallard count 4773). Year to year proportions ranged from 48.98 to 54.48 . In only one year did the male proportion go below 50\%. My own counts in 1977 and 1978 confirmed the trend shown by Caithness and Pengelly. In July 1977 I recorded a male percentage of 53.6 (sample 246). In June and July 1978 the male proportion was 54.28 (sample 328). In the tiny populations of mallards which overwinter in the northern extremes of North America and Europe there tends to be a far heavier bias in favour of males compared to the more southern localities where migrants have gathered. Aldrich (1973), in discussing the differential distribution of sexes and ages in overwintering grounds in North America, wrote, "Generally females and juveniles winter further south than do drakes and adults (Bellrose et al., 1961; Gollop, 1965). In the Central Flyway States wintering mallard flocks at the northern edge of the wintering range are predominantly 
drakes (60-70 per cent)." Sugden et al. (1974) reported that "A striking feature of mallard flocks that overwinter in Alberta is the predominance of males which exceed 70\%". (See also Lebret, 1950; Pulliainen, 1963; Raitasuo, 1964 with reference to Europe.)

Smith and Prince (1973) stated that "...the relatively low thermal conductivity (body heat loss) of $0.053 \mathrm{cc} \mathrm{O}_{2} / \mathrm{gm} / \mathrm{hr} /{ }^{\circ} \mathrm{C}$ for the mallard indicates it is capable of surviving at thermal extremes". However, this figure is evidently an average figure for the species as a whole since Smith and Prince (and others) have indicated that adult females and juveniles have a slightly higher thermal conductance than the adult male. (size in birds seems to be linked to capacity to thermoregulate at low ambient temperatures. On the basis of data collected on several avian species Gordon (1968) found that a general curvilinear relationship existed between increasing body weight and decreasing thermal conductance.) Smith and Prince (1973) wrote, "The sex difference in metabolic rates suggests that males can produce more energy in the form of heat per gram body weight than the females. Thus, with a similar food supply, males should be able to withstand lower ambient temperatures before homeostasis is jeopardised. This difference in metabolism plus the male's larger size provides an explanation for the greater percentage of males in overwintering populations in the northern part of the mallard's winter range as reported by Bellrose et al. (1961) and Reed and Prince (1974)". (Emphasis mine.)

Note: The relatively even sex ratios shown in winter flocks at Pukepuke (probably typical of the rest of New Zealand) are similar to the ratios shown in winter flocks throughout North America (with the exception of the tiny populations at northern extremes) . 
Because of this it seems reasonable to assume that the forces shaping season to season sex ratios are similar in both places. Because specific mention has not previously been made of factors governing New Zealand ratios I have chosen to draw attention to a particular North American study which may provide a parallel. However, because this aspect is somewhat peripheral to the main objectives of this study I have included it in Appendix 5. Particular mention is made of the sex-selective effect of hunting. 8.1.4 The possibility of energy stress during the hunting season (pre-winter solstice)

It might be expected that some loss of body condition would be suffered by mallards during the hunting season (generally occurring in May, sometimes extending to early June). At this time the normal pattern of feeding is often disrupted. Birds are frequently forced into unpreferred habitat. There is, however, no evidence to suggest that significant body wastage or starvation is a problem at this time in New Zealand. Although this aspect has not been investigated quantitatively, the impressions of Mr T. A. Caithness, a waterfowl biologist with the Wildlife Service, are of interest. Having been responsible for collating and interpreting the findings of the national waterfowl hunting diary scheme for many years, and having maintained a close personal and professional involvement with duckshooting as a sport, he has been in an ideal position to note trends in the condition of waterfowl during the shooting season. His strong impression is that the body condition of game ducks (including mallards) throughout the country is very good during this period (Caithness, pers. comm.) • 
A perusal of Mr Caithness' annual waterfowl game season summaries from 1970 to 1979 clearly showed that negative comment from diarists on the condition of ducks had been rare - and this from what is traditionally a very forthcoming and vocal sporting group in terms of expressing points of concern. In one very isolated reference to body condition in his waterfowl summaries over the years $\mathrm{Mr}$ Caithness wrote (with reference to the Auckland District shooting season of 1976 - see Caithness, 1976):

\footnotetext{
"Many hunters commented on the influence of maize growing on duck flights, condition, behaviour, etc. I cannot really comment here except to say that if stubble is still available in laxge areas during May then it would undoubtedly have an effect on some flight patterns. I doubt though that it would have much influence on the ducks' condition. Where I shoot there is very little maize grown, or any other crop for that matter, and I have rarely handled a skinny duck and I doubt whether the Auckland hunters have either."

(Mr Caithness shot at Pukepuke Lagoon.)
}

It may be that mallards in New Zealand are particularly resilient to the effects of food deprivation in the shooting season, since, unlike their continental counterparts, they do not expend body fat reserves in migration. I believe that it is quite probable that 'pre-migratory' fat build-up still occurs in this country even though migration does not take place. (Fat build-up provides for metabolic water and energy en route in migration.) Light, as in diminishing or increasing daylength (associated with southward and northward migration) appears to be an important determinant of this in migratory birds. (The influence of light on associated phenomena such as fat deposition, migratory behaviour and hyperphagia is discussed by king (1970). There are several reviews covering the extensive literature, e.g. Lofts et al., (1970). That some mallards 
may forego migration in winter extremes of North America when open water and food is made available (the former as in warm water outlets from factories and the latter as in supplied grain - see e.g. Sugden et al., 1974) indicates that migration does not necessarily follow from the physiological processes associated with migratory preparedness. It is highly unlikely that mallards in this country would have lost their migratory capacity. The first introductions into New Zealand (from Europe) occurred in the late 1800s, (Thomson, 1922). Between 1920 and 1940 a large number of birds from North America were liberated in the North Island (Balham and Miers, 1959).

\subsection{Summer - autumn feeding}

It is important to note that the feeding graphs relating to this period do not include birds in the secretive flightless phase of the moult. Because of the risk of predation by hawks, wing-moulters are forced to remain concealed in the daytime. Their feeding is probably therefore largely restricted to the hours of darkness. I have often disturbed flightless birds feeding in concealed drains within Pukepuke Reserve just after dawn, but never during the daytime proper. It was also very noticeable that whenever flocks of mallards were disturbed in the summer period, they could all respond by taking flignt.

Large permanent shallow waters with dense cover, food, and seclusion are important habitat needs for dabbling ducks during the flightless period (Salmononsen, 1968; Hochbaum, 1944; Lebret, 1971; Gilmer et al., 1977). Judging by the large number of mallards which gather at Pukepuke in the summer, the Reserve adequately fulfills their needs in this regard. 
The much higher levels of feeding shown by mallard populations in the summer compared to the winter is probably largely attributable to two factors: (1) Adult birds have high energy demands associated with the moult (see 8.1.1). (2) Ducklings and juveniles have high energy demands associated with feather development and rapid growth.

Activities of ducks are less well understood during the post-breeding period than during the breeding season. Mobility following the termination of breeding, secretive behaviour during the flightless period, and difficulty experienced in distinguishing sexes have discouraged extensive studies. The question of relative sex or age-class vulnerability to food stress in this period was not studied at Pukepuke, although it would appear that adult males as a group may be the least susceptible of all age or sex groupings to food shortage (such as may occur as a result of a total macrophyte collapse). Firstly, drakes start moving into this moulting area in significant numbers in October - early November after leaving hens involved in incubation. They immediately enter the eclipse (post-nuptial) moult. At the height of this moult phase, which lasts about one month, the drake loses its wing feathers. The flightless period lasts until these feathers are replaced and the birds move into a second moult (the pre-nuptial moult), wherein all but the wing feathers are replaced by winter plumage. This second moult is considerably longer than the first. By March or April most drakes have their full winter plumage, indicating that the flightless phase is generally well past. (What may be construed as adults in full winter plumage may also include juveniles coming into their 'first winter' plumage.) It is probable that most males have 
passed their flightless phase by January, or at least by February, i.e. in advance of the usual macrophyte collapse. They are then free to move elsewhere should the need arise. The tendency of drakes to moult flight feathers earlier and more simultaneously than hens has been described by various authors (e.g. Hochbaum, 1944; Balat, 1970; Bellrose, 1976). Two deductions may be made here: one is that if food supply is still important in the flightless phase (and this is very probable), then the drakes are virtually assured of ready access to a plentiful supply. Macrophytes and their associated invertebrates begin to peak at Pukepuke in the early summer. Water levels rarely begin to recede drastically until at least January, so that many of the invertebrate-rich small emergents and grasses around the margins are still flooded. The second deduction to be made is that regardless of whether or not food supply is particularly critical in the flightless phase, drakes are virtually guaranteed to have acquired the flight capability to move to more favourable areas when a macrophyte collapse occurs should this prove disadvantageous.

From even a cursory examination of population figures collected from Pukepuke since 1969 it is clear that the very high mallard populations occur around January, February and March. Sometimes the birds - or at least the visible fraction - have disappeared almost entirely by early March. There is often a lot of interchange between waters in the general locality in March and April. Birds may arrive en masse and stay for a while then leave the lagoon largely deserted for several days. The extent to which birds have tended to remain or move elsewhere at this time cannot be analysed retrospectively with respect to any one environmental element. Contributory factors may include a general restlessness associated 
with a 'pre-migratory' state, the availability of aquatic weed (living, or dead but structurally intact, as in the case of Chara), the presence or absence of swans (these may assist ducks to obtain food), the availability of crops and other food supplies, and disturbance within and around Pukepuke - particularly that associated with pre-season hunter activity such as the repair of shooting stands. The employment of grain trapping in and around Pukepuke in certain years would also have had a considerable influence on the number of birds remaining or being drawn into the area.

The vulnerability of adult females to food stress as a consequence of macrophyte collapse is unknown. However, since they begin their wing-moult later than drakes it is possible that they are more vulnerable. However, as has been noted by a number of authors (e.g. Boyd , 1960; Balat, 1970; Eygenraam, 1957; Gilmer et al., 1977) a large percentage of mallard hens may still be flightless by late autumn. Gilmer et al. found this to be common among mallard hens in his study in North-Central Minnesota, and speculated that hens of this species may have the capacity to delay wing-moult until after migration when they arrive on the wintering grounds. This capacity, should it exist, would certainly imbue females with a degree of flexibility with regard to late sumner - autumn food exploitation.

The success of grain trapping in and around Pukepuke in the late summer and autumn is probably related to a combination of factors, and is undoubtedly indicative of a broad shift from aquatic feeding to a more opportunistic foraging pattern. Many of the birds, being capable of flight after the wing-moult, are in a position to exploit alternative food sources. Apart from the typical occurrence of a 
macrophyte collapse other reasons which may contribute to this grain trapping success - as compared to the conspicuous lack of success experienced in the winter pre-breeding flock phase - are the following:

- Birds in the summer - autumn period appear to have a far higher energy demand than do winter flock birds. (A continuation of a high level of feeding in the general population into the autumn month of March - by which time most drakes have entered the full winter plumage phase may reflect a merging in the population and in individuals of demands made by the moult and demands imposed by physiological processes associated with 'pre-migratory' fat deposition - see 8.1.4.)

- Temporary ponds and many semi-permanent ponds have disappeared in the summer. Most remaining small, shallow ponds in the area are highly enriched from a combination of direct fertiliser run-off and heavy stock use. They characteristically produce very heavy phytoplankton blooms (resulting in macrophyte decay) well in advance of the deeper Pukepuke Reserve waters.

- Water level recession in permanent and semi-permanent waters leaves many edge plants (previously flooded and invertebrate-rich) high and dry.

The general mobility of the birds in the later summer - autumn period, as well as reflecting the altered nature of the food supply, may be associated with disturbance and a certain 'pre-migratory' restlessness.

In order to draw attention to the flatness of winter - early spring 
feeding graphs, and to account for them, reference was made to the tendency of summer graphs to show morning and evening peaks (indicating high night-time feeding levels) (see 8.1.1). In this regard the activity depressing effects of high solar radiation and temperature were mentioned as was the tendency for aquatic invertebrate activity to increase at night (compared to the daytime) during the sumer. This latter aspect is now considered more fully. The influence of predation on the feeding activity of broods is also discussed.

A general increase in aquatic invertebrate activity toward and during the night in the summer has been widely reported. Mundie (1959), for instance, recorded night-time surface migration in a variety of insect and non-insect species, including chironomids, amphipods, water mites and leeches (he did not discuss causation). Dense swarms of midges and caddis flies were a conspicuous feature at Pukepuke during the pre-dusk and night-time periods of late spring through to autumn.

Swanson and Sargeant (1972) studied the spring and summer feeding activity of a variety of immature and adult ducks including mallards on several small permanent and temporary waters in North Dakota. Using a nightscope they found that feeding activity intensified significantly at night, and that this was related to increased invertebrate activity.

A variety of causes may be involved in stimulating increased night-time activity among aquatic invertebrates. Low levels of dissolved oxygen are undoutedly an important cause in standing waters. Low night-time dissolved oxygen conditions are likely to 
apply when primary production is high and when water is warm. In these conditions the oxygen pattern is one of super-saturation in the daytime (net photosynthesis) followed by oxygen depletion late at night and in the early morning (respiration induced). Swanson (1977) found that ducks (including mallards) on sewage ponds in North Dakota in the summer fed voraciously on enormous concentrations of zooplanktonic Cladocera (particularly Daphnia magna) which had become available at night (midnight - sunrise) in the upper few centimetres of water (undoubtedly dissolved oxygen from atmospheric diffusion - would have been very much higher here than in the rest of the water column). These cladocerans had developed heavy concentrations of haemoglobin (conspicuously reddish-orange) in response to this recurring pattern of night-time oxygen deficiency. (The Daphnia carinata which were so prevalent at Pukepuke in the winter did not exhibit pronounced vertical migration of this sort; nor were concentrations of haemoglobin visibly present. The shallow water column characteristically remained at or near oxygen saturation throughout the 24 hour period.)

The influence of predation appears to have a significant, if not an overriding, bearing on the feeding patterns of the young. That broods of mallard, greys, and shoveler were generally observed for a short time after dawn and shortly before dusk indicated that most feeding by this age group was done at night. Harrier hawks (Circus approximans), which were so prevalent and active over Pukepuke (particularly in the summer), are strictly diurnal feeders (Baker-Gabb and Robertson, 1978). Swanson and Sargeant (1972), using a nightscope on small ponds, stated that duck hens with broods (including those of the mallard) appeared less wary about venturing into the open water at night than during the day. Ringelman and 
Flake (1980) found that blue-winged teal and mallard broods became more visible during the daytime with age. Wind speed in excess of $24 \mathrm{~km} /$ hour and air temperature above $23^{\circ} \mathrm{C}$ were associated with decreased visibility.

The modifying influence of various weather factors on feeding patterns was not assessed in this study in any quantitative way. Prevailing weather is always the sum of the effects of a number of factors, and whilst statistical methods may be applied to point up significant factorial linkages, such analysis, to be meaningful, would require input $\mathfrak{A}_{A}^{e} l$ beyond a simple gathering of weather and feeding data. For instance, the influence of high wind - whilst often an overriding factor with respect to other factors such as temperature or incident radiation - could in itself be nullified or overridden by conditions associated with a changing environment. For example in the winter, when aquatic weed in the open water tended to be scarce, high winds would churn the water to such an extent that mallards would invariably seek shelter in calmer waters. In the summer, when aquatic weed clogged much of the lagoon, the water remained stable even in very high winds. Dabbling or loafing in such conditions was largely unaffected.

8.2.1 The feeding relationship between mallard and black swan in the summers of $1977 / 78$ and $1978 / 79$ 1977/78:

The phytoplankton-related collapse of all macrophytes beginning in January represented a decisive turning point in the availability of waterfowl food within Pukepuke. This was reflected in a sudden temdency for swans and ducks to feed within the substrate. By February, when all macrophytes had decomposed, and edge plants were 
well away from the receding waterline, about 908 of duck feeding was done in direct association with swans.

Swan feeding was almost invariably preceded by water paddling, a strategy which involved a vigorous paddling - or perhaps more a water treading action - on the spot for about five seconds to shift bottom material. The bird would then use its bill to dig into the evacuated area for food. This paddling-feeding process was often seen to occur more or less continuously during the course of a day's feeding. It was probable that the swans were taking embedded tubers of potamogeton pectinatus. They were not seen to leave the lagoon to feed, possibly because the vegetation in the area was not flooded or wet.

Up to seven ducks were commonly seen to feed in association with a single swan. They would wait for stirred up food particles or would 'tail' to feed in the spot which the swan had disturbed. Quite often one would move so close to a swan - sometimes literally under its feet - that the swan would snap at it. Such feeding commonly occurred in situations where the water was too deep for the mallards to obtain their own food (this is the usual circumstance described for duck/swan feeding associations in the literature). However, in addition, the association was extremely common at depths where mallards often paddled and bottom fed independently when swans were not about. No doubt they were attracted to swans, since being larger, they had the capacity to more effectively churn the bottom layer. 
That many swans and ducks remained at Pukepuke through to mid-April was somewhat unusual. Perhaps the extreme drought experienced in this summer had a bearing on the availability of food elsewhere.

\section{8/79:}

Since only a partial macrophyte collapse occurred in this year, the swans and ducks were not forced to obtain all of their food from the substrate. Some bottom feeding was seen, but this was quite rare. Likewise very few instances of associative feeding were observed.

The relative extent to which the birds were forced to feed within the substrate in $1977 / 78$ and $1978 / 79$ may have been reflected, at least to some degree, in lead poisoning mortality.

In the total macrophyte collapse summer - autumn period of early 1978, 14 swans and 11 mallards (mostly drakes) were found dead in the lagoon by the resident technician, Mr A. Garrick. The swans, collected from early February to the end of April, contained lead pellets ranging in number from 4 to 377 . The mallards were found in March. All were in an advanced state of decomposition, making the cause of death difficult to establish. Only two contained lead pellets, although on the basis of previous study of waterfowl deaths at Pukepuke by Caithness (1974) it is likely that the majority died of lead poisoning.

It is possible that the swans, by churning the substrate, increased the chances of ducks obtaining lead pellets embedded therein.

In the summer - autumn period of early 1979 five swans were found dead. Three contained lead pellets. No ducks were found. 
PART 2 - BREEDING AND BROOD PRODUCTION

Although it was often possible to deduce from the behaviour, population structure, or mere presence of fledged birds whether or not they were experiencing difficulty in obtaining food or maintaining energy balance, such ready indicators did not appear to exist for ducklings. The food quality of Pukepuke Lagoon with respect to ducklings, and the whole question of energy balance in this age group is now discussed on the basis of what is known of their dietary requirements, the components of the environment known to indicate good food stocks, and the literature pertaining to brood survival in enriched versus unenriched environments. (The food needs of mallard ducklings in the early downy phase of their development are not now thought to be as fixed and certain as was suggested by major studies undertaken in the 1960 s and early 1970s.) The possible evolutionary significance of close-to-the-water nesting by mallards is discussed.

\subsection{The meaning of local production}

One of the things which has been amply demonstrated by many North American waterfowl breeding and population studies over the years is the value of long-term ground studies, looking simultaneously at a large number of breeding habitats contained within extensive land blocks. (The 'community of potholes' study by Evans and Black (1965) is one example of this. Others include those of stoudt (1964) and Smith (1969).) This broad ecological or overview approach has been emphasised in recogmition of the fact that any diverse breeding range is in a constant state of fine balance or flux with respect to a large number of density-dependent and density-independent variables, and that production and survival on one water cannot always be interpreted in terms of the 
characteristics of that one water alone, nor can they be interpreted as representing the population at large.

Dzubin (1969) pointed out that a general relationship exists between high May to July pond numbers and high breeding populations in the Canadian prairies. Good production in these conditions is apparent from examination of pond and population figures published by the U.S. Bureau of Sport, Fisheries and Wildlife from 1955 to 1963. (See also Bellrose et al., 1961; Gollop, 1965; Crissey, 1963a, 1963b, 1969). Jahn (1961), commenting on the relationship between the availability of July ponds in the southern prairie provinces and the total number of mallards produced in North America wrote, "The relationship is clear. July ponds must be available in the prairies, parklands, as well as elsewhere, to ensure the survival of broods to flight stage. Drought reduces the number of July ponds and lowers brood survival, especially in the prairies and parklands". Wheeler and March (1979) concluded that wetland abundance and permanency, as dictated by variations in precipitation, appeared to be the major factor controlling waterfowl production on the scattered wisconin wetland complex. Since on the evidence and $\log i c$ of these kinds of studies, the important variable of habitat availability is likely to override a whole host of variables (such as slight seasonal differences in food availability in just one water), I would suggest that from a management point of view, this aspect deserves attention on a long.term study basis in New Zealand. Considering the rather limited financial and manpower resources available in this country, this emphasis should perhaps be at the expense of local, more concentrated research projects. After all, as far as a management oriented organisation such as the wildlife service is concerned, such fine detailed research must have a 
management objective, and without a broad appreciation of dominating forces governing overall production and breeding distribution in the population, and therefore in particular waters, such application may be difficult or impossible. In other words, I believe that the main management philosophy should be to seek to work from the general to the particular as resources allow.

Information on the seasonal availability of semi-permanent and temporary wetlands, in addition to just permanent waters, could well be used in conjunction with other population information for indexing or predicting production. Of course, as the North Americans have found, there are considerable problems involved in relating this kind of information to the status and productivity of a population in a particular year. It must be emphasised that the relationships referred to above constitute only general or overriding influences, and a good deal of added information input and fine-tuning would be necessary before reliable conclusions could be drawn in particular years. Apart from immediate considerations like hunting mortality, lag effects would have to be taken into account. For example, a drought may result in low breeding habitat availability, and therefore low general recruitment in a particular year. The high availability of breeding habitat in a subsequent year may not then be fully exploited. Bellrose et al. (1961) discussed the relationship between productivity of mallard breeding pairs and pond availability in grassland and aspen parklands of North America, and speculated that an inverse relationship existed between population density and production (i.e. Errington's Inversity Principle). Dzubin (1969) developed a similar hypothesis with respect to mallard populations. 
Dzubin (1969), Crissey (1969) and Smith (1969) have useful comments to make on various habitat availability/production assessment problems pertaining to the prairie regions of North America - from the application of ground and aerial surveys to the kinds of effects discussed above. Without wishing to imply direct similarity between New Zealand and North American conditions, these comments and principles may well be considered in the light of New Zealand conditions.

In view of the points raised above it is clear that production and survival figures obtained in one relatively large, permanent water body such as Pukepuke Lagoon cannot be used in isolation as an indicator of recruitment, or the pattern of recruitment into the population in any wider locality. Indeed in theory, high production on this one water may conceivably be associated with a relatively low overall production and recruitment in the population at large, due to low availability of semi-permanent and temporary breeding habitat. Conversely, low production on Pukepuke may be associated with quite high production in the population at large. In theory also, visible results of overcrowding in a population, such as reduced fertility or fecundity (brood survival), may not become evident on any one water. "Surplus" pairs may disperse elsewhere or fail to breed (see e.g. Crissey, 1969). Even if negative effects such as low fecundity do manifest themselves, a whole host of density-independant factors may be involved (carrying capacity is not a fixed attribute of the environment). 
8.4 The food requirements of ducklings. Is food likely to be limiting to duckling production on Pukepuke Lagoon? The effects of chill in the early downy phases of duckling development (class la, b, c) (when most mortality occurs) is the most critical factor contributing to mortality. Susceptibility to chill is mainly related to food supply since it is this which influences rate of development and general body condition (Street, 1977). It follows therefore that high duckling survival indicates that the habitat is food-rich (in terms of the food needs of ducklings). (Low survival on the other hand cannot be interpreted by itself to indicate poor food conditions. Mortality may, for example, have resulted from predation or over-crowding.)

I am unable to supply figures pertaining to duckling survival on Pukepuke Lagoon. Certain data have been gathered for this water during the period from 1969 to 1975. However, the Wildlife Service officer responsible for this research has yet to prepare and present the data. My intention here is simply to look at the duckling food supply characteristics of the lagoon (and similar waters) in the light of what has been published on the requirements of the agegroup.

The question of which foods are necessary for good duckling development is a lot less hard and fast than it appeared to be up until a few years ago. The two most extensive and widely quoted studies of mallard duckling foods up until this point were those of Churu (1961) and Bartonek (1972). These studies, undertaken in North America, suggested that ducklings seemed to depend heavily on animal foods, particularly flying insects, during the vulnerable downy phase of their development (after this period they were highly 
adaptable). This indicated that the quality of the substrate with respect to flying insect larvae such as chironomids would be the most important factor guaranteeing an adequate food supply. It is widely known that where rich organic sediments occur in eutrophic environments, insect density and diversity tends to be extremely high (e.g. Mundie, 1957). See also Jupp and Spence (1977) with reference to Loch Leven, a similarly enriched lake to Pukepuke. Boyd and Campbell (1966) found mallard duckling survival to be extremely high on this water, i.e. $67 \%$.

The idea that ducklings necessarily depend on animal foods, or more particularly flying insects, for high survival in the early stages of their development was challenged by street (1977). He maintained that early class ducklings may have the option of attaining protein requirements and amino acid balance by exploiting alternative non-insect invertebrate and seed sources, particularly where these are plentiful and easily obtained. With regard to this point it is noteworthy that the findings of Wheeler and March (1979) cast further doubts on the indispensibility of a flying insect diet to very young ducklings. Whilst on the basis of their small sample they did not want to infer too much, they stated that foods found in the oesophagae of a sample of three class Ia ducklings taken from the very fertile wetlands of south-eastern wisconsin 'were quite different than expected' in the light of Chura's (1961) findings. By aggregate volume $98 \%$ were seeds, $1 \%$ vegetation, and only $1 \%$ were insects. This appeared to the authors to roughly reflect the proportionate availability in the habitat. With respect to all classes of wetland in the Wisconsin study area, wheeler and March (1979) concluded that food was not limiting insofar as mallard production was concerned. 
Street (1977) concluded that where a variety of foods is not easily obtainable a high protein insect diet may be favoured by downy ducklings. (This may be particularly so where weather conditions are harsh.) In an examination of the oesophagal contents of ducklings obtained from a ecologically immature flooded quarry pit he found that flying insects predominated in the early classes (seeds more so in later classes), even though larval densities were low in the stony substrate. Presumably because of the relative scarcity of these high protein forms duckling survival was still poor, i.e. less than 238 .

On the basis of the evidence provided by street (1977), and on the basis of what has been recorded of the food items of early class ducklings, Pukepuke would appear to be assured of a high capacity to sustain ducklings. Firstly, it has an extensive and often deep organic substrate layer contributed to by its enormously productive raupo (Typha orientalis) border. This is undoubtedly a rich repository of insect larvae (judging not only from evidence relating to insect densities in high versus low organic substrates provided by Mundie (1957) and others, but also on the evidence of the extremely dense swarms of caddis and chironomids which typically emerge from the water in the spring and summer). Secondly, it has a highly abundant and diverse vegetation component, both submerged and marginal. (The abundance and diversity of organisms obtained in systematic and ad hoc net sweeps in flooded edge or near-edge vegetation has been described in Chapter 3. The studies of chura (1961), Bartonek (1972) and street (1977) show that downy ducklings are quite eclectic with respect to the kinds of small invertebrate foods they will take. These include such forms as molluscs and 
crustaceans (amphipods, etc.). Many of the grasses and

low-emergents represented, such as Polygonum spp. , Juncus, Rumex and Eleocharis, provide seeds known to be taken by early class ducklings - see street (1977)). Thirdly, in the spring and early summer the lagoon's zooplankton community is typically dominated by high populations of the large cladoceran species Daphnia carinata. Cladocerans and ephippia of cladocerans were reported as being taken by downy ducklings in the studies of Bartonek (1972) and Street (1977) .

Apart from clarifying the issue of what foods ducklings require (and under what conditions) street's (1977) study - and in particular his literature survey - made it clear that there is a strong correlation between duckling survival and trophic status (of the habitat). This is an important finding since it provides a simple basis for classifying waters with respect to mallard production potential. Because raupo (Typha orientalis) dominated wetlands - such as Pukepuke - tend by their very nature toward eutrophy (see 4.1.3), then such waters may reasonably be expected to offer good production prospects.

\subsection{The possible evolutionary significance of close-to-the-}

\section{water nesting}

The influence of spring water levels on hatching success at Pukepuke from 1969-1972 has been documented by Caithness and Pengelly (1973) . They wrote:

\footnotetext{
"In 1970-71... a rise of $230 \mathrm{~mm}$ in water level in late september, when egg laying and incubation are near their peak, had an adverse effect on hatching. Only three broods appeared in October compared to 30 the previous year. Renesting apparently occurred, with these broods appearing in November, but despite renesting only 30 broods were produced in the whole season compared to 53 the previous year, a drop of 43 percent.
} 
Again, when water levels recorded in 1971-72 are compared with the mallard hatching success in that year a similar sequence of events was recorded ... Despite renesting, the brood hatching success was 17 percent overall lower than that of the stable water level year 1969-70 but was 32 percent better than in 1970-71."

It is possible that the distinctive close-to-the-water nesting habit of mallards - which makes them particularly vulnerable to egg loss through relatively minor water level increases - has been selected for largely in the interests of the overall survival of the young. Because the mallard begins its annual breeding cycle earlier than most other duck species its young would seem to be particularly vulnerable to the effects of chill in the downy phase, especially in its native breeding range where conditions are often much more severe than in New zealand. (The supply of protein so important to the fast development and condition of ducklings in the face of chill is also likely to be more problematic at this time in much of its

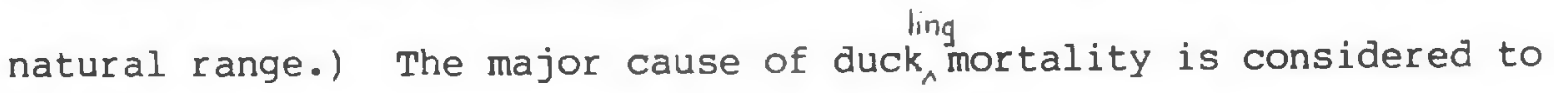
be chill induced by bad weather, especially at temperatures below $2^{\circ} \mathrm{C}$, precipitation and high winds (Bengston, 1972; Boyd and Campbell, 1966). It may be that close-to-the-water nesting offers a selective advantage. By linking nest and egg viability to water level it would tend to reduce the possibility of the young hatching in high rainfall and cold storm conditions. Once a nest had been flooded in early spring, renesting could begin. Thus energy expended on rearing ducklings, which statistically speaking may be doomed, could be avoided.

Although black swans produce their young even earlier than mallards, their nests, although often over water, are not so vulnerable to flooding as are those of mallards. However, their young are not so susceptible to chill as are the young of mallards (survival of 
cygnet broods is often $100 \%$ at Pukepuke - see Section 3). As has previously been noted, capacity to thermoregulate at low ambient temperatures is probably linked to size in birds (the larger the size the lower the thermal conductance). 


\section{SECTION 3}

FACTORS CONTROLLING THE PRESENCE AND DISTRIBUTION

OF BLACK SWAN IN THE PUKEPUKE-CENTRED WETLAND COMPLEX 
Chapter 9

\section{SEASONAL OCCURRENCE AND PRODUCTION}

\section{IN PUKEPUKE RESERVE}

\subsection{Introduction}

To make sense of the way in which black swans use various waters in the Pukepuke-centred wetland complex it was necessary to come to terms with some of the behavioural aspects involved - particularly those pertaining to flocking and the selection of flocking sites. Whilst at the outset of the study it seemed reasonable to assume that flock birds disappeared from Pukepuke Lagoon in the spring due to territorial exclusion by breeding pairs (such an effect had previously been described for small waters by Braithwaite, 1970), observations relating to some of the smaller peripheral waters indicated that, insofar as these were concerned, more was involved in spring removal than just the force of on-site territorial exclusion. It gradually became apparent that what happened on these waters was very much linked to events on Pukepuke Lagoon.

In this chapter the record of swan presence and production within Pukepuke Reserve is examined. In the following chapter an hypothesis is developed to account for the way in $w_{i}$ ich the species distributes itself in the wetland complex as a whole, i.e. in the waters within Pukepuke Reserve as well as those outside. Although research has been carried out on large-scale movements and distribution of black swans throughout New Zealand (Williams, 1977, 1980) previous research has not been done (either in New zealand or Australia) on the factors governing distribution in a localised wetland grouping. 


\subsection{Methods}

Information on the seasonal occurrence and production of black swans in Pukepuke Reserve was obtained from raw day-count data gathered by the Wildlife Service. This information was extracted and interpreted with the permission of Mr T. A. Caithness (Wildlife Service scientist in charge of Pukepuke Wildlife Management Reserve).

\subsection{Results}

The pattern of black swan occurrence on Pukepuke Lagoon is shown for the years 1971, 1973-77 in Figs. 9.3.1-9.3.5.* Quite large numbers of flock birds may occur in the summer, followed by a fall-off toward and during the shooting season, a subsequent build-up, and then a sharp decline and eventual disappearance of non-breeding birds as broods begin to develop in the spring and territorial aggression intensifies. No build-up of non-breeding birds then occurs until the broods have almost fully developed and broken up, and parent territorial aggression has waned around the end of December. In many years no summer build-up occurs.

\footnotetext{
*Data collected in 1978 were not included, since in this year the population was experimentally manipulated (see next chapter).

Prior to 1973 the swan population in the area west of the Tararua Ranges, which includes Pukepuke, was extremely low due to heavy hunting pressure exerted over a number of years. From 1973 until the present time swan have been excluded from the hunting licence, and, as a consequence, and as wildlife service records for the region show, have increased dramatically in the region. With the exception of 1971 the pre-1973 Pukepuke data, extending back to 1968 , clearly reflects this relative scarcity. Rarely were more than about two or three non-breeding birds at a time ever seen on the Reserve in these years, either after the shooting season, or in the summer. With reference to spring broods, two were produced in the Reserve in 1968, one in 1969, two in 1970, and one in 1972. In the light of the general consistency in population trends at Pukepuke before and after 1973, i.e. low before and high after, and in view of the general wildlife Service counts for the whole region, it is evident that the sudden and atypical high population observed at Pukepuke following the shooting season in 1971 did not reflect the overall regional position.
} 
Figs. 9.3.1. - 9.3.5.

The occurrence of black swans on Pukepuke Lagoon from 1971-1978. Sloping lines represent developing broods. The numbers at the beginning and end of each of these lines indicate numbers of cygnets. It is evident that the flock birds depicted in the mid-summer to autumn histograms often included individuals which had remained on the lagoon after their families had disbanded. In the absence of marked birds, and to put a conservative estimate on the proportion of new arrivals, it is assumed that where a histogram depicts a number less than the number of individuals from the families produced on the lagoon, all are from the latter group. where the histogram depicts more, all individuals from the families are assumed to contribute. The family individuals are represented by shading within the histograms.

Classification of cygnets: In N.Z. the classification of cygnets, as with ducklings, has followed a 1 to 6 scale based on plumage characteristics. This scale is deemed to approximate the widely used classification system of Gollop and Marshall (1954) in the following way: N.z.I = la, $2=1 b, c, 3=2 a-b, 4=2 b-c, 5=3 a$. N.z. 6 (flying young, brood disintegrating) has no equivalent in the classification of Gollop and Marshall. 

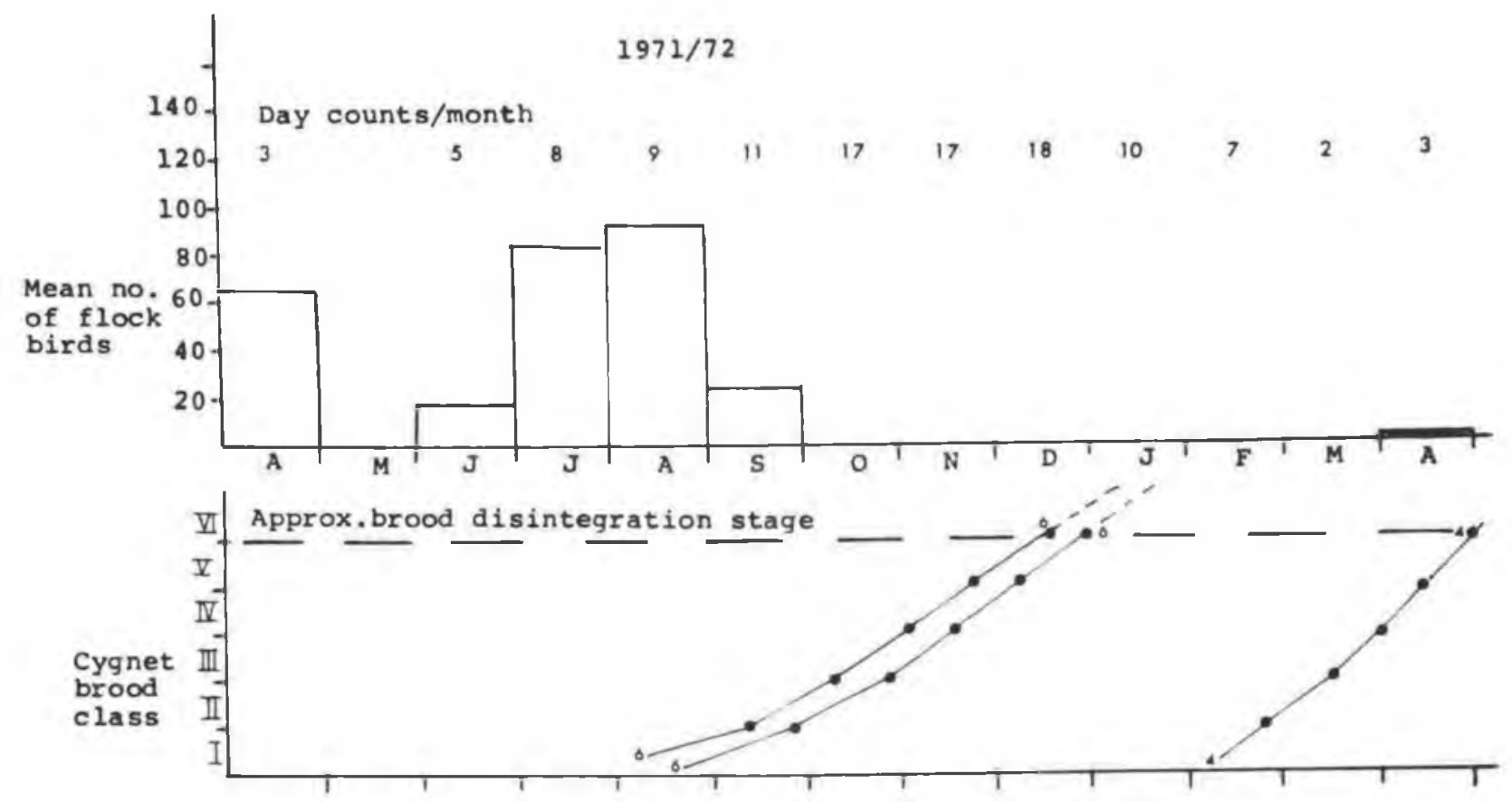

Fig. 9.3.1.

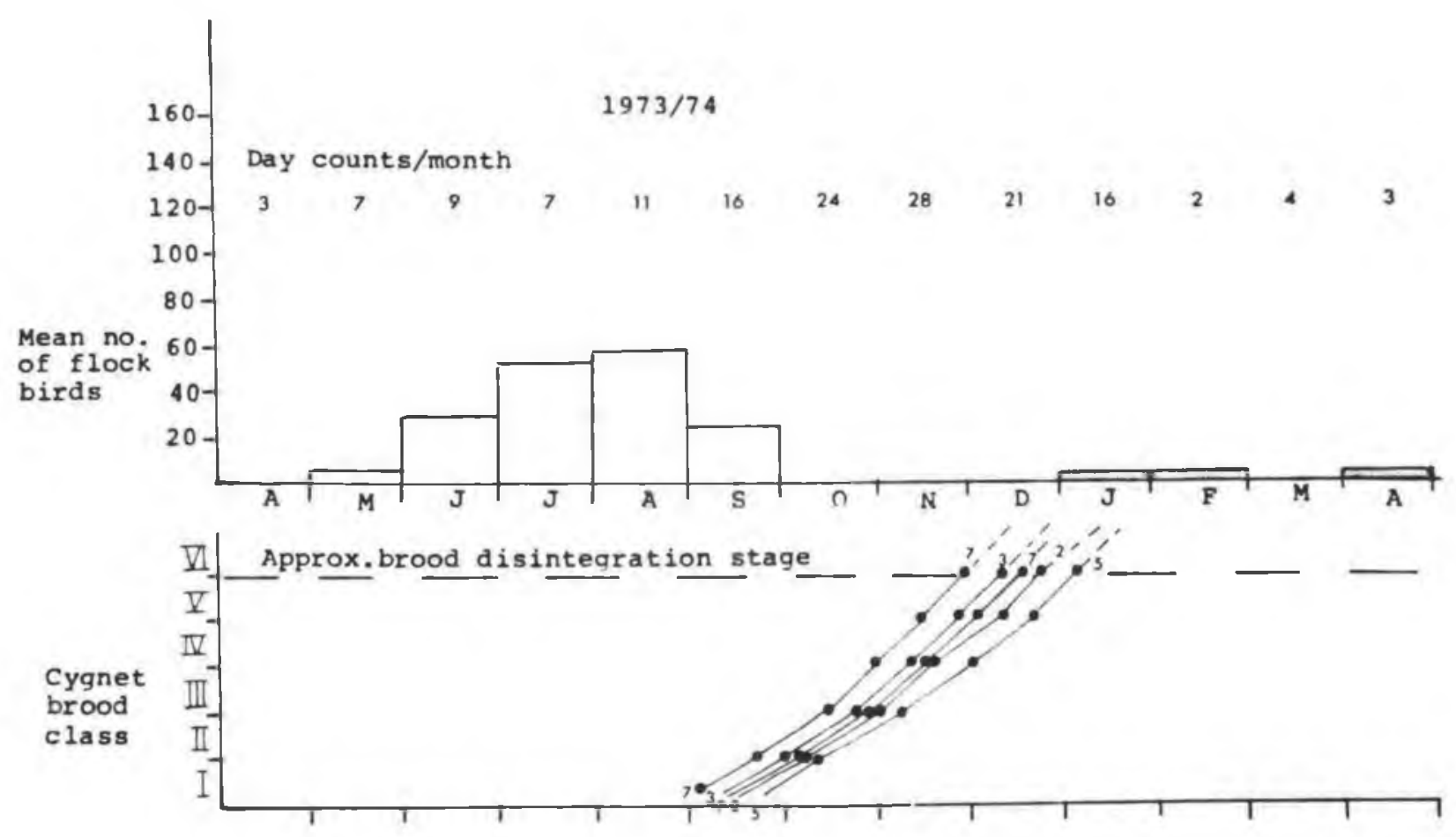

Fig. 9.3.2. 

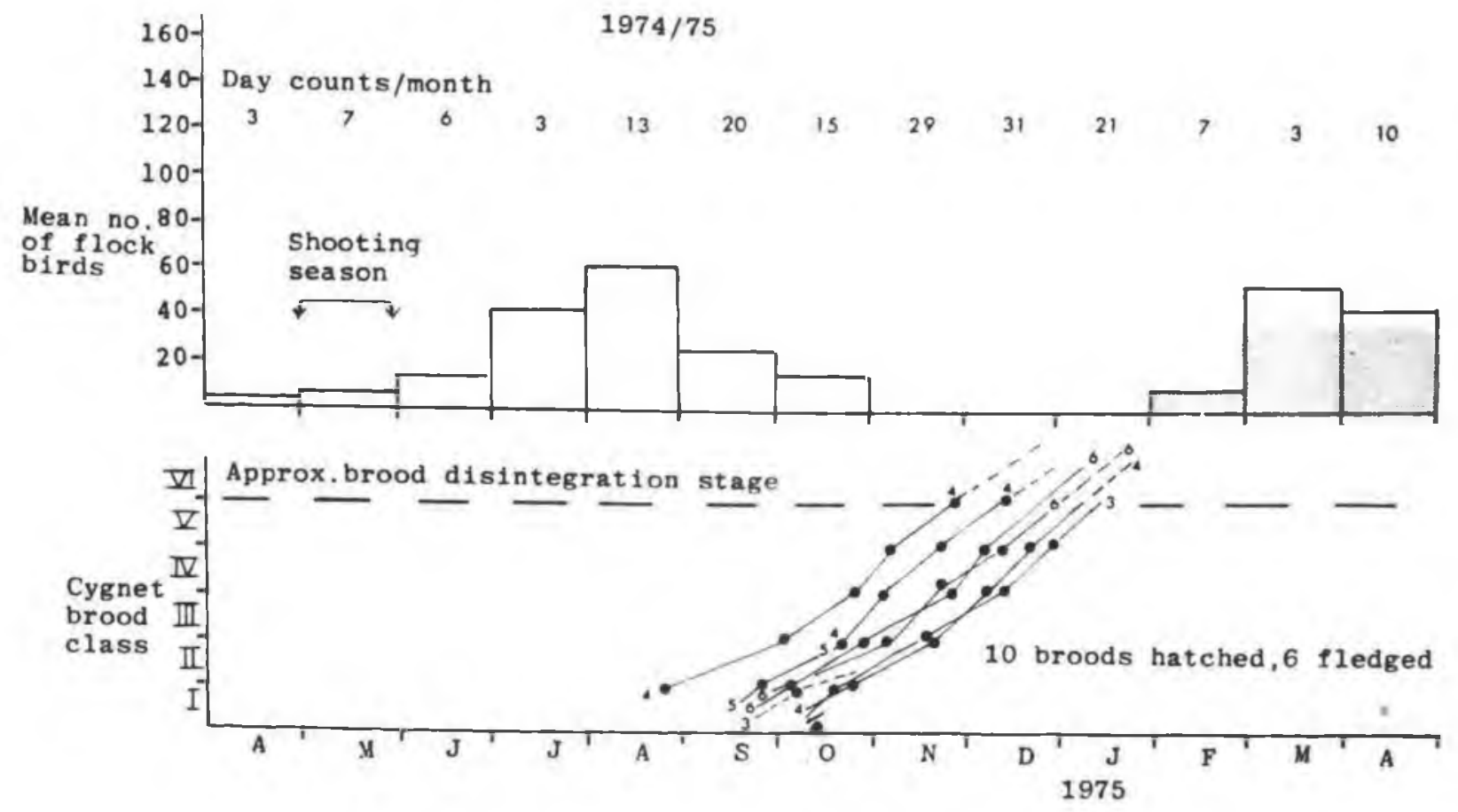

Fig. 9.3.3.

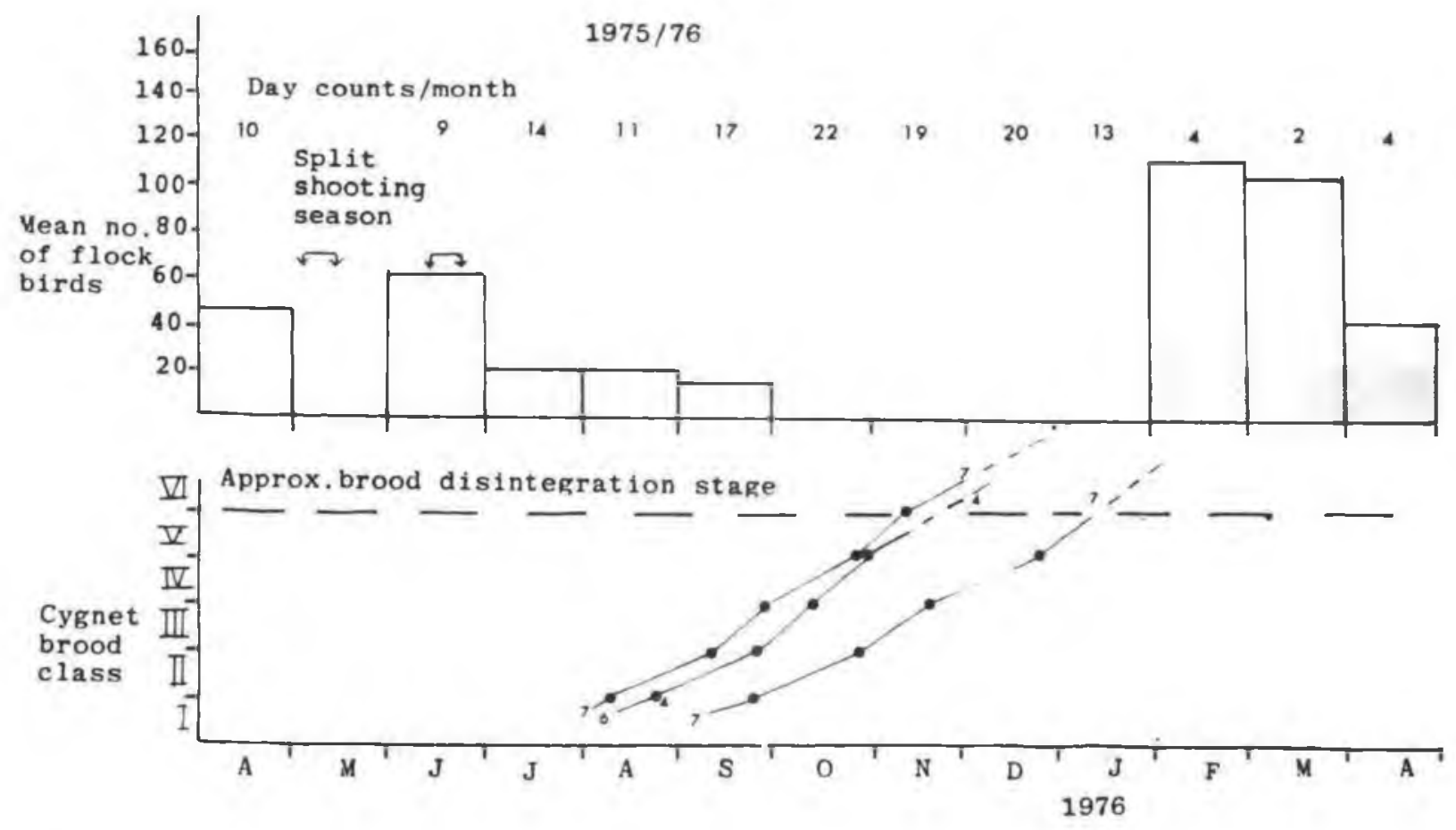

Fig. 9.3.1. 


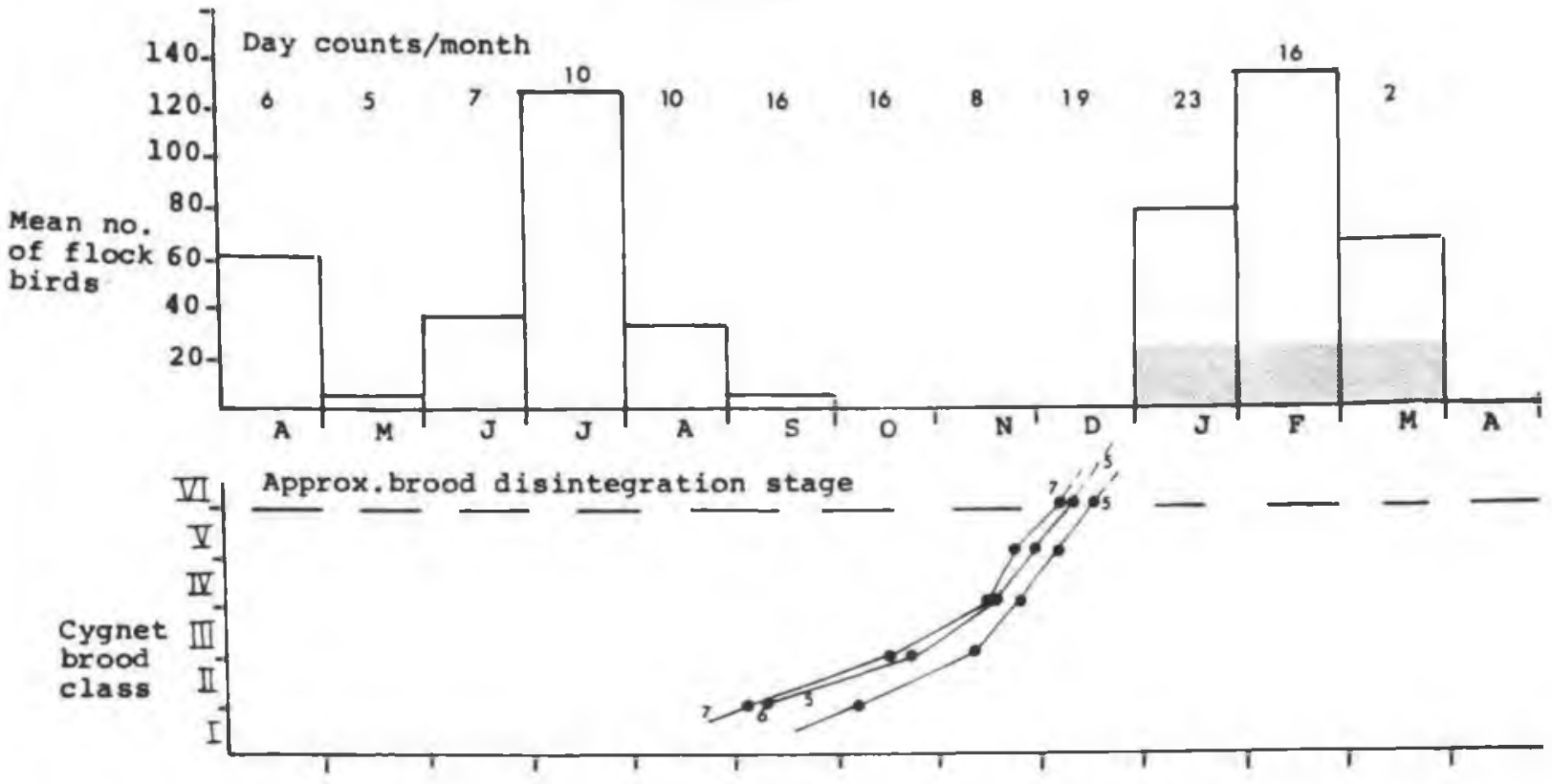

Fig. 9.3.5. 
Since waterfowl population recording began at Pukepuke Reserve in 1968 the only other sites apart from on Pukepuke Lagoon to be used for swan breeding were in the Small Lagoon/I.A.D. Pond vicinity. Generally only one brood was produced in the vicinity per year, although occasionally two, one on the Small Lagoon and the other in the I.A.D. Pond area.* Whenever a nesting pair occupied one of these waters all other swans were driven off, i.e. even before the broods hatched. Many observatonal references to this effect were recorded in the Wildlife Service diaries and day-sheets by the resident waterfowl technician at Pukepuke, Mr W. Pengelly (1968-75), and by subsequent observers, including myself. The counts reported in the diaries also showed that no overlap between breeders and non-breeders existed, or existed for long.

Table 9.1.1 summarises production and survival to fledging of cygnets reared in the spring - summer period on Pukepuke Lagoon and on the Reserve as a whole from 1971 to 1977 . Only twice in this eight year span did broods appear outside the normal spring period. In early February 1972 a brood of four was hatched on Pukepuke Lagoon (Fig. 9.3.1). This survived intact to at least class five, whereupon the shooting season intervened and observations ceased. Another brood (three class three) was reported as occurring for a brief period on the lagoon in March of this same year, although details of its origin and subsequent survival were not obtained.

*The Clover Leaf Ponds have been completely clogged with Scirpus lacustris in most years and have therefore lacked open water. The New Pond and the House Pond have a marked tendency to be disturbed. The only other waters in the Reserve which would seem to approach the requirements for acceptable breeding habitat are the two Four Islands Ponds. They are quite deep and have some Typha orientalis cover, al though maybe not enough to make it preferred breeding habitat. Because of the tracks nearby, disturbance may also have been a negative factor. Most of the many permanent and semipermanent farm ponds peripheral to Pukepuke Reserve, with the exception of "Death Hole", were unsuitable for swan breeding. Most were far too small and shallow and did not contain suitable emergent vegetation, such as Typha orientalis, so necessary for cover and nest construction. 


\begin{tabular}{|c|c|c|c|c|c|c|}
\hline Season & & $\begin{array}{c}\text { Total } \\
\text { Cygnets }\end{array}$ & $\begin{array}{l}\text { Cygnets } \\
\text { survived }\end{array}$ & $\begin{array}{l}\text { \% Cygnets } \\
\text { survived }\end{array}$ & $\begin{array}{l}\text { Broods } \\
\text { produced }\end{array}$ & $\begin{array}{l}\text { Broods } \\
\text { survived } \\
\text { (fully or } \\
\text { partially } \\
\text { intact) }\end{array}$ \\
\hline 1971 & $\begin{array}{l}\text { RESERVE } \\
\text { PUKEPUKE }\end{array}$ & $\begin{array}{l}12 \\
12\end{array}$ & $\begin{array}{l}12 \\
12\end{array}$ & $\begin{array}{l}100 \\
100\end{array}$ & $\begin{array}{l}2 \\
2\end{array}$ & $\begin{array}{l}2 \\
2\end{array}$ \\
\hline 1972 & $\begin{array}{l}\text { RESERVE } \\
\text { PUKEPUKE }\end{array}$ & \multicolumn{5}{|c|}{ No broods produced } \\
\hline 1973 & $\begin{array}{l}\text { RESERVE } \\
\text { PUKEPUKE }\end{array}$ & $\begin{array}{l}24 \\
24\end{array}$ & $\begin{array}{l}24 \\
24\end{array}$ & $\begin{array}{l}100 \\
100\end{array}$ & $\frac{5}{5}$ & $\frac{5}{5}$ \\
\hline 1974 & $\begin{array}{l}\text { RESERVE } \\
\text { PUKEPUKE }\end{array}$ & $\begin{array}{r}49 \\
37\end{array}$ & $\begin{array}{l}39 \\
27\end{array}$ & $\begin{array}{l}80 \\
73\end{array}$ & $\begin{array}{l}12 \\
10\end{array}$ & $\begin{array}{l}8 \\
6\end{array}$ \\
\hline 1975 & $\begin{array}{l}\text { RESERVE } \\
\text { PUKEPUKE }\end{array}$ & $\begin{array}{l}24 \\
20\end{array}$ & $\begin{array}{l}22 \\
18\end{array}$ & $\begin{array}{l}92 \\
90\end{array}$ & $\begin{array}{l}4 \\
3\end{array}$ & $\begin{array}{l}4 \\
3\end{array}$ \\
\hline 1976 & $\begin{array}{l}\text { RESERVE } \\
\text { PUKEPUKE }\end{array}$ & \multicolumn{5}{|c|}{ Inadequate data collection } \\
\hline 1977 & $\begin{array}{l}\text { RESERVE } \\
\text { PUKEPUKE }\end{array}$ & $\begin{array}{l}23 \\
18\end{array}$ & $\begin{array}{l}20 \\
17\end{array}$ & $\begin{array}{l}87 \\
94\end{array}$ & $\begin{array}{l}5 \\
3\end{array}$ & $\begin{array}{r}4 \\
3\end{array}$ \\
\hline
\end{tabular}

Table 9.1.1. Survival of black swan cygnets produced on Pukepuke Lagoon and on the Reserve as a whole in the spring breeding seasons of 1971 to 1977 . 
It is evident from Table 9.1.1 that 1008 survival of cygnets in the spring-summer period is not unusual. The average yearly survival of cygnets to fledging was estimated to be $87 \%$ for the Reserve in toto and $88 \%$ for Pukepuke Lagoon (range 80-1008 Reserve, 73-1008 Lagoon). The mean number of broods produced on the Reserve per year disregarding 1972 - was 5.6 and on Pukepuke alone 4.6. The highest number of broods produced in the spring months of 1971, 1973-77 was 12, in 1974. Eight of these broods survived. (Ten of the 12 broods were produced on Pukepuke Lagoon. Four of these disappeared. Two broods produced on the Small Lagoon and the I.A.D. Pond survived intact.)

\subsection{Discussion}

9.4.1 The relationship between Pukepuke Lagoon and outlying waters

Pukepuke Lagoon, like nearby Omanuka and Kaikokopu Lagoon (of similar size to Pukepuke), is a gathering water. Many birds fan out from this water in the late afternoon or at dusk to feed in flooded pasture areas or in smaller ponds and drains. They generally return in the period between dawn and 9 am.

\subsubsection{Territorial breeding}

The occurrence of territorial breeding on various waters in the Reserve was in accord with the findings of Braithwaite (1970) and Williams (1980).

Braithwaite (1970) suggested that two pair-bond systems existed among black swans in Australia and that these were related to habitat differences. The first was a strong monogomous bond 
observed in territorial birds on small waters. Braithwaite stated that "It seems that even in a drought year those birds that maintain a strong pair-bond annex for themselves a sufficient area of suitable habitat for them to at least begin breeding. Should this territory comprise a small swamp or pond then all other swans are driven from such a habitat".* The second pair-bond system was characterised by a weak pair-bond, little or no territoriality and colonial nesting on large waters.

Williams (1980) listed the characteristics of waters where territorial and colonial nesting occur in New Zealand. Whilst territorial nesting usually occurs on small waters, it may also occur on large water bodies, where non-breeding birds do not occur throughout the breeding season, or where aquatic macrophytes are distributed only in a thin band around the margins. Williams (1980) stated that colonial nesting appears to be an adaptation which allows food to be exploited in conditions of unstable water levels.

A large pool of non-breeding birds is characteristic of black swan populations. Only about $20 \%$ of New Zealand black swans breed in any year, implying that the onset of breeding maturity is delayed several years, or that not all mature adults breed each year, or both (Williams, 1980).

9.4.3 The relationship between flock birds and breeding pairs. The fact that no overlap occurred between flock birds and breeding pairs on the I.A.D. Pond or Small Lagoon evidently conforms to Braithwaite's (1970) above-cited observation that the annexation of 
a territory on a small water may result in the removal of all other swans (the implication, as I interpret it, being that other swans are driven away prior to the appearance of a brood). On the adjacent Pukepuke Lagoon there has always been a period of overlap between the presence of flock birds and the appearance and development of broods. The size of the water seems to have a strong bearing on whether or not such overlap occurs. That is, on a very small water territorial removal is easier to effect than on a large one. In the earliest stages of the breeding season on Pukepuke Lagoon only one or two pairs may have begun to nest, so there is plenty of room for flock birds to move after being chased from the near vicinity of a nest-site, or even from one or two expanded brood territories. In my experience, flock birds may be repulsed, but they are not forced off the water, and certainly not en masse, until broods begin to develop and competition between pairs for space intensifies. (As broods develop beyond about class two they begin to feed outside the shelter of the extreme margin, and greater territorial expansion and consolidation by the cob begins.) However, in seeking to explain the seasonal presence or absence of flock birds on these relatively small waters peripheral to Pukepuke Lagoon, the evidence suggests that two factors, apart from territorial behaviour in the waters concerned, need to be taken into account. These are: (1) the relationship of Pukepuke Lagoon to these smaller waters, and (2) the behavioural propensity of flock swans to gather on Pukepuke Lagoon. These factors are discussed in the following chapter.

9.4.4 Production, survival, carrying capacity and timing of breeding

The high percentages of cygnet survival shown in Table 9.1.1 would 
appear to reflect an abundant food supply. As was discussed in Chapter 8 , the effects of chill in the early downy phase of duckling development (when most mortality occurs) is probably the most critical factor contributing to mortality. Susceptibility to chill is mainly related to food supply since it is this which influences rate of development and general body condition. It is evident from the literature that in temperate climates the survival of duckling broods in the wild would rarely if ever exceed a population mean of 708 (Street, 1977). The far higher survival figures shown for black swans in Table 9.1.1 is probably related to their larger size. Size seems to be linked to capacity to thermoregulate at low ambient temperatures. On the basis of data collected on several bird species Gordon (1968) found that a general curvilinear relationship existed between increasing body weight and decreasing thermal conductance.

Although an inadequate food supply will lead to high mortality in waterfowl, so too will predation, disease and overcrowding (see e.g. Stoudt, 1964; Crissey, 1969). The lowest cygnet survival figures shown in Table 9.1.1 occurred in 1974 (80\% survival for the Reserve, 738 for Pukepuke Lagoon). It is significant that in this year the highest number of broods were produced, i.e. 12 for the Reserve, 10 for Pukepuke Lagoon, compared to annual means of 5.6 for the former and 4.6 for the latter. The only other time since 1968 when the number of broods has exceeded five was in 1979 loutside the period shown in Table 9.1.1) when 13 were produced. Again, as in 1974, a high proportion of these broods (nine) either died or were driven out (A. Garrick, pers. comm.). According to inspections undertaken in the spring and summer of this year food was highly abundant. I would suggest that in both 1974 an 1979 overcrowding leading to 
competition by territory holders, and would-be territory holders, for space was the cause of the drastic reduction in the number of broods. Once families had been denied territory they may have been forced to move out of the area altogether. (Survival figures shown in 1974 may conceivably, therefore, be underestimated.)

Alternatively, cygnets may have been abandoned or subjected to predation as a consequence of neglect by parents engaged in sustained territorial conflict.

It would appear that the carrying capacity of Pukepuke Lagoon in a given spring - summer rearing period may vary within the range of about four to seven broods. The degree of territorial aggression shown by the parents, particularly the cobs, is likely to be a major determining factor. As will be discussed in the following chapter with reference to an experiment conducted on the lagoon in 1978, a cob was observed to annex and vigorously defend a territory comprising about half the lagoon. Another occupied a much smaller area.

The general, although not complete, absence of breeding in the mid-summer - autumn period may relate to two factors. Firstly, macrophytes generally disappear around this time. Although fully fledged birds can apparently sustain themselves quite easly in the absence of leafy vegetation by unearthing tubers of potamogeton pectinatus (see 8.2 .1 ), it is highly unlikely that early class cygnets would be able to do so. The interruption provided by the shooting season may also be implicated. Taking this as a fixed point the breeding pattern would seem to develop in the following fashion: the first opportunity for breeding occurs as the birds gather soon after the shooting season. The first breeders, by 
virtue of their territoriality, set a breeding limit. This territorially-induced restriction does not cease until the broods finally break up around the end of January or in February. By the time potential replacement breeders undertook the necessary pre-hatching activities a phytoplankton-related macrophyte collapse may have rendered the water unsuitable for rearing purposes. In some years food supply may not be scarce, although the question of whether a lack of food is the overriding reason for an absence of breeding around this time is debatable. Indeed, the time availalbe for rearing broods to fledging in undisturbed conditions may be more critical. Assuming breeding was to occur, and given the time needed for pre-hatching activity to take its course, it would be unlikely that broods would appear before late February on in March, in which case some or all of them may not be fledged by the time the shooting season begins in early May. Disturbance created by hunters preparing shooting stands may also be a factor. The establishment of traditions relating to whether or not breeding will occur may be implicated. These may enable successive generations of birds to avoid food problems or problems associated with disturbance. (The way such traditions could be established may proceed along similar lines to the way the tradition has been established for waterfowl to move into refuges before the shooting season. For a discussion of this topic see Potts, 1978.) 
Chapter 10

AN HYPOTHESIS TO ACCOUNT FOR FLOCK BIRD USE OF VARIOUS WATERS

IN THE PUKEPUKE-CENTRED WETLAND COMPLEX

\subsection{Introduction}

Despite the fact that territoriality appeared to have a large part to play in the disappearance of flock birds from the

Pukepuke-centred wetland complex in the spring, I still had strong reservations about whether the disappearances from each of the waters were purely independent events, i.e. related directly to the effect of territorial exclusion on each water. These reservations revolved around several observations:

(1) Flock birds were rarely seen on small food-rich waters outside the Reserve in the spring - early summer period, even though no breeding, and hence territoriality, existed thereon.

(2) In most years only one brood was reared on the entire Small Lagoon/I.A.D. Pond area, yet from my own observations in 1977 it was evident that even if this one brood habitually occupied only one of these waters, as was usual, the other water and the interconnecting water course still remained unused by flock birds. It seemed quite evident that this large area with its indentations and secluded parts was not cleared by the territorial activity of a single pair.

(3) A search of the records showed that whilst breeding occurred on Pukepuke Lagoon in 1973 (Fig. 9.3.2), none occurred on the Small Lagoon or I.A.D. Pond (this was the only time on record breeding has occurred on Pukepuke Lagoon but not on any of the other nearby waters). 
No build up of flock birds occurred in the Small Lagoon I.A.D. Pond area as numbers fell away on Pukepuke Lagoon. (Figures in the daily diary sheets showed only a few swans were seen in the Small Lagoon/I.A.D. Pond area for a short period after the last non-breeders disappeared from Pukepuke. All had disappeared toward the end of October.)

To account for these observations, and in so doing account for the way in which swans tend to use various waters in the wetland complex, two options appeared to be open:

(a) The disappearance of flock birds from the entire wetland complex in the spring is due to the fact that once they are denied access to the large gathering water of Pukepuke Lagoon (by territorial exclusion) they prefer to move out of the area altogether rather than move their centre of flocking to a smaller, territorially vacant outlying water. That is, the disappearance of flock birds from the outlying waters is related purely to territorial exclusion from the gathering water; whether territorial ownership occurs or does not occur on the outlying waters is immaterial.

(b) In the late spring the flock birds voluntarily moved away from the wetland complex. What appeared to be an enforced removal from Pukepuke Lagoon was in fact not so. The territories of the breeding birds merely expanded to fill the space made available by the departure of the flock birds. If this was not the case then there was no reason why the flock birds would not have shifted their centre of 
flocking to the large, territorially vacant Small Lagoon I.A.D. Pond area in 1973 (see (3) above).

Although I favoured option (a) it was decided to test option (b) experimentally. If it could be shown that flock swans on Pukepuke Lagoon were in fact shifted by territorial aggression then (b) could be eliminated as a possibility.

10.2 An experiment to test the hypothesis that flock swans will only leave Pukepuke Lagoon in the spring if they are forced to do so by territorial aggression

10.2.1 Objective

In 1978 I undertook to forestall the onset of hatching on Pukepuke Lagoon (by the removal of eggs) to at least October. (A full-scale prevention of breeding for the year was not considered due to the fact that the lagoon was also the focus of purely behavioural research on swans by another worker.*) The usual onset of hatching was in August. The last brood of the season usually appeared by the end of september. The very latest a brood had appeared since swan numbers had built up to more than a handful was mid-october. This occurred in 1974 (see Fig. 9.3.3). The theory was that if flock birds were driven away from Pukepuke Lagoon by territorial aggression, then by delaying the onset of hatching, the flock birds, which normally disappeared by september (the latest they had disappeared was toward the end of October 1974), would continue to remain on the lagoon until at least the end of November, i.e. a full

* After I had planned on the basis of observations in 1977 to conduct this experiment a study of the reproductive behaviour of swans on Pukepuke was begun by MS A. Bimler of Massey University. This was initiated with prior knowledge of my experimental intentions and research priority as far as this water was concerned. Ms Bimler's study is to be submitted as a doctoral thesis. 
two months beyond the recorded norm, and over one month beyond the maximum date recorded. At the same time observations on territorial activity and the relationship of breeding birds to flock birds would be made to provide a behavioural explanation for the results obtained. It was also arranged to collect at least some parallel information on the occurrence of flock birds on other large lagoons along the coast.

\subsubsection{Methods}

The initial problem was to locate nests. This was done by a combination of observing the movements and attachment of particular birds to particular areas as well as by exploiting the reactions of the swans themselves to disturbance. This latter strategy involved rowing into the lagoon and observing nesting or incubating birds emerge from a section of raupo margin. I found that if I rowed onto the lagoon quite slowly and gave the main flock birds plenty of time to react and swim away they did not take flight. They tended to bunch together quite closely in this situation. The movement of the birds and the continual alarm noises they emitted seemed then to attract the nesting and pre-nesting pairs around the lagoon. They would invariably swim out to join the group. In my experience they showed no sign of aggression toward these flock birds even though aggression, particularly by the cob, was invariable close to a nest site. By observing the emergence from the raupo of a nesting female, and by observing her return, a close estimation of the site of the nest was established. (Pairs would always return to the nest site rapidly after the disturbance ceased.) Having used this method and this was only necessary once or perhaps twice a month - these sites were visited to establish whether nesting had in fact begun or to establish how far the eggs had proceeded in their development. 
Having located a clutch the procedure was then to establish the stage of incubation. This was done at the nest site using a flotation method developed and described by Braithwaite (1977). According to the angle of flotation of eggs measured in a specially constructed glass flotation tub filled with water, a reasonably accurate determination of development could be made. Two eggs within a clutch were checked in this way. Emphasis was placed on speed of operation since it was noted by Braithwaite that prolonged disturbance could result in desertion of the nest. Such desertion could be followed by renests which were potentially difficult to locate.

Having established the stage of incubation several considerations had to be taken into account before a decision to remove eggs was to be made. The first question asked was: would the eggs, on being left to develop, be likely to hatch before about mid-october? If the answer, based on the flotation technique, was yes, then the next decision was when the eggs should be removed, at that point or at some later stage of development? If, for example, the incubation stage was found to be early, a decision may have been made to let the incubation process continue and to remove the eggs toward the end of their development, so that any hatching resulting from a renest would occur after the deadline in October (assuming, say, a month to six weeks' interval following first clutch removal). If they were taken too early a further removal from the same nest, or a relocated one, may have been necessary. This could have resulted in a complete abandonment of nesting by the pair. 


\subsubsection{Results}

In all, three clutches from different nests were removed. Several nests were deserted after initial inspection.

The first brood appeared on Pukepuke Lagoon after the beginning of October as intended. Significant numbers of flock birds remained, not only beyond all times previously recorded, but right through the breeding season (Fig. 10.1.1). The hypothesis was therefore upheld; or, in the terminology of Karl Popper's scientific methodology of falsificationism (Popper, 1972), it was not falsified. That flock birds continued to use the lagoon right through to the summer was due to the fact that the two territory-holders did not control the entire lagoon. One $\mathrm{cob}$ was able to second and retain about half in the face of continuous territorial impingement by large numbers of flock birds. The other was far less expansive and aggressive, controlling less than an eighth. This left ample room for flock birds.*

Pukepuke Lagoon was the only lake in the coastal district (including Omanuka and Kaikokopu Lagoons) to retain flock birds throughout the spring - mid-summer period of 1978. Mr A. Garrick (Wildlife Service technician) undertook an aerial waterfowl survey of the region on December 14 th and recorded 90 plus flock swans on Pukepuke Lagoon and only broods (plus parents) elsewhere.

*Two highly aggressive territory holders would certainly be capable of affecting a totai shift of flock birds. Figs. 9.3.1 and 9.3.3 (referring to events in 1971 and 1975) indicate that in fact two territory holders did produce this effect. It may not be necessary for two cobs to completely divide up the lagoon and in so doing directly exclude the flock birds. It is probable that provided enough space is seconded in the first instance, it will make it exceedingly uncomfortable for the flock birds. That is, the squeeze and harrassment becomes unacceptable. Then once the flock birds leave, the territories may be expanded to fill the space available. 
1978/79 HATCHING CONTROL EXPT.

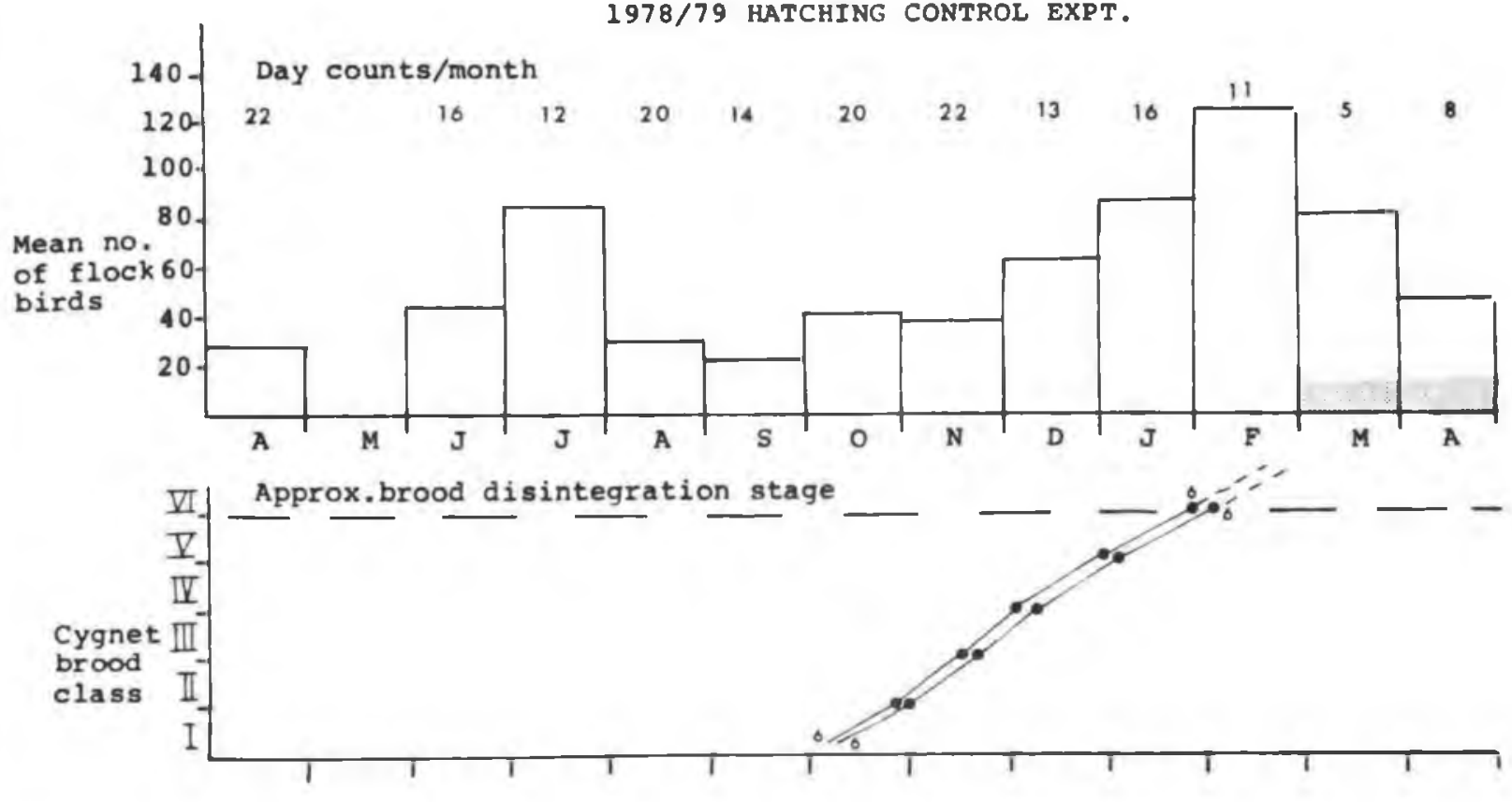

Fig. 10.1.1. The occurrence of flock swans on Pukepuke Lagoon in relation to an induced delay and restriction in hatching. 


\subsubsection{Conclusions}

Given the above finding the most logical explanation for the typical disappearance of flock birds from the various waters in the wetland complex in the spring is that once flock birds are forced off the large gathering water of Pukepuke Lagoon, rather than move their centre of flocking to unoccupied smaller outlying waters, they prefer to move right away (possibly to congregate on some other relatively large water, where, if breeding is undertaken it is colonial, or, if territorial, restricted). That is, the disappearance of flock birds from the outlying waters is related purely to territorial exclusion from the gathering water; whether territorial ownership occurs or does not occur on the outlying waters is immaterial.

This 'spatial/behavioural' aspect is, I would suggest, an important key to understanding the dispersion of black swans throughout the entire coastal region and throughout the country. The other lagoons of similar size to Pukepuke Lagoon in the region, i.e. Omanuka and Kaikokopu, probably function with respect to swan dispersion and in relation to their peripheral waters in a similar way to Pukepuke. The typical departure of flock birds from the region in the spring may be linked to a general shift toward very large waters outside the immediate district, such as Lake Wairarapa (approx. $100 \mathrm{~km}$ to the south-east). 
SUMMARY

\section{SECTION 1 - HABITAT EVALUATION}

Physical, chemical and biological aspects of Pukepuke Lagoon were investigated, primarily within the period from early 1977 to mid-1979. Apart from collecting information on such aspects as trophic status and some of the major components and patterns of waterfowl food supply (the ecological relationship between macrophytes and their associated invertebrates was an important aspect of this) emphasis was placed on describing why either phytoplankton or macrophytes tended to dominate within the system at different times. The balance between these two modes was principally hydrologically determined. In the winter when considerable flushing occurred macrophytes were favoured. In the summer when flushing ceased, and water temperatures and evaporation increased, visible phytoplankton populations developed. In the summer of $1977 / 78$ the phytoplankton 'blom' was sufficiently intense to cause the decline of the macrophytes by shading (see below). Although the termination of the summer phytoplankton bloom was guaranteed by a resumption of flushing after heavy autumn rainfall occurred, it is possible, because of the chlorococcalean nature of the phytoplankton, that this physical dissipation effect may on occasions be pre-empted by chemical limitation. Pukepuke, unlike other highly enriched systems of this sort, is not considered to be susceptible to sudden phytoplankton-directed change as a consequence of damage to its macrophyte beds by heavy swan grazing or storms. In the winter when macrophytes, because of low recovery and high swan populations, are most susceptible to damage, flow is high and significant phytoplankton accumulation is therefore not possible. Large populations of filter-feeding (as opposed to predatory) 
Cladocera (Daphnia carinata) also occurred in the lagoon during the winter - spring period. Such forms have been shown to provide a buffer against phytoplankton irruptions.

It is suggested that swan grazing may pose an insidious threat to the quality of waterfowl habitat, i.e. by encouraging (in certain conditions) the development of phytoplankton at the expense of macrophytes (on which waterfowl may depend for food). The difficulties involved in linking swans to this effect are discussed.

The processes whereby macrophyte declines occur at Pukepuke are examined. When a heavy phytoplankton bloom occurred in conjunction with a full macrophyte collapse in the summer of $1977 / 78$ it was considered that shading by the phytoplankton caused the collapse. In the summer of $1978 / 709$ when only a partial macrophyte collapse occurred (accompanied by a much lighter phytoplankton presence than in the previous summer) the species-differential nature of the collapse suggested that phytoplankton shading was not the primary cause. The partial collapse was considered to be essentially a manifestation of the Potamogeton's intrinsic tendency to die back vegetatively once it reached its production climax, (after seeding) .

\section{SECTION 2 - MALLARD FEEDING}

The major seasonal feeding features described for mallards at Pukepuke on the basis of daytime scan counts were: low levels of feeding by unpaired birds in the winter, intense feeding by females of pairs in both the winter and spring, and intense feeding by moulting birds in the summer and autumn. 
The only time a degree of food shortage appeared to occur was in the late summer of $1977 / 78$ when the macrophytes disappeared. This resulted in mallards feeding in close association with black swans to obtain food items stirred up from the substrate (the swans were presumably feeding on embedded potamogeton pectinatus tubers).

Indications of winter food adequacy were listed. Although most feeding by pre-breeding flocks occurred within Pukepuke Lagoon (the flocking water) a high reserve of food existed in temporary and permanent waters in the near vicinity.

The conspicuously low level of feeding recorded for unpaired mallards in the winter is interpreted in relation to the following combination of factors:

- the birds were outside of the high energy demand period of breeding

- the energy demands associated with feather replacement were minimal

- the climate is relatively moderate (there is less pressure to feed to maintain thermal homeostasis than in much of their natural home range) 
- a plentiful animal food supply located within the flocking water itself. Analysis of oesophagal contents of birds shot on Pukepuke in the winter indicated that animal forms constituted a highly significant food source. (Previous research on the food habits of mallards in New Zealand involved the analysis of gizzard contents. This method greatly over-emphasised the value and use of seeds.) There is considerable evidence in the waterfowl literature to show that feeding time-budgets are greatly influenced by the nature of the food exploited, be it predominantly animal or vegetable. Vegetable matter has a higher water content and lower digestibility than animal forms. Therefore a comparatively much larger intake of the former is required to meet energy needs.

Energy stress is unlikely to be a significant problem for mallard populations in New Zealand during the winter. It is suggested that mallards in this country may be particularly resilient to the effects of food deprivation in the shooting season (the pre-solstice period of winter), since unlike their continental counterparts, they do not expend fat reserves in migration. Because the species is a relatively recent introduction to New zealand it is quite probable that 'pre-migratory' fat build-up still occurs in the autumn (stimulated by decreasing daylength). That some mallards may be induced to forego migration in the winter extremes of North America when open water is made available (the former as in warm water outlets, the latter as in supplied grain), indicates that migration does not necessarily follow from the physiological processes associated with migratory preparedness. 
The early morning and evening feeding peaks observed in mallard flocks in the summer are deemed to indicate high night-time feeding. Such increased night-time feeding may be related to an increase in aquatic invertebrate activity at this time, and to the activity-depressing effect of high solar radiation and temperatures during the day.

The capacity of Pukepuke to supply duckling food is considered to be extremely high. (Mortality is characteristically highest in the early downy phase when ducklings are most susceptible to chill. Because food supply is the critical factor influencing rate of development and body condition, survival is likely to be highest in food-rich environments.) Raupo (Typha orientalis) dominated wetlands as a group are considered likely to be high duckling food producers.

It is suggested that close-to-the-water nesting may have been selected for in the early breeding mallard in the interests of overall survival of the young.

SECTION 3 - BLACK SWAN DISTRIBUTION AND PRODUCTION

Black swans breed territorially on Pukepuke Lagoon and some of its outlying waters. The results of an experiment involving the delay of hatching, combined with general behavioural observations, and an evaluation of population data obtained over several years from Pukepuke Reserve, allowed the general pattern of dispersion in the area to be described. The pattern which emerged showed that vigorous territorial behaviour by pairs rearing cygnets in the 
spring - summer period was the single most significant mechanism affecting gross population changes in the Pukepuke Lagoon wetland complex. However, the evidence very clearly indicates that the operation of this mechanism, and its effect of removing the large flocks of non-breeding swans from the entire wetland complex, has a configurational or spatial aspect to it based on the relationship between the various waters and the behavioural propensities of the swans. The key to this seems to revolve around the accessibility (to flock birds) of Pukepuke Lagoon. This water is the traditional gathering water of the area. (Its selection probably has much to do with its larger size relative to the other waters.) Other nearby smaller waters and flooded areas are visited from this base, usually at night. It is apparent that once Pukepuke is denied the flock birds due to territorial exclusion, they will then move out of the area completely, even though smaller food-rich waters in the vicinity like the Small Lagoon may not be occupied by breeding pairs. This finding would appear to have important implications for understanding the wider distribution of swans throughout the general coastal region and throughout the country.

The average yearly survival of cygnets to fledging from 1977-1979 was estimated to be $87 \%$ for the Reserve in toto, and $88 \%$ for Pukepuke Lagoon (range 80-100\% Reserve, 73-100\% Lagoon). Overcrowding of pairs was considered to be the main density dependent factor governing mortality.

Carrying capacity on Pukepuke Lagoon may vary from about four to seven broods. The exact figure in any given year probably depends largely on the aggressiveness of the cobs and the territory they annex. 
Food supply was not considered to be limiting to cygnet survival in the winter - mid-sumner period. The general occurrence of a summer phytoplankton bloom and associated collapse of macrophytes may be involved in explaining the typical absence of breeding once the spring-initiated broods have broken up around January, although perhaps the overriding factor relates to the onset of the shooting season in early May and the limited time available to rear broods to fledging in undisturbed conditions.

The higher survival of cygnets at Pukepuke compared to what has been reported in the literature for ducklings in food-rich environments is probably primarily a function of the larger size of the cygnets and their capacity to withstand chill in the early downy phase of their development. 


\section{ACKNOWLEDGEMENTS}

Special thanks to Dr R. W. Balham (Victoria University) for supervision and criticisms offered on earlier drafts of this manuscript; also to Dr G. W. Gibbs (Victoria University) for helpful criticisms of the final draft and for advice on limnological matters. I am indebted to my employer, the wildlife service, for allowing me to undertake this study and for material support throughout. (In particular I would like to thank my colleagues in the Waterfowl Section, Mr T. A. Caithness, Dr M. J. Williams and Mr A. Garrick, whose willingness to assist and advise was invaluable. Mr Caithness, Dr Williams and Dr P. M. Moors kindly commented on parts of an earlier draft of this manuscript. Mr J. Kendrick provided photographs allowing for the construction of panoramic composites shown in Plate 3.) In addition, I gratefully acknowledge the help and encouragement of the following people: Mr J. Whetren (Victoria University) for statistical assistance; Mr I. A. Vidal (Wellington City Council Laboratories) for kindly arranging water chemical analyses; Dr V. Cassie (Botany Division, D.S.I.R.) and Dr B. V. Sneddon (Victoria University) for identifying various plant and algae samples; Drs S. F. Mitchell (Otago University) and J. Ogden (Auckland University) for useful correspondence relating to macrophyte studies; Mrs J. Benfield (Victoria University) for photographic reductions; Peter and Pat Barber for providing farm access and generous hospitality at Pukepuke; the Department of Civil Aviation, Ministry of Transport, for providing aircraft for aerial photography; Mrs Mary Hayward for so expertly typing the final thesis manuscript. Finally, I would like to thank my wife Carol for encouragement and forebearance during the difficult times of this study and for assistance in carrying out a bathymetric survey of Pukepuke Lagoon. 


\section{REFERENCES}

ADAMS, J.S. (1971). Black swan at Lake Ellesmere. Wildlife - A Review 3: 23-5.

ALDRICH, J.W. (1973). Disparate sex ratios of waterfowl. In: Breedina Bioloay of Birds (Ed. D.S. Farmer). Nat. Acad. of Sci., Washington D.C.

ALLEN, E.D. (1973). An ecophysiological study of the effects of thermal discharge on the submerged macrophytes of Lake wabamum. M.Sc. thesis, Univ. of Alberta.

BAILEY, R.O. and BATT, B.D.J. (1974). Hierarchy of waterfowl feeding with whistling swans. The Auk 91: 488-93.

BAKER-GABB, D. and ROBERTSON, H.A. (1980). Harrier studies at Pukepuke Lagoon. Wildlife - A Review 11: 53-7.

BALAT, F. (1970). On the wing-molt of the mallard (Anas platyryhnchos), in Czechoslovakia. Zoologicke Listy $19(2)$ : 135-44.

BALHAM, R.W. (1952). Grey and mallard ducks in the Manawatu District, New Zealand. The Emu 52: 163-91.

and Miers (1959). Mortality and survival of grey and mallard ducks in New Zealand. N.Z. Dept. Int. Affairs Wildl. Pub. 5: $56 \mathrm{pp}$.

BARTONEK, J.C. (1972). Summer foods of American widgeon, mallard and green-winged teal near Great Slave Lake, N.W.T. Can. Field-Naturalist 86 : 373-6.

BAYLY, I.A.E. and WILLIAMS, W.D. (1973). Inland Waters and Their Ecology. Longman, Australia.

BELLROSE, F.C. (1976). Ducks, geese, and swans of North America. Stackpole Books, Harrisburg, P.A. 543 pp.

BELLROSE, F. C. Jr., SCOTT, T.G., HAWKINS, A.S. and LOW, J.B. (1961). Sex ratios and age ratios in North American ducks. Ill. Nat. Hist. Surv. Bull. $27(6): 391-474$.

BENGSTON, S.A. (1972). Reproduction and fluctuations in the size of the duck populations at Lake Myvatn, Iceland. Oikos 23: 35-58.

BLACK, M.A. (1973). Mechanisms and ecology of photosynthetic use of exogenous inorganic carbon sources by freshwater macrophytes. M.Sc. thesis, Univ. of St. Andrews.

BOYD, H. (1960). The flightless period of the mallard in England. Wildfowl Trust Annual Rep. 12: 140-3. 
BOYD, H. and CAMPBELL, C.R.G. (1966). A survey of the ducks breeding at Loch Leven in 1966. Wildfowl 18: 36-42.

BRAITHWAITE, L.W. (1970). The Black Swan. Aust. Nat. Hist. 16: $375-9$.

(1977). Ecological studies of the black swan. I. The egg, clutch and incubation. Aust. Wildl. Res. 4: 59-79.

and FRITH, H.J. (1969). Waterfowl in an inland swamp in New South Wales. III. Breeding. CSIRO Wildl. Res. 14: 65-109.

BRISTOW, J.M. and WHITCOMBE, M. (1971). The role of roots in the nutrition of aquatic vascular plants. Am. J. Bot. 58: 8-13.

BROWN, A.L. (1971). Ecology of Freshwater - Harvard Univ. Press, Cambr. Massechusetts.

BUCKNELL, E.S. (1969). Black swan at Lake Ellesmere. Wildlife - A Review 1: 51-2.

BUTCHER, R.W. (1933). Studies on the ecology of rivers. I. On the distribution of macrophyte vegetation in the rivers of Britain. J. Ecol. 21: 58-91.

CAITHNESS, T.A. (1974). Lead poisoning in waterfowl. Wildlife - A Review 5: 16-19.

(1976). A summary of the 1976 waterfowl shooting season (Roneo). N.z. Wildl. Serv., Dept. of Int. Affairs, Wellington. 19pp.

and PENGELLY, W.J. (1973). Use of Pukepuke Lagoon by waterfowl. Proc. N.Z. Ecol. Soc. 20: 1-6.

CAMPBELL, R.M. and SPENCE, D.H.N. (1976). Preliminary studies on the primary productivity of macrophytes in Scottish freshwater lochs. Underwater Research (Ed. by E.A. Drew, J.N. Lythgoe and J.D. Woods), pp. 347-55. Academic Press, London.

CARRITT, D.E. and KANWISHER, J.W. (1959). An electrode system for measuring dissolved oxygen. Anal. Chem. 31: 5-9.

CASSIE, R.M. (1971). Sampling and statistics. In: A Manual of Methods for the Assessment of Secondary Productivity in Fresh Waters. IBP Handbook No. 17. (Eds. W.T. Edmondson and G.G. Winberg.) Blackwell Scientific Publications, oxford and Edinburgh.

CHURA, N.J. (1961). Food availability and preferences of juvenile mallards. Trans. North Am. Wildl. Conf. 26: 121-33. 
COWIE, J.D., FITZGERALD, P. and OWERS, W. (1966). Soils of the Manawatu-Rangitikei sand country. D.S.I.R. Soil Bureau

Bull. 29.

and Smith, B.A.J. (1958). Soils and agriculture of Oroua Downs, Taikorea and Glen Oroua districts, Manawatu County. D.S.I.R. Soil Bureau Bull. 16.

CUNNINGHAM, B.T., MOAR, N.T., TORRIE, A.W., PARR, P.J. (1953). A survey of the western coastal dune lakes of the North Island, New Zealand. Aust. Jour. Mar. and Freshw. Res. $\underline{4(2)}$ : $343-86$.

CRISSEY, W.F. (1963a). WildIife population management. In: Hearings before Sub-Committee on Fisheries and Wildlife Conservation. 88 Congress, First Session. July 18, 19, Aug. 5, 1963. Serial 88-9. U.S. Gov. Print. Office, Washington, D.C. pp 136-66.

(1963b). Exploitation of migratory waterfowl populations in North America. Proc. Ist European Meeting on Wildlife Conserv., st. Andrews. pp 105-120. The Nature Conservancy, London.

(1969) Prairie potholes from a continental viewpoint. In: Saskatoon Wetlands Seminar. pp 161-71. Can. Wildl. Serv. Rep. Ser. No. 6.

DOUGLAS, B. (1958). The ecology of the attached diatoms and other algae in a small stony stream. J. Ecol. 46: 295-322.

DREWIEN, R.C. and SPRINGER, P.F. (1969). Ecological relationships of breeding blue-winged teal to prairie potholes. In: Saskatoon Wetlands Seminar. pp 105-15. Can. Wildl. Serv. Rep. Ser. 6.

DZUBIN, A. (1969). Comments on carrying capacity of small ponds for ducks and possible effects of density on mallard production. In: Saskatoon Wetlands Seminar. pp 113-52. Can. Wildl. Serv. Rep. Ser. 6.

EBBINGE, B., CANTERS, K. and DRENT, R.H. (1975). Foraging routines and estimated daily food intake of Barnacle Geese wintering in the northern Netherlands. Wildfowl 26: 5-19.

EVANS, C.D. and BLACK, K.E. (1956). Duck production studies on the prairie potholes of South Dakota. U.S. Fish and Wildl. Serv. Spec. Sci. Rep. Wildl. No. 32: $59 \mathrm{pp}$.

EYGENRAAM, J.A. (1957). The sex-ratio and the production of the mallard (Anas platyrhynchos) L. Ardea 45: 117-143.

FLINT, E.A. (1975). Phytoplankton in some New Zealand lakes. In: New Zealand Lakes, (Eds. V.H. Jolly and J.M.A. Brown). Auck. Univ. Press. 
FREY, D.G. (1967). Reservoir research - objectives and practices with an example from the Soviet Union. In: Reservoir Fishery Resources Symposium. pp 26-36. Southern Div. Am. Fish. Soc. 569 pp.

GAARDER, T. and GRAN, H.H. (1927). Investigation of the production of plankton in Oslo Fjord. Rapp. Cons. Explor. Mer. 42: 1-48.

GERKING, S.D. (1957). A method of sampling the littoral macrofauna and its application. Ecology 38: 219-226.

GIBB, J.G. (1977). Sediment data for beaches and rivers North Island, New Zealand. Publ. of Geol. Dept. Vict. Univ. of Wellington, No. 7 .

GIBBS, G.W. (1973). Cycles of macrophytes in Pukepuke Lagoon following a severe drought. Proc. N.Z. Ecol. Soc. 20: 13-20.

GILMER, D.S., KIRBY, R.E., BALL, I.J., RIECHMANN, J.H. (1977) . Post-breeding activities of mallards and wood ducks in north-central Minnesota. J.Wildl. Manage. 4l(3): 345-59.

GOLLOP, J.B. (1965). Dispersal and annual survival of the mallard (Anas platurynchos). Ph.D. thesis. Univ. of Saskatchewan, Saskatoon. 174 pp.

and MARSHALL, W.H. (1954). A guide for aging duck broods in the field. Miss. Flyway Counc. Tech. Sec. $14 \mathrm{pp}$.

GORDON, M.S. (1.968). Animal Function: Principals and Adaptations. Macmillan Co., New Yor $\bar{k}$.

HARTLEY, J.M. (1971). Spring and summer Chironomidae of University Lake, Chapel Hill, North Carolina. Univ. N.C. M.S. thesis. $40 \mathrm{pp}$.

HASLER, A.D. and JONES, E. (1949). Demonstration of the antagonistic action of large aquatic plants on algae and rotifers. Ecology 30: 359-64.

HAWKINS, A.S. (1964). Mississippi flyway. In: Waterfowl Tomorrow. pp 185-207. (Ed. J.P. Linduska). U.S. Gov. Print. Off. Washington D.C. 770 pp.

HOCHBAUM, H.A. (1955). Travels and Traditions of Waterfowl. Univ. of Minnesota Press, Minneapolis.

HOGETSU, K., OKANISHI, Y. and SUGAWARA, H. (1960). Studies on the antagonistic relationship between phytoplankton and aquatic plants. Jpn. J. Limnol. 21: 124-129.

HOHN, E.O. (1947). Sexual behaviour and seasonal changes in the gonads and adrenals of the mallard. Proc. Zool. Soc. Lond. 117: 281-304.

HUGHES, H.R. MCCOLL, R.H.S., RAWLENCE, D.J. (1974). Lake Ellesmere - a review of the lake and it's catchment. D.S.I.R. Inf. Series No. $99.27 \mathrm{pp}$. 
HUTCHINSON, G.E. (1967). A Treatise on Limnology. Vol. II. John Wiley and Sons, New York.

JAHN, L.R. (1969). Summary of Part 1: The significance of small wetlands. In: Saskatoon Wetland Seminar. pp 29-34. Can. Wildl. Serv. Rep. Ser. 6.

JESSEN, R.L., LINDMEIR, J.P. and FARMES, R.E. (1964). A study of duck nesting and production as related to land use in Mahnomen County, Minnesota. In: Ducks and land use in Minnesota. pp 26-85. (Ed. J.B. Moyle). Minn. Dep. Conserv. Tech. Bull. 8.

JOHNSON, D. and WALKER, A.F. $(1972 / 73)$. The zooplankton on Loch Leven, Kinross. Proc. Roy. Soc. Edin. (B) 74: 285-94.

JOHNSTONE, I.M. (1972). Limnology of Western Springs, Auckland, New Zealand. N.Z. Journ. Mar. and Freshw. Res. $\underline{6(3)}: 298-328$.

JUDAY, C. (1942). The summer standing crop of plants and animals in four Wisconsin lakes. Trans. Wisc. Acad. Sci.' Arts and Letters 34: 103-35.

JUPP, B.P. and SPENCE, D.H.N. (1977). Limitations of macrophytes in a eutrophic lake, Loch Leven. I. Effects of phytoplankton. J. Ecol. 65: 175-86.

KADLEC, J.A. (1969). The effect of a drawdown on the ecology of a waterfowl impoundment. Mich. Dep. Conserv. Game Div. Rep. 2276. 181 pp.

KEAR, J. (1972). Reproduction and family life. In: The Swans. pp 80-124. (Ed. Peter Scott and The Wildfowl Trust). Michael Joseph, London.

KENDEIGH, S.C. (1944). Effect of air temperature on the rate of energy metabolism in the English sparrow. J. Exp. Zool. 96: $1-16$.

KING, J.R. (1970). Photoregulation of food intake and fat metabolism in relation to avian sexual cycles. In: La photorequlation de la reproduction chez les Oiseaux et Mammiferes: 365-97. (Eds. Benoit, J. and Assenmacher, I.) Paris: Collog. Intern. C.R.N.S. No. 172.

KLOPATEK, J.M. (1974). Production of emergent macrophytes and their role in mineral cycling within a freshwater marsh. Univ. Wis. - Milwaukee, M.S. thesis. $278 \mathrm{pp}$.

KOTT, P. (1953). Modified whirling apparatus for the subsampling of plankton. Aust. J. Mar. and Freshw. Res. 4: $387-93$.

KRAPU, G.L. (1974). Foods of breeding pintails in North Dakota. J. Wildl. Manaqe. 38(3): 408-17.

(1977). Nutrient factors affecting reproductive potential in dabbling ducks. (Info. obtained from summary of paper given in 39 th Midwest Fish and Wildl. Conf. Copy provided by G.A. Swanson, N. Prairie Wildlife Res. Centre, U.S. Fish and Wildl. Service, Jamestown.) 
KRULL, J.N. (1970). Aquatic plant-macroinvertebrate associations and waterfowl. J. Wildl. Manage. $34(4): 707-18$.

LASIEWSKI, R.C. (1963). Oxygen consumption of torpid, resting, active and flying hummingbirds. Physiol. Zool. 36: $122-40$.

LEBRET, T. (1971). Observations of surface feeding ducks (Anatinae), in wing moult in tidal habitat in the Biesbosch Hollands Diep Haringbliet area. Limosa 44(1-2): 29-44.

LOFTS, B. (1975). Environmental control of reproduction. pp 177-224. In: Avian Physiology. (Ed. M. Peaker. Symp. of Zool. Soc. Lon. 35. Academic Press, London.

, FOLLET, B.K. and MURTON, R.K. (1970). Temporal changes in the pituitary-gonodal axis. Mem. Soc. Endocr. 18: 545-575.

LONGCORE, J.R. and ORR, O.P. (1982). Lead shot incidence in sediments and waterfowl gizzards from Merrymeeting Bay, Maine. Wildl. Soc. Bull. 10: 3-10.

MACAN, T.T. (1970). Biological Studies of the English Lakes. Camelot Press Ltd., London and Southampton.

MARK-BROWN, N.V. (1978). The water resources of the Oroua Downs drainage area. Rep. to Rangitikei-Wanganui Catchment and Regional Water Boards, New Zealand.

MARSHALL, A.J. (1961). Breeding seasons and migration. In: Biology and Comparative Physiology of Birds, Vol. II. pp 307-39. (Ed. A.J. Marshall). Academic Press, New York and London.

MITCHELL, S. F. (1971). Phytoplankton productivity in Tomahawk Lagoon, Lake Waipori, and Lake Mahinerangi. Fish. Res. Bull. 3. 88 pp. (Fish. Res. Div. N.z. Marine Dept.)

MOSS, B. (1969). Limitation of algal growth in some central African waters. Limnol. Oceanogr. 14: 591-601.

MOYLE, J.B. (1945). Some chemical factors influencing distribution of aquatic plants in Minnesota. Amer. Midland Natur. 34: 402-20.

(1956). Relationships between the chemistry of Minnesota surface waters and wildlife management. J. Wildl. Manaqe. $20(3): 303-20$.

(1961). Aquatic invertebrates as related to larger water plants and waterfowl. Minn. Dep. Conserv. Invest. Rep. 233. $24 \mathrm{pp}$.

MUNDIE, J.H. (1957). The ecology of Chironomidae in storage reservoirs. Trans. Roy. Ent. Soc. Lond. 109: 149-233.

(1959). The diurnal activity of the larger invertebrates at the surface of Lac la Ronge, Saskatchewan. Can. J. Zool. 37: 945-956. 
OWEN, M. (1980). Wild Geese of the World B.T. Batsford Ltd. London. 
NICHOLS, K.H. (1976). Nutrient-phytoplankton relationships in the Holland Marsh, Ontario. Ecol. Monoqr. 46: 179-99.

OGDEN, J. and CAITHNESS, T.A. (1982). The history and present vegetation of the macrophyte swamp at Pukepuke Lagoon. N.Z. J. Ecol. 5: 108-20.

ORDAL. N.J. (1964). A study of duck nesting and production as related to land use in Otter Tail County, Minnesota. Minn. Dept. Conserv. Tech. Bull. 8.

OWEN, M. (1972). Some factors affecting food intake and selection in white-fronted geese. J. Anim. Ecol. 41: 79-92.

and KEAR, J. (1972). Food and feeding habits. In: The Swan. (Ed. P. Scott and The Wildfowl Trust.) Michael Joseph, London.

and THOMAS, G.J. (1979). The feeding ecology and conservation of widgeon wintering at the Ouse Washes, England. J. Appl. Ecol. 16: 795-809.

OWEN, R.B. (1970). The bioenergetics of captive Blue-winged Teal under controlled and outdoor conditions.

Condor 72: 153-63.

PATTERSON, J.H. (1969). Relationships between aquatic macro invertebrate populations and water chemical concentrations in Beaver Ponds overlying precambrian and ordovician bedrock. Carleton Univ., Ottawa, M.s. thesis.

PAULUS, S.L. (1982). Feeding ecology of gadwells in Louisiana in winter. J. Wildl. Manaqe. 46(1): $71-9$.

PERRET, N.G. (1962). The spring and summer foods of the common mallard (Anas platyrhynchos L.) in south central Manitoba. Univ. B.C., Vancouver, M.S. thesis.

PETR, J. (1975). On some factors associated with the initial high fish catches in new African man-made lakes.

Arch. Hydrobiol. $75(1): 32-49$.

PHILLIPS, G.L., EMINSON, D. and MOSS, B. (1978). A mechanism to account for macrophyte decline in progressively eutrophicated freshwaters. Aquatic Botany 4: 103-26.

POPPER, K. (1972). The Logic of Scientific Discovery. Hutchinson, London.

POTTS, K.J. (1977). Food of game ducks. Wildlife-A Review 8: $28-34$.

(1978). The influx of ducks into parks, sanctuaries and the sea prior to the shooting season - a question of tradition. N.Z. Outdoor, Mar. 1978. 
PULLIAINEN, E. (1963). On the history, ecology and ethology of the mallards (Anas platyrhynchos L.) overwintering in Finland. Ornis Fenn. 40: 45-66.

RAITASUO, K. (1964). Social behaviour of the mallard (Anas platyrhynchos) in the course of the annual cycle. Pap. Game Res. 24: $72 \mathrm{pp}$.

REED, L.W. and PRINCE, H.H. (1974). Daily and seasonal activity of mallards and black ducks wintering in south eastern Michigan. (Cited and summarised by SMITH, K.G. and PRINCE, H.H. (1973) - see below.) Listing of 'Auk. In Press' untraceable.

RINGELMAN, J.K. and FLAKE, L.D. (1980). Diurnal visibility and activity of blue-winged teal and mallard broods. J. Wildl. Manage. 44(4) : 822-29.

ROBEL, R.J. (1961). Water depth and turbidity in relation to growth of sago pondweed. J. Wildl. Manage. 25(4): 436-38.

RODHE, W. (1948). Environmental requirements of freshwater plankton algae. Experimental studies on the ecology of phytoplankton. Symb. Bot. Ups. 10: 1-149.

RYTHER, J.H. and DUNSTAN, W.M. (1971). Nitrogen, phosphorus and eutrophication in the coastal marine environment. Science 171: 1008-13.

SALOMONSEN, F. (1968). The moult migration. Wildfowl Trust Annual Rep. 19: 5-24.

SCULTHORPE, D.C. (1967). The Biology of Aquatic Vascular Plants. Edward Arnold Ltd., London. 610 pp.

SEDDON, B. (1972). Macrophytes as limnological indicators. Freshw. Biol. 2: 107-30.

SMITH, A.G. (1969). Waterfowl-habitat relationships on the Lousana, Alberta, waterfowl study area. In: Saskatoon Wetlands Seminar. pp 116-22. Can. Wildl. Serv. Rep. Ser. 6.

SMITH, L.G. and PRINCE, H.H. (1973). The fasting metabolism of subadult mallards acclimatized to low ambient temperatures. Condor 75(3): 330-35.

SPENCE, D.H.N. (1964). The macrophyte vegetation of freshwater lochs, swamps and associated fens.

In: The Veqetation of Scotland. (Ed. J.H. Burnett.) pp 306-425. Oliver and Boyd, Edinburgh.

STEWART, R.E. and KANTRUD, H.A. (1972). Population estimates of breeding birds in North Dakota. Auk 89(4): 766-88.

STOUDT, J.H. (1964). Factors affecting waterfowl breeding populations and the production of young in the parklands of Canada. Ann. Progress Rep. Wildl. Res. Work Unit A-8.2. U.S. Fish. and Wildl. Serv., Jamestown, N.D. Unpubl. mimeo Rep. 55 pp. 
STREET, M.M. (1977). The food of mallard ducklings in a wet gravel quarry, and its relation to duckling survival. Wildfowl 28: 113-25.

SUGDEN, L.G. , THURLOW, W.J. , HARRIS, R.D. and VERMEER, K. (1974). Investigations of mallards overwintering at Calgary, Alberta. The Can. Field-Nat. 88: 303-11.

STRICKLAND, J.D.H. (1960). Measuring the production of marine phytoplankton. Bull. Fish. Res. Bd. Can. 122: 1-172.

SWANSON, G.A. (1977). Diel food selection by Anatinae on a waste-stabilisation system. J. Wildl. Manage. $\underline{41(2)}: 226-31$.

and BARTONEK, J.C. (1970). Bias associated with food analysis in gizzards of blue-winged teal. J. Wildl. Manage. $34(4): 739-46$.

and MEYER, M.I. (1977). Impact of fluctuating water levels of feeding ecology of breeding blue-winged teal. J. Wildl. Manage. 4I(3): 426-33.

MEYER, M.E. and SERIE, J.R. (1974). Feeding ecology of breeding blue-winged teals. J. Wildl. Manage. $\underline{38(3)}: 396-407$.

and NELSON, H.K. (1970). Potential influence of fish rearing programs on waterfowl breeding habitat. In: A symposium on the management of midwestern winterkill lakes. pp 65-71. Special. Publ. N. Cent. Div. Am. Fish. Soc. $75 \mathrm{pp}$.

and SARGEANT, A.B. (1972). Observation of nighttime feeding behaviour of ducks. J.Wildl. Manage. $\underline{36(3)}: 959-61$.

and THORNSBERRY, W.H. (1972). Avian food habits analysis using a modified counter. J. Wildl. Manage. $\underline{36(3)}$ : $949-950$.

TEBRO, L.B. (1955). Bottom fauna of a shallow, eutrophic lake, Lizzard Lake, Pocahontas County, Iowa. Am. Midl. Nat. 54: 89-103.

THOMSON, G.M. (1922). The Naturalisation of Animals and Plants in New Zealand. Cambridge Univ. Press. 607 pp.

WESTLAKE, D.F. (1963) . Comparisons of plant productivity Biol. Rev. 38: 385-425.

(1965). Some basic data for investigations of the productivity of aquatic macrophytes. Mem. 1st. Ital. Idrobiol. 18 Suppl.: 229-48.

(1975). Primary production of freshwater macrophytes. In: Photosynthesis and Productivity in Different Environments (Ed. J.P. Cooper.) Cambridge Univ. Press. Int. Bio. Prog. 3. 
WHEELER, W.E. and MARCH, J.R. (1979). Characteristics of scattered wetlands in relation to duck production in south eastern Wisconsin. Wisc. Dept. Nat. Resources. Tech. Bull. 116. $61 \mathrm{pp}$.

WILLIAMS, J.E. (1965). Energy requirements of the Canada Goose in relation to distribution and migration. Ph.D. thesis. Univ. Illinois, Urbana.

WILLIAMS, M.J. (1967). Observations on the behaviour of New Zealand Anatinae in captivity. B.Sc. (Hons) project. Vict. Univ. of Wellington, N.Z.

- A Review 8: 23-7.

(1979). The status and management of black swans 'Cygnus atratus), Latham, at Lake Ellesmere since the Wahine' storm, April 1968. N.Z. Jour. of Ecol. 1979: $34-41$.

(1980). The demography of New Zealand's Cygnus atratus population. Proc. Second International Swan Symposium in Sapporo, Japan.

WINSTANLEY, W.J. (1979). Rapid over-winter development in Austrolestes colensonis (White) (Zygoptera: Lestidae) and Aeshna brevistyla Rambur (Anisoptera: Aeshnidae) at Pukepuke, New Zealand. Notul. odonatol. I(4): 69-71.

WOOLEY, J.B. and OWEN, R.B. (1978). Energy costs of activity and daily energy expenditure of the black duck. J. Wildl. Manaqe. 42(4): 739-45.

ZAFAR, A.R. (1967). On the ecology of certain fish ponds of Hyderabad, India. III. The periodicity. Hydrobiologia 30: 96-112. 


\section{APPENDIX 1}

\begin{tabular}{|c|c|c|c|c|}
\hline & Jul. & Aug. & oct. & Dec. \\
\hline $\begin{array}{l}\text { Veronica } \\
\text { anaqallis-aquatica }\end{array}$ & 1.1 & 0.05 & 2.32 & 6.54 \\
\hline R. fluitans & 6.56 & 5.2 & 8.95 & 9.1 \\
\hline Chara sp. & 75.6 & 96.7 & 136.2 & 206.1 \\
\hline P. pectinatus & 0.03 & 0.24 & 2.67 & 14.3 \\
\hline P. crispus & 2.52 & 0.33 & 7.48 & 38.2 \\
\hline Myriophyllum & 11.3 & 2.48 & 3.12 & 4.61 \\
\hline$\frac{\text { Zannichellia/ }}{\text { Ruppia }}$ & - & - & 0.48 & 1.89 \\
\hline Filamentous algae & 3.95 & 38.5 & 18.4 & 28.6 \\
\hline
\end{tabular}

Table 1: Monthly maximum densities of macrophytes obtained by the $0.1 \mathrm{~m}^{2}$ rake method in 1977 (g. dry wt.). (Note: because the plants

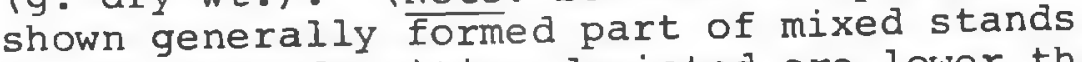
the maximum densities depicted are lower than from the maximum densities of macrophytes per se as recorded in Fig. 3.4.2.) 


\section{APPENDIX 2}

Veronica

anagallis-aquatica

R. fluitans

$\underline{\text { R. sceleratus }}$

P. pectinatus

$\underline{\text { P. crispus }}$

Myriophyllum

Zannichellia/ Ruppia

Filamentous

algae

Nasturtium

officranale

Cotula

coronopifolia

Juncus

articulatus

\begin{tabular}{|c|c|c|c|}
\hline Jun. & Aug. & Oct. & Dec. \\
\hline 27.1 & 10.1 & 5.8 & 53.8 \\
\hline 1.8 & 1.9 & 7.7 & 16.3 \\
\hline 27.5 & - & - & - \\
\hline 0.21 & 0.43 & 2.65 & 8.2 \\
\hline- & 1.85 & 4.1 & 21.3 \\
\hline 1.73 & 0.008 & 43.6 & 162.6 \\
\hline- & - & 0.3 & 10.04 \\
\hline- & 0.66 & 35.8 & 28.5 \\
\hline 0.06 & - & 0.001 & - \\
\hline 0.08 & - & - & - \\
\hline 1.93 & - & - & - \\
\hline
\end{tabular}

Table 2: Monthly maximum densities of macrophytes obtained by the $0.1 \mathrm{~m}^{2}$ rake method in 1978 (g. dry wt.) 


\section{APPENDIX 3}

Oesophaqal Contents of Mallards Shot on Pukepuke Lagoon (Collectors: W. Pengelly, A. Garrick, K. Potts)

(1) 29 July, 1975 (adult male)

2 water-boatmen (Sigara arguta) Fragments of duckweed (Lemna minor)

(2) 2 Auqust, 1975 (adult male)

188 gastropods 93 Potamopyrgus antipodarum

13 Physa sp.

82 Gyraulus corinna

27 amphipods

(3) 21 December, 1976 (adult male)

3 seeds (Polygonum decipiens)

I gastropod (Gyraulus corinna)

Full of duckweed (Lemna minor)

(4) 4 January, 1977 (adult male)

22 gastropods (20 Gyraulus sp., 2 Physa sp.)

7 Trichoptera larvae

1 chironomid

1 mite

2 winter buds (turions) of Potamogeton crispus

Fragments of Chara sp.

(5)

10 January, 1977 (adult female)

Full of Lemna minor

36 turions of $\underline{\mathrm{P} .}$. Cr ispus

1 amphipod

28 gastropods

(6) 23 March, 1977 (adult male)

Empty • 


\section{APPENDIX 4}

\section{Winter Grain Trapping Attempts at Pukepuke}

The Wildlife Service technician stationed at Pukepuke, Mr A. Garrick, mounted an intensive, well planned grain trapping programme in July and August 1977. Noting the large flock present in the lagoon he considered the prospects were good for obtaining females for nasal saddling purposes. (This offered the opportunity of identifying and following subsequently produced broods.) No ducks were obtained. The operation proceeded as follows:

July 10-25:

Up to about 70 mallards were observed on the lagoon. A camouflaged platform (approx. $2.5 \times 2.5 \mathrm{~m}$ ) sloping from the water was set near a favoured flocking site in the bay immediately to the right of hide number 2. Grain was placed thereon and observations were made. Ducks fed in the flooded edge zones near the grain but did not take the grain. This effort lasted until the 25 th.

\section{July 26 - August 3 :}

Two more sites were established after dismantling the above platform. No captures.

\section{August 7-12:}

A trap was set near the I.A.D. Pond. No captures.

\section{August 12:}

A trap was set near the mouth of the Interconnecting Drain. No captures.

On the basis of his experience in this his first year at Pukepuke Mr Garrick made no further attempts to trap from winter flocks. 
Mr W. Pengelley, the technician stationed at Pukepuke prior to Mr Garrick, also made concerted attempts to grain trap ducks in several winters but had very little success. For instance, in his monthly report of August 1976 he reported that seven mallards were captured. He referred to 'the reluctance of ducks to come to the trap sites to feed'.

Both Mr Pengelly and Mr Garrick found that large numbers of mallards could very easily be trapped in and around Pukepuke in the sumner and autumn. 


\section{APPENDIX 5}

Mallard winter sex ratios in New Zealand: An examination of the major forces operating to produce these results, including the sex-selective effect of hunting

As was noted in chapter $8,(8.3 .1)$, the generally rather slight bias toward males recorded in winter flocks at Pukepuke is similar to what could be expected in southern migrant flocks in North America, and indeed in the North American population as a whole (given the fact that over-wintering populations constitute only a tiny fraction of the continental population - probably less than 18 ).

The difficulties involved in collecting reliable information on seasonal changes in sex ratios by direct field sampling methods have been discussed by Bellrose et al., (1961). The problem of differential dispersion with respect to age and sex has been a fundamental difficulty. W. F. Crissey (unpublished, 1972) attempted to evaluate sex ratios of populations of mallards in the Mississippi area by an indirect approach involving the analysis of band recoveries and harvest yields. (This general approach was described in an unpublished report by Anderson et al., 1970.) Whilst the fine details of Crissey's particular study are not available, a summary of his estimates was presented with comment to an international symposium on birds by J. R. Rogers (reported in Aldrich, 1973). Rogers believed Crissey's findings to be highly relevant to an understanding of mallard population dynamics in North America. It is probable that Crissey's findings are also relevant to an understanding of mallard population dynamics in New Zealand (given that winter sex ratios were similar at Pukepuke and in Crissey's Mississippi population) . 


\section{Extracts from Rogers' paper are as follows:}

\section{(Note: The figures given in the table below refer to the ratios of} males only. The female ratio in all cases is 1.0.)

"The following table summarises Mallard sex ratios calculated for different times of the year for three years beginning with the hunting season 1967-68.

$$
\underline{1967-68}
$$

\section{Adults Immature}

$\underline{1968-69}$

Adults Immature
1969-70

Prehunting

season

0.88

1.33

1.13

1.62

0.99

population

\section{Hunting}

season

harvest

Post

hunting

$$
1.08
$$

a

1.16

a

1.12

a

season

population

ammatures combined with adults in post-season period.

These figures show that in early fall, just prior to the hunting season, the sex ratio among adult Mallards is strongly unbalanced in favour of males, while that for immatures is nearly even. It is probable that a sex ratio of 1.6 males per female among adults, and 1.0 males per female among immatures closely approximates the true situation...

Sex ratios in the harvest (second line) show that, for both age groups, hunting takes a higher proportion of the males than of the females present in the population ... Regardless of the reasons, the differential harvest of males and females is sufficiently great that by the end of the hunting season the sex ratio is nearly even, and there is only a relatively slight preponderance of males.

At present there is no evidence that population losses between the end of the hunting season and the beginning of the breeding season affect one sex more than the other. Thus, it is believed that the sex ratio in the posthunting season population is practically identical to that at the beginning of the breeding season.

The following conclusions are suggested by this analysis: In the annual cycle of the Maliard, large and significant changes in sex ratio occur (1) during the hunting season and (2) during the breeding season. During the hunting season, losses of males (due to hunting) change the sex ratio from a strongly unbalanced to a nearly balanced condition. During the breeding season, losses of females (due to natural mortality) are sufficiently great to cause a return to a strongly unbalanced sex ratio favouring males.

It appears that there is (1) no great excess of males in the continental Mallard population in terms of the population available to begin breeding; and (2) natural mortality of females, associated with breeding, is greater than previously expected." 
The slight male predominance recorded in the pre-breeding phase at Pukepuke agrees with Crissey's findings. Also, as in Crissey's study, the pre-hunting bias toward males is likely to be greater than in the post-hunting period (due to the sex-selective effect of shooting) .

Based on throughout-life band recovery data from a sample of 5651 mallards (3061 males and 2590 females) banded as juveniles, Caithness (pers. comm.) calculated that males were about $39 \%$ more likely to be shot than females, i.e. males were selected for by hunters by a ratio of 1.386 males to one female. My own $2 \times 2$ contingency analysis of this data indicates that the bias favouring males is significant $\left(\Psi^{2}=27.83, \mathrm{df}=1, \mathrm{P}<.001\right)$. Caithness considers that a major cause of this selection could be the conspicuousness of males, since in a similar study he implemented on the monomorphic N.Z. grey duck (which is similar in size, morphology and behaviour to the mallard, and which hybridises with it) he found very little sex related difference $(11,424$ juveniles were banded; $31.88 \%$ male and $30.12 \%$ female bands were recovered. $2 \times 2$ contingency analysis indicates this sex difference is significant $\Psi^{2}=3.94$, df $\left.=1, P<.05\right)$.

The proportion of mallards harvested in any one year in New Zealand is estimated on the basis of band returns to fall between 158 and a maximum of $20 \%$ of the total population (Caithness, pers. comm.)

From the above information an estimate can be made of the impact of hunting on sex ratios in New Zealand.

Assumptions:

(i) Post-hunting male proportion 51.68 (the mean proportion 
obtained for Pukepuke from 1969 to 1972 by Caithness and Pengelly, 1973)

(ii) $\frac{\text { Probability of male kill }(27.518)}{\text { Probability of female kill }(19.85 \%)}=1.38607$ (as obtained by Caithness)

(iii) $k=$ percent kill.

The pre-hunting proportion of males in the population is calculated using the quadratic equation $a x^{2}+b x+c=0$ where:

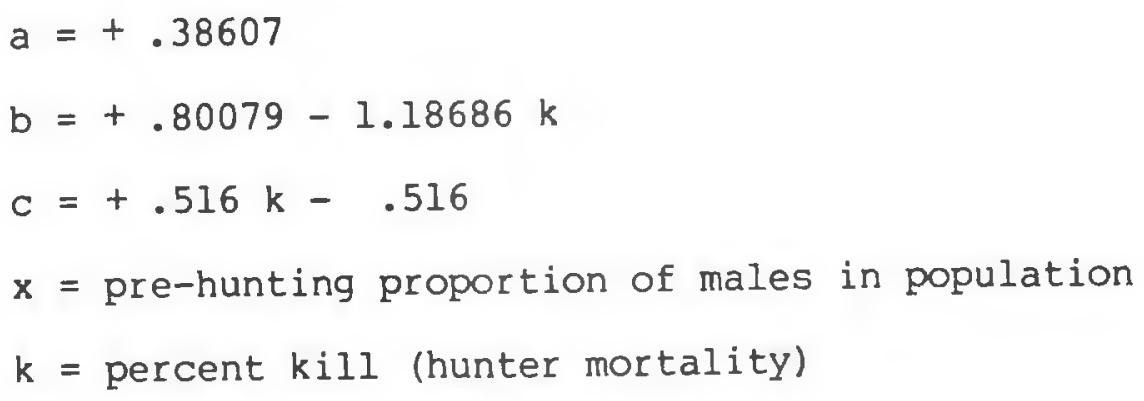

Given that the harvest is $15 \%$ then the pre-hunting male percentage is theoretically 538, i.e. hunting at this level reduces the percentage of males from $53 \%$ to $51 \%(1.4 \%)$. If the harvest is $20 \%$ the male proportion is reduced from 53.68 to 51.68 (28).

At the 1.39 male to one female hunter selection ratio the level of harvest is not a particularly critical factor in determining winter sex ratios. Theoretically a 58 harvest would reduce male predominance by 0.48 , a $10 \%$ harvest by $0.8 \%$, a $30 \%$ harvest by $3.3 \%$, and a 508 harvest by 7.68 . The effect of harvest level on sex ratio would increase if the hunter bias was higher in favour of males. The small effects shown in the above calculation are unlikely to be under-estimated; indeed, they may be over-estimates. Crissey's table indicates a lower hunter bias in favour of males than Caithness estimated. His sample sizes are not given but his table shows an average hunter bias in favour of males of $28 \%$ for adults 
(min. 218, $\max .408$ ) and 268 for immatures (min. $88, \max .398$ ). The maximums are therefore similar to Caithness' overall throughout-life bias figures.

The pre-hunting preponderance of males indicated by my calculations refers, unlike Crissey's sumary, to combined age classes. Consequently my estimated 53 to 53.6 pre-hunting male percentages must reflect a much higher percentage than 53.68 for adult males (compared to adult females), since the large numbers of immature birds which come into the population in the summer are unlikely to show a significant sex imbalance. (If the immatures occur at a ratio of $1: 1$ and represent, for example, $50 \%$ of the total population, then the percentage of males in the adult fraction would be in the region of 56 to $57 \%$.)

Crissey's post-hunting sex ratios, like those of Pukepuke, refer to immatures and adults combined. In the three years shown, his male predominances are likewise quite slight, i.e. 51.98, 52.898 and 53.78.

My conclusion as to the effect of shooting on sex ratios is that a harvest of 15-20\% taken in May and/or June will produce up to about a $2 \%$ decrease in the overall percentage of males. The recruitment of large numbers of young into the population is the other major factor involved in redressing the sex imbalance in the combined age class counts in the post-hunting period (Rogers in commenting on Crissey's findings, omitted to mention this important factor. He attributed quite erroneously I believe - the change to a nearly balanced post-hunting sex ratio purely to hunting.) 
The influence of lead poisoning on mallard sex ratios:

Lead poisoning due to the ingestion of lead pellets has been shown in both New Zealand and overseas to affect mainly adult males, (see e.g. Caithness, 1974; Longcore and Orr, 1982). Caithness' (1974) study of this aspect on several lagoons in the wider Pukepuke coastal region (including pukepuke Lagoon) indicated poisoning occurred more in low rather than high water level conditions.

As is discussed in Chapter 8 the degree to which ducks and swans feed within the substrate at Pukepuke is not determined primarily by water level or shallowness per se, but by the occurrence and timing of the summer macrophyte collapse.

Even assuming that reliable poisoning figures could be obtained from study areas like Pukepuke - and a number of difficulties are involved in this - extrapolation to other areas to obtain some sort of national estimate would be difficult. However, it may be construed from Caithness' comments on such things as the representativeness of shallow waters he studied, that it is highly unlikely that this factor is a very significant cause of mallard mortality throughout the country. By implication, therefore, its influence on overall sex ratio is likely to be negligible, and almost certainly much less than the influence of hunting for example. In the rather low water level summer of 1977/78 11 dead mallards were located at Pukepuke. Most were drakes, but due to their often advanced decomposition only two were found to contain lead pellets. Upwards of 700 moulting mallards were counted on this water during this particular period. In 1979 no dead mallards were found. 
I have not seen lead poisoning referred to in the literature as exerting a major influence on sex ratios of mallards or any other duck species. Aldrich (1973) stated that differential mortality of mallards on moulting lakes in North America was undocumented. 